\title{
PRE-SLIDING \\ BEHAVIOUR OF MULTI \\ ASPERITY CERAMIC CONTACTS
}
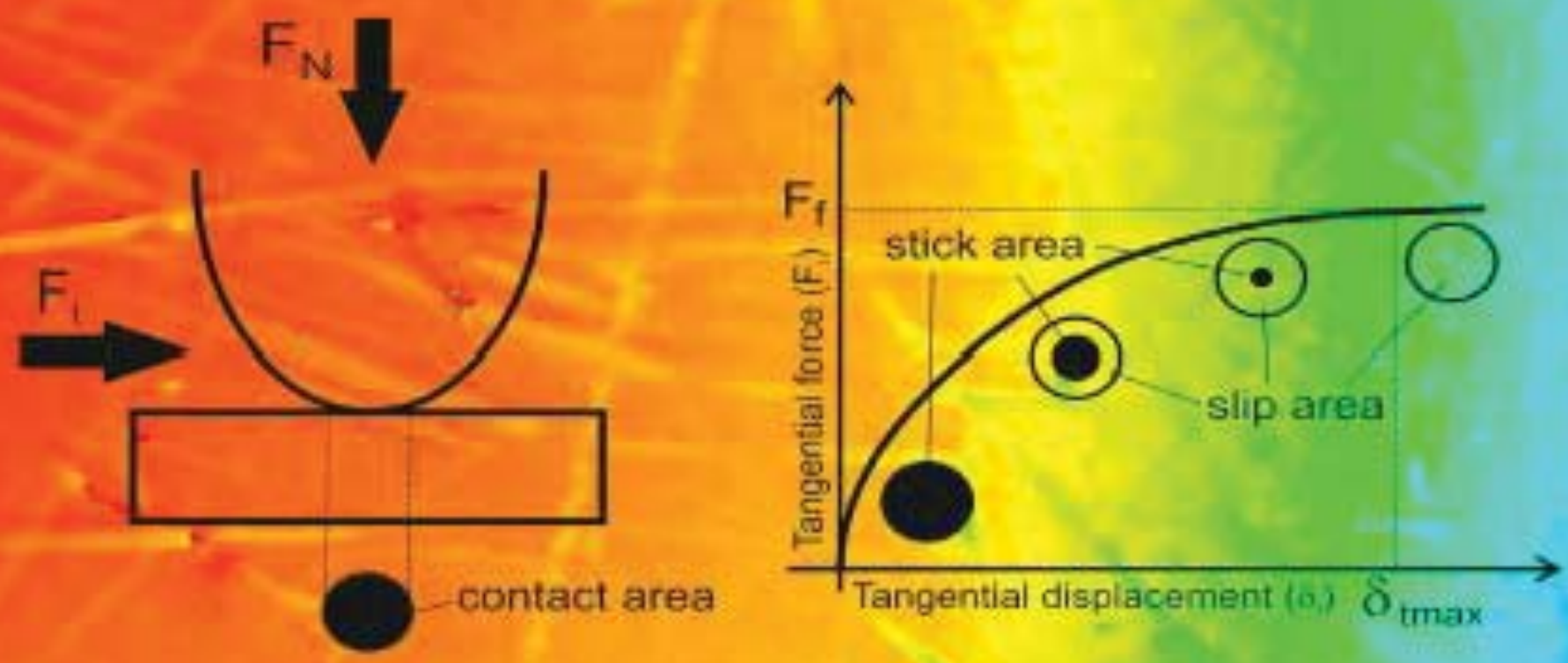

Agnieszka Winogrodzka 


\section{PRE-SLIDING \\ BEHAVIOUR OF MULTI \\ ASPERITY CERAMIC \\ CONTACTS}

Agnieszka Winogrodzka 
De promotiecommissie is als volgt opgesteld:

prof.dr. G.P.M.R. Dewulf, Universiteit Twente, voorzitter en secretaris prof.dr.ir. D.J.Schipper, Universiteit Twente, promotor dr.ir. M.B. de Rooij, Universiteit Twente, assistent promotor prof.dr.ir. A de Boer, Universiteit Twente prof.dr.ir. J.L.Herder, Universiteit Twente prof.dr. W. Wieleba, University of Wroclaw prof.dr. A.Matthews, University of Sheffield

Winogrodzka, Agnieszka

Pre-sliding behaviour of multi asperity ceramic contacts PhD Thesis, University of Twente, Enschede, The Netherlands, December, 2015

ISBN: 978-90-365-4013-1

DOI: $10.3990 / 1.9789036540131$

Copyright $\odot 2015$ A.Winogrodzka, Enschede, The Netherlands 


\section{PRE-SLIDING BEHAVIOUR OF MULTI ASPERITY CERAMIC CONTACTS}

\section{PROEFSCHRIFT}

ter verkrijging van

de graad van doctor aan de Universiteit Twente, op gezag van de rector magnificus,

prof.dr. H. Brinksma,

volgens besluit van het College voor Promoties

in het openbaar te verdedigen

op woensdag 16 december 2015 om 16:45 uur

door

Agnieszka Winogrodzka

Geboren op 9 september 1985

te Wroclaw, Poland 
Dit proefschrift is goedgekeurd door:

de promotor : prof.dr.ir. D.J.Schipper

de assistent promotor: dr.ir M.B de Rooij 


\section{SUMMARY}

Accurate positioning mechanisms are required for the proper and effective functioning of high-tech mechatronic systems. The tribological behaviour of sliding contacts in such mechanisms plays an important role in the performance of these systems. The geometrical changes of the surfaces, where geometry is defined as a multi asperity contact, will influence the frictional behaviour. This thesis focuses on the pre-sliding and sliding behaviour of contacts with the aim of determining the parameters which influence the errors in positioning accuracy.

The single asperity contact is the first step in understanding the pre-sliding behaviour between two elements. It is from this model that the tangential displacement is calculated, based on an applied normal load and the coefficient of friction. The normal load can be constant, either increasing or decreasing; this will depend on the operating conditions within the application. Adhesion plays an important role in a single asperity contact, whilst for a multi asperity contact adhesion can often be ignored.

This thesis introduces the test setup, which consists of a confocal height sensor for surface roughness measurement and a confocal Raman spectroscopy setup for chemical changes in the contact. Using this setup, it is possible to analyse the formation of chemical transfer layers as well as any geometrical changes in the wear track.

The single asperity contact model shows good agreement with the experimental work performed for silicon and silica against glass. With respect to high and low 
contact pressures, $(<100 \mathrm{MPa})$ the Mindlin theory can be used to predict pre-sliding behaviour. However, at very low loads the adhesion starts to significantly affect the results.

The pre-sliding behaviour of multi asperity contact, so rough surfaces, can be described on the basis of results obtained from theoretical calculations and experiments. The calculation of the tangential displacement for rough surfaces is presented in this thesis. The main assumption in the model presented is that rough surfaces can be modelled as a set of Hertzian contacts, where each asperity has its own radius and summit height. One asperity with a maximum value of tangential displacement will determine when a multi asperity contact starts sliding. The asperities will have no mutual influence apart from sharing the total tangential and normal load. Calculations for different applied loads, surface roughness and autocorrelation lengths show that roughness plays an important role in the preliminary displacement.

In the design of surfaces for positioning accuracy, parameters such as surface roughness, applied normal load and tangential load should be taken into account. Textured surfaces give better results to minimize drift as compared to random rough surfaces. A surface composed of asperities with large radii gives less variation in the tangential displacement and, as a result, less drift. 


\section{SAMMENVATTING}

Nauwkeurige positioneringsmechanismen zijn nodig voor een correcte en efficiënte werking van high-tech mechatronische systemen. Het wrijvingsgedrag van de contacten in dergelijke systemen, al dan niet opererend in een vacuüm omgeving, speelt hierbij een belangrijke rol. Het contact op ruwheidsniveau tussen twee in contact zijnde oppervlakken is daarbij van belang. Dit proefschrift richt zich op het wrijvings- en tangentiële verplaatsingsgedrag van de contacten, welke typerend zijn voor een positioneringsmechanisme. Het doel is om zowel experimenteel als modelmatig de factoren te bepalen die de nauwkeurigheid en met name de drift in een dergelijk contact beïnvloeden en om het effect van deze parameters op de positoneringsnauwkeurigheid te voorspellen. Een testopstelling is ontworpen, bestaande uit een confocale hoogtesensor voor meting van de oppervlakteruwheid, en een confocale Raman spectroscopie opstelling voor het detecteren van chemische veranderingen in het contact. Bij deze opstelling is het mogelijk om de geometrische veranderingen in het slijtagespoor ten gevolge van slijtage en transfer lagen te analyseren. Met een tweetal tribo-testers zijn de wrijving- en tangentiële verplaatsing onder verschillende belastingen en condities gemeten.

Het modelleren van het één-punts ruwheids contact is een belangrijke eerste stap in het begrijpen van een multiasperity contact. Vanuit een model kan de pre-sliding verplaatsing worden berekend, gebaseerd op de opgelegde normaal belasting, geometrie en de wrijvingscoëfficiënt. De normaal belasting kan constant zijn, groter worden, of kleiner worden afhankelijk van de omstandigheden binnen een 
toepassing. Adhesie speelt een belangrijke rol in een single asperity contact, terwijl voor een multi asperity contact adhesie vaak kan worden genegeerd.

Het single asperity contact model toont een goede overeenkomst met de resultaten van experimenten, uitgevoerd met een enkele ruwheidstop van silicium of siliciumdioxide tegen glas. Een vergelijking tussen modelresultaten en experimenten laat zien dat zowel voor hoge als voor lage contact drukken (<100 MPa) de Mindlin theorie gebruikt kan worden om het wrijngs- en verplaastings gedrag te voorspellen. Echter, bij zeer lage drukken begint adhesie het resultaat te beïnvloeden en is een model dat adhesie verwaarloost niet meer geldig.

Het pre-sliding gedrag bij meerdere ruwheidscontacten (multiasperity contact), ten gevolge van de interactie van ruwe oppervlakken, kan worden beschreven op basis van de resultaten verkregen uit theoretische berekeningen en experimenten. Hoe deze pre-sliding voor ruwe oppervlakken kan worden gemodelleerd wordt beschreven in dit proefschrift. In het ontwikkelde model hebben de ruwheidstoppen geen wederzijdse invloed afgezien van het delen van de totale tangentiële en normale belasting. De belangrijkste aanname in het gepresenteerde model is dat ruwe oppervlakken kunnen worden gemodelleerd als een set van Hertze contacten, waarbij elke ruwheid zijn eigen radius en hoogte heeft. Uiteindelijk bepaalt één ruwheidstop, de ruwheidstop met de hoogste tangentiële verplaatsing, wanneer een multi asperity contact als geheel begint te glijden. Berekeningen voor verschillende opgelegde belastingen, oppervlakteruwheden en autocorrelatielengtes tonen aan dat de ruwheid een belangrijke rol speelt in de initiële verplaatsing van een contact.

In het ontwerp van oppervlakken ten behoeve van positioneringsnauwkeurigheid is het belangrijk dat ten eerste de drift minimaal is en dat daarnaast het contact zo stabiel mogelijk zal opereren, ook bij eventuele veranderingen. Getextureerde oppervlakken, bestaande uit regelmatige structuren, zijn beter in staat om drift te minimaliseren dan random ruwe oppervlakken. Berekeningen laten zien dat een oppervlakte samengesteld uit ruwheidstoppen met grote radii minder variatie geeft in tangentiële verplaatsing. Het gebruik van een dergelijke oppervlaktetextuur in een positioneringsmechanisme zal daardoor resulteren in minder drift. 


\section{ACKNOWLEDGEMENTS}

I would like to thank many people who supported and encouraged me to finish this thesis. I want to thank the program Point One of Ministry of Economic Affairs, Agriculture and Innovation of the Netherlands for all the financial support of the project MOV-ET. Also thanks to the companies FEI, TNO and Demcon, which were all involved in this project and the discussions we had during group meetings.

First of all I need to express my sincere gratitude to my promotor Prof. Dik Schipper and my daily supervisor Matthijn de Rooij for the support of my $\mathrm{PhD}$ studies, for their motivation, patience and immense knowledge. Dik, your guidance and sharp comments helped me in writing my papers and finishing this thesis. Matthijn, thank you for all the time we spend discussing my project, your helpful comments and answers to all my questions, from the very basic to the sometimes stupid ones.

Besides my supervisors, I would also like to thank the rest of my thesis committee: Prof. Andre de Boer, Prof. Just Herder, Prof. Allan Matthews and Prof. Wojciech Wieleba for reading and accepting the final draft of my thesis and also for their comments.

I would like to thank Hartmut Fisher and Edwin Gelinck from TNO for the opportunity of doing experiments using U-NAT and for all the interesting discussions about adhesion and friction.

I would like to thank Paweł Owczarek for the opportunity to do my internship in Enschede, which helped me in deciding to do my $\mathrm{PhD}$ here in Twente. 
I cannot forget about my colleagues from the tribology group at the University of Twente. Belinda and Deby; thank you for all the arrangements for the conferences and train trips. Eric and Walter; thank you for all your technical support in the lab, with doing experiments and building the setup. Your knowledge about LabView was very impressive and I learned a lot from the two of you. Also thanks to my colleques: Adriana, Aydar, Ellen, Emil, Febin, Ioan, Milad, Julien, Lydia, Marina, Mark, Matthijs, Michel, Natalia, Noor, Piet, Rob, and Xiao for a friendly atmosphere, discussions during lunches or coffee brakes about everything and nothing, and that I learned something new from you every day. I want to say thanks to my roommates during my four years at University, Adeel, Dinesh, Dariush, Geert, Mahdiar, Jincan, Jianchang, Sheng and Yibo for a nice working atmosphere in the room and the small talks during free time.

My sincere thanks also goes to my friends who supported me outside of University; Andrzej, Ashvin, Avijit, Cams, Edson, Gintas, Haishan, Isil, Sangram, and all the others whom I met in Macandra. Thanks to you guys I was able to have a good time during my free hours; all the trips we took together, the dinners we had, and all the conversations we had, will always stay cheerfully in my mind. Thank you Ashvin, for all your motivation, support and convincing me together with Cams to start doing PhD.

I want to thank also my friends from Poland who always supported and motivated me; Ania, Agnieszka, Beata (thank you for everything), Monika and all the rest with whom I can always meet during my visits to Poland to get a lot of positive energy.

A special thanks goes out to my parents and brother, Kamil. Your love, encouragement and the knowledge that you will always be there for me helped me a lot during all these years doing my $\mathrm{PhD}$, and in my life in general.

Kochani rodzice i Kamilu, bardzo wam serdecznie dziękuję za miłość jaka mnie obdarzyliście, wsparcie oraz cierpliwość nie tylko podczas pisania pracy ale również przez cale dotychczasowe życie. 
Last but not least, thank you Wilco, for your love and patience which helped me to finish this thesis. Of course, a big thanks will go to my lovely daughter Laura, for all the happiness you brought (and still bring) into my life in the last year of finishing my thesis, and your smile which will always melt my heart. 


\section{TABLE OF CONTENTS}

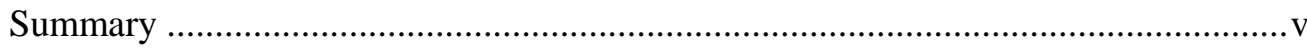

Samenvatting …...........................................................................................

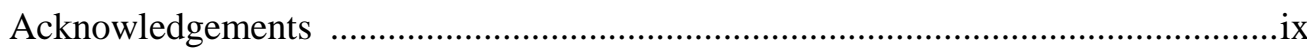

Nomenclature …..................................................................................

CHAPTER 1 INTRODUCTION …........................................................... 1

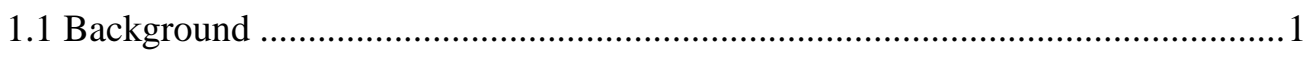

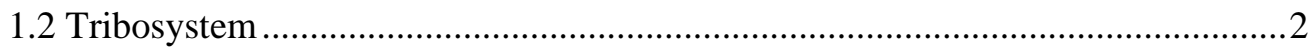

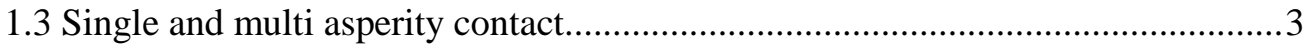

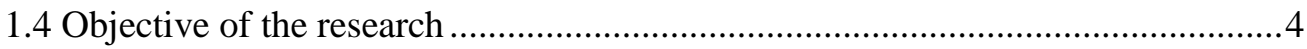

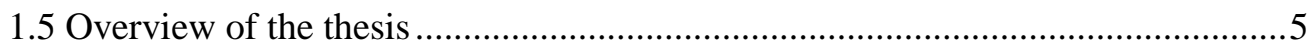

CHAPTER 2 PRE-SLIDING BEHAVIOUR OF CONTACT ...............................

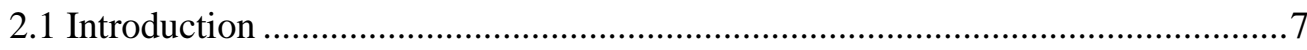

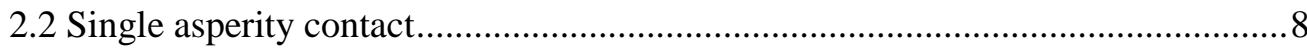

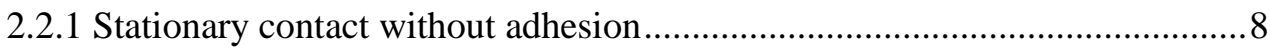

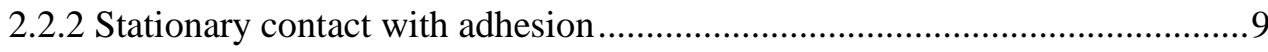

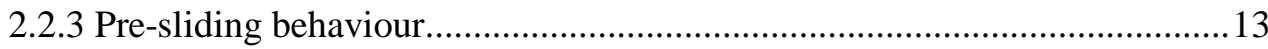


2.2.3.1 Increasing normal load during pre-sliding..........................................17

2.2.3.2 Decreasing normal load during pre-sliding .............................................19

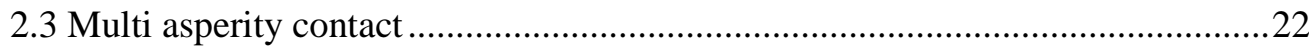

2.3.1 Pre-sliding behaviour for multi asperity contact ……………......................25

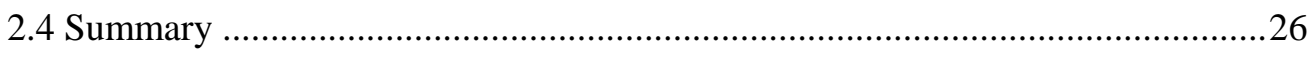

CHAPTER 3 MEASUREMENT TECHNIQUES FOR SURFACE

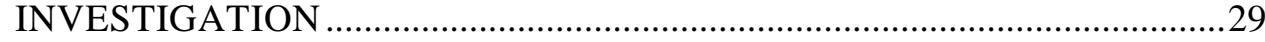

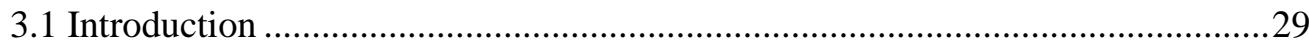

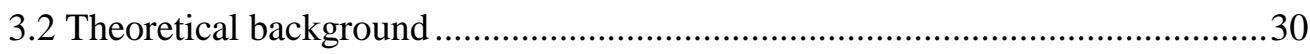

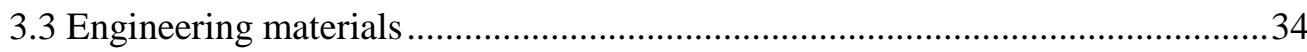

3.4 Surface measurement setup and obtained results ……………….........................35

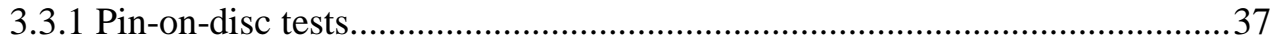

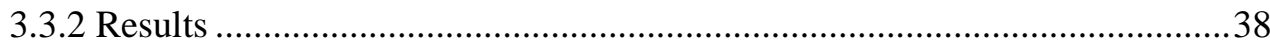

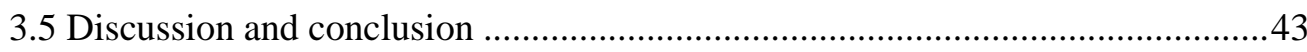

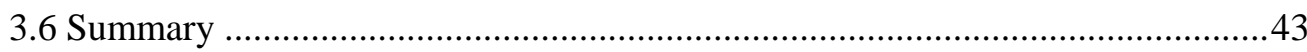

CHAPTER 4 NORMAL LOADING OF A SINGLE ASPERITY CONTACT ....45

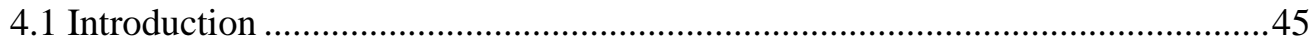

4.2 Pre-sliding behaviour of single asperity contact.................................................46

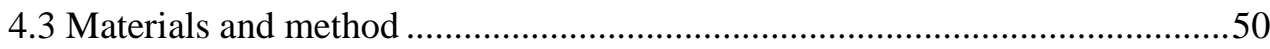

4.4 Experimental validation for a ball against flat contact .......................................52

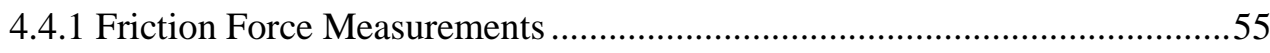

4.4.2 Preliminary displacement .......................................................................57

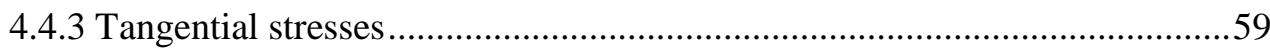

4.5 Varying normal load for a single asperity contact during sliding .......................61

4.5.1 Increasing normal load during sliding ...................................................61 
CHAPTER 5 PRE-SLIDING BEHAVIOUR OF A MULTI ASPERITY CONTACT

5.1 Introduction .67

5.2 Model representation for a rough surface ………………...................................68

5.3 Pre-sliding behaviour of a multi asperity contact including loading history ........73

5.3.1 Normal load is constant and tangential load is oscillating ............................73

5.3.2 Different normal load and oscillating tangential force ..................................75

5.3.3 Oscillating tangential force with different surface roughness .......................78

5.3.4 Oscillating tangential force for surfaces with different autocorrelation length .80

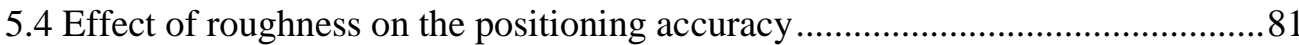

5.4.1 Statistical variations of the generated surface model ....................................83

5.5 Experimental validation with varying normal load on multi asperity contact.....84

5.5.1 Constant normal load applied in the contact ................................................. 84

5.5.2 Increasing and decreasing normal load during sliding ...............................89

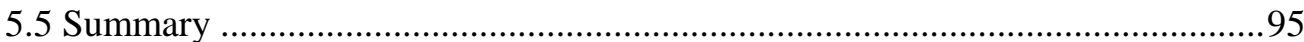

CHAPTER 6 DESIGN OF SURFACES FOR POSITIONING ACCURACY ........97

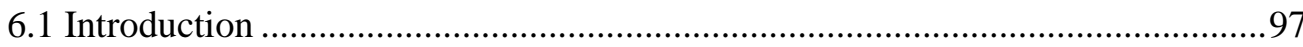

6.2 Design of a surface for a positioning mechanism................................................98

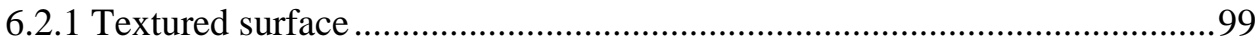

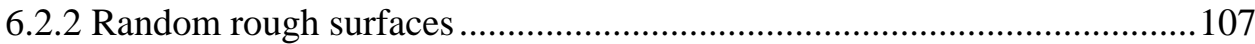

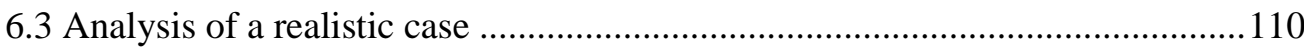

6.3.1 Method and materials ........................................................................111

6.3.2 Contact changes over sliding distance...................................................113 
6.4 Effect of roughness and friction on positioning accuracy for a realistic surface

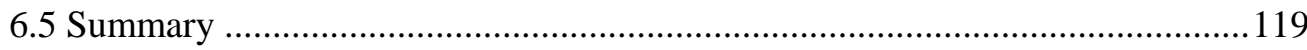

CHAPTER 7 CONCLUSIONS AND RECOMMENDATIONS .......................121

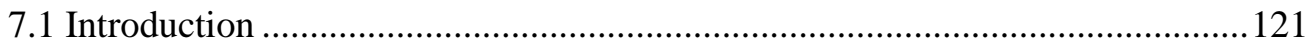

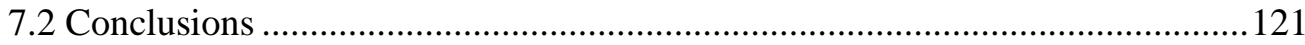

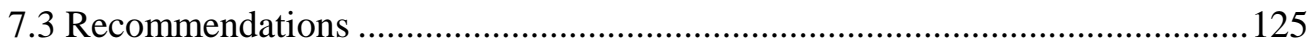

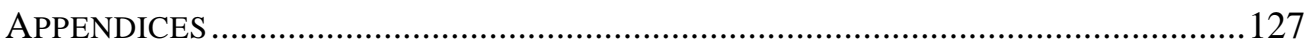

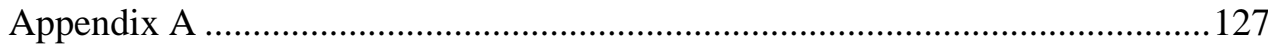

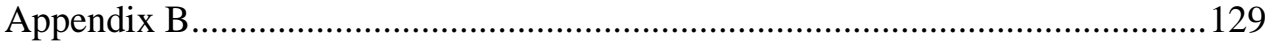

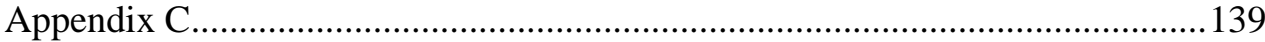

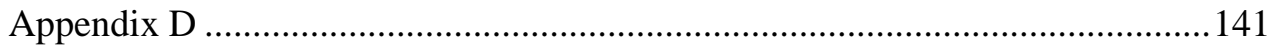

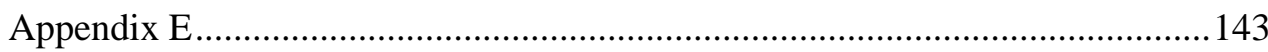

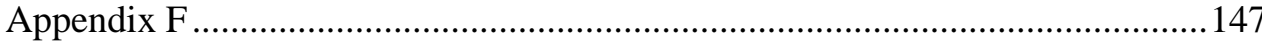

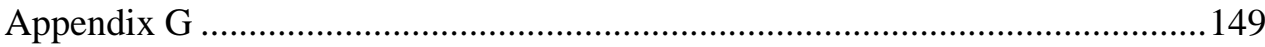

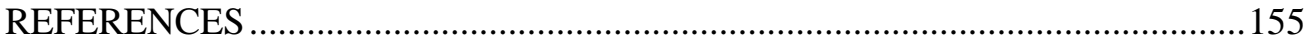





\section{List of Roman symbols}

Symbols

A

$\mathrm{A}_{\text {real }}$

$\mathrm{A}_{0}$

a

b

c

$\mathrm{D}_{\text {sum }}$

d

$\mathrm{E}_{1}, \mathrm{E}_{2}$

$\mathrm{E}^{*}$

$\mathrm{F}_{\mathrm{adh}}$

$F_{f}$
Descriptions

Contact area

Real contact area

Nominal contact area

Contact radius of circular contact

Depth of penetration for counter slip

Adhesive radius

Number of summits per unit area

Separation between two bodies in contact

Young's elastic modulus

Reduced Young's modulus

Adhesion force

Friction force
Units

$\left[\mathrm{m}^{2}\right]$

$\left[\mathrm{m}^{2}\right]$

$\left[\mathrm{m}^{2}\right]$

[m]

[m]

[m]

[-]

[m]

[Pa]

[Pa]

[N]

[N] 


\begin{tabular}{|c|c|c|}
\hline $\mathrm{F}_{\mathrm{N}}$ & Normal load & {$[\mathrm{N}]$} \\
\hline $\mathrm{F}_{\mathrm{t}}$ & Tangential load & {$[\mathrm{N}]$} \\
\hline $\mathrm{G}^{*}$ & Reduced shear modulus & {$[\mathrm{Pa}]$} \\
\hline $\mathrm{h}_{0}$ & $\begin{array}{l}\text { Separation distance } \\
\text { / effective range of action }\end{array}$ & {$[\mathrm{m}]$} \\
\hline $\mathrm{k}_{\mathrm{t}}$ & Contact stiffness in tangential direction & {$[\mathrm{N} / \mathrm{m}]$} \\
\hline 1 & Autocorrelation length & {$[\mathrm{m}]$} \\
\hline $\mathrm{n}$ & Number of micro - contacts & {$[-]$} \\
\hline $\bar{P}$ & Pull - off force parameter & {$[-]$} \\
\hline $\mathrm{p}_{\mathrm{m}}$ & Mean contact pressure & {$[\mathrm{Pa}]$} \\
\hline $\mathrm{R}_{\mathrm{a}}$ & $\begin{array}{c}\text { Arithmetic average of absolute value of surface } \\
\text { roughness }\end{array}$ & {$[\mathrm{m}]$} \\
\hline $\mathrm{R}_{\mathrm{q}}$ & Root mean square surface roughness & {$[\mathrm{m}]$} \\
\hline $\mathrm{R}_{\mathrm{z}}$ & $\begin{array}{c}\text { Maximum height between highest peak and lowest } \\
\text { valley profile for surface roughness }\end{array}$ & {$[\mathrm{m}]$} \\
\hline $\mathrm{R}_{1}, \mathrm{R}_{2}$ & Radius & [m] \\
\hline $\mathrm{r}$ & $\begin{array}{c}\text { Instantaneous value of the radius / } \\
\text { radial distance }\end{array}$ & {$[\mathrm{m}]$} \\
\hline$r_{n}$ & Radius for each asperity & {$[\mathrm{m}]$} \\
\hline s & Partial stick zone radius & {$[\mathrm{m}]$} \\
\hline $\mathrm{T}$ & Tangential load & {$[\mathrm{N}]$} \\
\hline $\mathrm{W}$ & Work of adhesion & $\mathrm{m}^{2}$ \\
\hline
\end{tabular}




\section{List of Greek symbols}

Symbols

$\gamma_{\mathrm{s}}$

$\delta$

$\delta_{\mathrm{a}}$

$\delta_{\mathrm{t}}$

$\delta_{\mathrm{tc}}$

$\delta_{\operatorname{tmax}}$

$\delta_{\mathrm{t} 1}$

$\delta_{\mathrm{t} 2}$

$\lambda$

$\mu$

$v_{\mathrm{n}}$

$\sigma_{\mathrm{z}}$

$\sigma_{0}$

$\tau$

\section{Descriptions}

Surface energy

Penetration

Elastic displacement

Tangential displacement

Complete tangential displacement

Maximum pre-sliding tangential displacement

Theoretical tangential displacement

Measured tangential displacement

Elasticity parameter

Coefficient of friction /

parameter in adhesion map

Poisson ratio

Standard deviation

Normal stress

Shear stress
Units

$\left[\mathrm{J} / \mathrm{m}^{2}\right]$

[m]

[m]

[m]

[m]

[m]

[m]

[m]

$[-]$

$[-]$

$[-]$

[-]

[Pa]

[Pa] 


\section{List of Abbreviations}

\section{Abbreviation}

$\mathrm{Al}$

AFM

$\mathrm{Al}_{2} \mathrm{O}_{3}$

BGT

DMT

EDS

FMM

JKR

M-D

MEMS

NT

$\mathrm{RH}$

RMS/rms

$\mathrm{Si}$

$\mathrm{SiO}_{2}$

UNAT

\section{Descriptions}

Aluminium

Atomic force microscopy

Alumina

Bush, Gibson and Thomas model

Derjaguin, Muller and Toporov model

Energy dispersive microscopy

Force measuring mechanisms

Johnson, Kendall and Roberts model

Maugius-Dugdale model

Micro electro mechanical systems

Nayak-Thomas model

Relative humidity

Roughness (Root mean square)

Silicon

Silica

Universal Nanomechanical Asmec's tester 
VAFT

XPS

Y-TZP

$\mathrm{ZrO}_{2}$
Vacuum adhesion and friction tester

X-ray photoelectron microscopy

Yttria stabilized zirconia

Zirconia 



\section{ChAPTER 1}

\section{INTRODUCTION}

\subsection{Background}

Nowadays, high tech systems have become more and more important in many aspects of human life. Laptops, tablets or cell - phones are used by many people and each year new designs and features are launched to attract more customers. The electronic industry needs to find a way to improve products and impress customers with new and innovative technologies while at the same time making the components smaller. Behind each product there is lot of work which needs to be done by using mechanical systems to, for example, produce chips or very precise elements made from different materials. The reliability, performance and precision of these systems are critical. The Micro Electro Mechanical Systems (MEMS) and Nano Electro Mechanical Systems (NEMS) behave differently than they do in macro scale problems and phenomena, which needs to be taken into account during the design process. The positioning mechanisms need to be very accurate, sometimes in the order of nanometres, to be able to meet high industrial demands. 
The precise positioning systems can also be found in applications like electron microscopes, ion beam profiling, semi-conductors, optical polishing, and components of satellite where they increase the system's performance. Another aspect is the environment of these systems, as very often, vacuum conditions are necessary to avoid contamination during the production process. Also, the tribological behaviour of sliding contacts in such mechanisms plays an important role in the system's performance $[1,2]$.

\subsection{Tribosystem}

Tribology is the science of interacting surfaces in relative motion under different environmental conditions. The study is focused on friction and wear phenomena, which was already introduced by Leonardo da Vinci in the 15th century [1]. In general, friction is the force that resists relative motion of the solid surfaces, fluid layers or material elements sliding against each other.

A tribosystem is a type of system which is built by tribological components such as, for example, bearings, where wear between bodies can occur [2]. Many operating conditions will influence this type of system like, for instance, the applied load, kinematics, temperature, sliding velocity and environment. The material composition of the elements in the tribosystem will also influence the resulting behaviour.

Contact between two surfaces can cause material transfer from one body to another and changes in surface roughness. This implies that the friction level can change because of changes in the contact and surface forces. In an ideal system, friction is constant and independent of time. However, in real-life systems the friction force depends on many parameters such as time, temperature, load, motion and can vary in time as shown schematically in Figure 1.1 [2]. The effect of these parameters needs to be understood.

A stable friction level will be important to improve the accuracy of positioning mechanisms as discussed in Section 1.1. 


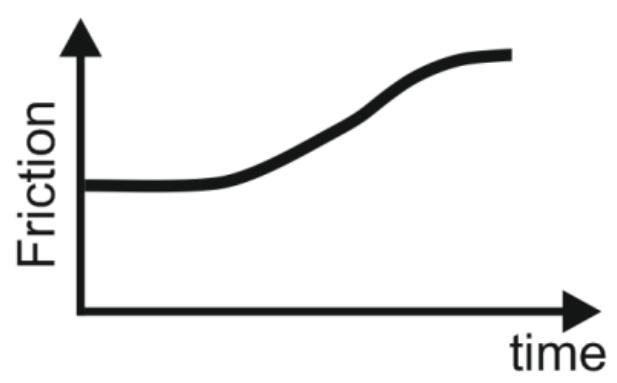

Figure 1.1: Changes of friction in time.

\subsection{Single and multi asperity contact}

When two different surfaces are pressed onto each other by applying a normal load then contact between them occurs, as schematically shown in Figure 1.2. Many operating conditions influence the resulting tribological behaviour. The geometry of the surfaces plays an important role in friction as discussed in [3, 4]. Even a perfectly smooth surface shows some unevenness or roughness under a microscope. In this thesis, the contact formed by several asperities will be called a multi asperity contact. A single asperity contact is a single contact between two elements, for example a ball against a flat surface.

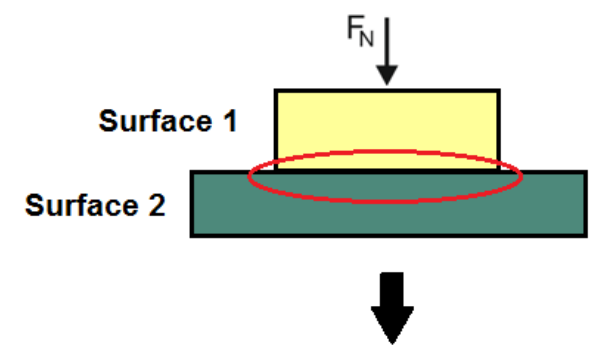

Multi asperity contact

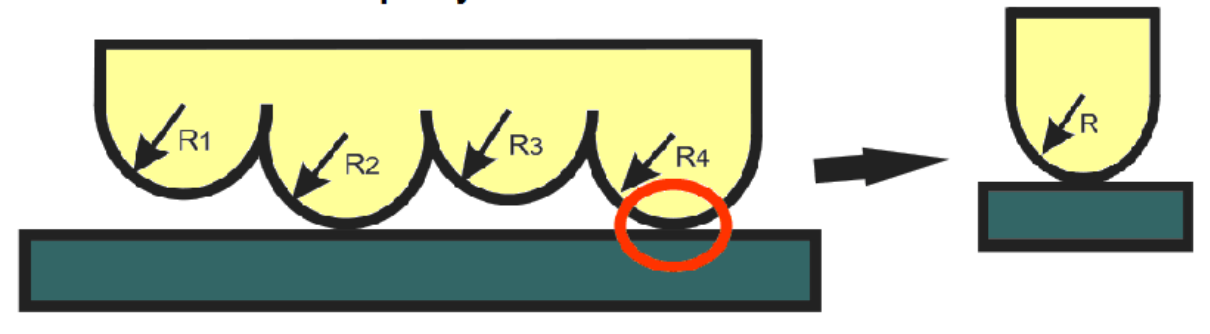

Figure 1.2: Rough surface in contact with a flat. 
Many models are available to characterize asperities, for example, by a radius and a height depending on the assumed geometry.

To analyse the movement of elements perpendicular to the normal force, a tangential force can be applied. In a multi asperity contact the higher asperities will wear after several movements in tangential direction, so that lower asperities come into contact and start to carry load. The results in time are dependent on the loading conditions at asperity level. The coefficient of friction can change after each pass, which will have an influence on the tangential load. That is the reason why first a single asperity contact needs to be understood and its behaviour under different loading and operating conditions. The results can then be applied to a multi asperity contact.

\subsection{Objective of the research}

The main aim of the research is to analyse the influence of friction, and changes in friction level, on positioning accuracy. This study focuses on ceramics in ball-flat contacts, silica $(\mathrm{SiO} 2)$ and silicon $(\mathrm{Si})$ as a single asperity contact and alumina (Al2O3) and zirconia ( $\mathrm{ZrO} 2)$ as a multi asperity contact sliding against glass. The objectives of the research can be distinguished as follows:

- studying the effect of friction change in time for the ball-flat contact;

- developing a setup to study geometrical changes and material transfer from one surface to the other to explain changes in the coefficient of friction over time;

- modelling the pre-sliding behaviour for a single and multi asperity contact to explain the frictional behaviour and the preliminary tangential displacement;

- validating the model by experiments at single and multi asperity contact level under ambient and high vacuum conditions;

- explaining effects of surface roughness and surface roughness changes on the positioning accuracy under varying and constant applied normal load by theoretical calculations and experiments. 


\subsection{Overview of the thesis}

Understanding the pre-sliding behaviour for a single and multi asperity contact is the main topic of this research. Examples of applications where precision and reliability in a mechanical system are important for better system performance have already been described in this chapter. Also, some basics like tribosystems and the difference between a single and multi asperity contact were briefly explained. The objective of this research was given in the previous section.

In Chapter 2, a detailed explanation about pre-sliding behaviour of a single and multi asperity contact is described. The influence of adhesion and other surface forces which influence contact are depicted from already existing literature models. Furthermore, a model for pre-sliding behaviour and calculation of preliminary tangential displacement is shown. Different loading situations are also elaborated for a single asperity contact. Existing literature models for multi asperity contacts are also compared in this section.

To explain surface changes during wear of ceramics, the setup of a confocal height sensor and confocal Raman spectroscope was built and described in Chapter 3. The wear track obtained from pin-on-disc tests for an alumina ball against a zirconia plate was investigated with this setup to measure the local height changes on the wear track and to determine the chemical changes at the surfaces.

Chapter 4 focuses on a constant normal load applied on a single asperity contact. Pre-sliding behaviour was calculated based on existing models and compared with experiments. The tangential displacement was compared for two materials, i.e. silicon and silica, sliding against glass under different constant normal load and increasing applied normal load. Also, the friction force, coefficient of friction, preliminary displacement and shear stresses obtained from these experiments are presented.

In Chapter 5, the pre-sliding behaviour of a multi asperity contact is introduced. Firstly, a model to represent a rough surface is introduced for calculation. The tangential displacement behaviour is shown, under a constant and varying applied normal load and also with different roughness values. The effect of roughness on the 
positioning accuracy is elaborated in this chapter. The experimental results for an alumina and zirconia ball are compared with the theory.

More experiments and calculations for rough surfaces are shown in Chapter 6 . The textured surface and random rough surface are presented to design a proper surface to reduce drift. The results from ambient and vacuum conditions experiments for an alumina ball against a zirconia plate under two loading and sliding distances are compared. The influences of roughness and friction on positioning accuracy represented by the tangential displacement and load curves are shown.

Finally, in Chapter 7, conclusions and recommendations for future research are given. 


\section{Chapter 2}

\section{PRE-SLIDING BEHAVIOUR}

OF CONTACT

\subsection{Introduction}

Friction and wear depends on many parameters, such as the composition of the system, the operating variables or interaction between the system components. The load applied to the system, kinematics, time of contact or temperature are all of importance understanding the tribological behaviour between two elements [1]. There has been much analysis reported in the literature regarding the contact between two surfaces [3, 4, 5 - 9]. Typically, the contact between two rough surfaces under stationary loading conditions is analysed as the equivalent of a rough surface and a smooth flat rigid plane. A multi asperity contact is composed of many single asperities. It means that the real contact area is lower for rough surfaces and depends on the number, radii, and position of each asperity in contact. The concept of a single asperity contact is helpful to understand a multi asperity contact. In this chapter, contact models for single and multi asperity contacts will be introduced. 
The effect of adhesion will be introduced as well as the transition from pre-sliding to sliding behaviour, i.e. from a static to a dynamic situation.

\subsection{Single asperity contact}

\subsubsection{Stationary contact without adhesion}

A single asperity contact is defined as a point contact between two elements as it is schematically shown in Figure 2.1. A sphere is loaded on a plate with applied normal load $F_{N}$ where no surface forces exist, as has been studied by Hertz [6].

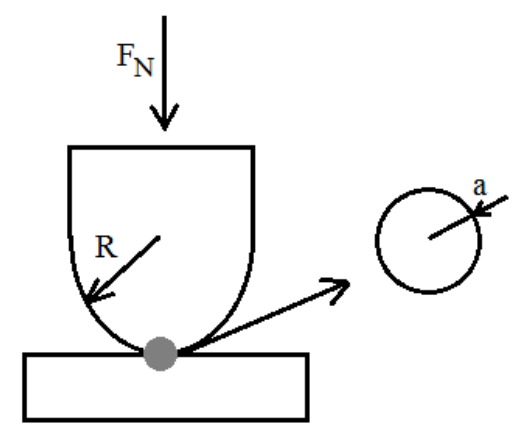

Figure 2.1: Single asperity contact.

According to Hertz [6], the contact radius $a$ from which the contact area can be calculated between a sphere with radius $R$ and a flat is defined as:

$$
a=\left(\frac{3 R}{4 E^{*}} \cdot F_{N}\right)^{1 / 3}
$$

Where $E^{*}$ is the reduced Young's modulus and defined according to [6]:

$$
\frac{1}{E^{*}}=\frac{1-v_{1}^{2}}{E_{1}}+\frac{1-v_{2}^{2}}{E_{2}}
$$

From Amontons' and Coulomb's law of friction it is known that the friction force is proportional to the normal load $\left(F_{N}\right)$ [4]. However, from the analysis presented below, it can be seen that in the case of a single asperity there is no proportionality 
between the applied load and the friction force. Bowden and Tabor [11] give a relation between the tangential force $F_{t}$, contact area $A$ and shear stress $\tau$, as:

$$
F_{t}=\tau \cdot A
$$

The contact area is calculated based on Equation 2.1 as:

$$
A=\pi \cdot\left(\frac{3}{4} \cdot \frac{R}{E^{*}}\right)^{2 / 3} \cdot F_{N}^{2 / 3}
$$

The relation between the friction force and normal load is, assuming the shear stress to be constant, $F_{t} \propto F_{N}^{2 / 3}$. The coefficient of friction $\mu=F_{t} / F_{N}$ so $\mu \propto F_{N}^{-1 / 3}$. In Chapter 4 this relation will be proven by experimental results.

\subsubsection{Stationary contact with adhesion}

For a single asperity contact, surface forces play an important role at microscopic scale. The magnitude of the forces will depend on the nature of the bodies in contact as well as on the environmental conditions like, for example, humidity. If a normal load is applied to the surfaces in contact and then released to zero, an additional tensile force is necessary to separate these surfaces. The force needed to separate the bodies is the pull - off force which is caused by adhesion. In the adhesion force, many forces are involved like, for example, the meniscus force which is shown in Figure 2.2 (a) and the atomic forces as shown schematically in Figure 2.2 (b) [12].

a)

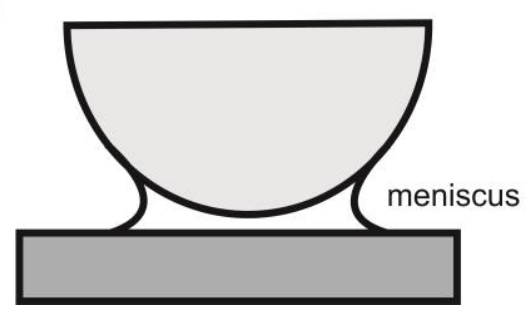

b)

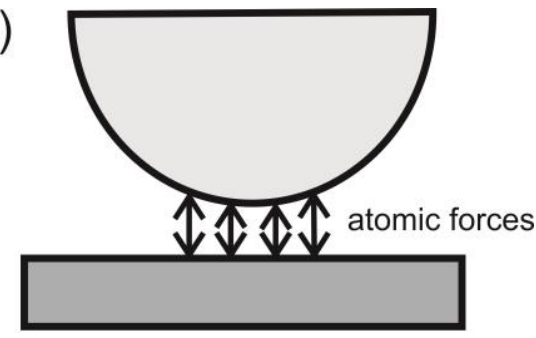

Figure 2.2: Surface forces influencing adhesion a) meniscus and b) atomic forces. 
In the Johnson, Kendall and Roberts model (JKR) [13], the authors consider that surface forces are present in the contact. When two solids are in contact, then the free surface forces disappear in the contact area. The energy loss of the system is correlated with work of adhesion $W$, which is associated with the energy gain per unit area, if the surfaces are separated. The elastic deformation is calculated by using the Hertz theory, where the contact area is limited by the required elastic deformation energy. The contact radius for a ball on a flat is calculated as follows, according to $J K R$ theory:

$$
a^{3}=\frac{3}{4} \cdot \frac{R}{E^{*}} \cdot\left(F+3 \pi W R+\sqrt{6 \pi W R F+(3 \pi W R)^{2}}\right)
$$

The adhesion force necessary to separate two solids is, according to the $J K R$ model, equal to:

$$
\mathrm{F}_{\mathrm{adh}}=2 \pi \mathrm{WR}
$$

In the $J K R$ theory it is assumed that surface forces are active only in the contact area. In reality this is also the case outside the direct contact zone. If adhesion of work is expressed in terms of surface energy $W=2 \cdot \gamma_{S}$, in the case of two similar materials in contact, then the adhesion force can be represented as [7]:

$$
F_{a d h}=3 \pi \gamma_{S} R
$$

Derjaguin, Muller and Toporov (DMT) [14] also developed an adhesion model. In their model, a kind of neck or meniscus forms at the contact [7]. The DMT model assumes that the contact displacement and stress profiles are the same as Hertz, but these quantities are for a higher effective load, which includes the applied normal force as well as the attractive adhesive stresses acting outside the contact area [14].

The DMT model is more suitable for small and hard solids. The adhesive force is given by [14]:

$$
F_{a d h}=4 \pi \gamma_{S} R
$$


Another contact model was developed by Maugis-Dugdale $(M-D)$ [16]. In their theory a circular contact between spheres is present over a central region of the contact radius $a$, stress $\sigma_{0}$ and radius $c$ as is shown in Figure 2.3 (a). The separation increases from zero to $h_{0}$.

Although developed for a dry adhesive contact, the Maugis-Dugdale model can also be used to model adhesion due to capillary forces exerted by a meniscus, such as shown in Figure 2.3 (b).

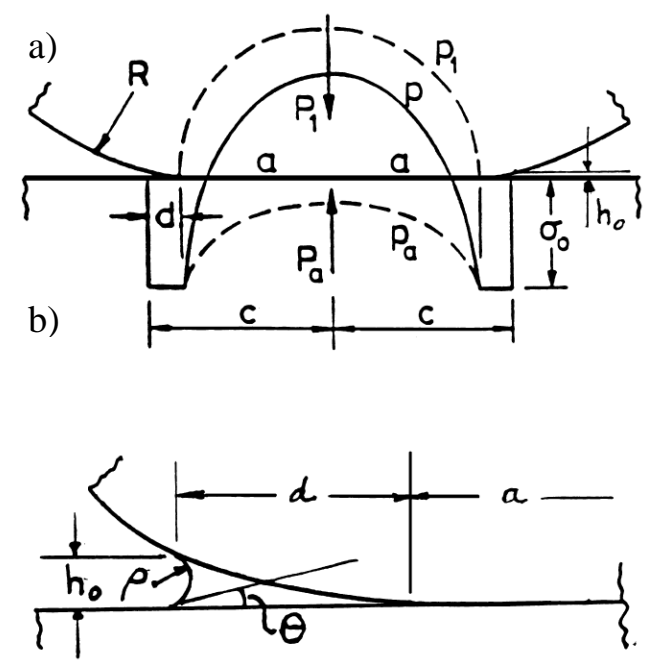

Figure 2.3: a) The Maugis-Dugdale distribution of surface traction comprises two terms: the Hertz pressure $P_{l}$ acting on area radius $a$ and the adhesive tension $P_{a}$ acting on radius $c$. b) A liquid meniscus at the edge of the contact gives rise to a Dugdale adhesive tension [7].

The Maugis-Dugdale theory is used to make an adhesion map (Figure 2.4); a detailed explanation is described in [16]. The important factor is the elasticity parameter $\lambda$ which is present on the horizontal axis and the adhesive pull - off force parameter $\bar{P}$ on the vertical axis. 


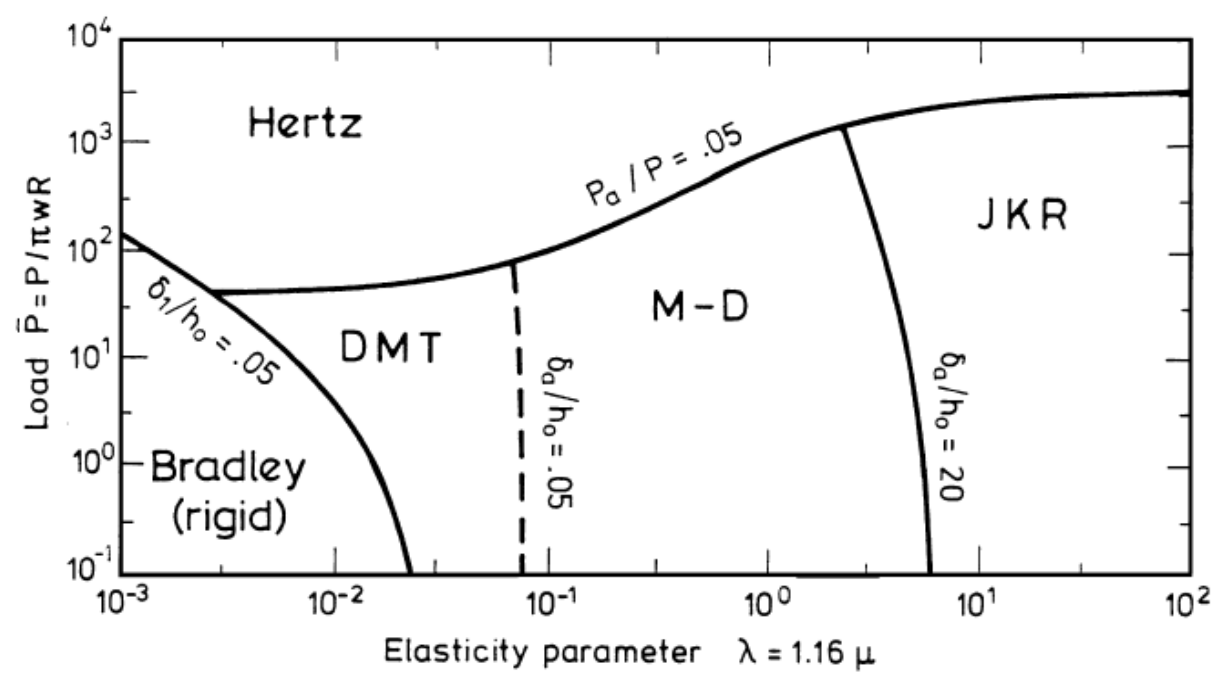

Figure 2.4: Adhesion map [16].

The parameter $\mu$ in this calculation represents the ratio of the elastic displacement of the surface at the point of separation to the effective range of surface force characterized by $z_{0}$, and is defined by:

$$
\mu=\left(\frac{R W^{2}}{E^{*^{2}} z_{0}^{3}}\right)^{1 / 3}
$$

The load parameter $\bar{P}$ is defined as:

$$
\bar{P}=\frac{P}{\pi W R}
$$

Where $R$ is the radius of the sphere, $E^{*}$ is the reduced elastic modulus, $z_{0}$ the equilibrium separation distance, $W$ is the work of adhesion and $P$ is the applied load.

The adhesion map has four zones, which correspond to the contact models of Hertz, DMT, JKR and M-D. The $\delta_{a}$ is the elastic displacement and $h_{o}$ is the effective range of action. Depending on the relation between the elastic parameter and the load, the right model can be chosen to calculate the contact between two bodies [16].

In the case of a rough contact the adhesion is not important, as was already described by Fuller and Tabor [18]. 


\subsubsection{Pre-sliding behaviour}

According to Mindlin [5, 19] a pre-sliding tangential displacement is observed when a normal $F_{N}$ and a tangential load $F_{t}$ are applied on a point contact. In Figure 2.5 on the left side, the single asperity contact is shown. Initially, the applied normal load will result in a contact area due to elastic deformation, Section 2.2.1. When a tangential force is applied two regimes in the contact area are observed, a stick and a slip zone, as presented in Figure 2.5 on the right side. An increase of the tangential force will reduce the sticking zone and an increase of the annulus of slip till full sliding will take place, as shown in Figure 2.5, indicated by $F_{f}$ and $\delta_{\operatorname{tmax}}$.
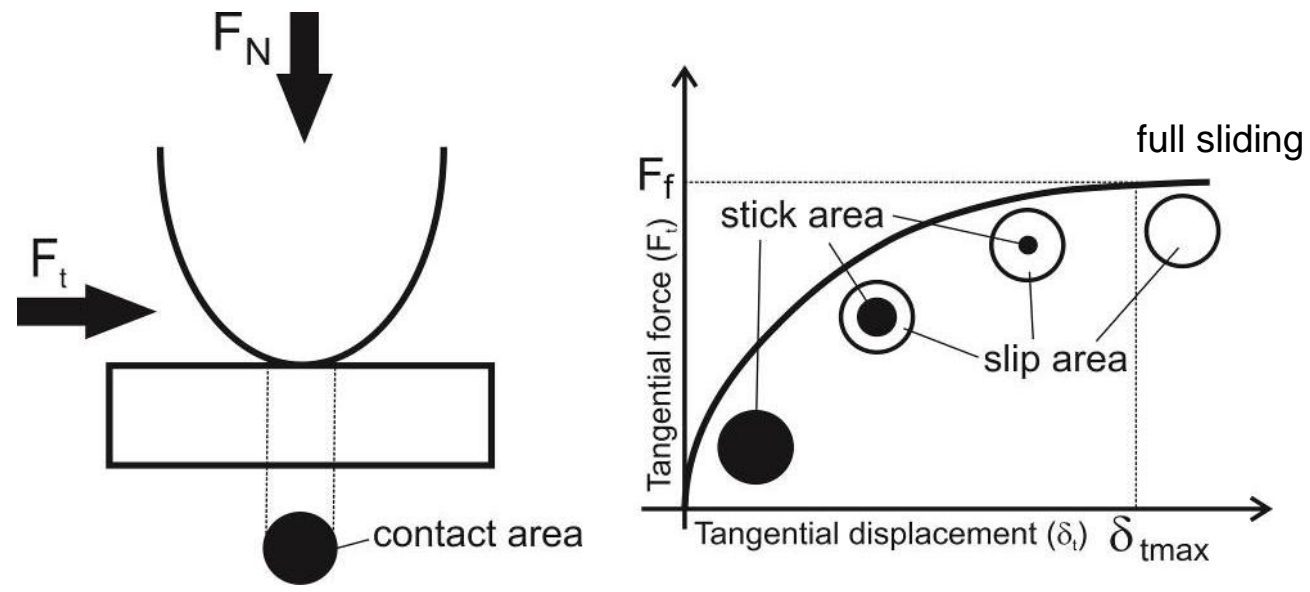

Figure 2.5: Slip to stick transition for a single asperity contact.

A typical pre-sliding behaviour is shown in Figure 2.6. In this figure, $F_{t}$ and $\delta_{t}$ are the tangential load and the tangential displacement respectively. The limits of $F_{f}$ as a friction force and $\delta_{\text {tmax }}$ as a maximum pre-sliding tangential displacement are defining the pre-sliding regime. 


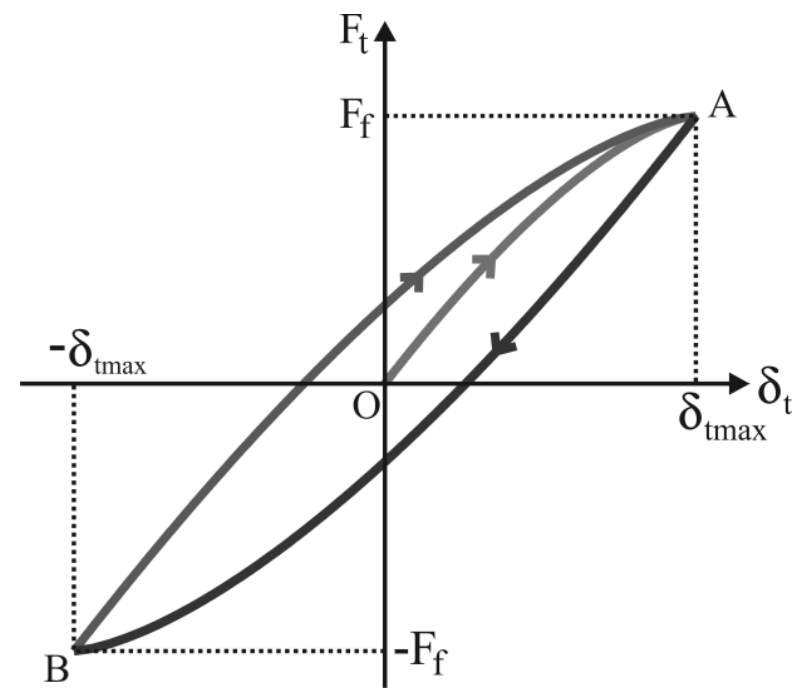

Figure 2.6: Oscillating tangential load with constant normal load. OA is the initial increase of $F_{t}$ till friction force $F_{f}, \mathrm{AB}$ is due to decrease in $F_{t}$ and BA is due to an increase in tangential load.

Starting from a stationary situation, the curve OA, the increasing tangential displacement $\delta_{\text {tinc }}$ for every value of increasing $F_{t}$ can be calculated by [19]:

$$
\delta_{\text {tinc }}=\frac{3 \cdot \mu \cdot F_{N}}{16 \cdot a \cdot G^{*}}\left[1-\left(1-\frac{F_{t}}{\mu \cdot F_{N}}\right)^{2 / 3}\right]
$$

Where $G^{*}$ is the reduced shear modulus, $a$ is the contact radius according to Hertz and $\mu$ is the coefficient of friction.

At point $A$, the system has reached the situation where $F_{t}=F_{f}=\mu \cdot F_{N}$, and the maximum tangential displacement is calculated as:

$$
\delta_{t \max }=\frac{3 \cdot \mu \cdot F_{N}}{16 \cdot a \cdot G^{*}}
$$

If the tangential load is reduced at this point, the system will follow curve $A B$. This curve can be calculated based on Equation 2.13.

$$
\delta_{\text {tdec }}=\frac{3 \cdot \mu \cdot F_{N}}{16 \cdot a \cdot G^{*}}\left[2\left(1-\frac{F_{f}-F_{t}}{2 \cdot \mu \cdot F_{N}}\right)^{2 / 3}-\left(1-\frac{F_{f}}{\mu \cdot F_{N}}\right)^{2 / 3}-1\right]
$$


At point B the contact will tend to slip in the reverse direction.

Consequently, the tangential force $F_{t}$ will have values in the range $-F_{f}$ and $+F_{f}$. For a tangential displacement higher than the limiting pre-sliding tangential displacement $\pm \delta_{\text {tmax }}$ of the system the tangential forces become constant, as is shown in Figure 2.5.

If the tangential load is increased from point $\mathrm{B}$, the system will follow curve $B A$. This curve can also be calculated using Equation 2.13 as it is a mirrored segment $A B$.

(a)

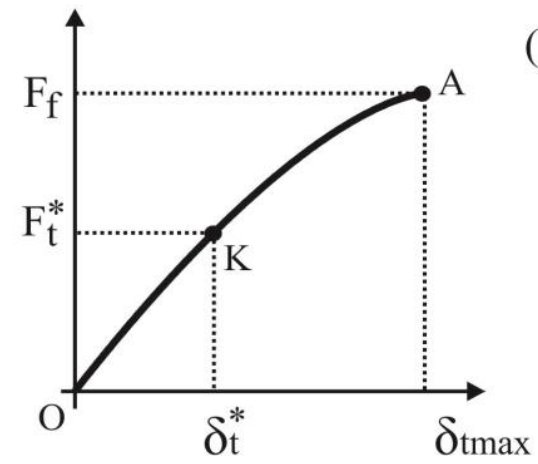

(b)

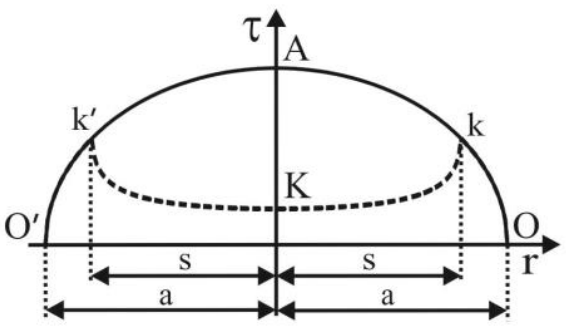

Figure 2.7: (a) Tangential force against tangential displacement showing only the forward scan. (b) Tangential traction against radial distance showing the partial stick and full slip conditions. The radius of the stick zone $s$ and the annulus of slip $a-s$ are also shown [5].

A shear stress will develop in the contact, as is shown in Figure 2.7. When the tangential force $F_{t}$ is applied and increases starting from point $O$ (Figure 2.7 (a)) to point $A$, then $F_{t}$ is equal to the friction force $F_{f}$. The friction force $F_{f}=\mu \cdot F_{N}$, and at this point full slip occurs, as was shown in Figure 2.5. In Figure 2.7 (b) the tangential traction (shear stress) distribution as a function of $r$ is presented. Where $\tau$ is the shear stress, $a$ is the contact radius and $s$ is the stick radius.

As an example, results are shown for $\mathrm{F}_{\mathrm{t}}{ }^{*}=1 / 2 \mathrm{~F}_{\mathrm{f}}$ to present the tangential traction distribution for a tangential force $\mathrm{F}_{\mathrm{t}}^{*}$, i.e. point $K$ on line $O A$, and corresponding tangential displacement is $\delta_{t}^{*}$ in Figure 2.7 (a). The tangential traction distribution at point $K$ is shown in Figure 2.7 (b), where the dashed line $O k K$ is presenting the partial stick zone $(s)$ and annulus of slip zone $(a-s)$. If the tangential force is increased till point $A$ (Figure 2.7 (a)) the contact is in the full slip condition (line $O A$ 
in Figure $2.7 \mathrm{~b}$ )), the stick zone is not present anymore. Then the preliminary tangential displacement $\delta_{\text {tmax }}$ is reached and can be calculated from Equation 2.12.

The shear stress distribution shown in Figure 2.7 (b) can be calculated based on Mindlin [5, 19] as:

$$
\begin{array}{cc}
\tau(r)=\frac{3 \cdot \mu \cdot F_{N}}{2 \cdot \pi \cdot a^{3}}\left(a^{2}-r^{2}\right)^{1 / 2} & s \leq r \leq a \\
\tau(r)=\frac{3 \cdot \mu \cdot F_{N}}{2 \cdot \pi \cdot a^{3}}\left[\left(a^{2}-r^{2}\right)^{1 / 2}-\left(s^{2}-r^{2}\right)^{1 / 2}\right] & r \leq s
\end{array}
$$

Where $r$ is the local value of the radius, $s$ is the radius of the stick zone.

For the case when the tangential force is oscillating, the resultant shear stress from initial loading and then unloading is shown schematically in Figure 2.8. The equations used to obtain the resultant stress distribution are given in Appendix A. In Figure 2.8 along the horizontal axis the annulus of the stick zone for loading $s$ and unloading $b$ is marked. That area is larger than the stick area for initial loading because during unloading the tangential displacement is shifted compared to the loading situation.

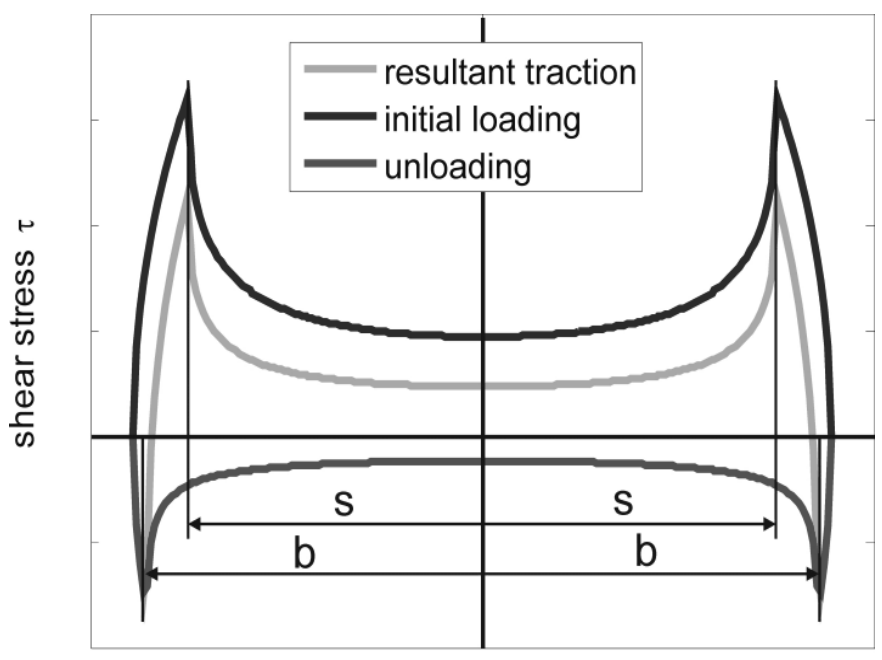

radial distance $r$

Figure 2.8: Partial stick and slip tangential traction for initial loading and unloading, with stick zone $s$ for initial loading and stick zone $b$ for unloading. 
Mindlin and Deresiewicz [19] discussed many more loading and unloading cases for the pre-sliding behaviour. The case where the normal load is changing together with the tangential force is explained below, as this will be relevant for wear with respect to a multi asperity contact to be discussed in Chapter 5.

\subsubsection{Increasing normal load during pre-sliding}

The situation when the normal load is increasing and the tangential load is also increasing was calculated based on [19]. The relation between the tangential displacement and the tangential force in the pre-sliding region for a changing load is presented in Figure 2.9 (a). The equations used for these calculations are given in Appendix A.

a)

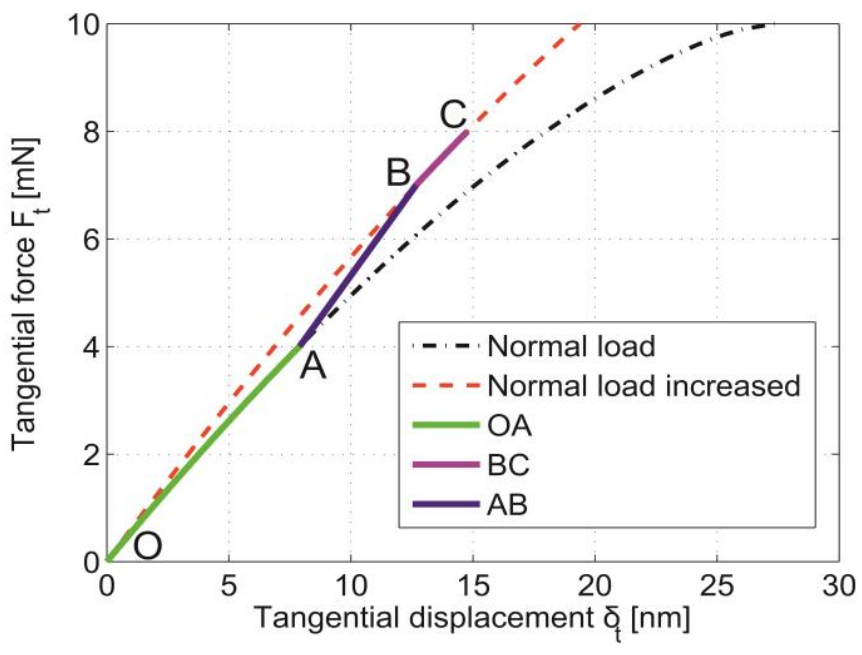

b)

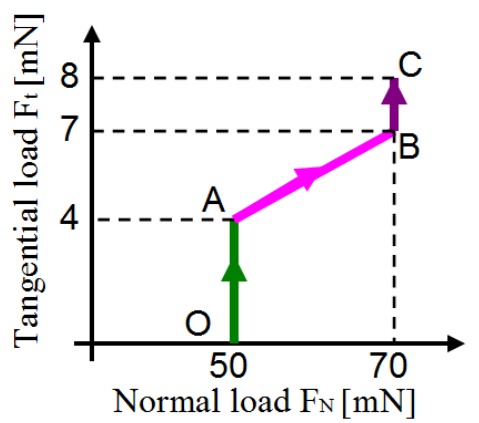

Figure 2.9: a) Tangential displacement and tangential force relation in the pre-sliding regime for increased normal load and tangential load and b) schematic representation of normal and tangential load. 
The calculations in this and the next section have been done as an example for silicon against glass with an applied normal load $50 \mathrm{mN}$ and a coefficient of friction 0.2 . The silicon ball radius was assumed to be $2.5 \mathrm{~mm}$ and the material properties are taken from Table B.1 in Appendix B. In the calculations, the normal load is increased by $20 \mathrm{mN}$ and the tangential load is also increased by $4 \mathrm{mN}$. In Figure 2.9 (b) a schematic representation of the assumed normal and tangential load is shown, steps are followed by arrows marked in the graph. In Figure 2.9 (a) the load and displacement curve is presented for a normal load of $50 \mathrm{mN}$ and $70 \mathrm{mN}$. The line $O A$ is the initial state of loading, after which the normal load and tangential load is increased (line $A B$ ). Then the curve for the $70 \mathrm{mN}$ normal load line is followed, till the required value for the tangential load (line $B C$ ) is obtained. The difference between $A$ and $C$ along the vertical axis is the increment of tangential load, and along the horizontal axis the increment of tangential displacement. During increasing of the normal load the final tangential displacement, will also be larger, including this increment.

In a similar way, a calculation was done to represent a decreasing tangential load with an increased normal load. The calculation is done following [19], as shown in Figure 2.10 (b). The normal load applied is $50 \mathrm{mN}$. Initially, the tangential force is increasing till point $A$, which is below the maximum tangential force. Then the tangential load is reduced (line $A B$ ) to a theoretically assumed value of $7 \mathrm{mN}$. In the next step, the normal load is increased by $20 \mathrm{mN}$ and then the tangential force is decreased (line $B C$ ) and further to point $D$. The tangential displacement obtained from these calculations is between points $B$ and $D$ along the horizontal axis, and the resultant tangential force from the vertical axis, respectively. The steps of applying the normal and tangential load are shown in Figure 2.10 (b). 
a)

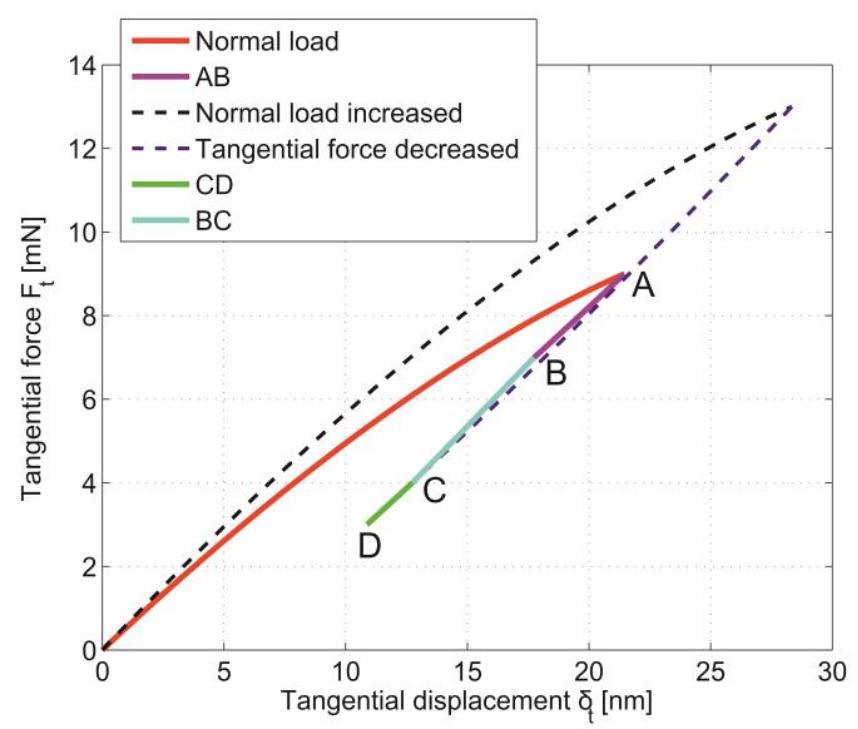

b)

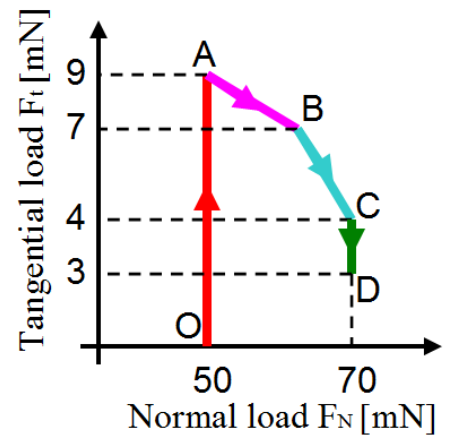

Figure 2.10: a) Tangential displacement and tangential force relation in the pre-sliding regime for increased normal load and decreased tangential load and b) schematic representation of normal and tangential load, after [19].

The theoretical calculations show that in the pre-sliding regime, when the normal or tangential load is increasing, the tangential displacement is changing as well. It explains why during pre-sliding even a small variation in the load can cause errors in the positioning accuracy.

\subsubsection{Decreasing normal load during pre-sliding}

Similar to the previous section, the calculation for decreasing normal load during pre-sliding will be presented following Mindlin and Deresiewicz [19]. 
The situation where the normal load is decreased and the tangential load was increased is presented in Figure 2.11. An initial normal load of $50 \mathrm{mN}$ is applied, and then the normal load is reduced by $20 \mathrm{mN}$, as is shown in Figure 2.11 (b).

a)

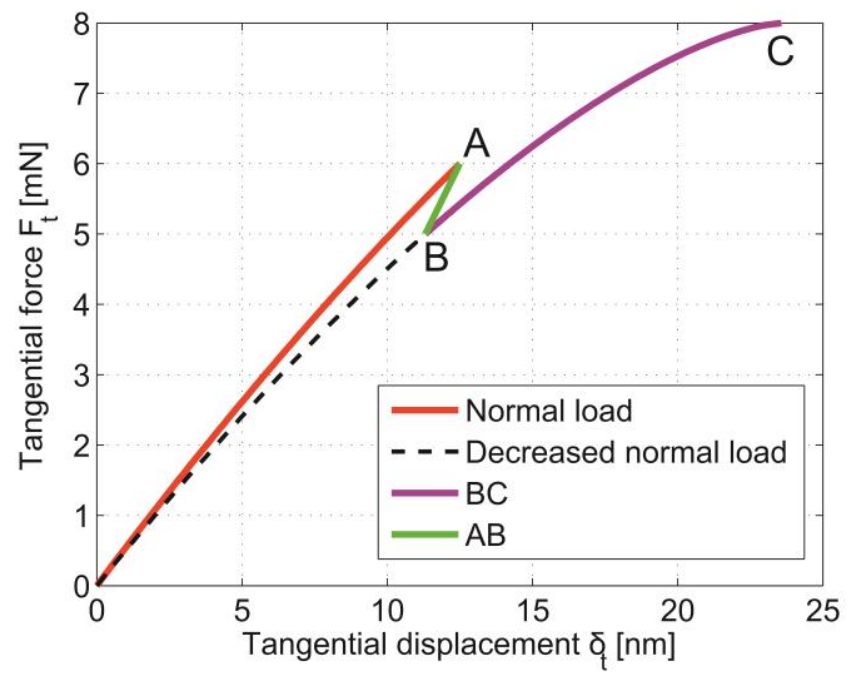

b)

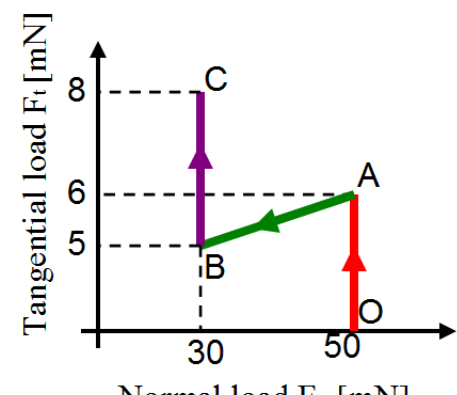

Normal load $F_{\mathrm{N}}[\mathrm{mN}]$

Figure 2.11: a) Tangential displacement and tangential force relation in the pre-sliding regime for decreased normal load and increased tangential load and b) schematic representation of normal and tangential load, after [19].

The tangential displacement will follow point $A$ to $C$ according to the marked lines. Reduction in normal load will cause the contact area to be reduced also. This means that the tangential traction will not be maintained in the contact for a short time, so it is necessary to release the existing tangential traction from this region. Slip will not take place and the distribution of traction needs to be approached. The contact area will be free of traction and this will help in calculations to avoid area where no slip occurs. 
The other situation is when the normal load is reduced and the tangential force is decreased as well. This is shown in Figure 2.12.

a)

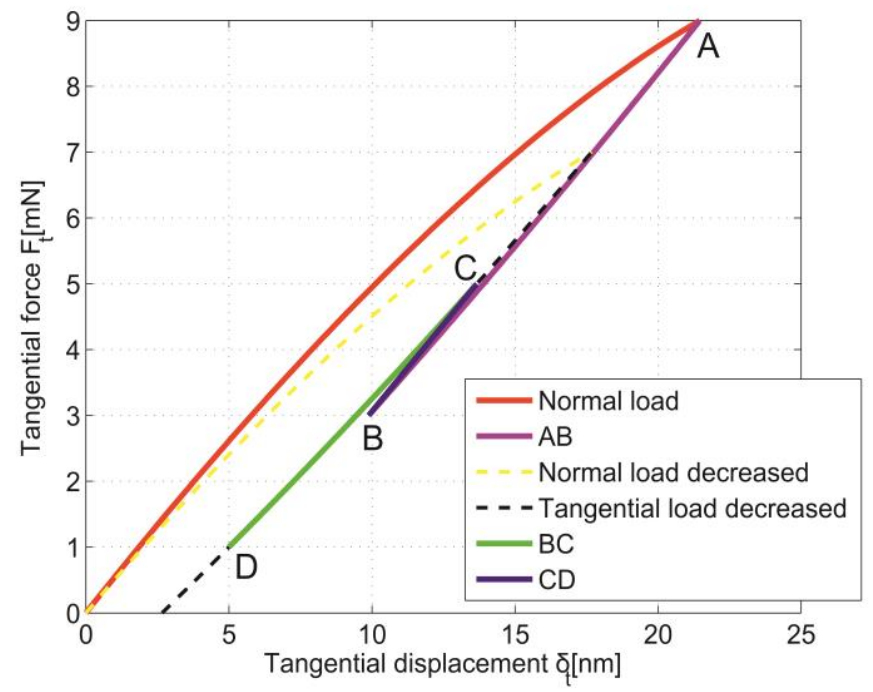

b)

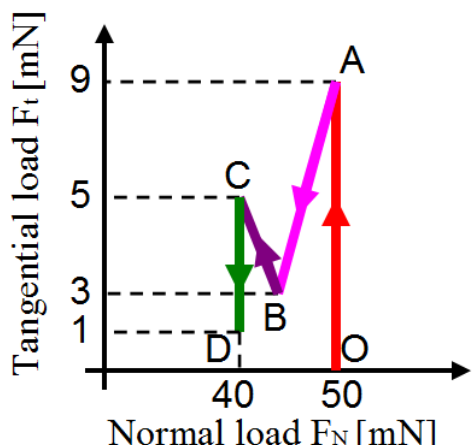

Figure 2.12: a) Tangential displacement and tangential force relation in the pre-sliding regime for decreased normal load and decreased tangential load and b) schematic representation of normal and tangential load, after [19].

The initial normal load is $50 \mathrm{mN}$, and then decreased to $40 \mathrm{mN}$ (Figure 2.12 (b)), and, similar to the previous case, in the contact area there will be no slip for a short time, so the area is 'frozen'. There will be no shear stresses in that area. The decrease in normal load will cause the removal in the traction, so the tangential force needs also to be decreased to reach the right traction distribution. In the next step, slip will progress in the opposite direction of the initial tangential force and the tangential displacement will follow path $B C$. With a further decrease in tangential 
load to, for example, $\operatorname{ImN}$ the displacement will follow curve $C D$. A decrease of the normal load in the pre-sliding regime similar to Section 2.2.3.1 presents how the tangential displacement can be influenced by variation of the normal and tangential loads. The loading history in all those cases has an influence on the preliminary tangential displacement.

In this section, only pre-sliding behaviour of the tangential displacement has been discussed and, even in this region, variations are possible which influence the moment when a system starts sliding. In the case of the full sliding situation, the tangential load is constant and the value depends on the applied normal load and the coefficient of friction. The tangential displacement after the maximum preliminary displacement will increase according to the given sliding distance.

\subsection{Multi asperity contact}

A multi asperity contact is relevant for the case of two rough surfaces in contact. The contact between surfaces occurs at discrete locations (visible as red) in Figure 2.13. The sum of these micro contacts is the real contact area, which is different from the nominal contact area. The analysis of such contact is more complex than a single asperity contact because the shape and the height of an asperity does not have a simple shape as a sphere, but can be irregular. Furthermore, a dispersive contact is composed of many different individual asperities.

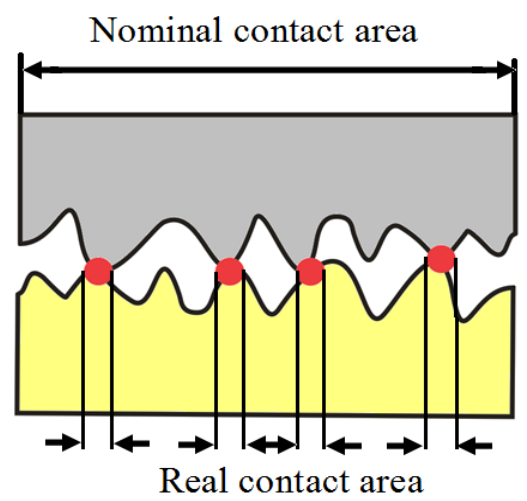

Figure 2.13: Multi asperity contact. 
Bowden and Tabor [11] assumed that asperities of rough solid surfaces in contact locally deform plastically. The result is a direct proportionality between the normal load and real area of contact.

Many multi asperity contact models are described and compared in the literature $[4,6,19]$. Bhushan [9] reviews contact models for rough surfaces under dry and wet conditions. The roughness distribution and mechanical properties will influence the real contact area, surface stresses and meniscus force for a wetted contact. Greenwood and Williamson were pioneers in developing a contact model for a multi asperity contact [8]. The authors made a model, based on Archard's idea, of two rough surfaces with given random height distribution, as shown in Figure 2.14, and assumed hemispherical asperities; with the same radius but each asperity has a different height.

\section{rough elastic body}

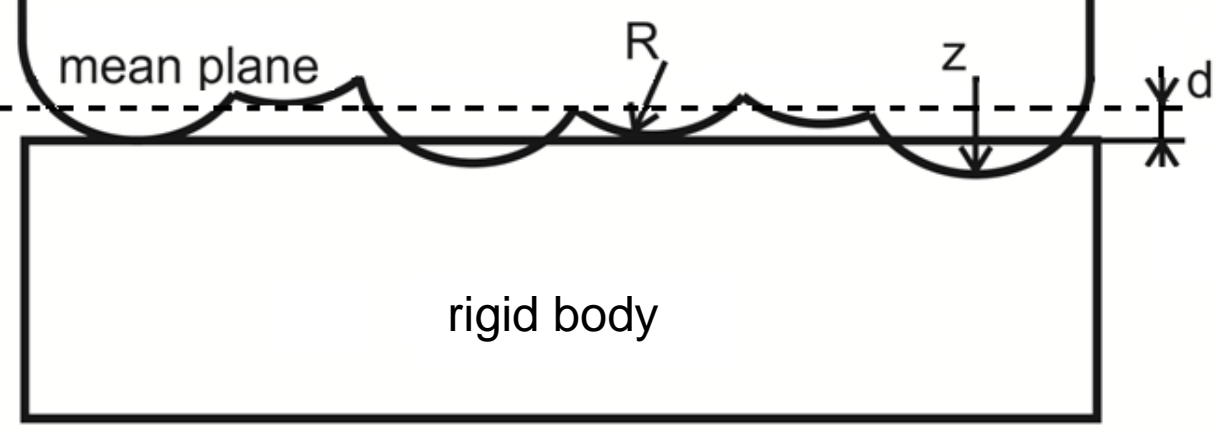

Figure 2.14: The Greenwood - Williamson model of contact for rough surfaces.

In Figure 2.14, the separation between the two bodies in contact is defined by $d$, the radius of an asperity $R$, summit mean plane and $z$ the summit height with the indentation $\delta=z-d$, and the radius $a$ of the circular contact area of one asperity is given by Hertz :

$$
a=(R \cdot \delta)^{1 / 2}
$$

and the contact area of an asperity contact is: 


$$
A=\frac{4 \cdot E^{\prime}}{3 \pi \cdot F_{N}} \cdot\left(\frac{\delta}{R}\right)^{1 / 2}
$$

Where $E^{\prime}=E /\left(1-v^{2}\right)$.

The summit heights with respect to the summit mean plane are distributed according to the Gaussian probability distribution with standard deviation $\sigma_{\mathrm{z}}$. The radius of the summits is assumed to be equal for all asperities. The estimated area of real contact $A_{\text {real }}$ and the mean pressure $p_{m}$ on the nominal contact area $A_{O}$ are given by Greenwood and Williamson [8]:

$$
\begin{gathered}
\frac{A_{\text {real }}}{A_{O}}=\pi \sigma_{z} R D_{\text {sum }} \int_{d^{*}}^{\infty}\left(x-d^{*}\right) \phi(x) d x \\
\frac{p_{m}}{A_{O}}=\frac{4}{3} E^{\prime} R^{1 / 2} \sigma_{z}^{3 / 2} D_{\text {sum }} \int_{d^{*}}^{\infty}\left(x-d^{*}\right)^{3 / 2} \phi(x) d x
\end{gathered}
$$

Where the $x=z / \sigma_{z}, d^{*}=d / \sigma_{z}$, and $\phi(x)=(2 \pi)^{-1 / 2} \exp \left(-x^{2} / 2\right)$. The values of $R, \sigma_{z}$ and number of summits per unit area $D_{\text {sum }}$ should be estimated [21].

Onions and Archard [22] presented a surface with random structure in contact. The important factor in their studies for a rough surface is the distribution of asperities. In that model the plasticity is included in the calculation and a distribution of asperity radii, which increase the contact area independently from load and nominal area and cause an increase in plastic flow. The elastic contact of a rough isotropic surface was investigated by Bush and Gibson [23]. The authors show that the separation value has an influence on contact area and load and will depend on micro geometry of the surface. It was shown that the relation between contact area and load is proportional or approximately linear. Carbone et al. [21] compare the relation between contact area and load of different multi asperity contact models of Greenwood-Willamson-McCool, Bush-Gibson-Thomas (BGT), Greenwood (2006), Nayak-Thomas (NT) and Persson's theory. It was shown that the linearity between nominal load and real contact area is possible for large separations which can be much more than six times the roughness $R M S$ of the surface profile, so not for realistic contact areas. Persson's theory shows that the linear behaviour between 
contact area and load is valid for a contact area of around $10-15 \%$ of the nominal contact area.

\subsubsection{Pre-sliding behaviour for multi asperity contact}

The single asperity contact and the Mindlin theory for pre-sliding behaviour helps to understand a multi asperity contact. The extension of the Mindlin model for a multi contact interface was already presented by Bureau et al. [24]. The authors present how to differentiate which asperities are in contact. The separation plays an important role in that approach. For those asperities whose height is lower than the separation distance between a rough and a flat surface, the tangential force will not be applied. Otherwise, asperities will carry a tangential force equal to the friction force and only sliding will take place for those asperities. It was also concluded that after shearing, the micro contacts are worn off and replaced by new asperities in contact. The original contact condition is therefore most probably not close to the contact situation after some sliding has occurred. Huang $[25,26]$ in his research focuses on rough interface behaviour. The calculations show that the energy dissipation is path dependent during loading. In his thesis [25] the extension of the Mindlin assumption was presented for a variety of loads and initial tangential traction. The coupling effect for a rough interface between normal and tangential load was compared for a smooth and rough contact. More studies on contact and asperity distribution influencing sliding behaviour have been done by [27 - 29].

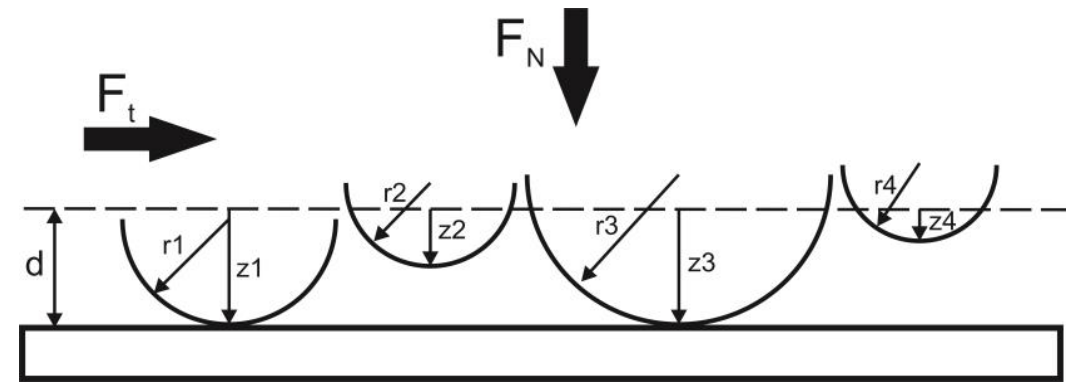

Figure 2.15: Multi asperity contact under normal $F_{N}$ and tangential load $F_{t}$. 
As an example, in Figure 2.15 a multi asperity contact is loaded by a normal $F_{N}$ and tangential force $F_{t}$. Each asperity has its own summit height $z_{n}$ and radius $r_{n}$, with separation distance $d$ between the mean plane from rough surface and smooth flat. The model of different summit heights and radii, where each asperity carries locally a normal load and tangential load, will be explained more in detail in Chapter 5 .

\subsection{Summary}

Theoretical contact models for a single and multi asperity were introduced in this chapter. There are many models available in the literature. The Hertz theory calculates the contact area under normal load condition. The $J K R, D M T$ or $M-D$ models include, besides normal load, surface forces also. Adhesion plays a very important role in a single asperity contact. The adhesion map is useful to decide which model is suitable for a given material and applied load.

The pre-sliding behaviour for a single asperity contact was introduced by the Mindlin theory, where besides the normal load also a tangential load is applied to the contact. With increasing tangential force, the maximum preliminary tangential displacement can be calculated to determine when the system starts sliding. In a situation where the normal load is decreasing during pre-sliding, wear then takes place. With increasing normal load there will be no influence on wear. The behaviour in the pre-sliding regime will influence the contact stiffness.

Multi asperity contact models have also been described in this chapter. Most of the models assume that the geometry of the summits is similar and the distribution of asperities is important. In the Greenwood-Williamson model the rough surface has asperities with the same radius but the summit heights are different. Based on separation distance and asperities in contact, the tangential displacement is calculated. However, more studies need to be carried out to analyse the pre-sliding behaviour of a multi asperity contact. Roughness or changes in load for a multi asperity contact will have a large effect on the pre-sliding behaviour. The wear of asperities in the contact is important to understand the tangential displacement 
changes in that region. Properly defined asperity details will then be very critical for the pre-sliding behaviour. 



\section{CHAPTER 3}

\section{MEASUREMENT}

\section{TECHNIQUES FOR SURFACE}

INVESTIGATION ${ }^{1}$

\subsection{Introduction}

Sliding friction is determined by the micro geometry of the surfaces as well as the physical and chemical properties of the materials (at the surface) in contact. Surface changes in a wear track due to wear and material transfer explain the drift in friction level which, for instance, causes inaccuracies in positioning of stages. In this chapter, the theoretical background of the measurement techniques used in the surface investigation will be described. A setup with a confocal height sensor to measure the local height changes on the wear track, combined with confocal Raman

\footnotetext{
${ }^{1}$ Reproduced from: Winogrodzka A., Valefi M., de Rooij M.B., Schipper D.J., Measurement of chemical and geometrical surface changes in a wear track by a confocal height sensor and confocal Raman spectroscopy, Archives of Civil and Mechanical Engineering 01/2014; 14(1), pp.1-5.
} 
spectroscopy to determine the chemical changes at the surfaces, will be introduced. The engineering materials used in this study are ceramics, which are widely used in industry as insulators in power transmission systems, optics, journal bearings, MEMS systems and so on [30]. The ceramics used in this study are commonly used ceramics such as silica $\left(\mathrm{SiO}_{2}\right)$, silicon $(\mathrm{Si})$, alumina $\left(\mathrm{Al}_{2} \mathrm{O}_{3}\right)$ and zirconia $(\mathrm{Y}-\mathrm{TZP})$.

In this chapter, the wear tracks resulting from wear experiments performed on a pin-on-disc tester between $\mathrm{Al}_{2} \mathrm{O}_{3}$ and $\mathrm{Y}$-TZP ware analysed at room temperature and at elevated temperature $\left(600^{\circ} \mathrm{C}\right)$. The wear tracks have been generated in the mild and severe wear regimes. It will be shown that the confocal height sensor and Raman Spectroscopy techniques as a combined setup can be successfully used to measure and understand the geometrical and chemical changes occurring at the surface of a wear track.

\subsection{Theoretical background}

Various measuring techniques are available to investigate wear between ceramics. Optical methods based on light scattering are widely used to study the change in the surface topography due to wear [31, 32]. Confocal microscopy can be used to analyse the micro geometry of surfaces in detail [33]. Miyake et al. [34] used the confocal laser microscopy to determine wear by observing profiles of microgrooves in $\mathrm{Al}-\mathrm{Al}_{2} \mathrm{O}_{3}$ composite surface. The advantages of using confocal microscopy are the high spatial resolution together with high accuracy and the possibility of applying it to different kinds of materials. In a confocal chromatic optical setup, the chromatic light is used to get complete parallelization of the depth scan, so rough surfaces within the measuring range are measured [31, 35].

Atomic force microscopy $(A F M)$, energy dispersive microscopy $(E D S)$ and X-ray photoelectron spectrometry $(X P S)$ are common techniques to measure the presence of elements on the surface [36,37]. Sample pre-preparation is required for some of the aforementioned techniques, which is a disadvantage when studing surface changes in a wear track. Furthermore, during a measurement there is the possibility of damaging the surface due to the test conditions. Raman spectroscopy is a non- 
intrusive technique, where sample preparation is not necessary. Confocal Raman spectroscopy is more suitable for ceramics, because of the high spatial resolution and reduced fluorescence effect [38, 39]. Many studies have been done on zirconia [40, $41,42]$ and alumina $[43,44]$ using Raman spectroscopy. For example, the structural phase transition of $\mathrm{Al}_{2} \mathrm{O}_{3}$ was observed by Cava et al. [44]. The ability of the Raman spectroscopy to detect phase changes in the contact due to mechanical stresses was demonstrated by several authors [40 - 44].

\subsubsection{Confocal microscopy}

A confocal microscope is generally used to obtain the surface micro geometry for a variety of materials. The optical lateral resolution is increased to get true depth discrimination with high numerical aperture objectives [45, 46]. In principle, parts of the object, which are in the region of focus, appear sharp and bright in the corresponding image plane, whereas parts that are outside the focus appear blurred and dark.

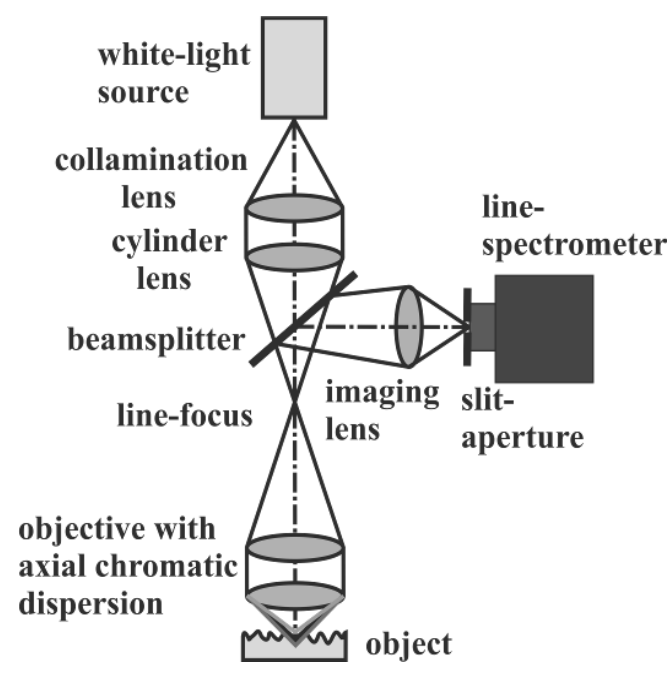

Figure 3.1: Chromatic confocal principle after [35].

A confocal chromatic optical setup [30,35] uses chromatic light, as shown in Figure 3.1. A rough surface within the measuring range can be measured. Compared 
to a standard confocal microscope, a chromatic confocal microscope uses an objective with chromatic light dispersion. That means that the signal is based on the wavelength and the frequency of the light.

\subsubsection{Confocal Raman spectroscopy}

A confocal Raman spectroscope analyses the chemical composition of materials with a high optical spatial resolution. Raman spectroscopy detects vibrations of molecules based on infrared absorption and Raman scattering. Raman scattering is shown in Figure 3.2 as vibrational and virtual energy states of the molecules. Depending on the material composition, each element has its own energy level. When light interacts with matter then some of the light is absorbed (infrared absorption), transmitted and the rest of the light is scattered. Rayleigh scattering is possible when an incident photon has the same frequency as the scattered photon; the absence of energy in that case is transferred (red arrow). In Stokes Raman scattering, the final state after scattering is not equal to the original state before scattering; there will be some shift in frequency due to rotational or vibrational states in the molecules. Raman scattering will take place when the light scattering is accompanied by a shift in frequency. When the frequency of light is less than the incident frequency then it is called Stokes Raman scattering. If the frequency is higher than the incident frequency then anti-Stokes Raman scattering occurs. The molecule at higher virtual energy level loses energy and ends in a lower vibrational energy level after interaction with incident photon (purple arrow) [47, 48]. 


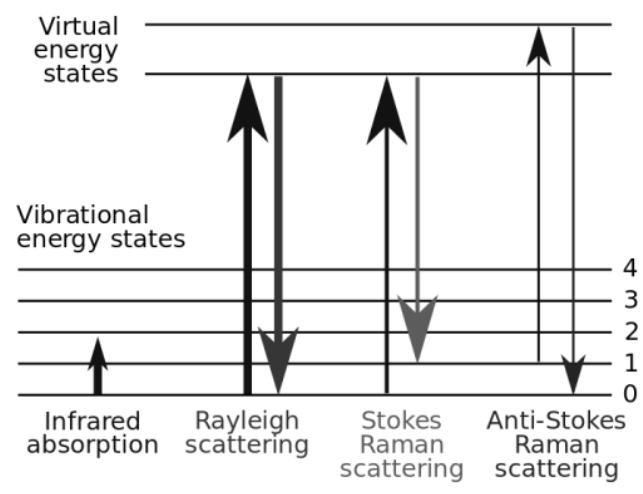

Figure 3.2: Light scattering with virtual energy states and vibrational energy states [47].

Raman scattering provides information on chemical structures and physical forms, to identify substances from characteristic spectral patterns and determine quantitatively or semi-quantitatively the amount of a substance in a sample [38]. The schematic layout of a confocal Raman microscope is shown in Figure 3.3. The laser light is focused on the sample through objectives and excites the molecules to vibrate. Due to changes in energy level and polarization, the back scatter light is reflecting with different wavelengths through optics to a spectrometer and $C C D$ camera. The results from the spectrometer are a Raman shift (wave number) and intensity. The Raman shift is characteristic for specific bonds between molecules present on the surface and is independent of the frequency of the incident light. 


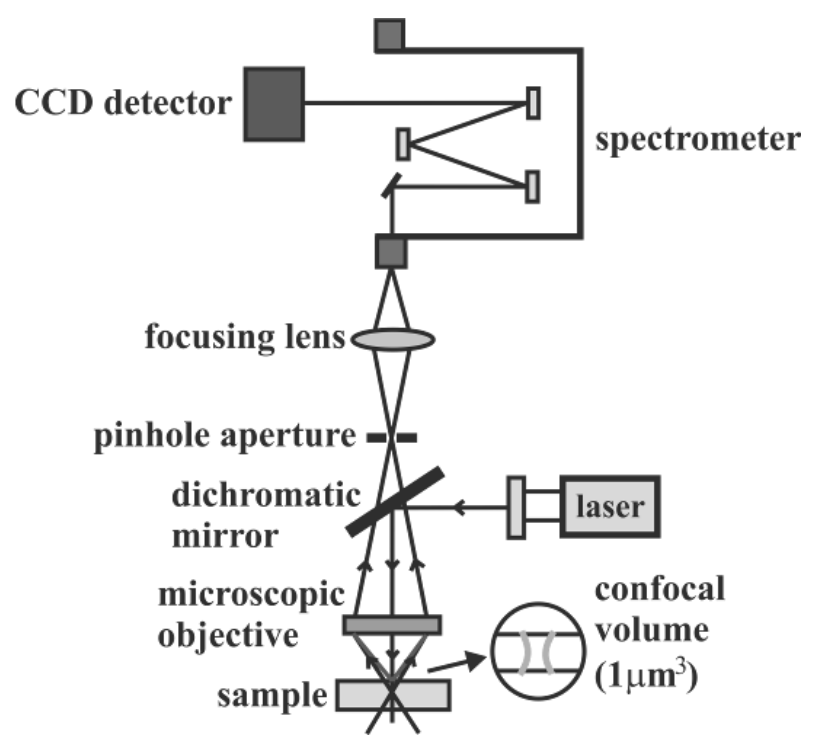

Figure 3.3: A confocal Raman microscope principle after [34].

\subsection{Engineering materials}

The engineering materials which have been chosen for this study are ceramics. Compared to metals or polymers, ceramics are normally brittle at room temperature, have a thermal expansion different from steel and often show poor thermal conductivity. The tribological applications of ceramics are mainly in environments where high temperatures are involved, corrosion can take place, high loads are applied or adhesion can cause problems [45].

The experiments performed are described in Chapter 4 and Chapter 5. Silicon is a non-metallic material which can share outer electrons and create chemical bonding with other elements. In room temperature $S i$ is solid with a high melting point; however, in liquid state the density is higher than in solid state. Silicon is a semiconductor so is very often used in electronics, especially in micro electric mechanical systems (MEMS).

Silica $\left(\mathrm{SiO}_{2}\right)$ is an oxide of silicon, a polymorphic raw material which can be found in an amorphous or crystallized form in nature. Pure silica melts at very high temperatures and produces a very viscous liquid. It can also crystallize in different 
forms of crystal symmetry depending on temperature conditions. In general, silica is used in the glass industry, biology and in electronics [30].

Alumina $\left(\mathrm{Al}_{2} \mathrm{O}_{3}\right)$ and zirconia $\left(\mathrm{ZrO}_{2}\right)$ are ceramics which represent a multi asperity contact because they are rougher than $\mathrm{Si}$ or $\mathrm{SiO}_{2}$ (Appendix B) as these materials are typically sintered from powder. Aluminium oxide $\left(\mathrm{Al}_{2} \mathrm{O}_{3}\right)$ is a very hard, temperature and corrosion resistant material of good strength and thermal conductivity. The thermal expansion coefficient is lower than steel. Seizure resistance is fair, but the material is not self-lubricating and it typically shows a high coefficient of friction against many counter surfaces. There are different forms of alumina which also influence application of that material. In a form as a single crystal it is used, for example, in windows and bearings. Hot - pressed powders can be found in electrical insulators, windows, electrical devices and as a polycrystalline in refractory brick, crucibles and spark-plug insulators [36].

Zirconium oxide $\left(\mathrm{ZrO}_{2}\right)$ is a material useful in high temperature optical and electronic technologies. It is typical for structural - phase transitions, because it can exist in several crystal structures. There are different types of zirconia depending on the composition:

- TZP (tetragonal zirconia polycrystal) - with 2-4 \% mol $\mathrm{Y}_{2} \mathrm{O}_{3}$.

- PSZ (partially stabilized zirconia) - with 5-7\% mol $\mathrm{MgO}, \mathrm{CaO}$ or $\mathrm{Y}_{2} \mathrm{O}_{3}$.

- CSZ (cubic stabilized zirconia) - with $>8 \%$ mol $\mathrm{Y}_{2} \mathrm{O}_{3}$.

- ZTC (zirconia toughened ceramics) - which contain $\mathrm{Al}_{2} \mathrm{O}_{3}$ [50].

Zirconia has a high melting temperature $\left(2700^{\circ} \mathrm{C}\right)$, low thermal conductivity and is used generally for insulation components. A high toughness is very good for a dry sliding system, which has to operate at low sliding velocities [46].

The material properties are given in Appendix B.

\subsection{Surface measurement setup and obtained results}

The measurement techniques which were described in Section 3.2 have been used to build a measurement setup for investigating the wear track. The setup is developed in such a way that it can be implemented in a vacuum system. A 
photograph of the experimental setup is shown in Figure 3.4 (a), and in Figure 3.4(b) the schematic is shown.

The confocal height sensor (STIL CL1-MG210) is connected through an optical fibre to a controller (CCS Prima). The chromatic light from the controller is measuring the local surface height with a working distance of $3.3 \mathrm{~mm}$ and a nominal measuring range of $100 \mu \mathrm{m}$. The spot diameter of the sensor is $2 \mu \mathrm{m}$ and it has a height resolution of $5 \mathrm{~nm}$. The controller sends data to a computer. The Raman setup is composed of a laser (Ventus Laser) with wavelength $532 \mathrm{~nm}$ and an average power of $50 \mathrm{~mW}$. The green light from the laser is transmitted from optical fibres to a sensor (Horiba Super Head - 532) with an objective lens of 50x (N.A. 0.5). Scattered light from the sample coming back through the sensor is sent to a spectrometer (iHR320) by fibre optics. The measured spectrum is continuously monitored and recorded by the computer. The linear translation stages with the DC motor are moving the sample in two directions ( $X$ and $Y$ ). The positioning accuracy of the stages is $1 \mu \mathrm{m}$. A Labview program has been written to control the system and record the data. As the relative position of the two sensors is accurately known and has about the same lateral resolution, the same spot on the wear track can be analysed by both sensors.

a)

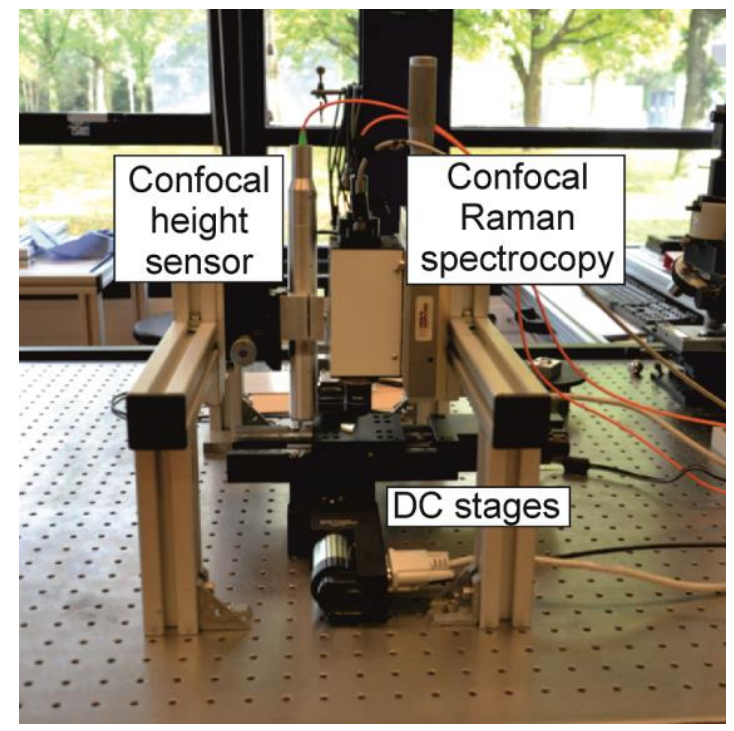


b)

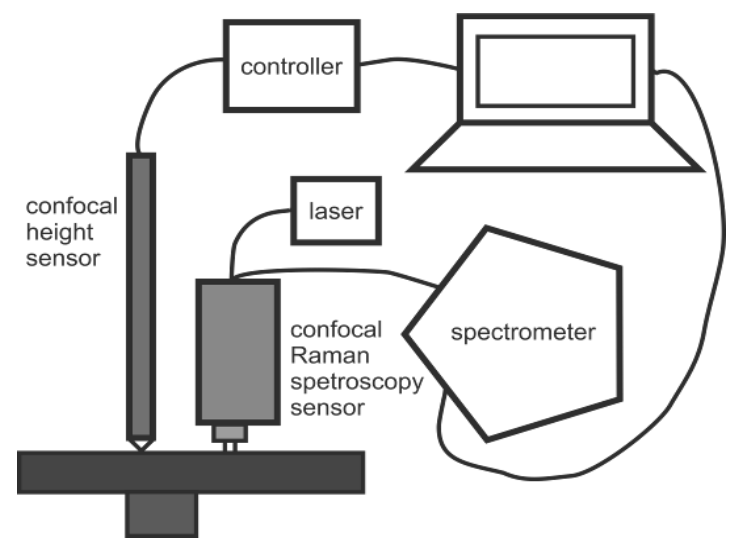

Figure 3.4: Confocal height sensor and confocal Raman spectroscopy setup a) picture and b) schematic layout.

The measurement setup has been used to analyse a wear track and the difference in the wear tracks generated in, respectively, the mild and severe wear regimes of alumina and zirconia. First the wear track was generated using a pin-on-disc tester for two temperature conditions and then investigated under the confocal sensor and Raman spectroscopy sensor. The results are presented below.

\subsubsection{Pin-on-disc tests}

Friction measurements were carried out using a high temperature pin-on-disc tester at two different temperatures, where an alumina ball with diameter of $10 \mathrm{~mm}$ was sliding against a zirconia disc. The tribological test conditions applied are: load $5 \mathrm{~N}$, velocity $0.1 \mathrm{~m} / \mathrm{s}$ and a sliding distance of $1 \mathrm{~km}$. The tribological tests were performed at room temperature and at $600^{\circ} \mathrm{C}$. More details of the sample preparation are discussed in [36]. The properties of the materials used in this study are summarized in Appendix B. The coefficients of friction which were measured during the experiments are shown in Figure 3.5 for the different temperature conditions. The sliding distance is presented along the horizontal axis and the coefficient of friction on vertical axis. The average coefficient of friction obtained at room temperature was 0.5 and at $600^{\circ} \mathrm{C}$ a coefficient of friction of 0.8 was measured. 


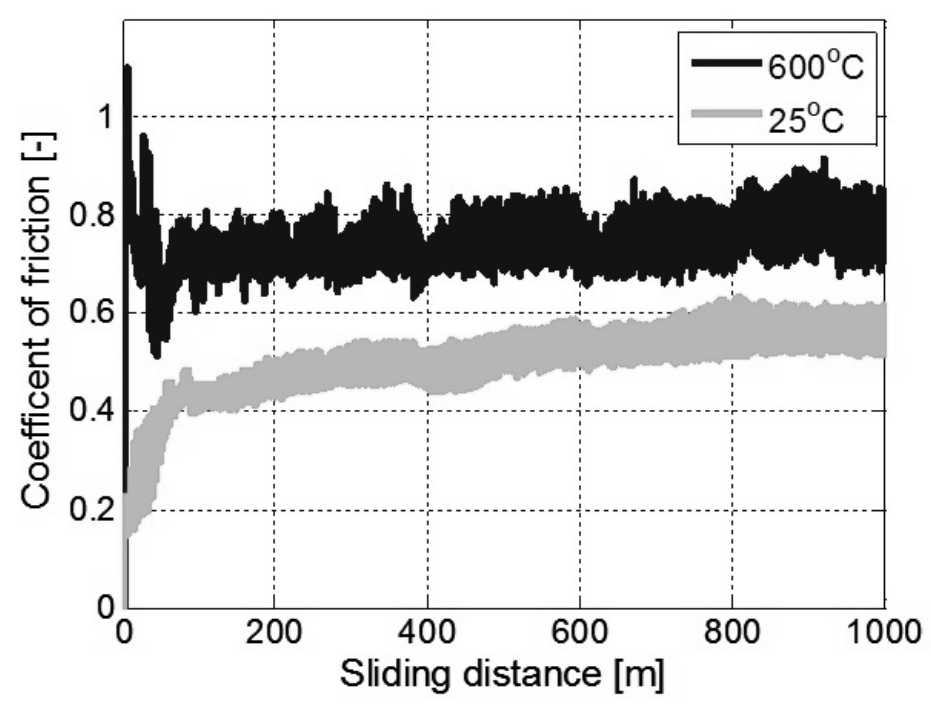

Figure 3.5: Friction level of $3 \mathrm{Y}$-TZP sliding against $\mathrm{Al}_{2} \mathrm{O}_{3}$ at room temperature and $600^{\circ} \mathrm{C}$.

\subsubsection{Results}

Figure 3.6 shows the schematic representation of the areas studied of the sample for geometrical measurements.

The area measured by the confocal height sensor across the wear track at room temperature is $1 \mathrm{~mm}$ in $X$ direction and $0.2 \mathrm{~mm}$ in $Y$ direction. For the high temperature $1.3 \mathrm{~mm}$ in $X$ and $0.2 \mathrm{~mm}$ in $Y$ direction is measured to cover the wide wear track.

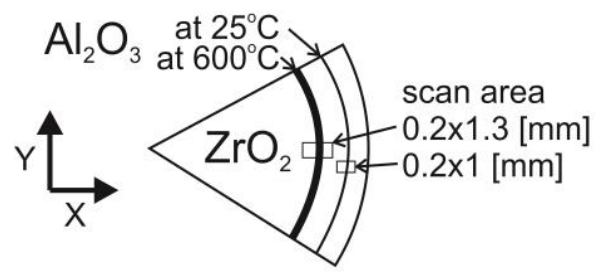

Figure 3.6: Area analysed on the disc sample.

The result of the surface height measurements obtained with the confocal height sensor is presented in Figure 3.7, where the overall view of the scanned area is 
visible as a 3D image. The wear track made at room temperature and at high temperature is shown in Figure 3.7 (a) and Figure 3.7 (b), respectively.

a) $3 \mathrm{D}$ view of wear track at room temperature
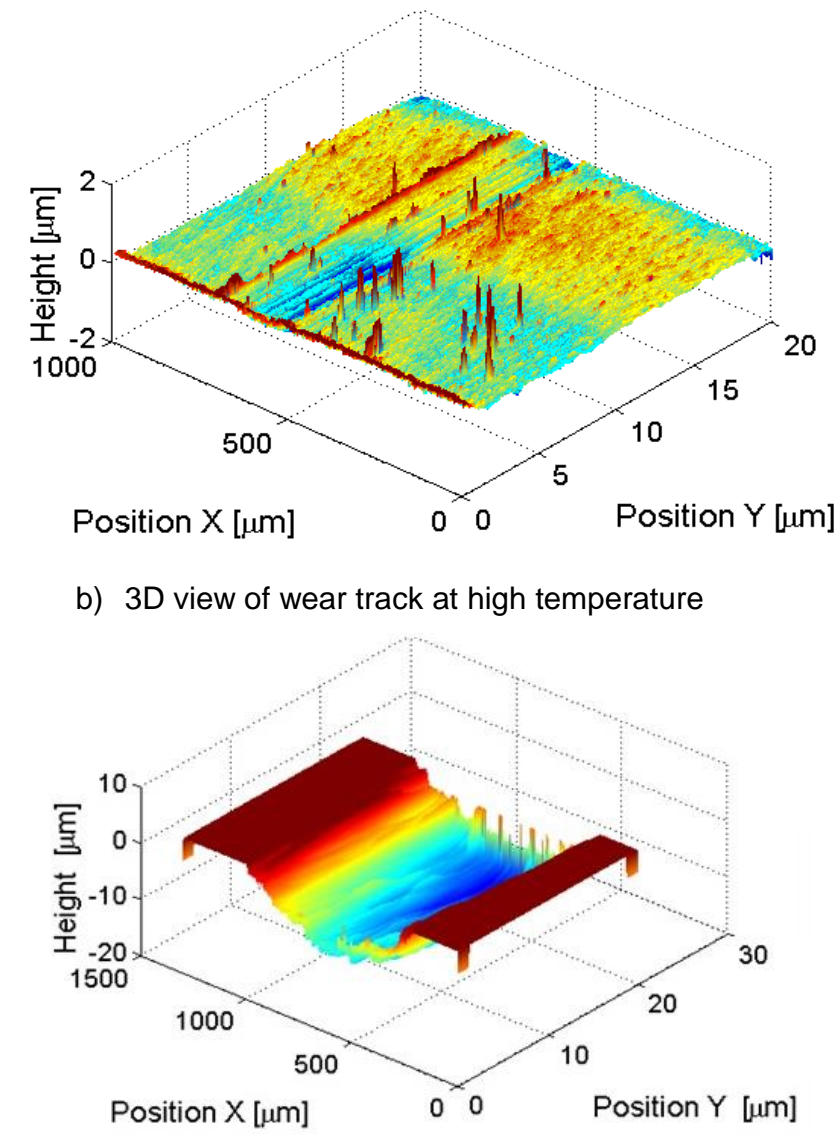

Figure 3.7: Confocal height sensor image in 3D view of wear tracks.

The profile across the wear track for images in Figure 3.7 is represented in Figure 3.8 (a) and (b) respectively for room temperature and at $600^{\circ} \mathrm{C}$. The horizontal axis corresponds to measured points across the wear track and the vertical axis represents the height changes.

The peaks with various heights were observed in the wear track due to the wear process, which is visible in Figure 3.7 and Figure 3.8. These peaks suggest also that material from the counter surface was transferred to the disc. 


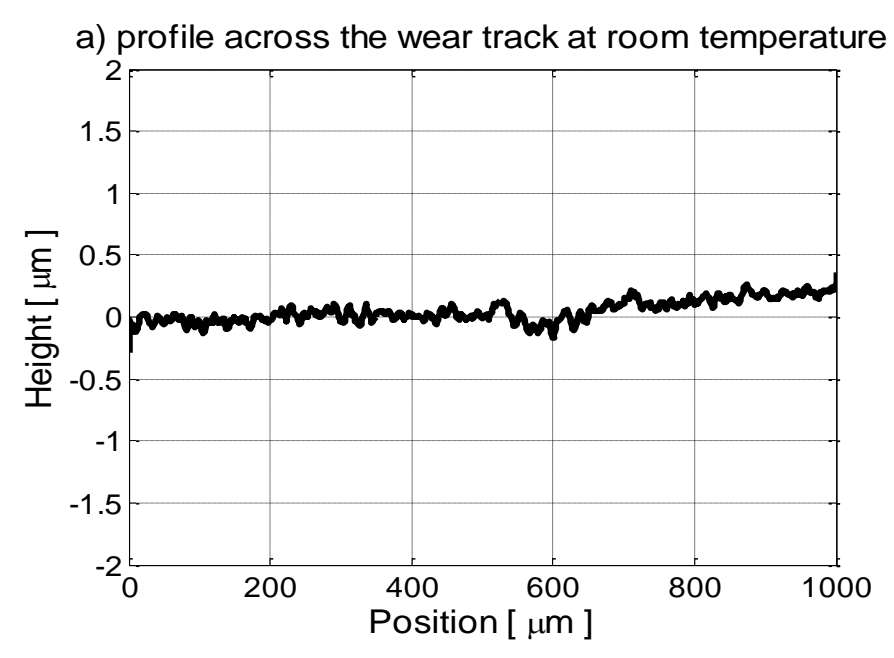

b) profile across the wear track at high temperature

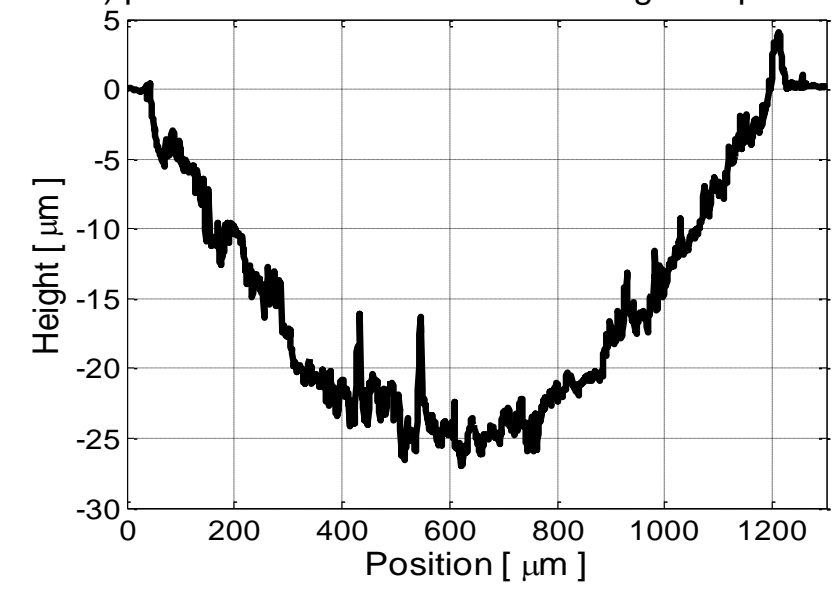

Figure 3.8: The surface height profile across the wear tracks.

At room temperature the wear track is significantly smaller in size as compared to $600^{\circ} \mathrm{C}$ where the contact is operating under severe wear conditions [46].

Material transfer observed in the profile of the wear track was confirmed by the confocal Raman spectroscopy. Measurements were conducted at three locations on the disc, one outside the wear tracks and one for each wear track. The wear track across the disc at room temperature is very narrow, approximately $200 \mu \mathrm{m}$. In this wear track no material transfer was observed; therefore, the Raman spectra are not shown. The results obtained for the disc at $600{ }^{\circ} \mathrm{C}$ are presented in Figure 3.9. 


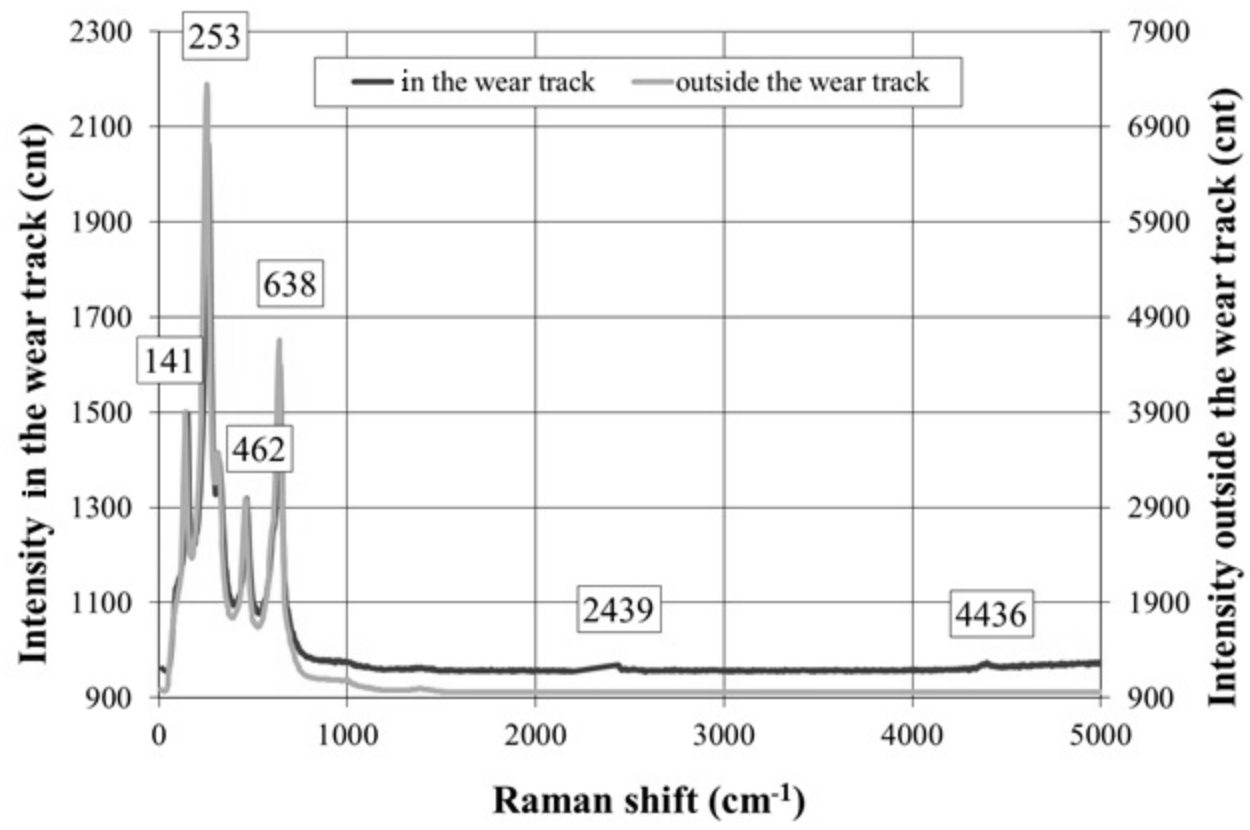

Figure 3.9: Raman spectrum outside and in the wear track of the zirconia disc, experiments have been performed at $600^{\circ} \mathrm{C}$.

Figure 3.9 shows the measured light intensity against the Raman shift for outside and inside the wear track. Outside the wear track only Raman shifts of zirconia are visible at $141,253,462,638,2439 \mathrm{~cm}^{-1}$ respectively [51]. Inside the wear track besides zirconia, an alumina bond can be observed at $4436 \mathrm{~cm}^{-1}$ for high temperature conditions [52]. The intensity and amount of alumina bonds is lower compared to zirconia, which indicates that only small amounts of $\mathrm{Al}_{2} \mathrm{O}_{3}$ are found in the wear track. The wear track tested under room temperature conditions does not show significant changes in the spectrum as compared to the spectrum measured outside the wear track. At room temperature the hardness of the ceramics is higher. Furthermore, the changes in the surface roughness at room temperature are lower than for $600^{\circ} \mathrm{C}$.

The ball used in the high temperature test was also measured at two spots, one in the wear scar and one outside the wear scar. The Raman shifts obtained for the $\mathrm{Al}_{2} \mathrm{O}_{3}$ ball at two locations are presented in Figure 3.10. 


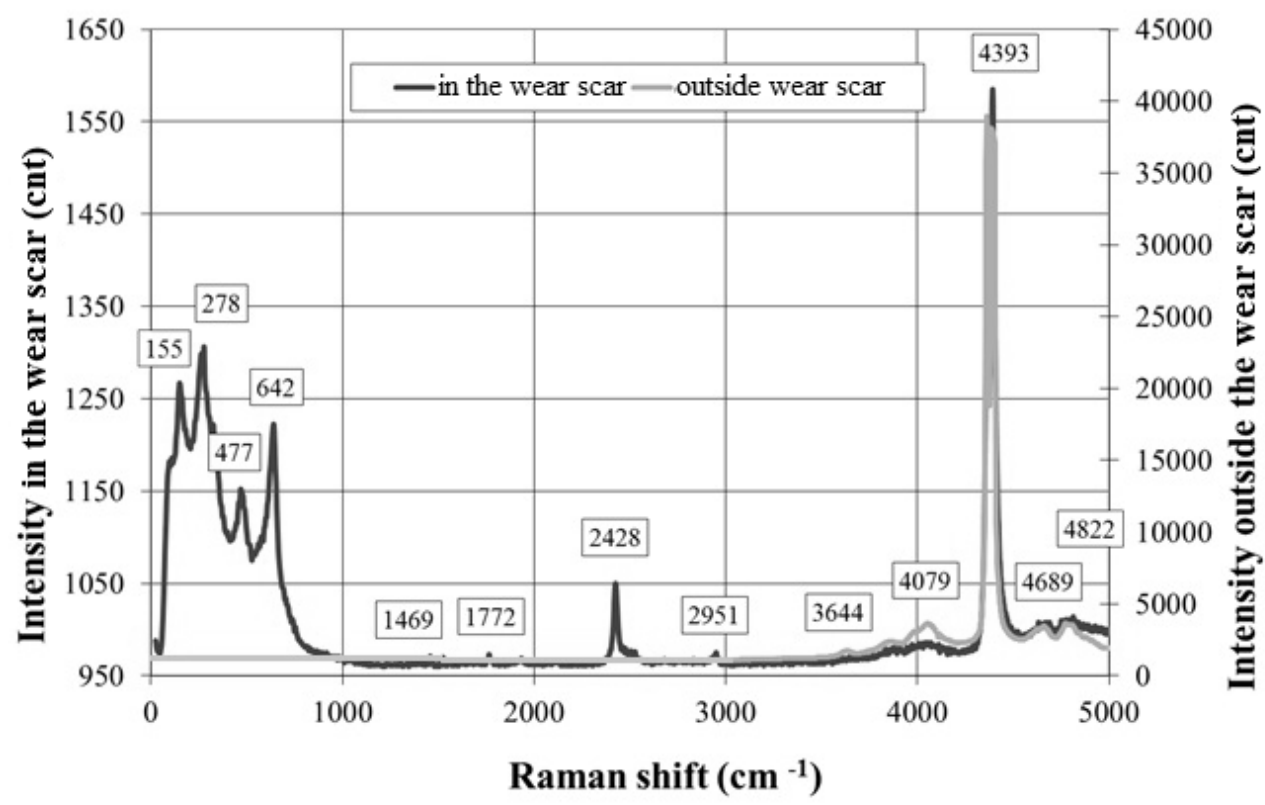

Figure 3.10: Raman spectrum of alumina ball in the wear scar and outside wear scar, experiments have been performed at $600^{\circ} \mathrm{C}$.

The Raman shifts for alumina bonds outside and in the wear scar of the ball are visible at 4079, 4393, 4689 and $4822 \mathrm{~cm}^{-1}$. In the wear scar, a zirconia transfer layer after the wear test was measured. The formation of a transfer layer during sliding of ceramics has been reported in the literature $[39,53]$. The shifts at $155,278,477,642$ and $2428 \mathrm{~cm}^{-1}$ represent zirconia bonds. When compared to the zirconia disc, those shifts have different values and correspond to the monoclinic phase of zirconia. It can be concluded that, with respect to zirconia, during the wear process the phase changed from tetragonal to monoclinic. The tetragonal to monoclinic transformation is ascribed to the presence of thermal stresses due to the sliding contact and poor thermal conductivity of zirconia [54]. Moreover, substances were found on the ball organic at 1469 and $1772 \mathrm{~cm}^{-1}$. 


\subsection{Discussion and conclusion}

The geometrical changes were measured by the confocal height sensor. The results clearly show how the surface topography changes in and outside the wear track. The difference of mild and severe wear due to temperature conditions was observed by comparing the surface geometrical modifications. At room temperature, where mild wear takes place, the resulting wear track is narrow compared to the wear track obtained at $600^{\circ} \mathrm{C}$. The coefficient of friction was significantly lower at room temperature than for the high temperature conditions. The confocal Raman spectroscopy shows chemical changes in the wear tracks of both the disc and the ball. The measured material composition inside and outside the wear track is different, which indicates that material transfer occurred during the wear process. The transfer was observed from the pin to the disc as well as from the disc to the pin. Material transfer has already been reported to occur for many ceramics [54]. With the increase in temperature, the hardness of ceramics decreases. Generally, materials with a larger expansion coefficient tend to soften with increasing temperature [55]. Based on the observation at $600^{\circ} \mathrm{C}$ the decrease in the mechanical properties resulted in more material transfer when compared to room temperature conditions. During material transfer between alumina and zirconia, a phase transformation from tetragonal to monoclinic was observed in the case of zirconia after the wear tests. The changes of the structure of the wear debris indicate that during the wear process at high temperature the particles of $Y-T Z P$ can transform to monoclinic $\mathrm{ZrO}_{2}$.

\subsection{Summary}

In this chapter, measurement techniques for surface investigation have been described. Engineering materials like ceramics have also been introduced in tribological applications. In addition, the measurement setup composed of a confocal height sensor and a confocal Raman spectroscopy was used to investigate the wear track generated on a ceramic sample at room temperature and at $600^{\circ} \mathrm{C}$. It was shown that wear transformed the crystal structure, which was especially clear at 
elevated temperatures. Confocal Raman spectroscopy was successfully used to investigate the wear tracks and formation of a transfer layer in the wear track. The measurement system can be used in future to analyse the composite layers of ceramics like, for example, in self-lubricating composites. Furthermore, in this thesis the setup will also be used to show changes in the wear track made under vacuum and ambient conditions. 


\section{Chapter 4}

\section{NORMAL LOADING OF A}

SINGLE ASPERITY

CONTACT $^{2}$

\subsection{Introduction}

The pre-sliding behaviour of a single asperity contact will be studied both experimentally as well as theoretically. The governing equations for a single asperity contact were already described in Chapter 2. In this chapter, a model of the presliding regime of a single asperity contact will be presented with experimental validation.

\footnotetext{
${ }^{2}$ Partly reproduced from: Yaqoob A.M, Winogrodzka A., Fischer H. R., Gelinck E. R. M., de Rooij M. B. and Schipper D. J., Pre-sliding Behaviour of Single Asperity Contact. Tribology Letters, 2013, Vol. 49(3), pp. 553-562.
} 
As indicated previously, the contact between a smooth ball sliding against a smooth flat surface has been studied in the literature $[4,6,26]$. However, it is not known if from the literature whether the Mindlin relation also holds for lower contact pressures under $100 \mathrm{MPa}$. For such contact, adhesion is more critical. The validity of the Mindlin relations will also be addressed in this chapter. The materials used for the experiments were silica $\left(\mathrm{SiO}_{2}\right)$, silicon $(\mathrm{Si})$, sapphire $\left(\mathrm{Al}_{2} \mathrm{O}_{3}\right)$ and float glass. Different values of a constant normal load between $10-90 \mathrm{mN}$ have been applied for a silicon or silica ball with radius $2.5 \mathrm{~mm}$ against float glass. The varying normal load experiments have been also studied in ambient and vacuum condition for the same material combination.

\subsection{Pre-sliding behaviour of single asperity contact}

The single asperity contact models were described in Section 2.2. The pre-sliding behaviour given by Mindlin was also explained in detail in subsection 2.2.2. In the pre-sliding regime two zones can be distinguished, stick and slip. Increasing the load in the tangential direction will cause an increase in the preliminary displacement till full sliding takes place. The equations used for calculating the tangential displacement and shear stress distributions are given in Appendix A.

In this chapter, the tangential load and displacement loops as shown in Figure 2.6 are compared and calculated for two different materials. The results for silicon $(\mathrm{Si})$ and silica $\left(\mathrm{SiO}_{2}\right)$ balls against glass are shown in Figure 4.1. The properties of the materials used for the calculations are given in Appendix B. As an input the measured values of the coefficient of friction for the $\mathrm{SiO}_{2}-$ glass interface $(\mu=0.1)$ are lower than the $S i$ glass interface $(\mu=0.12)$, so the tangential displacement is also lower and is shown in Figure 4.1 (a). 

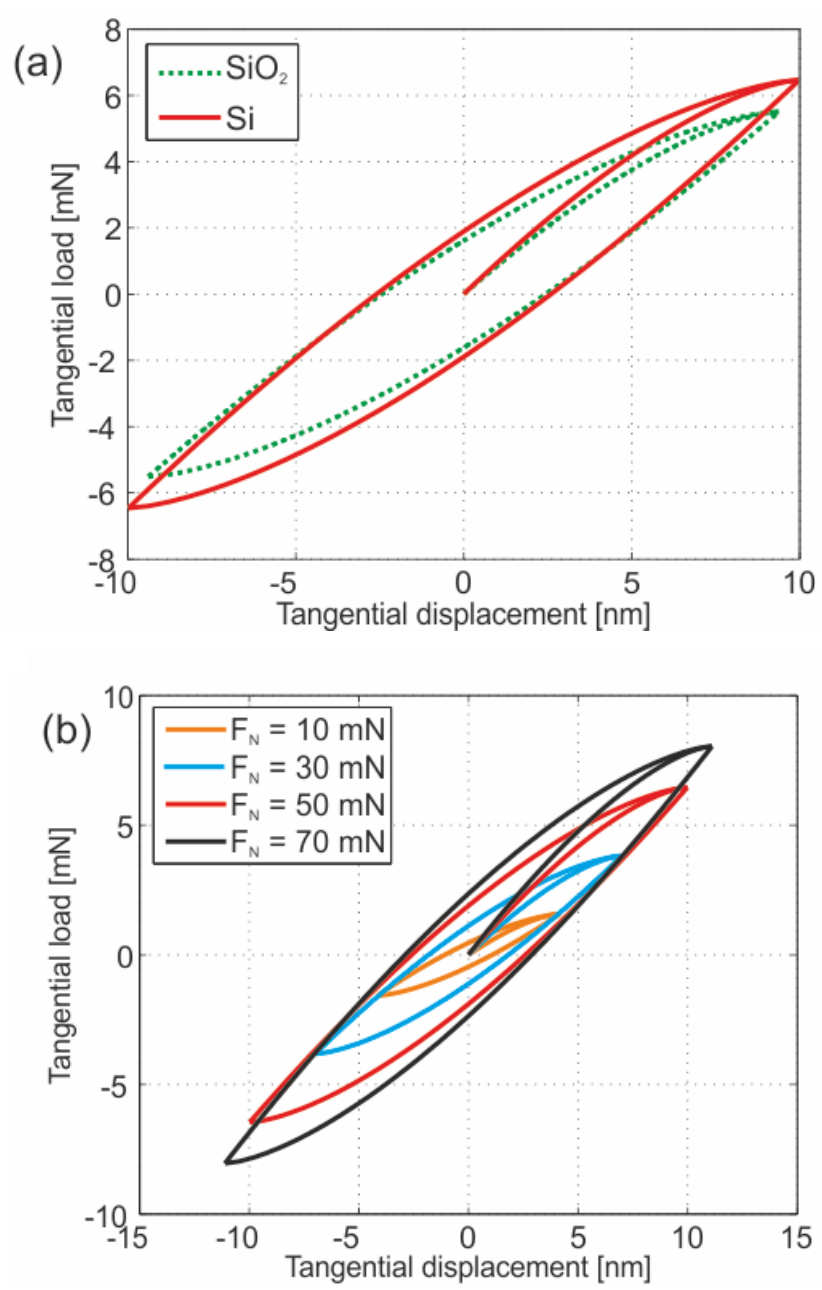

Figure 4.1: The force-displacement curves between the tangential load and the tangential displacement for (a) $\mathrm{SiO}_{2}$ and $\mathrm{Si}$ against a flat glass surface when a normal load of $50 \mathrm{mN}$ is applied and (b) for $\mathrm{Si}$, normal load changed from $10-70 \mathrm{mN}$ [57].

Calculated friction force loops for the Si against float glass, but loaded with different normal loads, are shown in Figure 4.1 (b). It can be seen that the maximum tangential force and corresponding tangential displacement increases with an increase in the applied normal load, according to the Mindlin theory [5] as was explained in Chapter 2 (Equation 2.12). When the applied normal load is $10 \mathrm{mN}$, the preliminary displacement can be calculated to be $4 \mathrm{~nm}$ and is increasing with the increase of normal load for the Si-glass interface as shown in Figure 4.1 (b). When 
the applied normal load is increased to $70 \mathrm{mN}$ the resulting preliminary displacement for the $\mathrm{Si}$-glass interface is $11 \mathrm{~nm}$. The variation in tangential displacement depends on different conditions and parameters; see Chapter 2.

In the following equations a theoretical background of the most important properties of these curves will be shown for a point contact. The relation between the friction force and normal load given by Bowden and Tabor [11] gives the relation $F_{t}$ $\propto F_{N}{ }^{2 / 3}$. This results in:

$$
\mu=\frac{F_{t}}{F_{N}}, \Rightarrow \mu \propto \frac{F_{N}^{2 / 3}}{F_{N}}, \mu \propto F_{N}^{-1 / 3}
$$

This relation is valid when a constant shear stress $\tau$ of the interface is assumed. Equation 4.1 shows that the coefficient of friction is proportional to the applied normal load to the power of $-1 / 3$. As was already mentioned in Chapter 2, this equation does not take into account the adhesion effect, which is important for low normal loads according to Johnson [7]. However, as can be shown by calculations, the normal load dependency of the contact area by the Hertz theory (Equation 2.4) remains more or less similar [12] when adhesion is also taken into account. The relation between the maximum preliminary displacement $\delta_{\text {tmax }}$ and applied normal load is shown in Equation 4.2 [12, 57]:

$$
\begin{aligned}
& \delta_{t \text { max }}=\frac{3 \cdot F_{t}}{16 \cdot a \cdot G^{*}} \Rightarrow \delta_{t \text { max }} \propto \frac{\mu \cdot F_{N}}{a} \\
& \propto \frac{F_{N}^{-1 / 3} \cdot F_{N}}{F_{N}^{1 / 3}} \Rightarrow \delta_{t \text { max }} \propto F_{N}^{1 / 3}
\end{aligned}
$$

Where, $\delta_{\text {tmax }}$ is directly proportional to the maximum tangential load at the point of slip $F_{t}=F_{f}$ and inversely proportional to the contact radius $a$. The coefficient of friction is proportional to the applied normal load to the power of $-1 / 3$ and the contact radius is proportional to the applied normal load to the power of $1 / 3$. This results in $\delta_{\text {tmax }}$ being proportional to the applied normal load to the power of $1 / 3$ as shown in Equation 4.2. 
With an increase in tangential load, the contact stiffness continuously decreases. At the point of slip, the contact stiffness will be equal to zero. The maximum contact stiffness in tangential direction $k_{t}$ is given by [19], and occurs at $F_{t}=0$ :

$$
k_{t}=8 G^{*} a
$$

The tangential shear stress in the contact is changing in magnitude as well as in direction depending on the magnitude and direction of the tangential load. Figure 4.2 shows the change in the tangential load which influences the area of the stick zone and the annulus of slip. The similar cycle as described in Section 2.2.2 in Figure 2.6 is shown in Figure 4.2 (a), but with the points that correspond to the tangential traction in Figure 4.2 (b) to illustrate how the shear stress changes according to a different tangential load.

With an increase in tangential load, the tangential traction is also increasing as shown in Figure 4.2 (b). For an arbitrary value of tangential load, point $K$, the radius of the stick zone and annulus of slip is shown by the tangential traction. For a contact which is loaded during a forward scan, the tangential traction is considered to be positive. Point $L$ is taken at the same tangential load as point $K$, but on the curve obtained during a backward scan. The corresponding tangential traction is also shown and the stresses have an opposite sign compared to the forward scan. It can be noticed that the values of the radius of the stick zone and annulus of slip are different than at point $K$. In the same way, the tangential traction at points $M, N$ and $P$ has been shown in Figure 4.2 (b). Points $A$ and $D$ are the points on the brink of gross slip and the tangential traction at these points is considered to be the maximum tangential traction required to break the contact. 

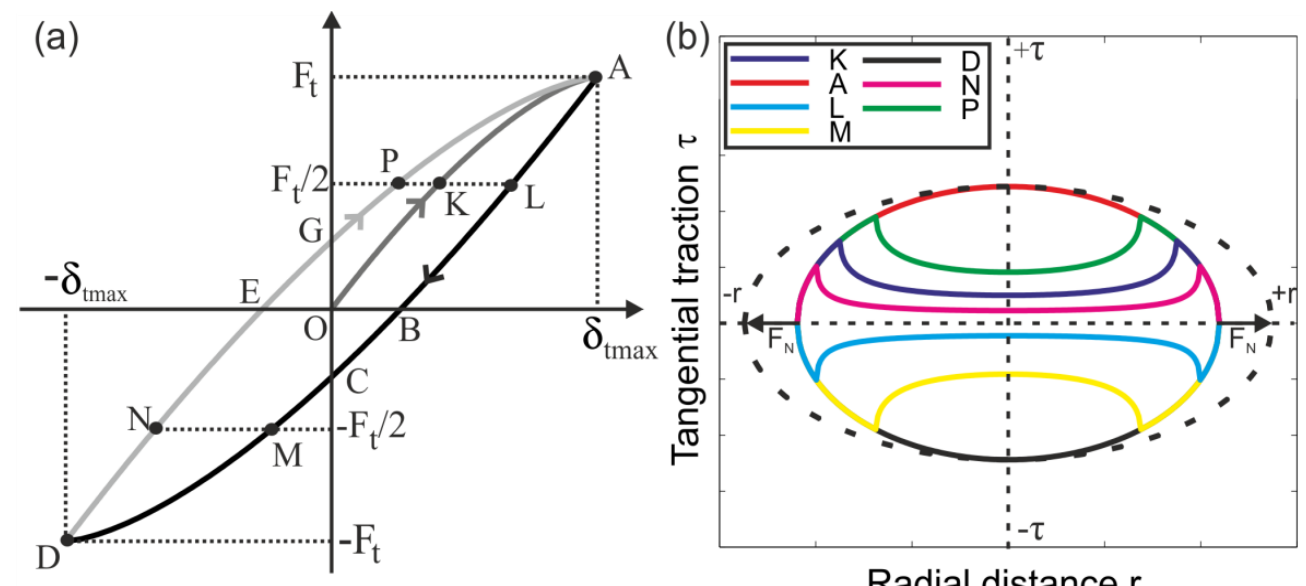

Radial distance $r$

Figure 4.2 (a) Oscillating tangential load against displacement showing points K, L, M, N and $\mathrm{P}$ where the tangential traction has been calculated. (b) The tangential traction as a function of radial distance calculated at different points [57].

The maximum shear stress acts at point $\mathrm{A}$ in the centre of the contact and it is given by:

$$
\tau_{\max }=\frac{3 \cdot \mu \cdot F_{N}}{2 \cdot \pi \cdot a^{3}}
$$

If the normal load dependence of the contact radius $a$ and coefficient of friction $\mu$ in the centre of contact is used, then at point A from Equation 2.14 the maximum shear stress is independent of the normal load. With increasing normal load the radial distance $r$ increases and the shear stress remains constant as shown in Figure 4.2 (b) with the dotted ellipse. In the literature $[58,59]$ this has been reported as well. The actual value of the tangential load is not important, because the shear stresses are determined by the ellipses shown in Figure 4.2 (b). In Section 4.4 .3 this representation will be used.

\subsection{Materials and method}

In order to validate the models described above, three different materials have been studied for the pre-sliding friction behaviour of a single asperity contact. The material properties of these materials are presented in Appendix B [12, 57]. Due to 
the very low roughness of the samples $(R q=8 \mathrm{~nm}$ or $R q=15 \mathrm{~nm})$ a single asperity contact is simulated in the experiments.

The friction experiments have been performed on a combined nanoindenter and scratch tester from ASMEC GmbH (ASMEC's Universal Nanomechanical Tester UNAT). The test rig has two force measuring sensors, where one is for the normal load and the second one for lateral (friction) direction. The system is designed in such a way that the normal force is barely affected by the tangential force. The sample holder is mounted on the normal direction measuring sensor, whereas the counter surface is placed on the lateral direction measuring sensor. The displacement resolution of UNAT is better than $1 \mathrm{~nm}$ and the force resolution is $6 \mu N$ [60].

The second measurement setup used is the VAFT (Vacuum adhesion and friction tester) developed by Yaqoob [12]. A detailed description of the setup is presented in [12]. In general, the setup consists of three positioning stages and two capacitive sensors along with a force measurement mechanism. The ball is mounted to the sample holder, which together with a force measuring mechanism (FMM) is installed on a positioning stage. The positioning stage can move downwards and upwards ( $\mathrm{Z}$ stage). By applying the normal load the contact with a flat counter surface can be realized. The flat counter surface is mounted on two positioning stages to be able to move in two directions. One stage is used to apply a tangential displacement for friction force measurement (X stage) and the second one to change the position in perpendicular direction ( $\mathrm{Y}$ stage). The accuracy of the positioning stages is $20 \mathrm{~nm}$ with a stroke of $20 \mathrm{~mm}$.

The capacitive sensor is used for measuring the deflections in the FMM in X and Z direction. The measuring range of the capacitive sensor is $50 \mu \mathrm{m}$ with an accuracy of $1 \mathrm{~nm}$. The normal force can be calculated by measuring the deflection of the stiffness calibrated mechanism with a capacitive sensor. The maximum normal load which can be applied in this setup is $100 \mathrm{mN}$ with an accuracy of $8 \mu \mathrm{N}$.

This setup also allows friction and adhesion measurements in vacuum to be performed. The measurement results under vacuum and ambient conditions with increasing normal load will be shown. 
The samples used in UNAT before a measurement were cleaned in an ultrasonic bath of acetone for 15 minutes and then dried in air. A ball made from silicon ( $\mathrm{Si}$ ), silica $\left(\mathrm{SiO}_{2}\right)$ and sapphire $\left(\mathrm{Al}_{2} \mathrm{O}_{3}\right)$ was used as a counter surface for float glass. For tests performed on the VAFT before and after a measurement the silicon $(\mathrm{Si})$ and silica $\left(\mathrm{SiO}_{2}\right)$ ball was examined under a standard confocal microscope. The samples were cleaned before the measurement for $30 \mathrm{~min}$ in $40^{\circ} \mathrm{C}$ in an ultrasonic bath of acetone and dried in air.

\subsection{Experimental validation for a ball against flat contact}

As an example, friction force loop measurements obtained during sliding of a silicon ball under a normal load of $50 \mathrm{mN}$ against float a glass as counter surface are shown in Figure 4.3.

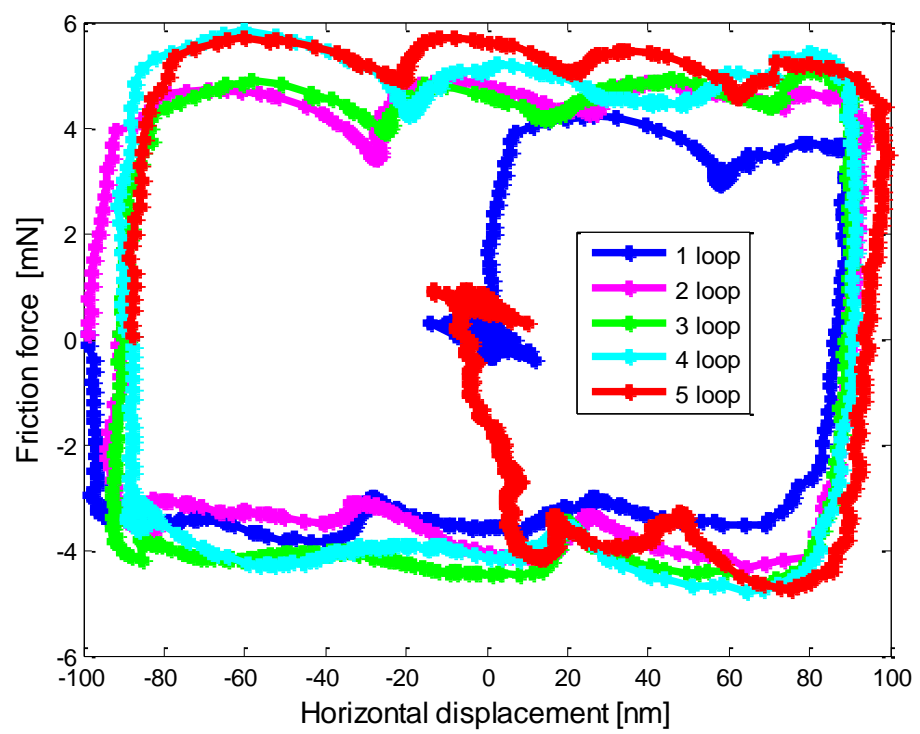

Figure 4.3: Friction force measurement loops with Si ball of $5 \mathrm{~mm}$ diameter in contact with a flat float glass surface. The applied normal load was $50 \mathrm{mN}$ and horizontal displacement 100 $\mathrm{nm}$ in both directions.

In the friction experiment 5 cycles have been performed. In Figure 4.3 each cycle is marked in a different colour to distinguish the different loops. On the horizontal axis the displacement of the lateral stage is shown with $100 \mathrm{~nm}$ of scan length in forward 
and backward direction starting from the zero position. In the normal direction the positioning stage is moved down to make contact between the ball and the flat sample. The ball approaches the flat with decreasing velocity when approaching the surface, so the contact is made without damaging the two surfaces. The contact is detected when the measured normal load is at least $50 \mu N$. In the next step, after the desired load is applied the flat sample is moved in forward direction as well as in backward direction to complete one measurement cycle, as shown in Figure 4.3.

The theoretical calculation based on Mindlin [5, 19] has been compared with the experimental result in Figure 4.4 for a) silicon $(\mathrm{Si})$ and b) silica $\left(\mathrm{SiO}_{2}\right)$ against glass under normal load $30 \mathrm{mN}$. For simplicity, only one cycle is shown for both material configurations. The theoretical calculations are based on values of parameters in Appendix A, the straight horizontal lines part is a distance according to lateral displacement used in measurement. The horizontal asymptote is drawn to show the maximum tangential force when the system is sliding.

It can be observed from Figure 4.4 that the theoretical values indicate a trend similar to the experimental results. However, a difference in the measured $\left(\delta_{t 2}\right)$ and theoretical $\left(\delta_{t l}\right)$ values of the preliminary displacement can be seen in Figure 4.4. The reason is that the measured values are the sum of the displacement in the contact and the displacement in the lateral direction measuring sensor of the UNAT. The calibrated lateral stiffness of the UNAT is $334 \mathrm{mN} / \mu \mathrm{m}$. The initial lateral contact stiffness for $\mathrm{Si}$ - glass interface was calculated from Equation 4.3 to be $767 \mathrm{mN} / \mu \mathrm{m}$ when the applied normal load is $10 \mathrm{mN}$. This value will decrease to zero when the sliding regime is approached. It is important to mention here that the lateral stiffness calculated from Equation 4.3 is the maximum lateral stiffness when there is no applied tangential load, so during the pre-sliding regime the average stiffness of the contact will be around $350 \mathrm{mN} / \mu \mathrm{m}$. As can be seen in Figure 4.4 the measured tangential displacement is indeed around twice the value of the theoretical displacement. 

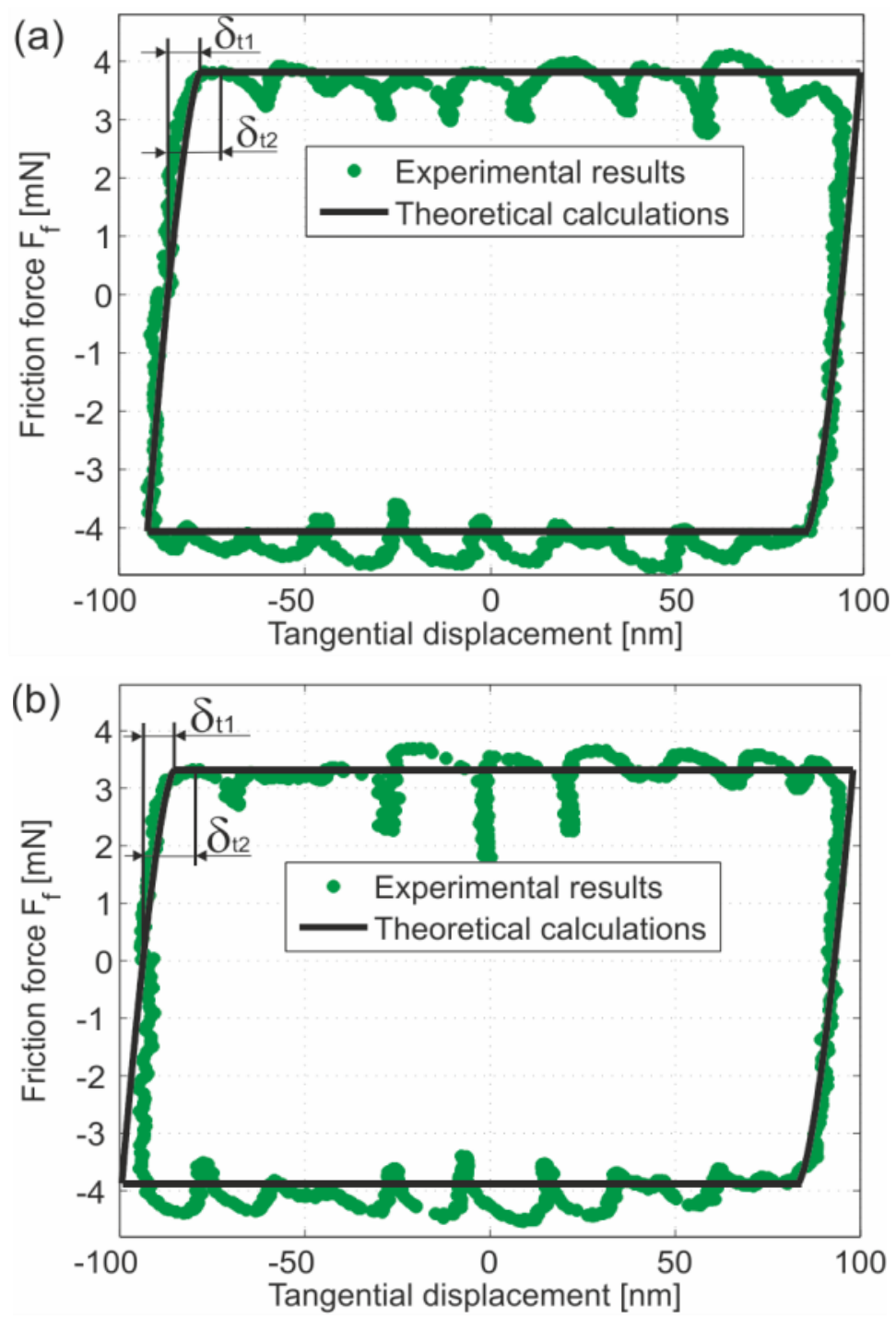

Figure 4.4: Comparison of experimental results of the tangential force-displacement curve with the theoretical calculations for (a) $\mathrm{Si}$ and (b) $\mathrm{SiO}_{2}$ balls against glass, $30 \mathrm{mN}$ of normal load is applied. Maximum preliminary displacement calculated $\delta_{t 1}$ and measured $\delta_{t 2}$ are also shown [57].

The results from the experimental measurements will be explained in more detail below. 


\subsubsection{Friction Force Measurements}

Friction force measurements have been performed under different normal loads, starting from 10 to $90 \mathrm{mN}$ for silica and silicon. In Figure 4.5 the normal load dependency on the friction force for silicon and silica balls against float glass for a forward scan ais shown. The results of the backward scans are similar to the forward scans. On the horizontal axis the normal load is presented, and on the vertical axis the corresponding friction force.

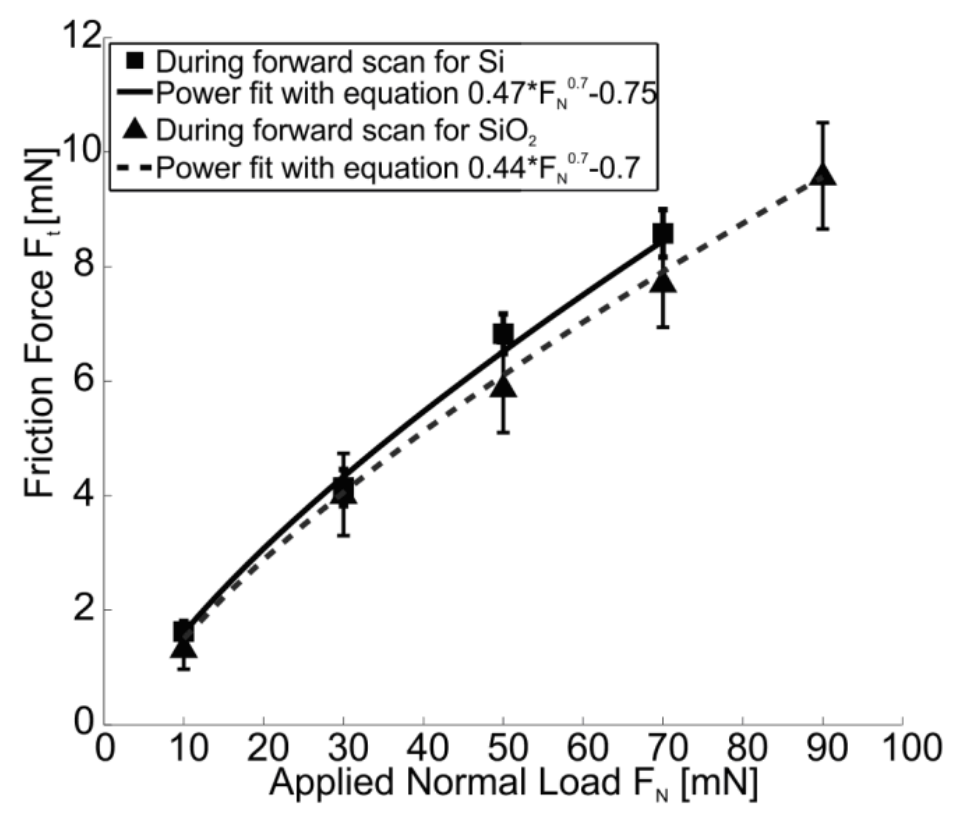

Figure 4.5: Measured static friction force $F_{t}$ as a function of applied normal load for $\mathrm{Si}$ and $\mathrm{SiO}_{2}$ ball measured in ambient conditions [57].

The static friction force for silica and silicon is increasing with increasing normal load. The power low curve through the measurement results shows that the friction force follows the power law $F_{N}{ }^{0.7}$, which is in agreement with the theory (Eq.2.5 and Eq. 2.6). The standard deviation of the friction force during the four cycles at each normal load is presented by the error bars. The value obtained from the first cycle is often lower than other cycles as can be seen from Figure 4.3, so the first cycle has not been considered. The reason for a lower value of the friction force in the first cycle is most probably due to the presence of some contamination on the surface. 
This is removed in subsequent passes over the track. The value of the friction force for both materials, $\mathrm{Si}$ and $\mathrm{SiO}_{2}$, is almost similar. This can be explained by the natural oxidation of $\mathrm{Si}$ ball resulting in an interfacial layer of the $\mathrm{SiO}_{2}$.

Experiments have also been performed for rougher surfaces, a sapphire $\mathrm{Al}_{2} \mathrm{O}_{3}$ ball against floated glass, with different constant normal loads. The measurements were compared in the same way as for $\mathrm{Si}$ and $\mathrm{SiO}_{2}$, so only values from loops two to five are shown in Figure 4.6. The initial value of the friction force will not be zero because of adhesion effects.

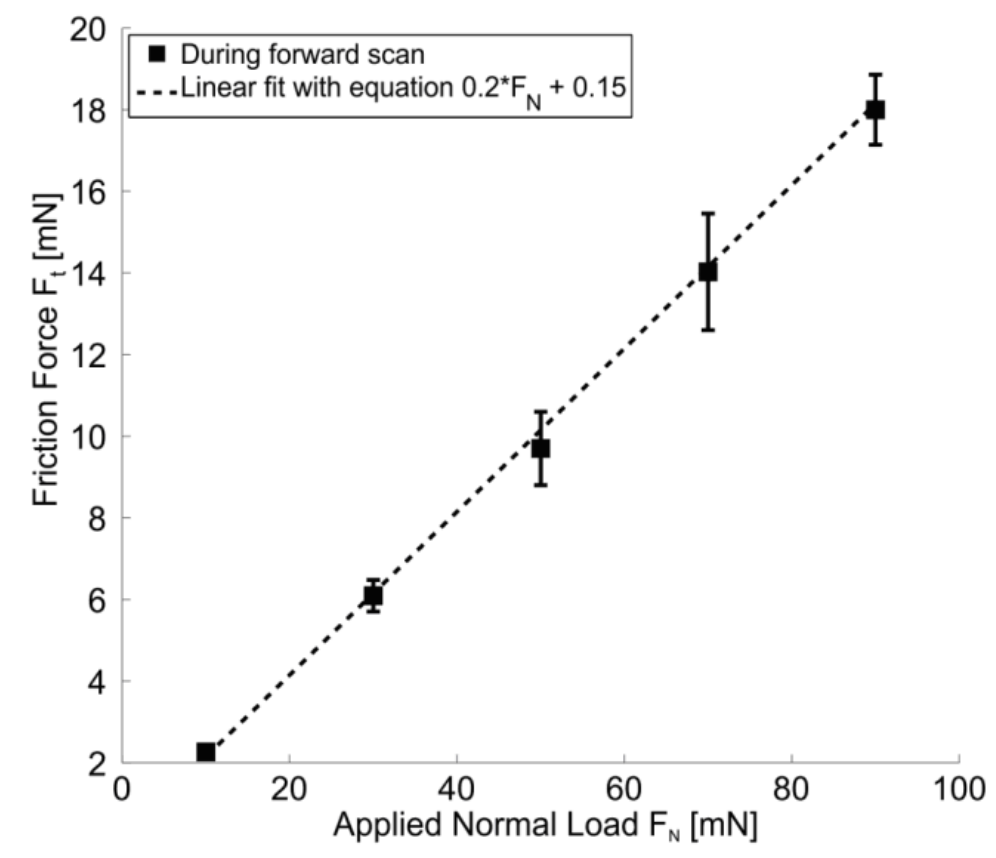

Figure 4.6: Measured friction force as a function of applied normal load in ambient conditions for a rough sapphire ball against a glass flat surface [57].

For random rough surfaces the real contact area is expected to follow $A \propto F_{N}$ see also Section 2.2 [12]. This means that a linear relation is expected between the applied normal load and the static friction force for a constant shear stress $\tau$. As shown in Appendix B, the $\mathrm{Al}_{2} \mathrm{O}_{3}$ ball is relatively rough compared to the $\mathrm{Si}$ and $\mathrm{SiO}_{2}$ balls ( $R q=8 \mathrm{~nm}$ and $R q=15 \mathrm{~nm}$, respectively). From experiments shown in Figure 4.6 the linear relation between the static friction force and normal load is expected for a rough surface, so $F_{t} \propto F_{N}$. 
The coefficient of friction can be calculated for $\mathrm{Si}$ and $\mathrm{SiO}_{2}$ as a function of the applied normal load from the friction force measurements. The coefficient of friction will decrease with an increase in normal load according to the power law. The difference in obtained values for the friction force and coefficient of friction can be explained by the presence of an adhesion force between the contacting surfaces. It is known that for smooth surfaces in a humid environment the adhesion force is mainly determined by the capillary force and plays a very important role in contact mechanics $[5,6]$.

\subsubsection{Preliminary displacement}

The preliminary displacement $\delta_{\text {tmax }}$, which is the tangential displacement in the contact just before sliding, was measured from the friction loops. In Figure 4.7 the results for $\mathrm{Si}$ and $\mathrm{SiO}_{2}$ balls against a float glass are shown. The relation between the constant normal load and preliminary displacement was shown in Equation 4.2 and theoretically depend on the normal load to the power of 1/3. In Figure 4.7 the power law curve fits on the measured data are also shown along with the governing equations. The displacement is increasing with an increase in normal load for both materials and also experimentally follows the power of 0.33 . The measured preliminary displacement is in nanometres and the error bars show one standard deviation for the measured data. 


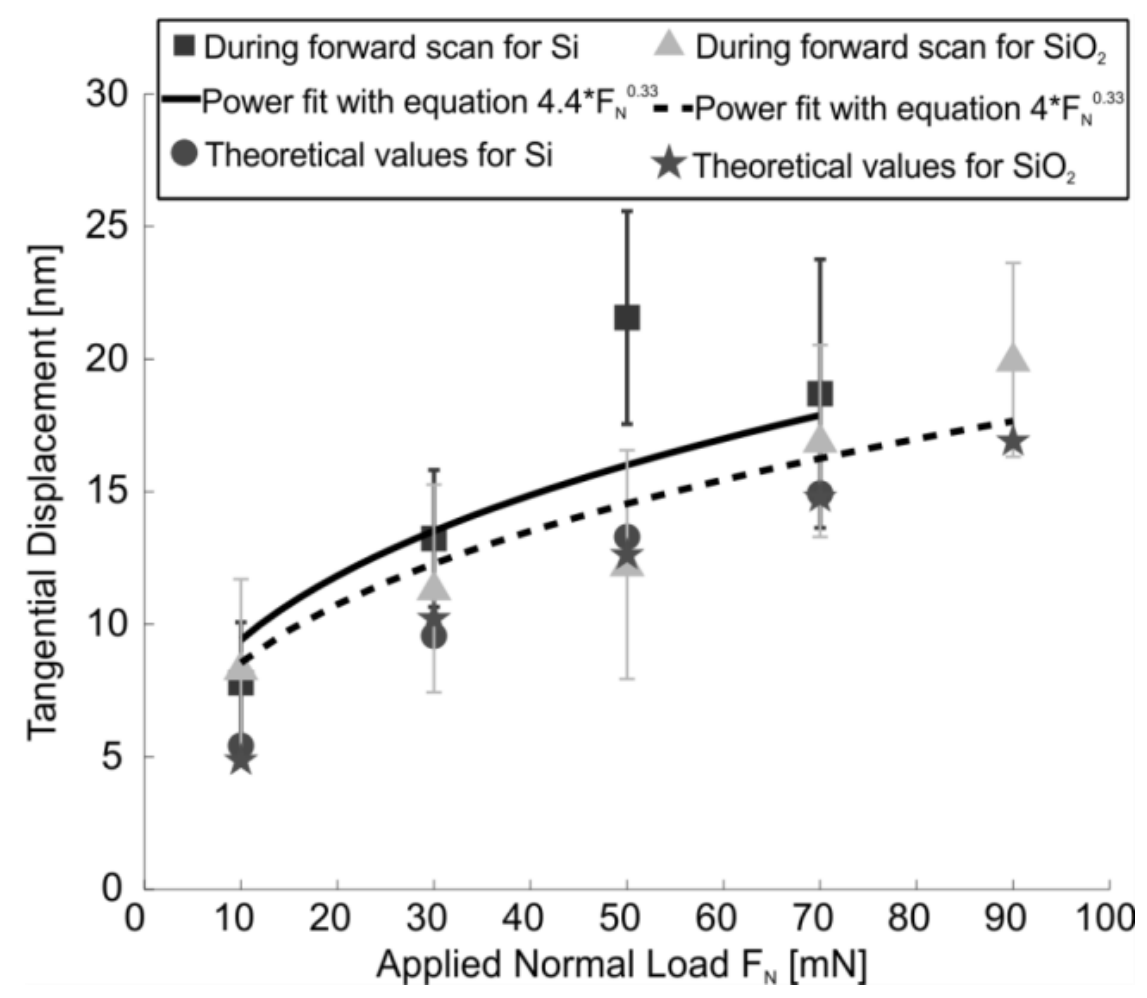

Figure 4.7: Measured tangential displacement and calculated maximum preliminary displacement $\delta_{\text {tmax }}$ as a function of applied normal load for $\mathrm{Si}$ and $\mathrm{SiO}_{2}$ ball against glass [12].

These values have been calculated based on Equation A.1 (Appendix A). In Figure 4.7 the theoretical values are the average of four measurements at each normal load. The theoretical values are calculated without the first measured cycle using Equation A.3 (Appendix A). It can be seen from the equation that when $F_{f}$ is equal to zero, the value of $\delta_{t}$ from the first loop is $26 \%$ of the maximum preliminary displacement $\delta_{t \max }$ in the subsequent loops. To calculate the displacement $\delta_{t c}$ (i.e. from point $E$ to point $A$ in Figure 2.6) the expression based on the geometry at the friction loops is:

$$
\delta_{t c}=\delta_{t}+0.26 \cdot \delta_{t \max }
$$

Equation 4.5 is valid for all values of the applied load. 


\subsubsection{Tangential stresses}

The limiting shear stress in the contact required to achieve the full slip condition for the $\mathrm{Si}$ and $\mathrm{SiO}_{2}$ balls is shown for different applied normal loads in Figure 4.8.

The maximum tangential traction was calculated using Equation 4.4 by putting the measured values of the friction force and the calculated values of the contact radius $a$ using Hertz. The obtained data is represented in a similar way as was shown in Figure 4.8 by a shear stress distribution over the contact diameter. With assuming a Hertzian contact area, the maximum tangential stress increases with the normal load. However, this is not expected as has been discussed in Section 4.2; the Mindlin's theory is based on non-adhesive contact and the shear stress is independent of the normal load. From Figure 4.8 (a) it can be seen that at higher loads the shear stress is more constant, which explains the fact that the contribution due to the adhesion force is almost negligible at high loads, but significantly influences the contact behaviour at low loads. In Figure 4.8 (b) the shear stress is also becoming constant at higher loads. Similarly, the increase in normal load also increases the width of the loop, hence the contact area. 

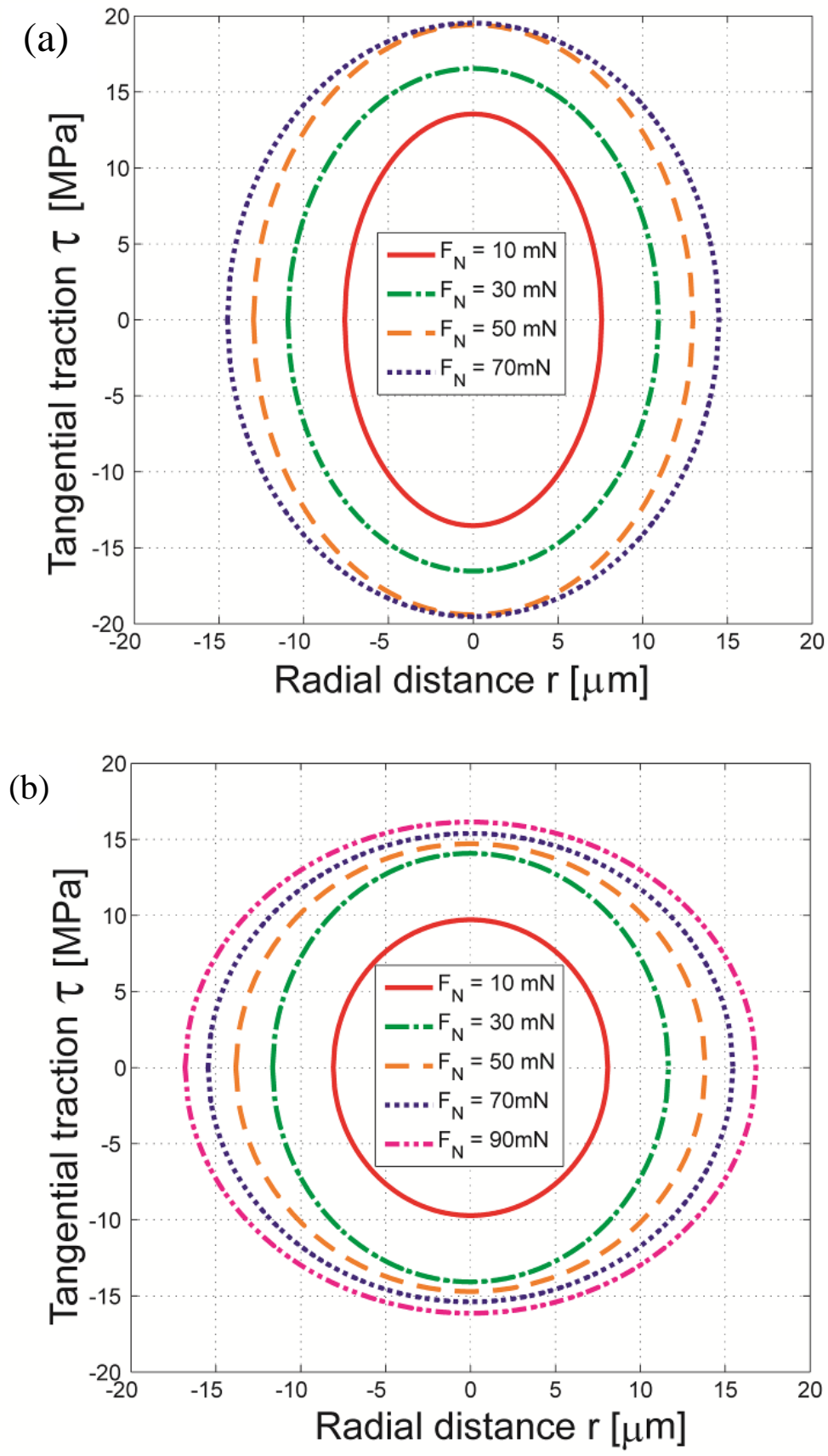

Figure 4.8: The tangential traction as a function of applied normal load for (a) $\mathrm{Si}$ and (b) $\mathrm{SiO}_{2}$ ball against a flat glass surface [12, 57]. 


\subsection{Varying normal load for a single asperity contact during}

\section{sliding}

In multi asperity contacts, the load of an individual asperity will vary if a change in micro geometry occurs, for example due to wear, as shown in Figure 4.9. Initially, some asperities will carry locally the normal load $F_{N}$. After wear, the load distribution is changed due to geometry changes resulting in an increased load for some asperities and a decreased load to be carried by the other asperities. Due to a changed load and geometry on asperity level, these variations also can cause changes in the pre-sliding behaviour as was discussed in Chapter 2. An alteration in friction can be the consequence of those variations [7]. It is necessary to understand how load changes influence the pre-sliding behaviour of a single asperity and then apply this knowledge to a multi asperity contact. When an asperity is worn the geometry is changed and during a next loading on the same contact area the pre-sliding behaviour will also change. The friction level during sliding will be affected as well.

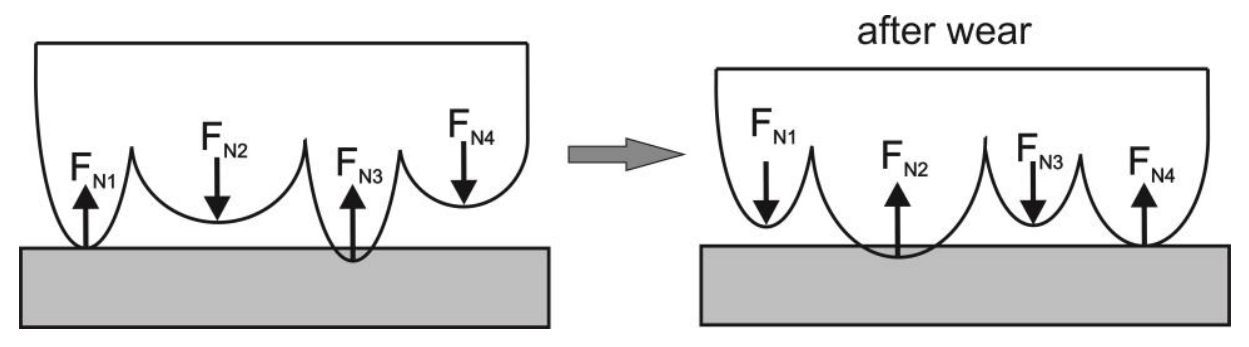

Figure 4.9: Multi asperity in contact before and after wear.

\subsubsection{Increasing normal load during sliding}

The normal load was increased from $30 \mathrm{mN}$ to $60 \mathrm{mN}$ and $90 \mathrm{mN}$ for a silica and silicon ball against glass under ambient and vacuum conditions. The humidity during the measurement was controlled, because a higher humidity also shows influence on the coefficient of friction [57]. The results presented were obtained by controlling the humidity at the same level of approximately $R H=28 \pm 5 \%$. 
The results obtained for the silica ball sliding against glass under ambient conditions are shown in Figure 4.10. The tangential displacement and tangential load are depicted along the horizontal and vertical axis, respectively. In the VAFT the stiffness of the measurement setup and the accuracy of the positioning stages is not the same as in the UNAT so the tangential displacement will not be presented.

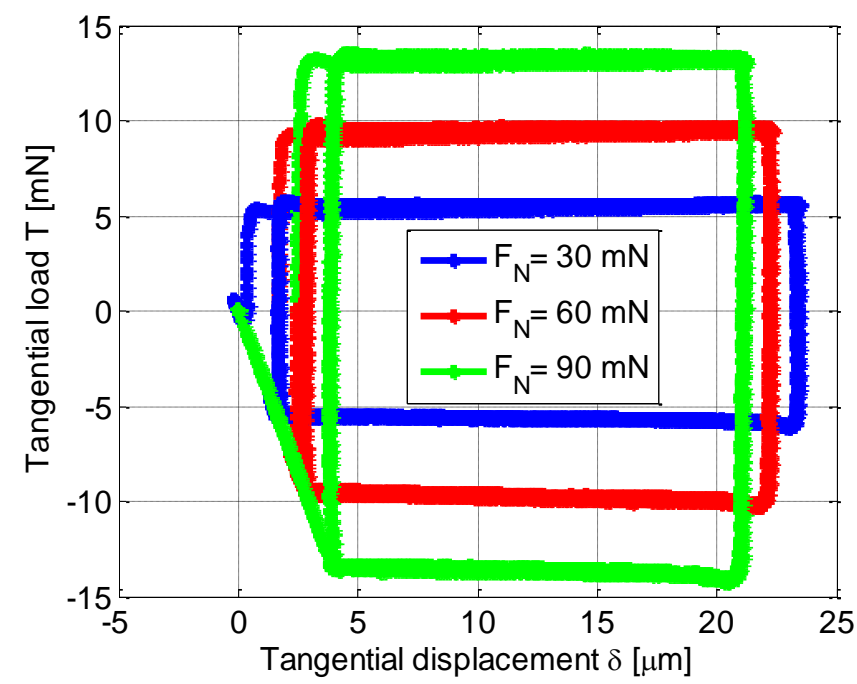

Figure 4.10: Silica against glass with the normal load increasing $30-60-90 \mathrm{mN}$ in ambient, VAFT setup.

The results for a silicon ball sliding against glass for a normal load increasing from $30 \mathrm{mN}$ to $60 \mathrm{mN}$ and $90 \mathrm{mN}$ in ambient are shown in Figure 4.11. 


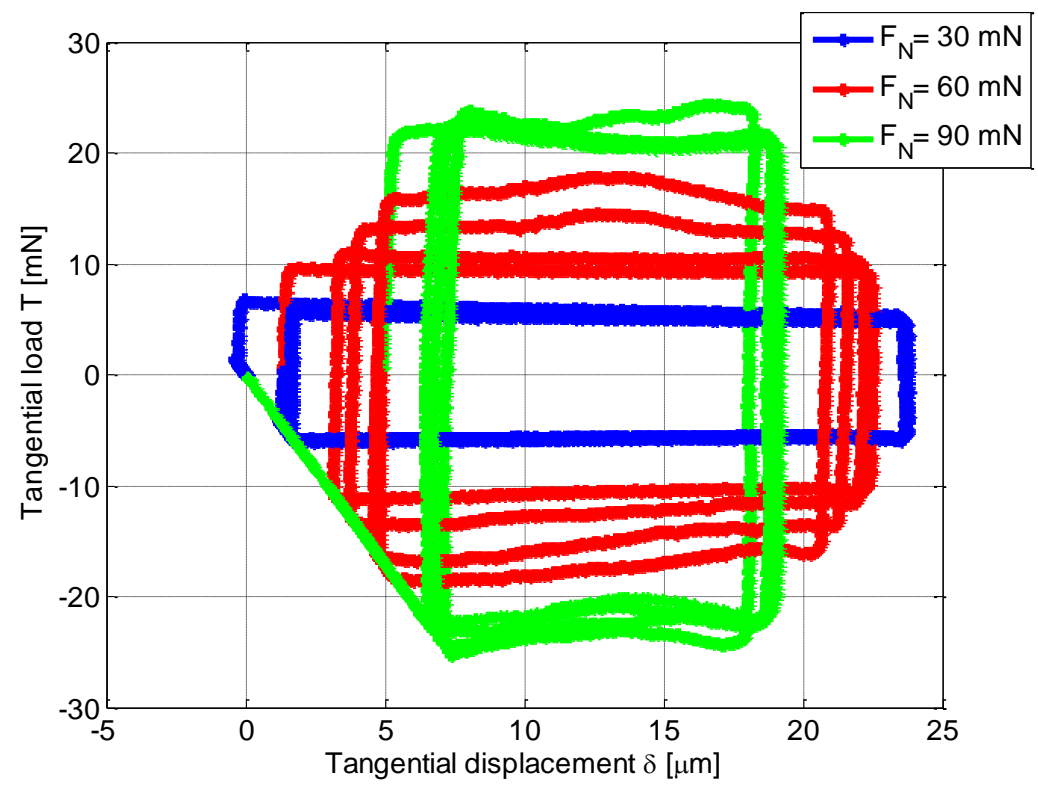

Figure 4.11: Silicon ball against glass with the normal load increasing $30-60-90 \mathrm{mN}$ in ambient, VAFT setup.

During sliding for the normal load of $60 \mathrm{mN}$ and $90 \mathrm{mN}$, the tangential load varies and increases after each loop. The measurement with increasing normal load during sliding has been repeated several times. It shows that when more tests are done with the same ball, then wear of the surface can occur, despite the low Hertzian nominal contact pressures of $115 \mathrm{MPa}$.

The coefficient of friction was compared for the silica and silicon ball in ambient and vacuum and presented in Figure 4.12. The measured values for the coefficient of friction have been averaged from several measurements taken for increasing normal load during sliding under ambient and vacuum conditions. The tangential loops in vacuum are shown in Appendix D. 
a)

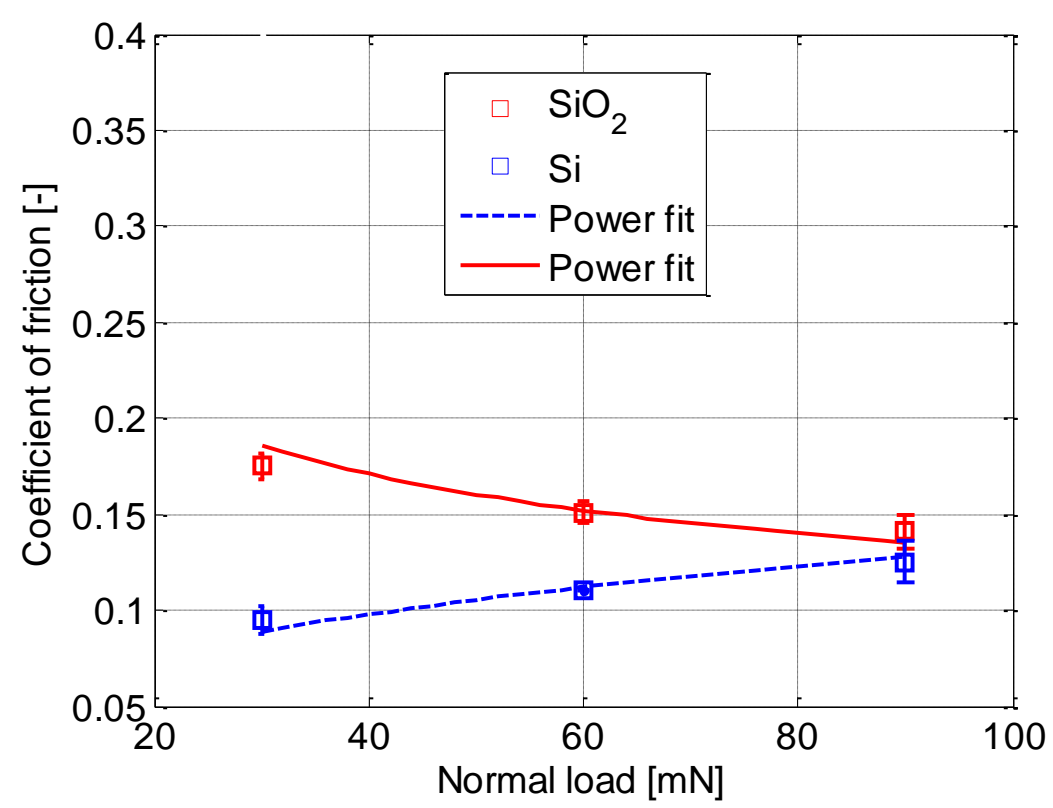

b)

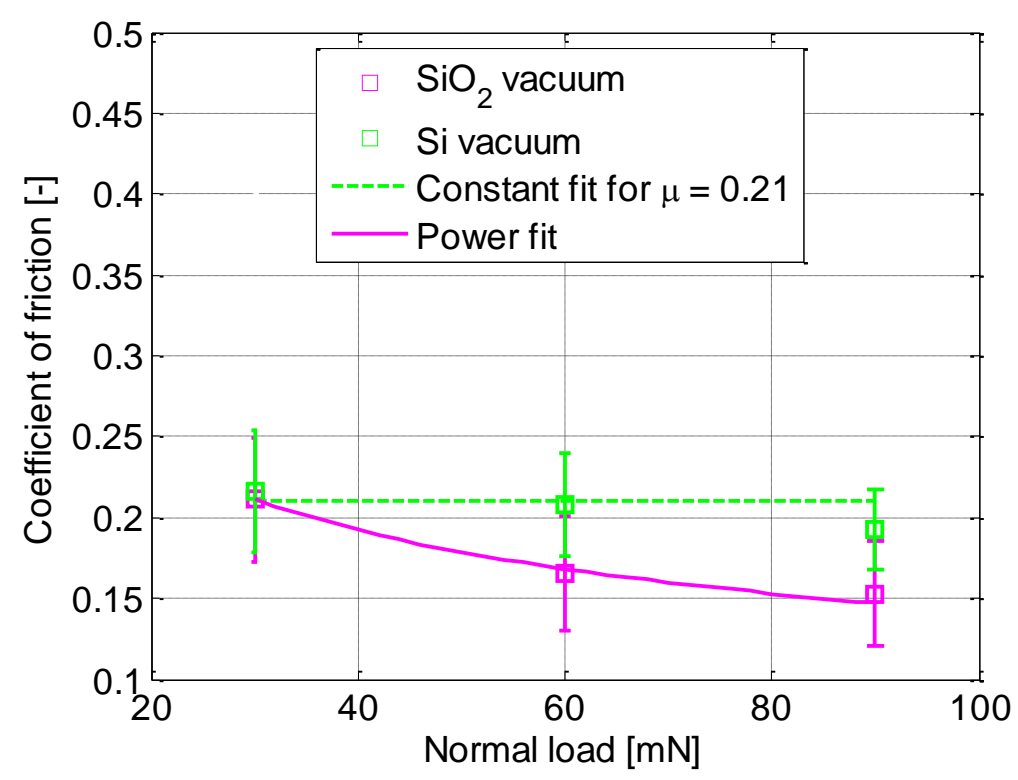

Figure 4.12: Coefficient of friction with increasing normal load for silica and silicon against glass from VAFT, a) ambient and b) vacuum.

The silica ball shows a decreasing value for the coefficient of friction with increasing normal load both in ambient and vacuum conditions. The curve fit follows the power $-1 / 3$, as was already explained in Section 4.2 Equation 4.1. 
The coefficient of friction for the silicon ball in ambient condition is increasing with increasing normal load according to power $1 / 3$. For the measurement in vacuum the coefficient of friction is almost constant with load. This is due to wear which occurs in the contact. The confocal images before and after the tests of the silicon ball are shown in Figure 4.13. After the measurements, which are shown in Figure 4.11, a wear scar was observed in the contact area. The obtained wear depth is 24 nm.

a)

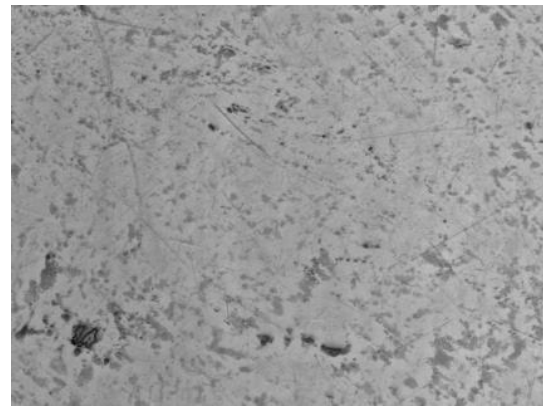

b)

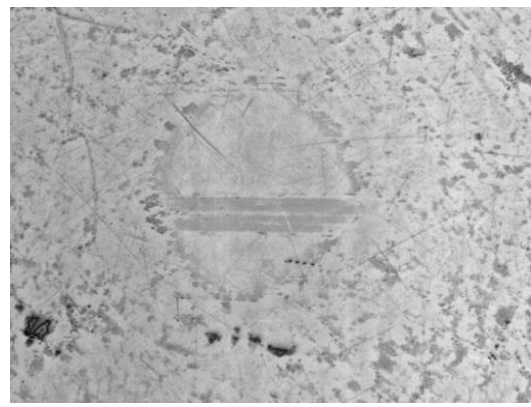

Figure 4.13: Silicon ball image of the surface a) before tests, and b) after tests.

The wear track explains higher values for the tangential load. An increase in contact area will cause an increase of the friction force and as a result an increasing value for the coefficient of friction.

\subsection{Summary}

The pre-sliding and static friction force behaviour for $\mathrm{Si}, \mathrm{SiO}_{2}$ and $\mathrm{Al}_{2} \mathrm{O}_{3}$ balls against a float glass surface were discussed for a constantly applied normal load during sliding. The measurement results were analysed using Mindlin's theory. A brief explanation of that theory was described in Section 4.2. From the measurement results it can be concluded that the static friction force, the coefficient of static friction and the preliminary displacement are dependent on the applied normal load. The experiments follow the expected theoretical trends. It has been shown that Mindlin's equations to calculate the preliminary displacement also hold for contact 
pressures in the order of $100 \mathrm{MPa}$ or less, so at relatively low applied loads and consequently low values of the preliminary displacement.

It is also observed that at low applied normal loads adhesion effects play an important role. At low loads the theory of Mindlin underestimates the friction values measured, resulting in an apparently high tangential stress if a Hertzian contact area is assumed. It has been shown that at low loads the calculated shear stress is dependent on the normal load whereas at higher loads it becomes constant, when analysed with the equations of Hertz and Mindlin. This effect is also an indication of the presence of adhesion at low loads.

Also in this chapter the effect of increasing normal load was presented from experimental results investigated by the VAFT setup. Roughness of the balls before and after measurement has been compared. Variations of normal load during sliding will influence the tangential load level. An increase in the coefficient of friction together with the normal load during sliding means that wear occurred in the contact. For materials like silicon and silica even loads in the range of 30-90 $\mathrm{mN}$ and nominal contact pressure of approximately $100 \mathrm{MPa}$ cause changes in the geometry of the surfaces which are in contact. A very small change in the contact can cause a large difference in the measured coefficient of friction. 


\section{Chapter 5}

\section{PRE-SLIDING BEHAVIOUR \\ OF A MULTI ASPERITY}

CONTACT $^{3}$

\subsection{Introduction}

In Chapter 4 the single asperity contact was described. In reality, the components in mechanisms which are in contact have rough surfaces. In order to analyse positioning accuracy and frictional drift it is important to gain a more detailed understanding of the pre-sliding behaviour of a rough surface contact. Roughness characteristics play a very important role in the pre-sliding behaviour. The effect of normal load applied on the contact, as well as the effect of a different roughness and autocorrelation lengths, will be presented in this chapter. The tangential force will be

\footnotetext{
${ }^{3}$ Partially reproduced, from: A. Winogrodzka, M.B de Rooij and D.J. Schipper, Modelling pre-sliding behaviour of a multi asperity contact including loading history, Submitted to Tribology Letters
} 
applied and the tangential displacement will be calculated and compared for the different cases mentioned.

\subsection{Model representation for a rough surface}

In this chapter, a random rough surface of an alumina ball against glass (material properties in Appendix B) will be described in the usual way. The summits are assumed to be spherical with each summit of its own radius $r_{n}$ and summit height $z_{n}$. In Figure 5.1 a typical example of a surface roughness generated for calculations is shown. In this case, the surface is numerically simulated based on the method 2-D FIR digital filters as described by $\mathrm{Hu}$ and Tonder [61]. From this data, asperities were characterized by summit height and curvature of each summit. It is explained in Appendix E how the generated surfaces are characterized [62, 63]. In Figure 5.1 and Figure 5.2 $x, y$ represent the dimensions of the surface and $z$ is the surface height where the value is represented by "false" colours. The nominal contact area is equal to $256 \times 256 \mu \mathrm{m}$ with a pixel size of $1 \mu \mathrm{m}$.
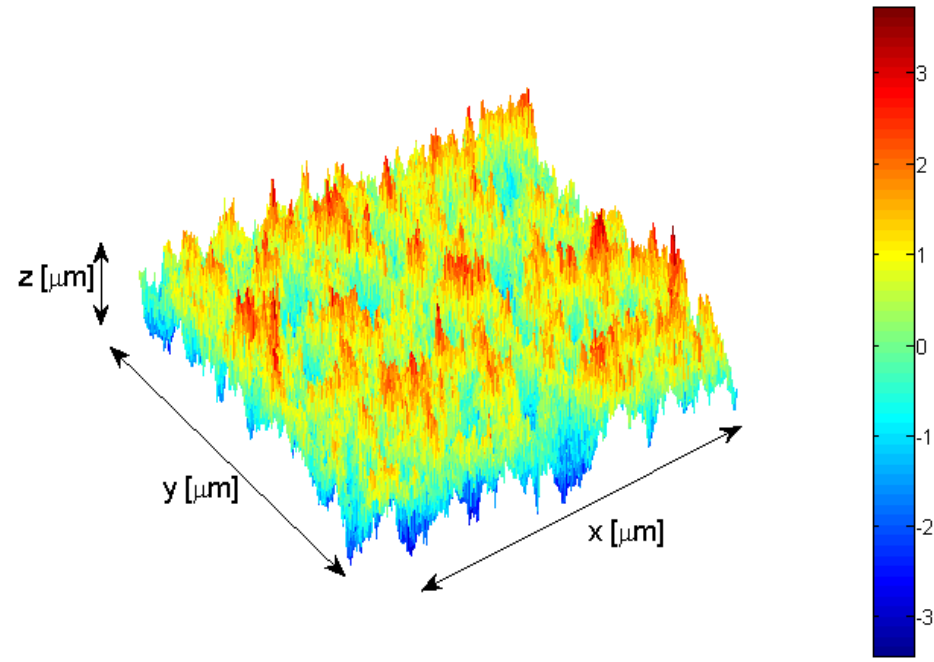

Figure 5.1: Surface obtained using the method described in [61]. 
Heights and radii values are directly determined from the micro geometry of the surface. The distribution of summits for three surfaces with different roughness values is shown in Figure 5.2 a). Data is obtained from scaling the Gaussian distribution of asperities to the desired roughness values. In this case the same asperities are present and the height differences between points of the surface are changed due to scaling. On the horizontal axis the summit height is given and on the vertical axis the summit radius is plotted.

a)

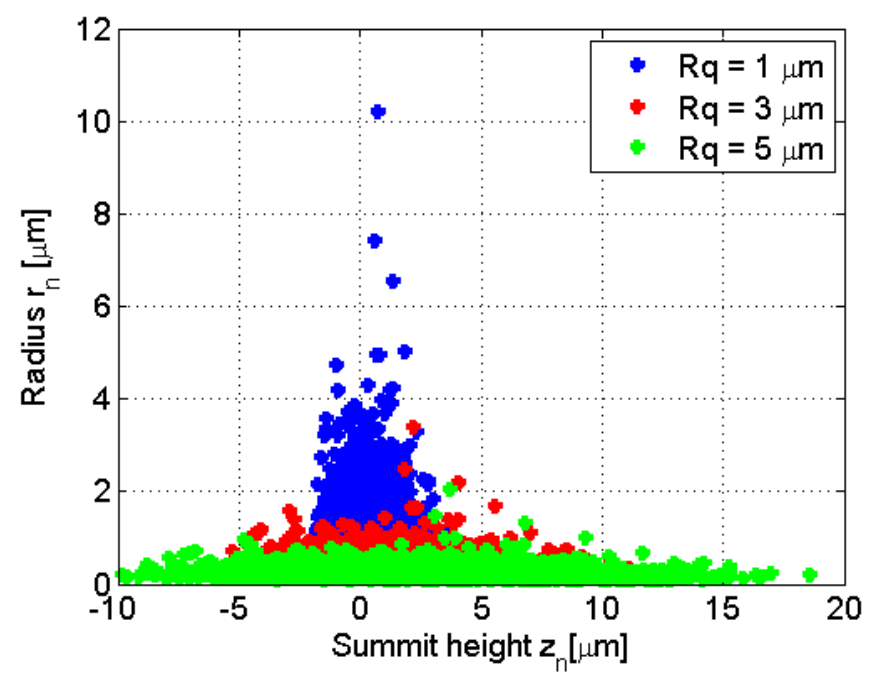

b)

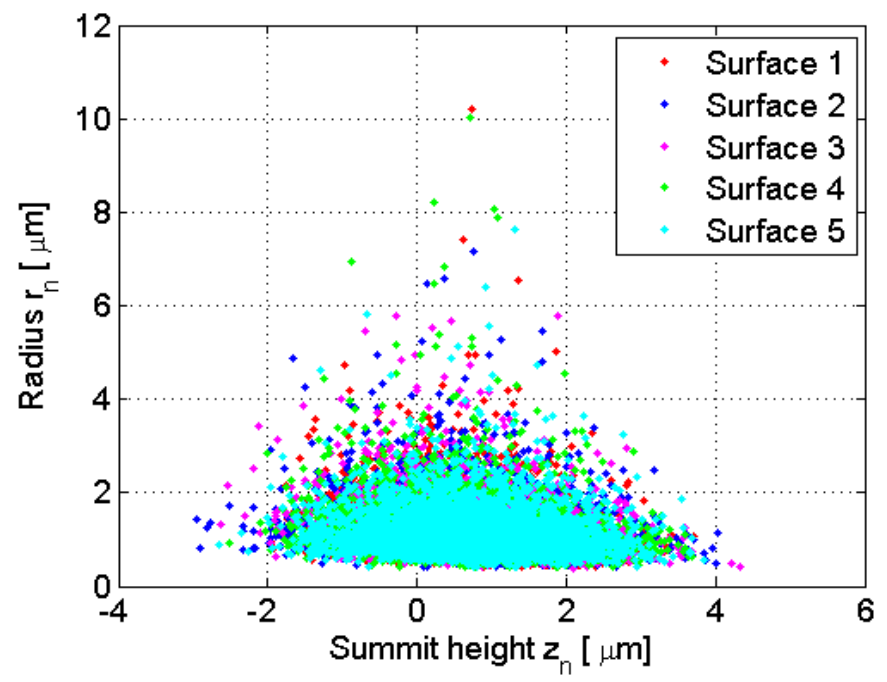

Figure 5.2: a) Summit distribution obtained from scaling the surface, b) summit distribution for surfaces generated for the same roughness settings $R q=1 \mu \mathrm{m}$. 
As can be seen in Figure 5.2 (a) by increasing the roughness of the surface, the summit properties are also changing. The radius is reducing and summit height is increasing for rougher surfaces as expected. It will be shown in this chapter, that the extreme values will determine the pre-sliding behaviour and not a mean average from statistical variations.

In Figure 5.2 (b) there are five surfaces numerically generated for a roughness $R q$ of $1 \mu m$ to represent the statistical distribution of summits. It can be noticed that even with the same roughness value the summit heights and radii vary. These differences are expected to influence the maximum preliminary tangential displacement of the rough contact.

The rough surface is modelled as a set of Hertzian micro contacts, each summit with own radius $r_{n}$ and summit height $z_{n}$. In Figure 5.3 the summits in contact with a flat surface are shown with different summit heights and radii, where a normal load $F_{N}$ and tangential load $F_{t}$ is applied.

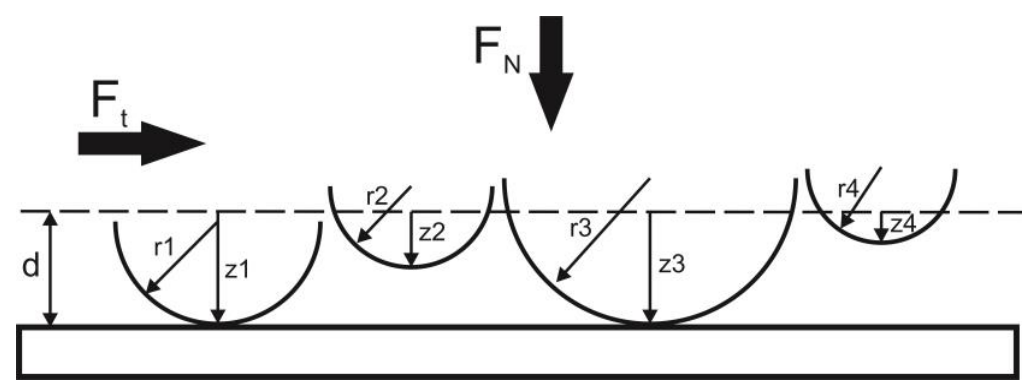

Figure 5.3: Multi summit contact with a normal load and tangential load.

First, from the load balance, the separation $d$ between the surface can be calculated if the applied load is known, see e.g [8]. Then, the contact area $A_{n}$ at each summit can be calculated from Equation 5.1, if the local radius $r_{n}$ and local height $z_{n}$ is known:

$$
A_{n}=\pi \cdot r_{n} \cdot\left(z_{n}-d\right)
$$

The normal force applied at each summit is obtained from integrating the Hertz pressure distribution per summit over the contact area, resulting in Equation 5.2: 


$$
F_{n}=\frac{4}{3} \cdot E^{*} \cdot \sqrt{r_{n}} \cdot\left(z_{n}-d\right)^{3 / 2}
$$

Where $E^{*}$ is the reduced elastic modulus.

In the model which will be discussed below, the tangential displacement is assumed to be the same for each summit in the contact. This means that the lateral stiffness of the bulk material will be ignored. Consequently, the summits will have no mutual influence apart from sharing the tangential load as well as the normal load. Finally, with increasing tangential load, the summit with the highest pre-sliding distance will determine when the total system starts sliding. This is typically, but not necessarily the highest summit.

In calculations, the assumed material combination is a silicon ball against float glass, which is assumed to be perfectly smooth. The properties of the materials used in the calculation are given in Appendix B. The steps used for calculation and repeated for each loading and unloading situation are shown in

Figure 5.4. 


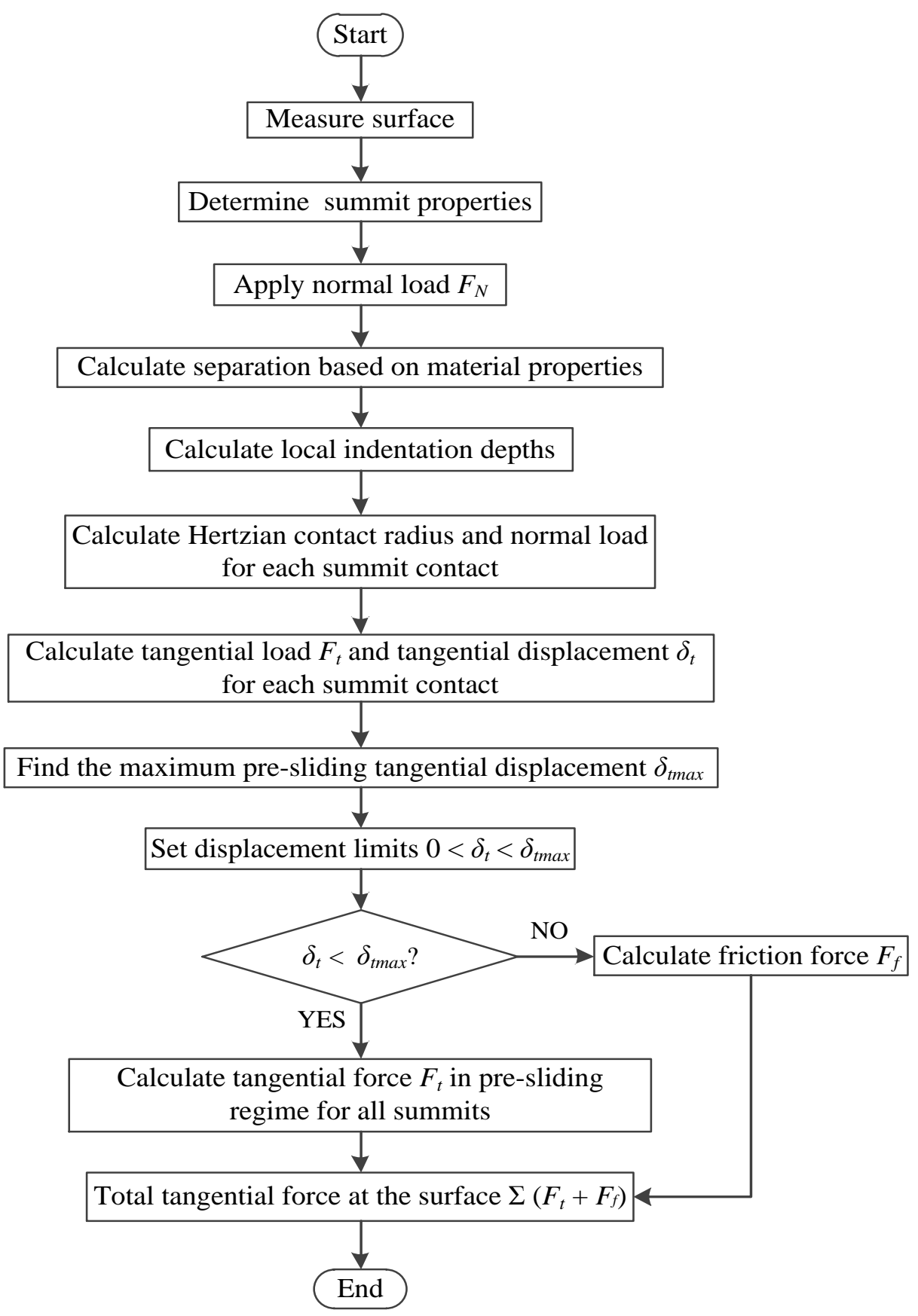

Figure 5.4: Flow chart of the steps used for numerical calculations. 


\subsection{Pre-sliding behaviour of a multi asperity contact including loading history}

The pre-sliding behaviour of a multi asperity contact was already introduced in Chapter 2. In this section, the theory will be illustrated for several loading conditions and surface roughness characteristics. The results are obtained from the model described in the previous section.

\subsubsection{Normal load is constant and tangential load is oscillating}

In the calculations, the applied normal load is set constant at $F_{N}=50 \mathrm{mN}$. The coefficient of friction $\mu$ is set at a value of 0.2 . The initial surface roughness $R q$ is 1 $\mu m$.

First, from the load balance the separation $d$ between the surfaces will be calculated. Then, the pre-sliding displacement of each individual summit will be calculated. The highest value, so the summit with the highest pre-sliding displacement, will be the tangential displacement at which the rough surface as a whole will start sliding. At each displacement value lower than critical value, the tangential force at each summit will be evaluated using the model. The total tangential force of the total contact area is the sum of the tangential force at each asperity. 
a)

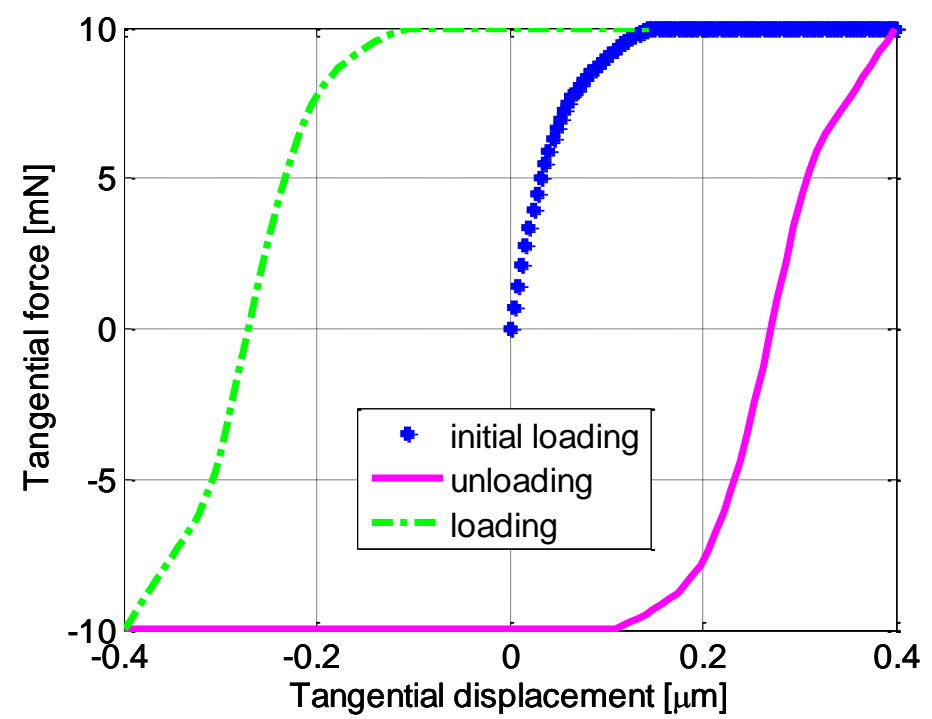

b)

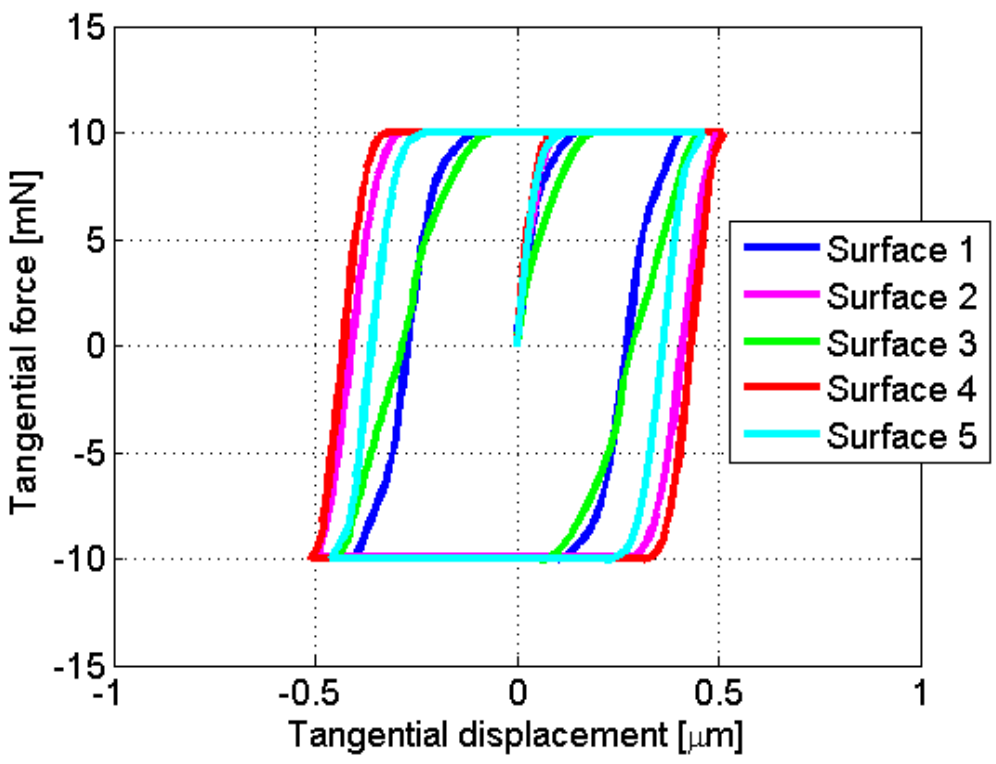

Figure 5.5: a) Oscillating tangential force for surface 5.1 and 5.2 with tangential displacement and b) oscillating tangential force for surfaces with roughness $R q=1 \mu \mathrm{m}$ at the same settings.

In Figure 5.5 (b) the surfaces that have been generated (Figure 5.2 (b)) show the sensitivity of the micro geometry on the pre-sliding behaviour. In the Figure 5.5 (b) the maximum preliminary tangential displacement value for each generated surface 
is different. For example, in the case of Surface 3 the maximum preliminary tangential displacement is almost twice as high as for Surface 4, even if both are assumed to have the same roughness value $R q$. This behaviour already indicates the influence of the summit distribution and role of 'extreme' asperities. Depending on this distribution the system starts sliding at a different tangential displacement value. However, it is expected that when the surfaces are run in the extreme, asperities are worn off and as a result the differences in pre-sliding behaviour between the contacts will become less.

\subsubsection{Different normal load and oscillating tangential force}

In this section, the effect of the normal force will be investigated for the same surface as shown in Figure 5.1. As the coefficient of friction is set at 0.2, the maximum friction force becomes higher for increasing normal load as does the maximum tangential displacement. In order to make the difference between the loops clear, the sliding distance is also increased in the graph for higher loads. The results are shown in Figure 5.6.

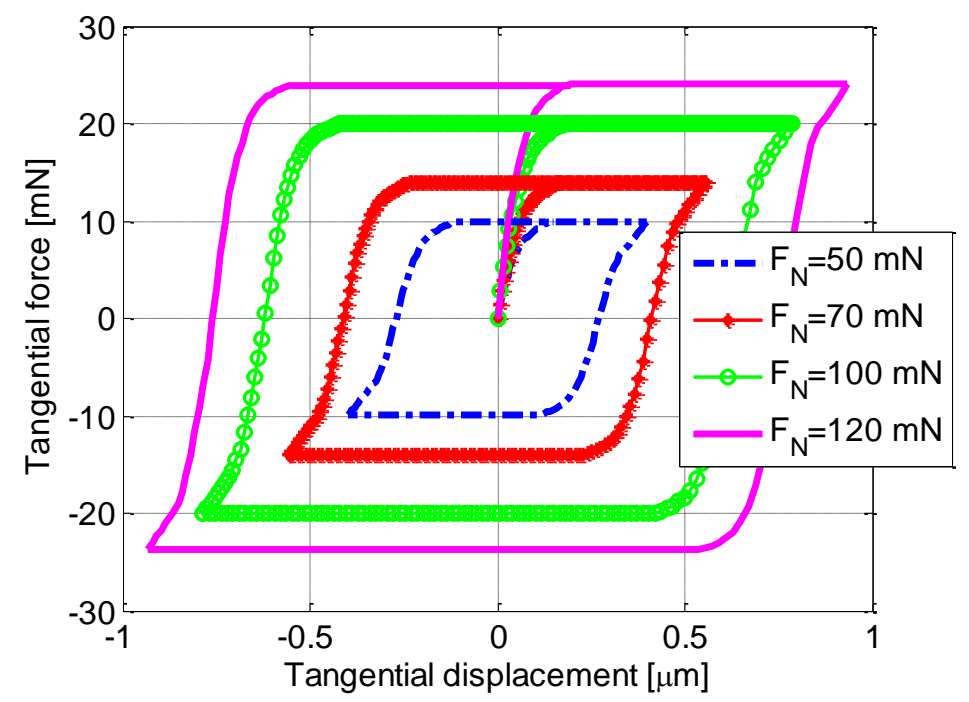

Figure 5.6: Oscillating tangential force for different values of normal load. 
It can be seen that the calculated maximum pre-sliding displacement is increasing for increasing loads. Furthermore, it can be seen that the shape of the obtained unloading and loading curves is different for higher normal loads, particularly the initial slope of the loading and unloading curves, so the stiffness in the pre-sliding regime is higher at higher loads. The unloading curve for a multi asperity contact is different than for a single asperity contact because more asperities are in contact. During the unloading part of the curve, gradually all individual asperities will leave the pre-sliding regime and enter the sliding regime.

A higher normal load for the same surface causes the transition from sticking to sliding to be smoother due to an increase in the number of micro contacts, and consequently a more gradual transition of the set of micro contacts from partial stick to slip.

In order to analyse these curves, some typical parameters will be obtained from these loops. First, the maximum pre-sliding displacement will be analysed. The area below loading and unloading curves, excluding the sliding regime, will be the mechanical work dissipated in the pre-sliding regimes, as is shown in Figure 5.7. This value will be analysed for several conditions. 


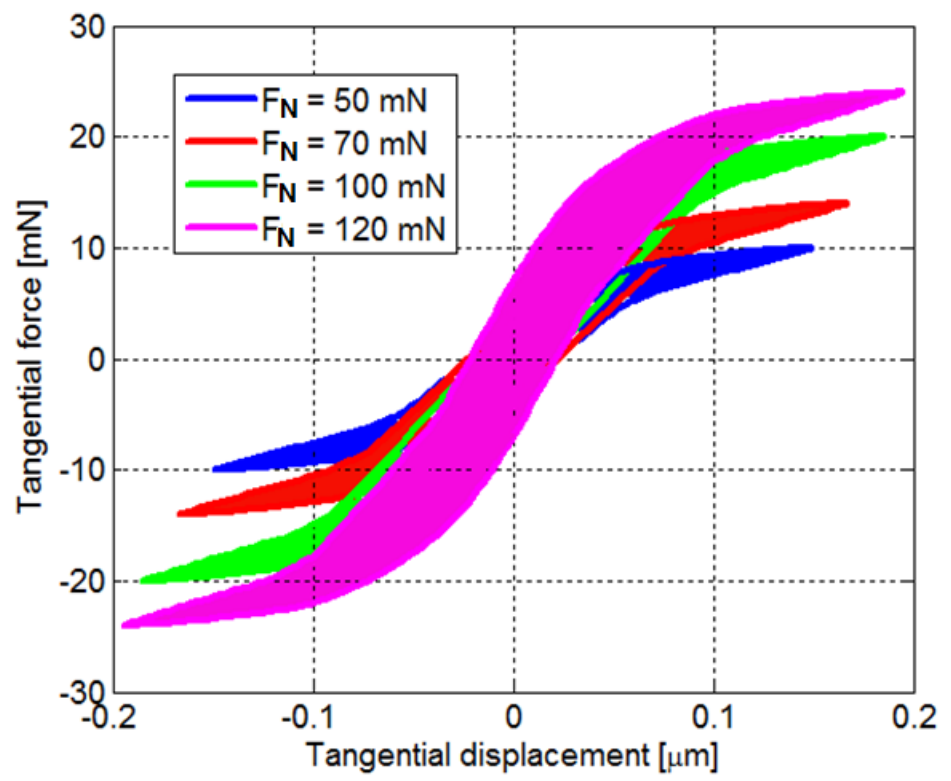

Figure 5.7: Tangential force as a function of tangential displacement for different normal loads.

The mechanical work is interpreted as the difference in work required in changing the contact from a stationary contact into a sliding contact and vice versa. In a sense, it is a measure for the frictional hysteresis in the system and its accuracy. Calculating the mechanical work shows clearly that for higher normal loads the mechanical work is increasing as shown in Figure 5.8. The relation between mechanical work in the pre-sliding regime and increasing normal load is almost linear for this case. This is not obvious from the equations as there is no direct linear correlation between tangential displacement and normal load. However, there is a linear relation between the applied load and the friction force as the coefficient of friction, assuming Coulomb friction, is set to a constant value in these calculations. 


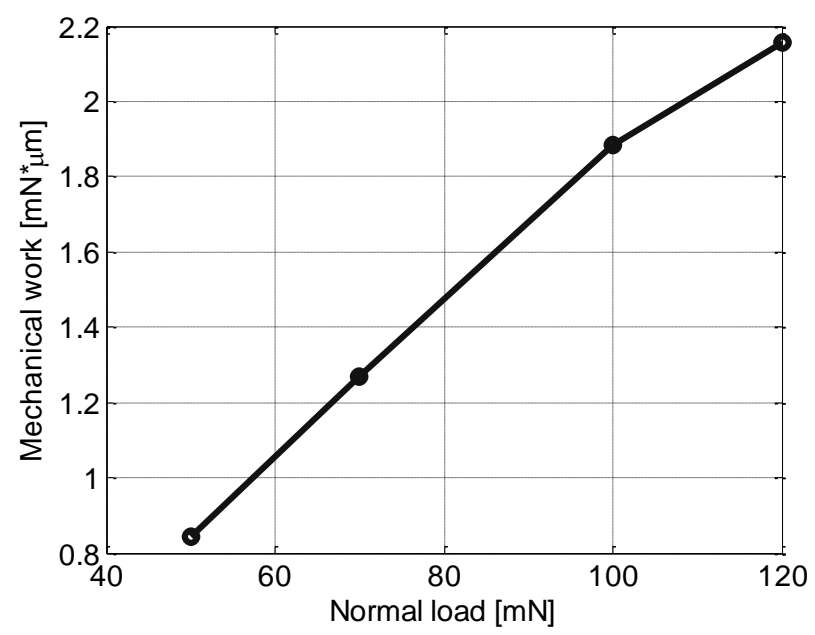

Figure 5.8: Mechanical work for increasing applied normal load.

\subsubsection{Oscillating tangential force with different surface roughness}

The pre-sliding behaviour with different surface roughness levels is compared for a normal load set to $50 \mathrm{mN}$ and a coefficient of friction to 0.2 . The results are shown in Figure 5.9.

It can be seen that the maximum tangential displacement is lower and, consequently, the stiffness in the pre-sliding regime, is higher for smooth surfaces as compared to rougher surfaces. This can be explained by the fact that a rougher surface shows a larger variety in summit heights and because of that a lower stiffness. In the theoretical case of $n$ equal micro contacts, the stiffness of a rough contact would be equal to a single micro contact with applied load $F_{N} / n$. 


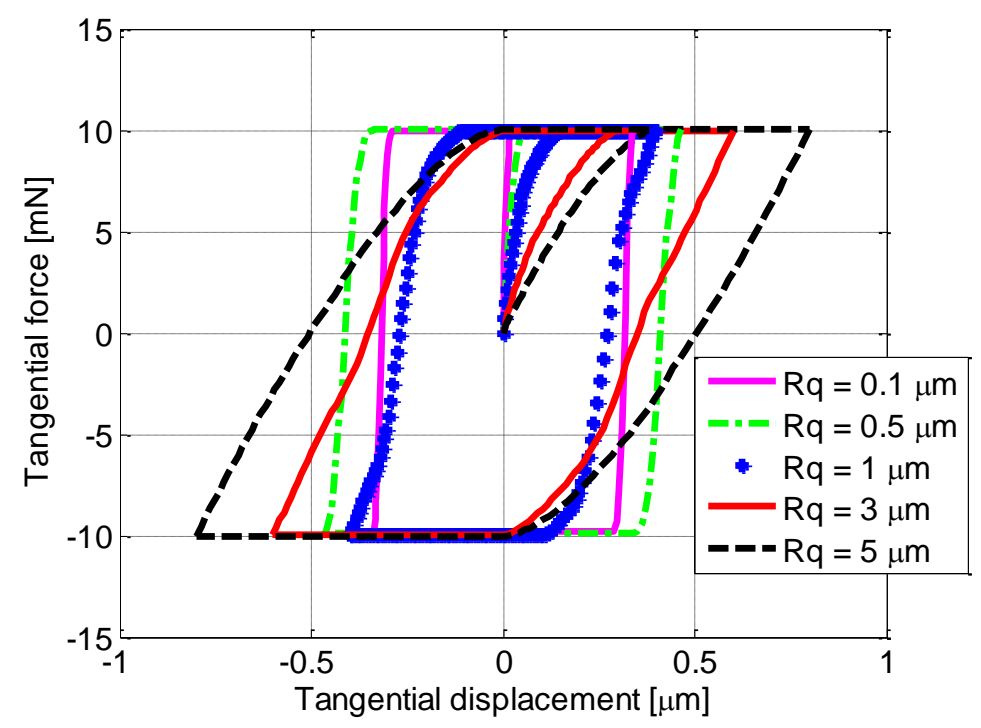

Figure 5.9: Oscillating tangential force for surfaces with different roughness values.

Next to the preliminary displacement, the roughness of the surface will influence the mechanical work dissipated in the pre-sliding regime, as presented in Figure 5.10. For a higher roughness, the summit radii are smaller and heights larger. In addition, the maximum tangential displacement is higher, so the mechanical work is also increasing with roughness.

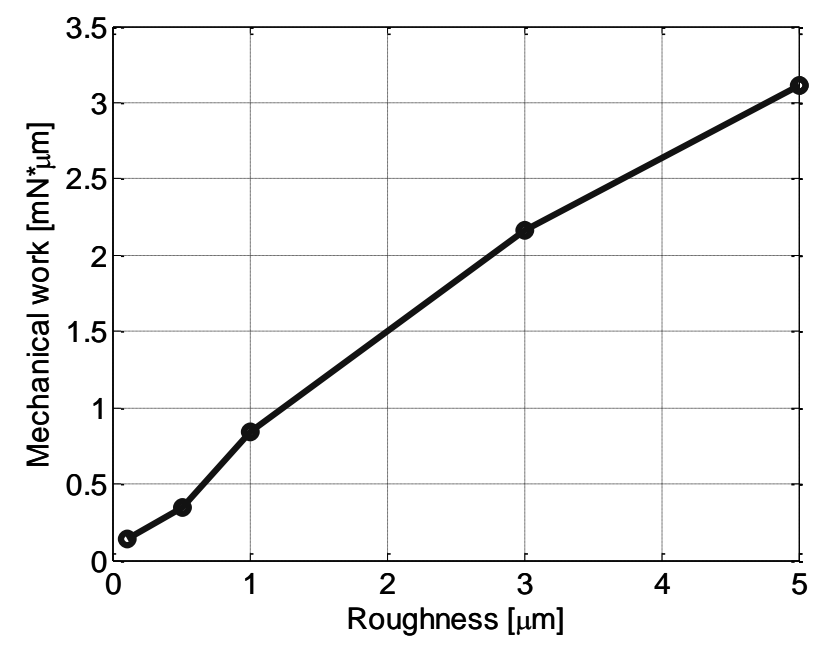

Figure 5.10: Mechanical work for different roughness. 


\subsubsection{Oscillating tangential force for surfaces with different autocorrelation length}

The results from surfaces with different roughness values show that the pre-sliding regime for a rough contact is strongly affected by surface roughness details. In a real contact the geometry of the surface will change in time due to wear. Typically, larger wavelengths are present in a surface which has been subjected to contact and sliding due to flattening of sharp asperities. An increase in asperity radius is a typical surface change caused by running - in. In this section this will be initially simulated by increasing the autocorrelation length of the surface. In the calculation, the normal load is set at $50 \mathrm{mN}$ and the coefficient of friction is kept at its value of 0.2 . For these calculations, the size of the surface has been increased to $512 \times 512 \mu \mathrm{m}$ to still have a reasonable number of micro contacts, also at larger autocorrelation lengths. Calculated pre-sliding loops for a variety of autocorrelation lengths $(l)$ are presented in Figure 5.11.

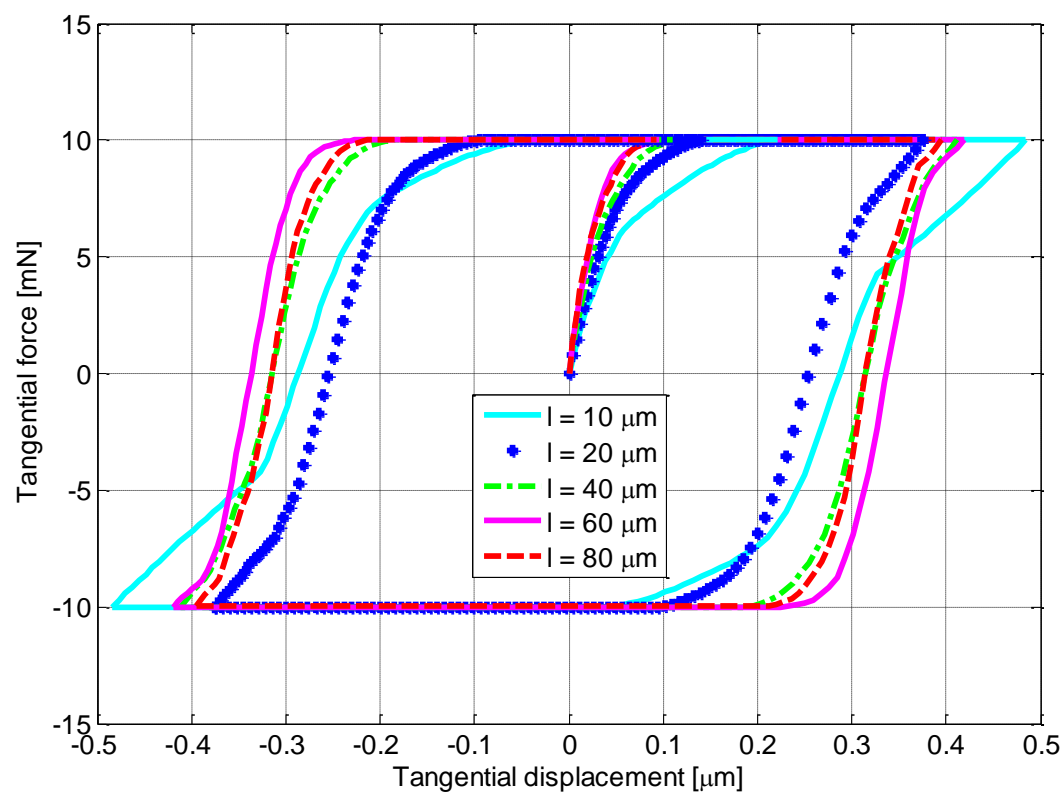

Figure 5.11: Oscillating tangential force for surface with different autocorrelation lengths for $F_{N}=50 \mathrm{mN}$. 
From Figure 5.11 it is observed that a larger autocorrelation length reduces the preliminary tangential displacement, in particular at low values of the autocorrelation length. At larger values, the loops at certain values stabilize. In Figure 5.12, the mechanical work is presented for different autocorrelation lengths. As in previous cases, the mechanical work in the pre-sliding regime is influenced by the maximum pre-sliding displacement. Also here, the mechanical work stabilizes at larger values of the autocorrelation length to a relatively low value.

It can be concluded that an increase in autocorrelation length results in reduction in the mechanical work dissipated in the pre-sliding regime.

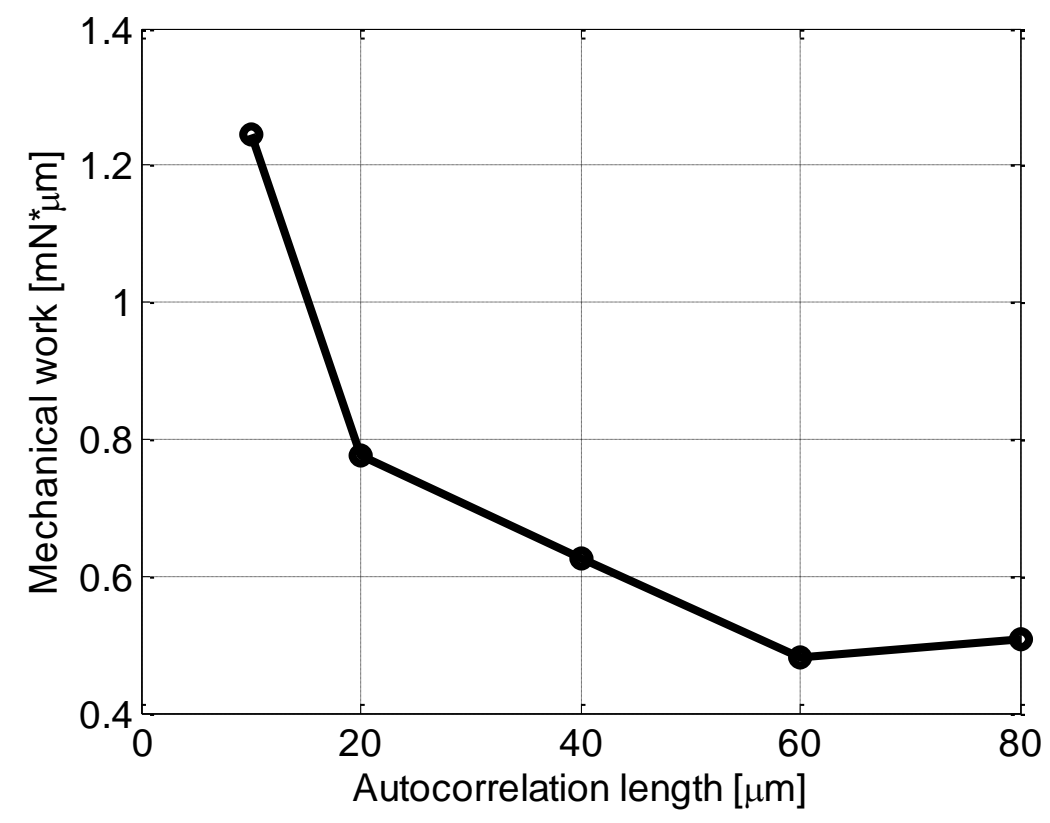

Figure 5.12: Mechanical work for different autocorrelation length.

\subsection{Effect of roughness on the positioning accuracy}

In the calculations below, the nominal contact pressure is calculated based on the total applied normal load and nominal contact area. The tangential displacement is calculated as a function of the nominal contact pressure for several roughness values and presented in Figure 5.13 a) and Figure 5.13 b). The calculated values for the pre-sliding displacement are in the order of $0.1 \mu \mathrm{m}$ or more. A change in the 
autocorrelation length, for the values given, could lead to positioning errors in the order of $0.1 \mu \mathrm{m}$ as the preliminary displacement changes in the same order. Similarly, a roughness reduction as a result of running - in during sliding will reduce the pre-sliding displacement. For the roughness changes shown, the pre-sliding behaviour of the contact will become less sensitive for contact pressure variations, see Figure 5.13.

a)

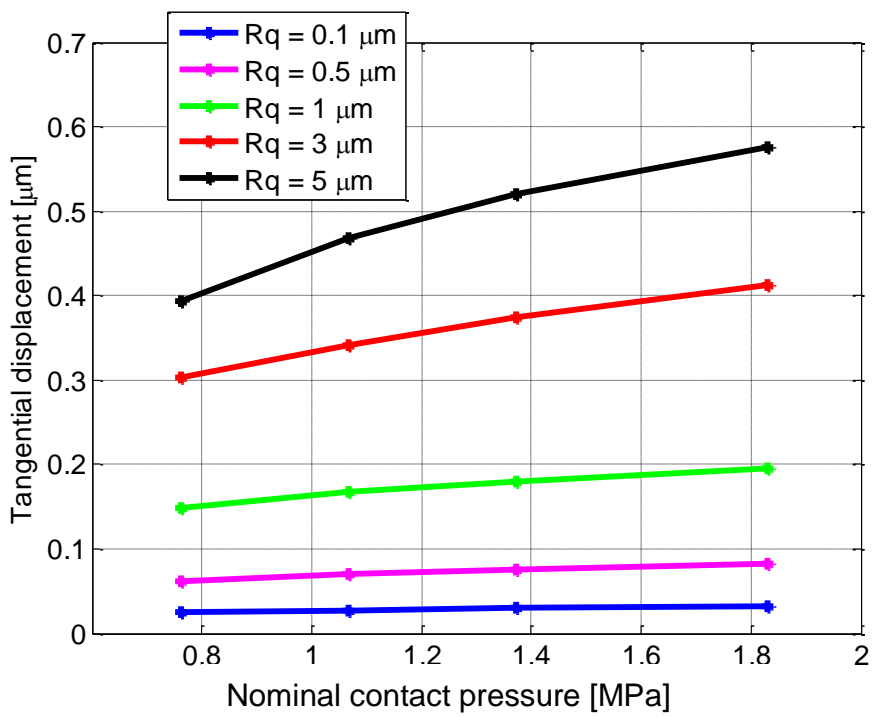

b)

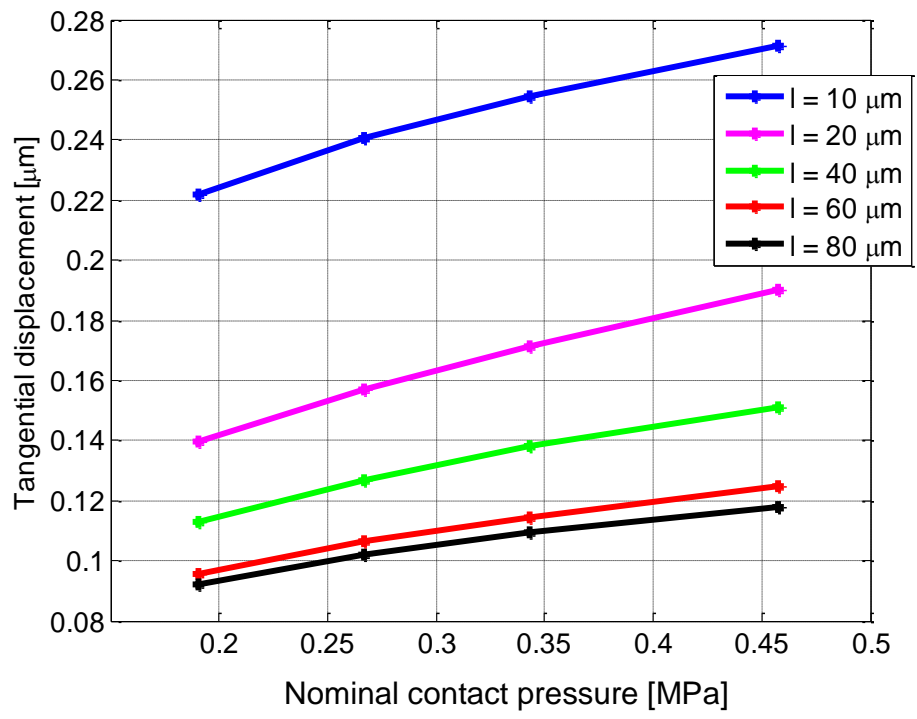

Figure 5.13: Tangential displacement against nominal contact pressure for a) different roughness and b) different autocorrelation length, both for a normal load of $50 \mathrm{mN}, 70 \mathrm{mN}$, $90 \mathrm{mN}$ and $120 \mathrm{mN}$ normal load, respectively. 


\subsubsection{Statistical variations of the generated surface model}

It has already been shown in Figure 5.2 how the summit heights and radii are distributed depending on assumed values for the surface roughness. In Figure 5.2 (b) it was visible that some of the summit heights are different for the same $R q$ settings. The generated surfaces have been used to compare the tangential displacement and applied normal load, see Figure 5.14. Tangential displacement was calculated in the same way as was explained in the previous sections and the material properties used here are for an alumina ball against a glass plate.

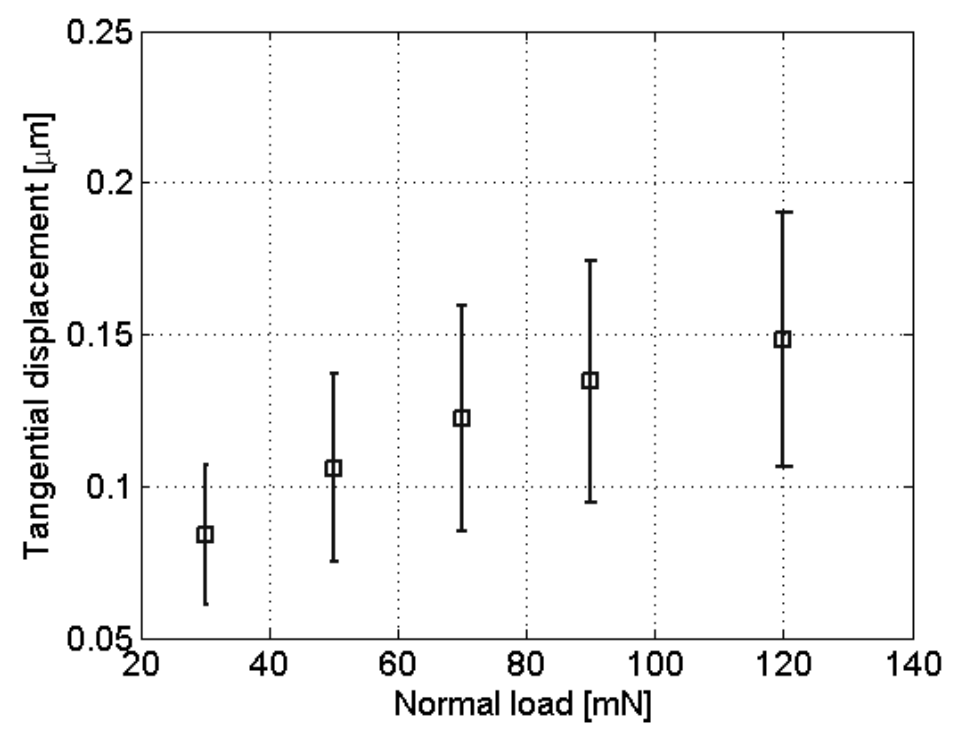

Figure 5.14: Statistical variations to calculate tangential displacement depending on applied normal load.

It can be concluded from Figure 5.14 that with higher applied normal load the tangential displacement is increasing. With a higher load the absolute difference of tangential displacement is also higher for surfaces with the same roughness values.

Statistical variations should be taken into account in the calculations to explain differences in the maximum preliminary tangential displacements. Although, as mentioned before, the spread in the preliminary displacement of run - in surfaces is expected to be smaller as the extreme asperities are more sensitive to changes during running - in. 


\subsection{Experimental validation with varying normal load on}

\section{multi asperity contact}

If load and micro geometry changes occur in the contact it will influence the presliding behaviour. The effects of the applied normal load which is constant, increasing or decreasing during sliding will be presented in this section. The experimental results, obtained from the two measurement setups UNAT and VAFT already introduced in previous chapters, will be shown here. The materials used for experiments to represent a rough surface are alumina $\left(\mathrm{Al}_{2} \mathrm{O}_{3}\right)$ and zirconia $\left(\mathrm{ZrO}_{2}\right)$ balls which were sliding against float glass. The material properties and roughness of the materials are shown in Appendix B.

The UNAT setup with higher instrument stiffness allows measuring the maximum pre-sliding tangential displacement, while the VAFT with lower instrument stiffness is used for measurements in ambient and vacuum conditions. Results obtained from both setups cannot be directly compared due to the difference in stiffness and operating conditions.

The maximum preliminary displacement obtained from the UNAT setup has been compared with theoretical calculations as well. In the calculations the same method has been used as described in Section 5.2.

\subsubsection{Constant normal load applied in the contact}

The experimental measurements have been performed in a similar way as for a single asperity contact using the UNAT setup. The applied normal load was constant and measurements using a sequence of five loops have been made. One of the results for constant normal load for an alumina ball against glass is shown in Figure 5.15. The tangential displacement and tangential load is presented on the horizontal axis and vertical axis, respectively. Each loop is made visible by a different colour and the stroke of the lateral stage was approximately $100 \mathrm{~nm}$. After stiffness correction of the UNAT setup the value of the tangential displacement is lower than $100 \mathrm{~nm}$. 


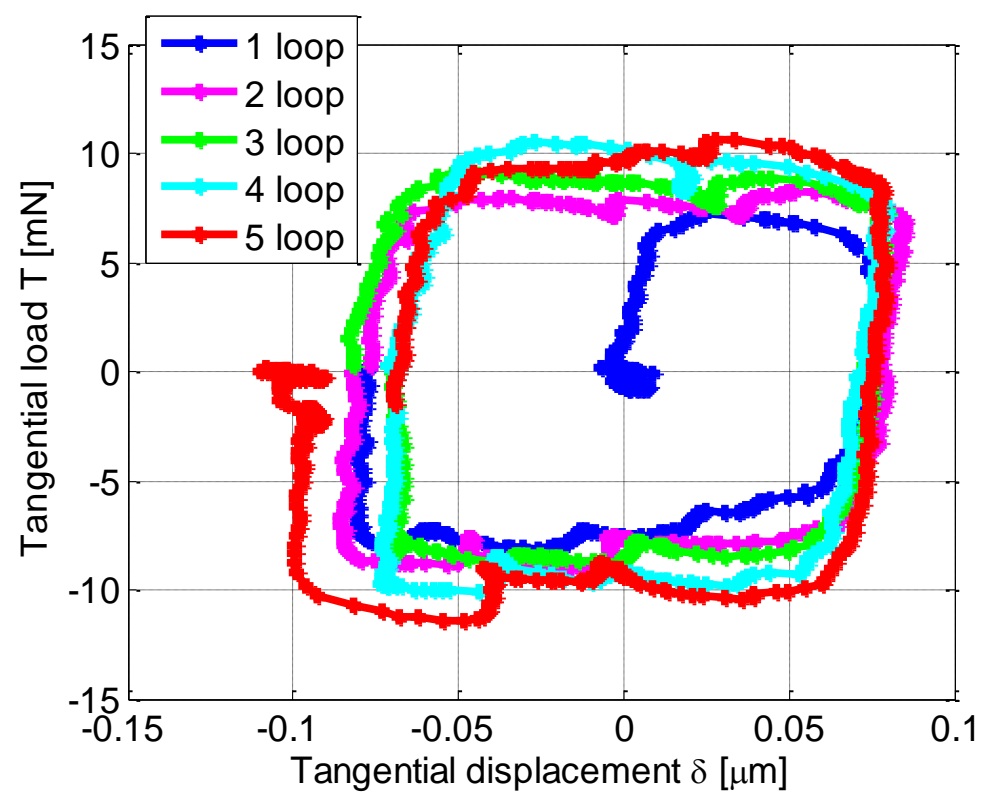

Figure 5.15: Tangential load and tangential displacement loops for constant normal load of $F_{N}=50 \mathrm{mN}$, displacement of $100 \mathrm{~nm}, \mathrm{Al}_{2} \mathrm{O}_{3}$ ball against glass, UNAT setup.

The roughness of the alumina ball is $R_{q}=24 \mathrm{~nm}$. In the experiments, the applied normal load was constant with a value of $50 \mathrm{mN}, 70 \mathrm{mN}$ and $90 \mathrm{mN}$.

The static friction force increases linearly with the higher normal load as is presented in Figure 5.16. It was already shown in Chapter 4 for a sapphire ball against glass that the static friction force for rough surfaces is increasing linearly with normal load, compared to smooth surfaces where the coefficient of friction decreased with the power $1 / 3$ with increasing load. The proportionality between the friction force and the normal load has already been explained and attributed to the proportionality between the real contact area and the load for random rough surfaces, so due to real contact area $A_{N} \propto F_{N}[8]$. 


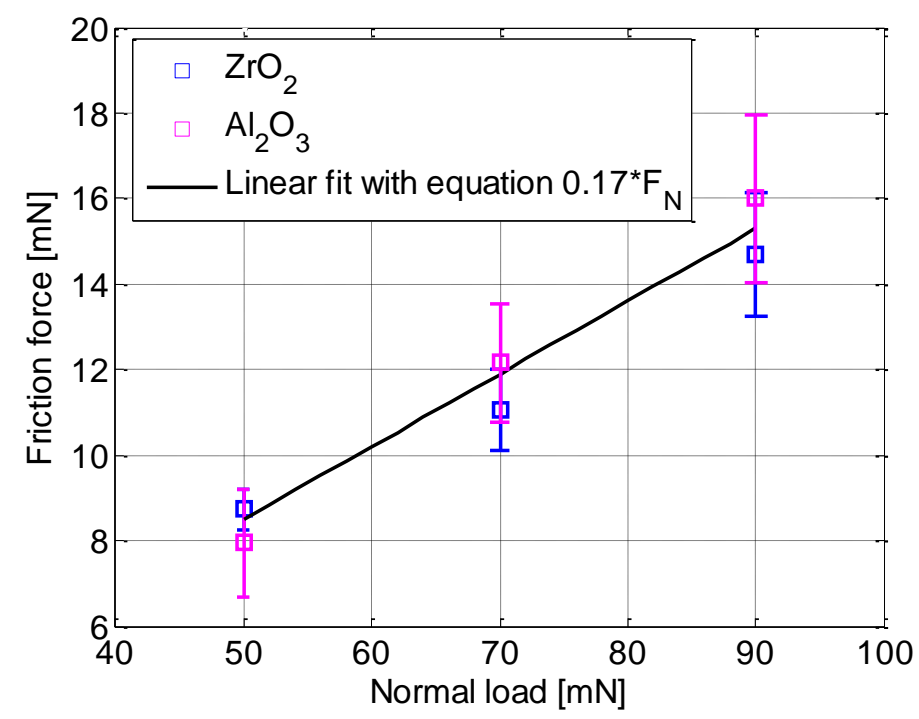

Figure 5.16: Friction force against normal load for $\mathrm{ZrO}_{2}$ and $\mathrm{Al}_{2} \mathrm{O}_{3}$ against glass, UNAT setup.

Due to the linear relation between the tangential load and normal load the coefficient of friction is constant irrespective of normal load, according to Equation 4.1. From Figure 5.16 it can be noticed that the coefficient of friction for zirconia is a bit higher $(\mu=0.17)$ than for alumina lower $(\mu=0.16)$.

The tangential displacement from the experimental results has been compared with calculations and shown in Figure 5.17. As can be seen in this figure, the tangential displacement is constant with increasing normal load. The theoretical calculations have been done with the assumed surface roughness for zirconia $R q=24 \mathrm{~nm}$ and alumina $R q=21 \mathrm{~nm}$ according to the measured roughness of the balls used in the experiments. The coefficient of friction used was obtained from the experiments. 


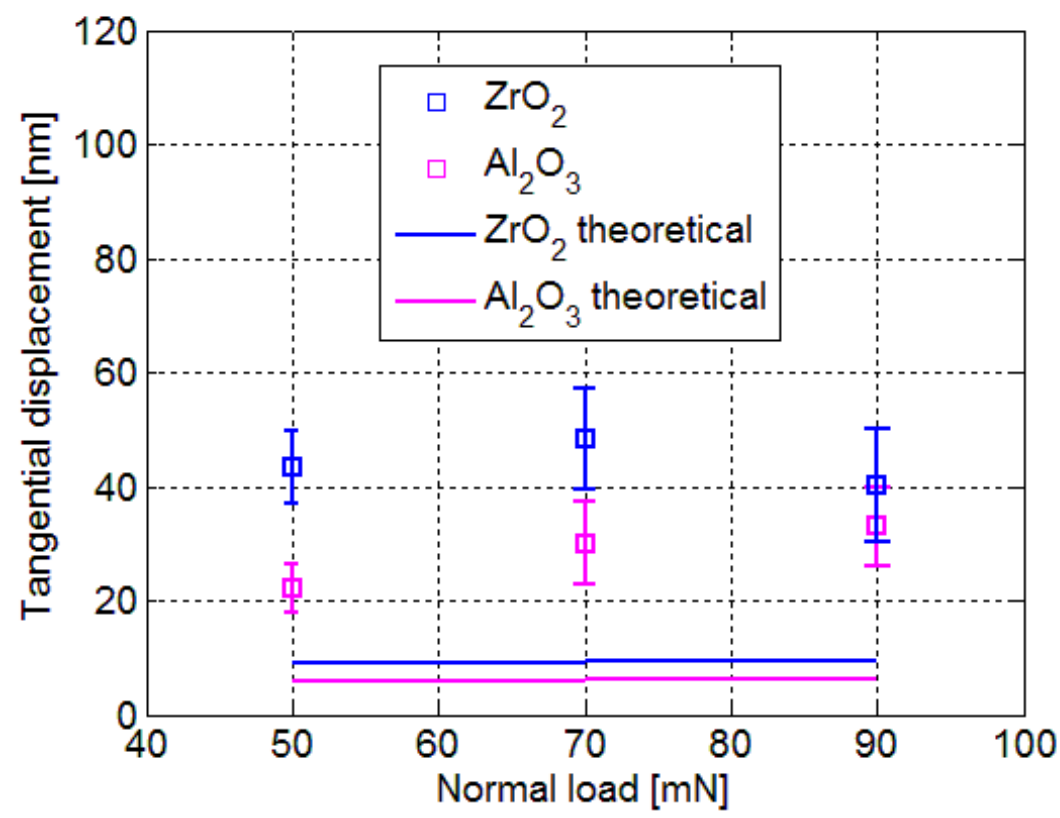

Figure 5.17: Tangential displacement against normal load for $\mathrm{ZrO}_{2}$ and $\mathrm{Al}_{2} \mathrm{O}_{3}$ against glass, UNAT setup.

In Chapter 4 it was explained that the maximum preliminary displacement is proportional to the maximum tangential load and inversely proportional to the contact radius for a single asperity contact as shown by Equation 4.2. For a rough contact it will be constant irrespective of applied normal load. Comparison between experimental data in Figure 5.17 with calculated data in Figure 5.13 (a) shows that the value of the tangential displacement is equal and load independent for low roughness values. Furthermore the calculated values are in the same order of magnitude as the measured values. Comparing the measured values in Figure 5.17 with the theoretical calculations also show the same constant trend. The lower calculated values are the consequence of the assumed surface roughness and as was already explained in Section 5.4.1 due to statistical variations.

The experimental tests performed under ambient and vacuum conditions by the VAFT setup in the case of a constant applied normal load are compared in Figure 5.18. The constant normal load was $30 \mathrm{mN}, 60 \mathrm{mN}$ and $90 \mathrm{mN}$ and the measurement 
procedure was kept similar to the one described in Chapter 4 for a single asperity contact.

a)

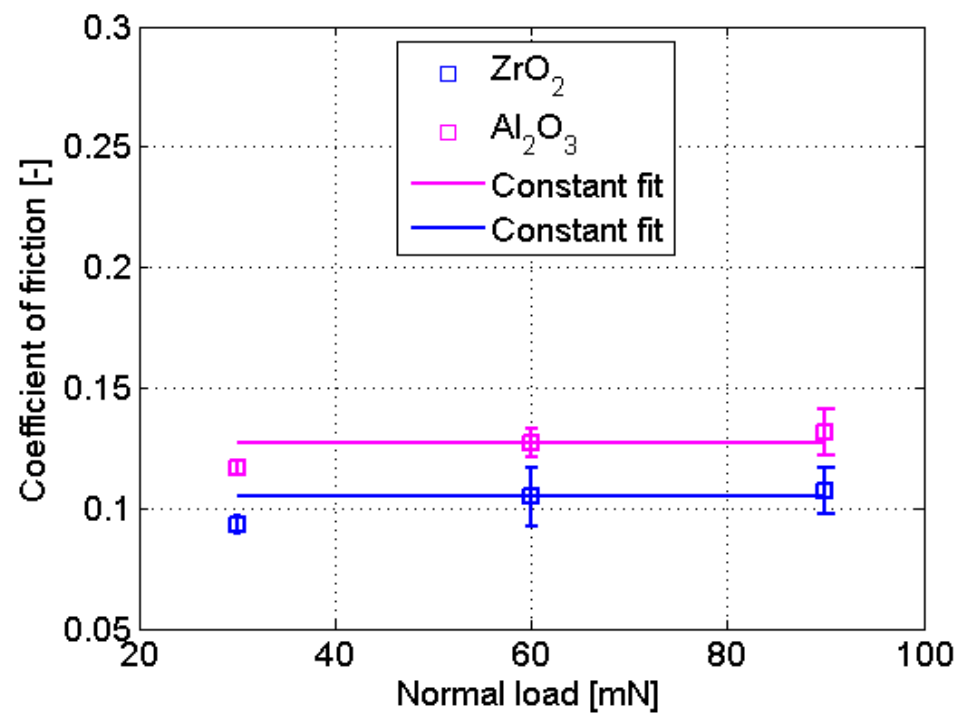

b)

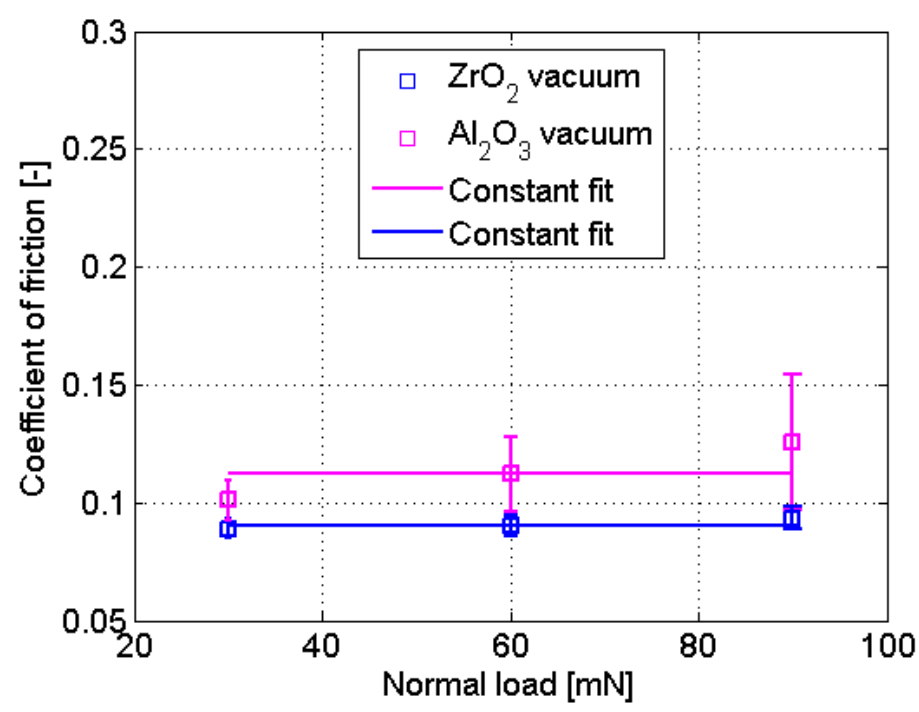

Figure 5.18: Coefficient of friction against normal load for $\mathrm{ZrO}_{2}$ and $\mathrm{Al}_{2} \mathrm{O}_{3}$ against glass in a) ambient and $b$ ) vacuum condition, VAFT setup.

The coefficient of friction as a function of the applied normal load also follows a constant relation, similar to the results obtained with the UNAT setup. 


\subsubsection{Increasing and decreasing normal load during sliding}

In the results shown below, the normal load was increased in a similar way as for the single asperity contact measurement. The load ranged from $50 \mathrm{mN}$ to $70 \mathrm{mN}$ and $90 \mathrm{mN}$. The results from an increasing normal load are shown in Figure 5.19 for an alumina ball against float glass. Each of the loads is marked in a different colour. The displacement of the lateral stage was $200 \mathrm{~nm}$.

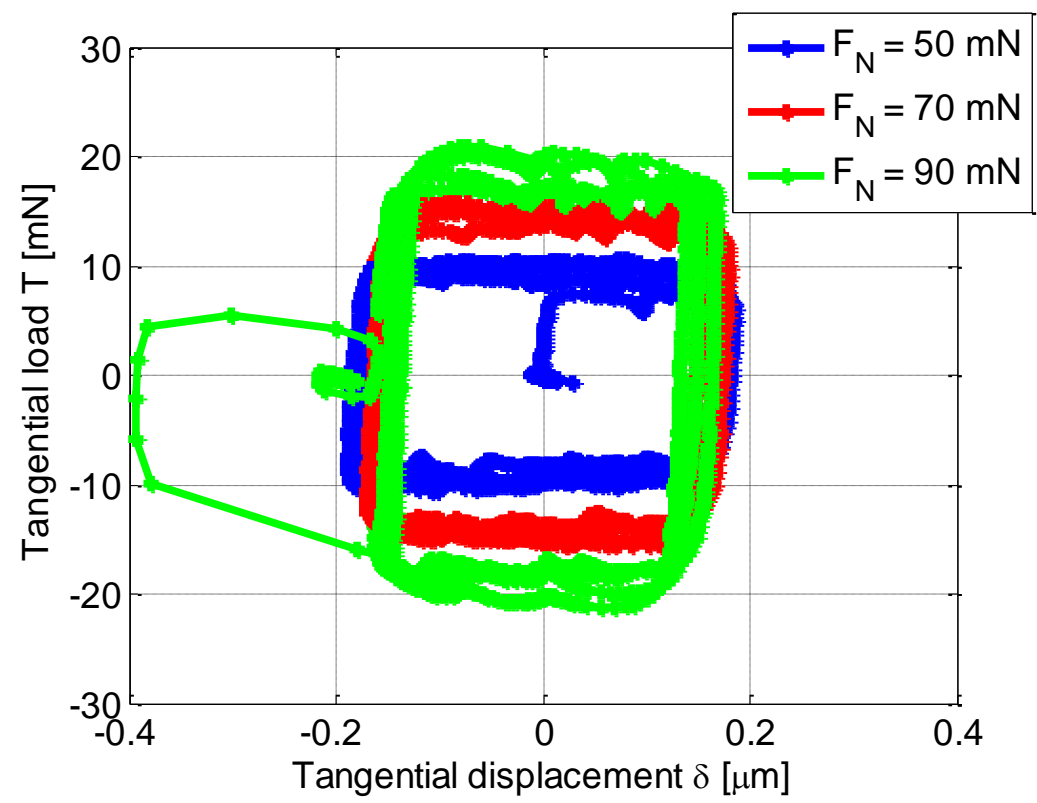

Figure 5.19: The effect of increasing normal load $(50 \mathrm{mN}-70 \mathrm{mN}-90 \mathrm{mN})$ on the tangential load and displacement for $\mathrm{Al}_{2} \mathrm{O}_{3}$ against glass, UNAT setup.

The coefficient of friction is compared for alumina and zirconia against glass in Figure 5.20. The increase of the normal load also causes an increase in coefficient of friction. As already mentioned before, the increasing level of the coefficient of friction indicates wear in the contact which will also take place for a rough contact. However, the roughness changes have not been investigated before and after the measurements. 


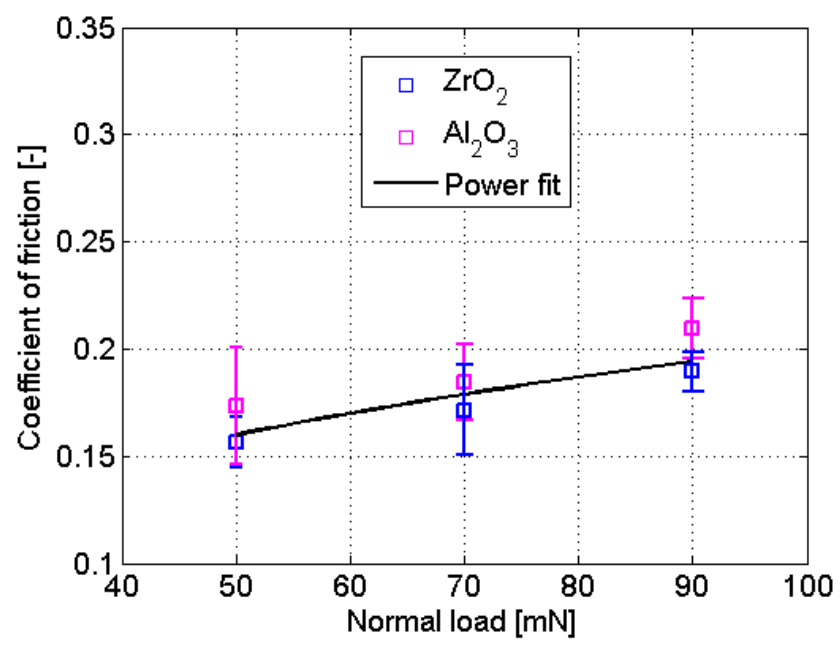

Figure 5.20: Coefficient of friction as a function of normal load for $\mathrm{ZrO}_{2}$ and $\mathrm{Al}_{2} \mathrm{O}_{3}$ against glass, UNAT setup.

The measured tangential displacement for $\mathrm{ZrO}_{2}$ and $\mathrm{Al}_{2} \mathrm{O}_{3}$ is shown in Figure 5.21 for increasing normal load, as well as the theoretical calculations. As in the previous calculations for constant load, the surface roughness and the coefficient of friction are taken from the test. The tangential displacement shows a slight increase with normal load.

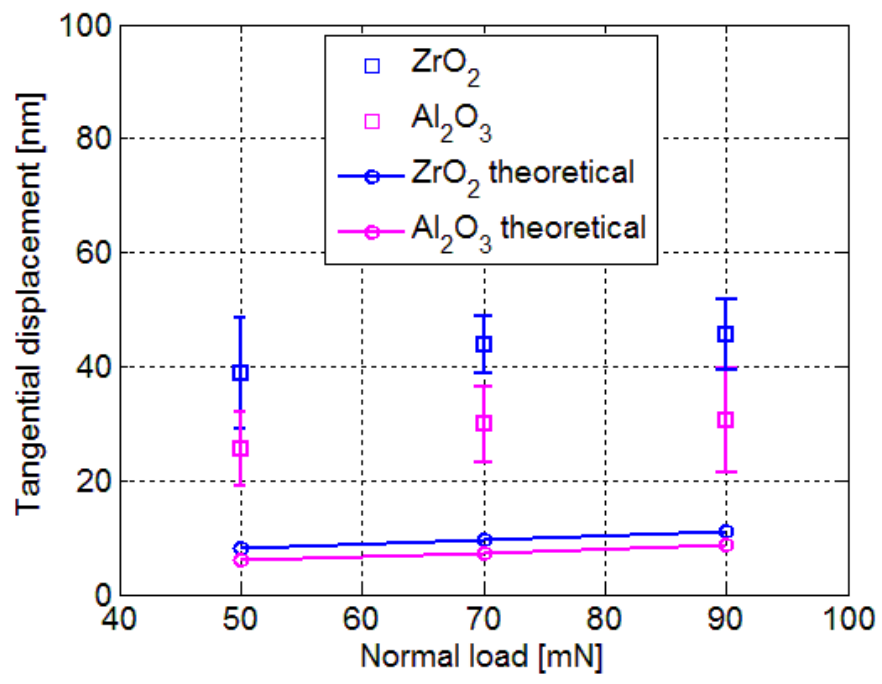

Figure 5.21: Tangential displacement as a function of normal load for $\mathrm{ZrO}_{2}$ and $\mathrm{Al}_{2} \mathrm{O}_{3}$ against glass, UNAT setup 
The VAFT setup was used to measure the effect of an increasing normal load in ambient and vacuum conditions. In Figure 5.22 the relation between the coefficient of friction and normal force is presented.

a)

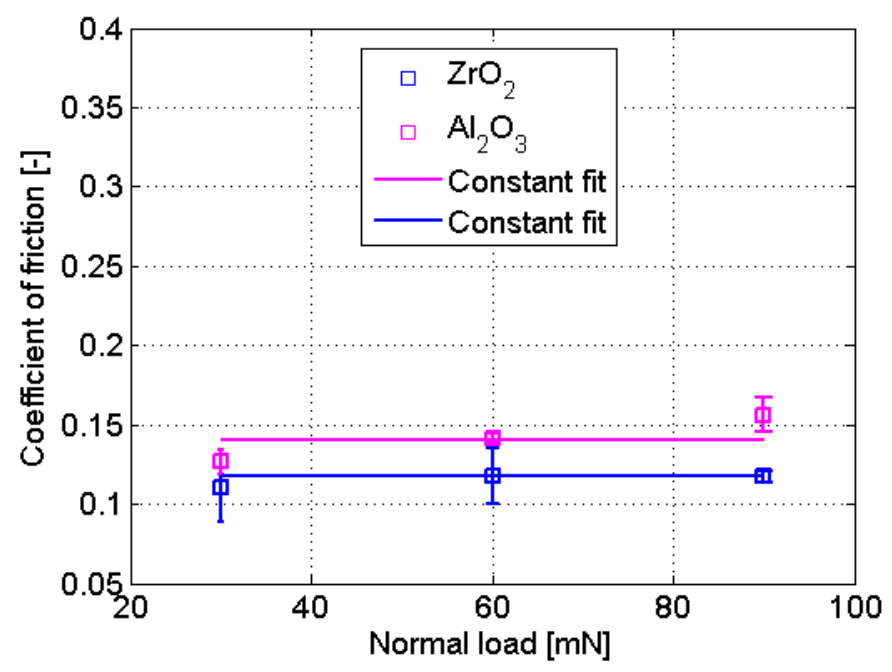

b)

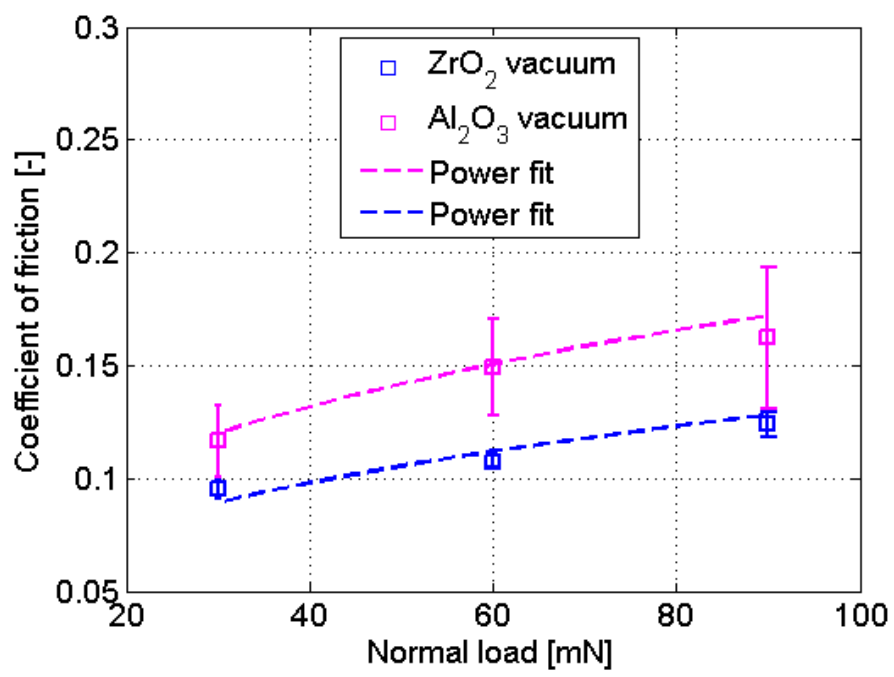

Figure 5.22: Coefficient of friction as a function of normal load for $\mathrm{ZrO}_{2}$ and $\mathrm{Al}_{2} \mathrm{O}_{3}$ against glass, a) ambient and b) vacuum condition, VAFT setup. 
Under ambient conditions, the coefficient of friction with increasing normal load is constant, as expected according to $A_{N} \propto F_{N}$ [8]. The alumina ball roughness was checked before and after the test to make sure that no wear took place during the measurement. Under vacuum some wear occurs in the contact, as a result the coefficient of friction increases with normal load.

As an example the tangential displacement has been calculated in the same way as described in Section 5.2 and 5.3. The surface roughness of the alumina and zirconia ball was measured before and after the tests (surface image is shown in Appendix B, Figure B.4). In Figure 5.23 the results are shown. The tangential displacement increases with normal load in the case of surface data of alumina before the tests, and for zirconia both before and after the tests. However, in the case of surface data of alumina after the test the tangential displacement is constant and the tangential displacement is reduced by two orders of magnitude. This indicates that if the asperities of the surface change the effect on the tangential displacement is significant.

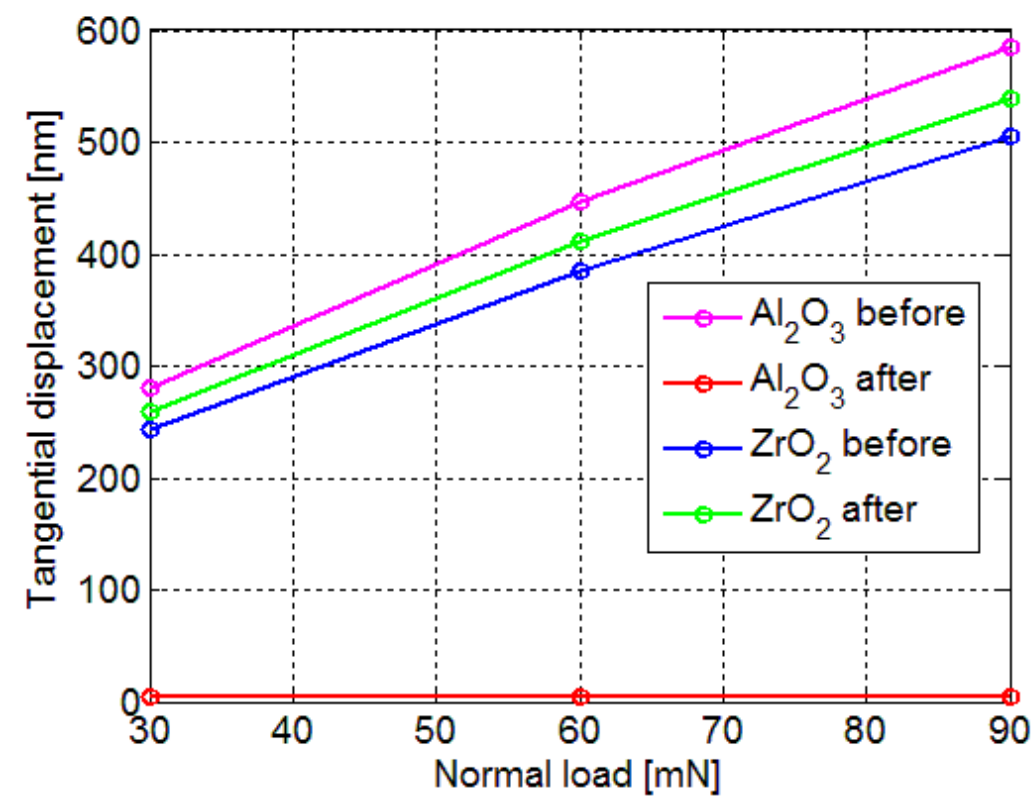

Figure 5.23: Theoretical calculation of the tangential displacement as a function of normal load with roughness values measured of alumina and zirconia ball before and after test, VAFT setup. 
Next, the normal load was decreased with the measurement sequence shown in Appendix C. The load started from $90 \mathrm{mN}$ to $70 \mathrm{mN}$ and $50 \mathrm{mN}$. One of the experiments where the normal load is decreasing is shown in Figure 5.24 for an alumina ball against float glass. Each of the load loops is marked in a different colour. The lateral displacement of stage was set to be $200 \mathrm{~nm}$.

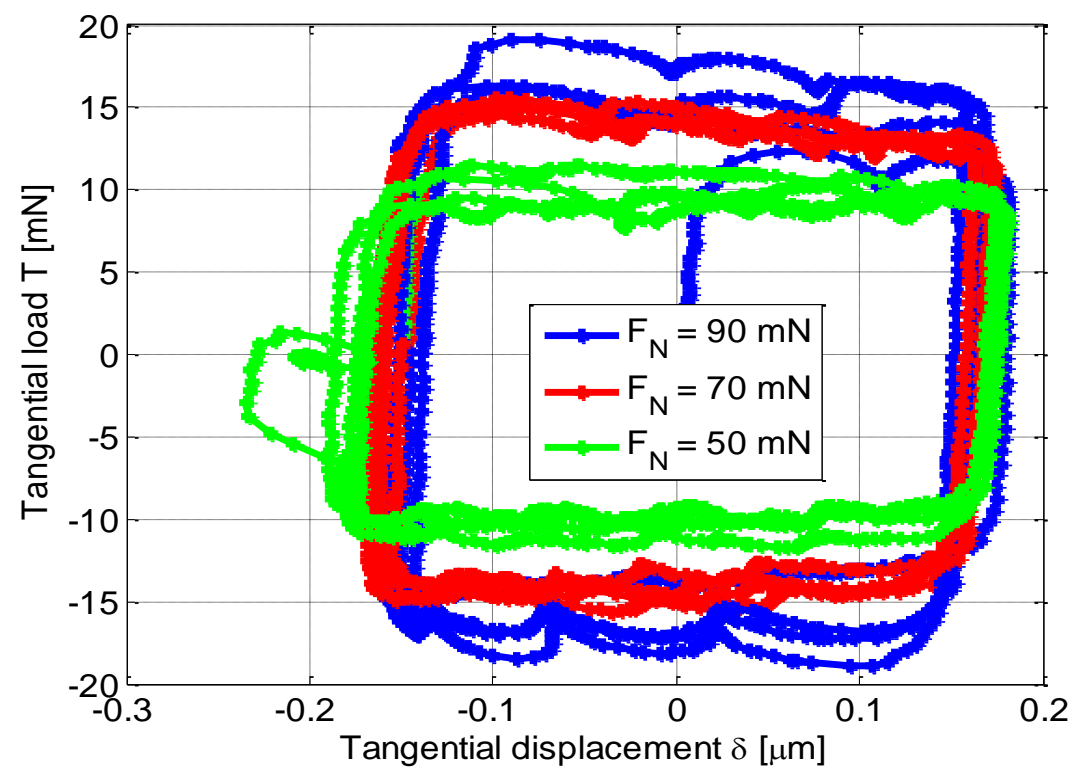

Figure 5.24 Tangential load as a function of tangential displacement for a decreasing normal load from $90 \mathrm{mN}-70 \mathrm{mN}-50 \mathrm{mN}$ for $\mathrm{Al}_{2} \mathrm{O}_{3}$ against glass, UNAT setup.

The coefficient of friction obtained from the experiments with $\mathrm{ZrO}_{2}$ and $\mathrm{Al}_{2} \mathrm{O}_{3}$ balls against glass is shown in Figure 5.25. 


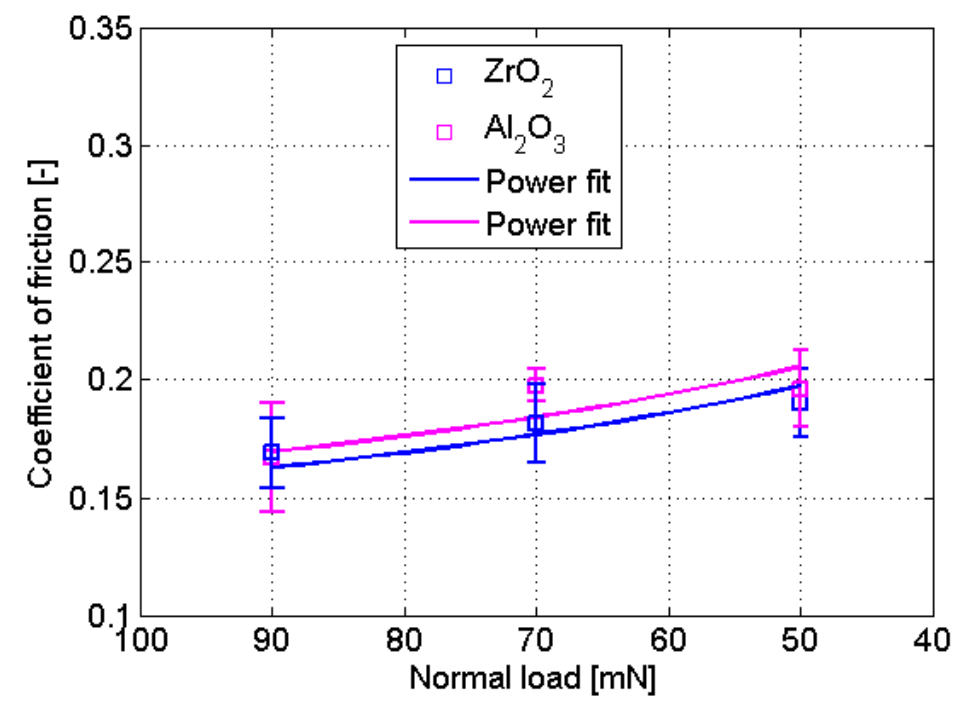

Figure 5.25 Coefficient of friction for decreasing normal load, $\mathrm{ZrO}_{2}$ and $\mathrm{Al}_{2} \mathrm{O}_{3}$ balls against glass, UNAT setup.

Decreasing the normal load during sliding shows that coefficient of friction increases with lower normal loads. The normal load does not influence the value of coefficient of friction for an increasing or decreasing normal load.

It is important to mention that the measurement has been performed in a short length of time. When two materials are in sliding contact the running - in effect may take place.

The tangential displacement obtained experimentally for a decreasing normal load and the theoretical results are shown in Figure 5.26. In this case, the tangential displacement is constant; for a low load the average value is almost equal to a high load. Theoretical calculations also show the same trend as obtained from the experiments. 


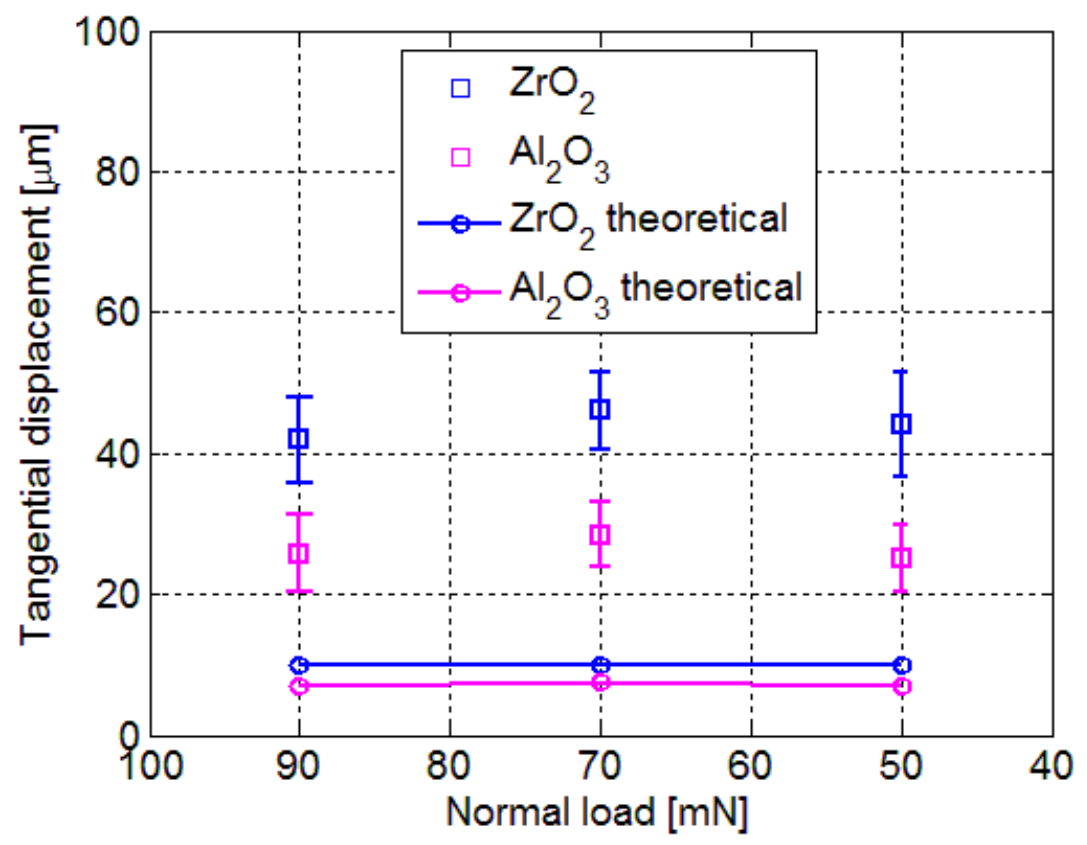

Figure 5.26: Tangential displacement as a function of the normal load for $\mathrm{ZrO}_{2}$ and $\mathrm{Al}_{2} \mathrm{O}_{3}$ against glass, UNAT setup.

\subsection{Summary}

The model for the pre-sliding behaviour of a single asperity contact has been applied to a multi asperity contact. In the model, it has been assumed that the tangential displacement is equal for each asperity. The results show that the detailed geometry and loading at asperity level will determine the pre-sliding behaviour of a multi asperity contact. In a multi asperity contact a critical asperity will determine when a rough surface starts sliding over a smooth flat. Model results show that the $R q$ roughness value as well as the autocorrelation length strongly influences the presliding behaviour. It was observed that a surface which becomes smoother in terms of a decreasing roughness and an increasing autocorrelation length results in a reduction of the pre-sliding displacement. The dissipated mechanical work shows the tendency to increase for increasing normal load and roughness. For a higher autocorrelation length the dissipated mechanical work is decreasing. 
Experimental results have been presented for rough surfaces to represent a multi asperity contact and validate the theoretical calculations. Applying a constant normal load with different values will result in a constant coefficient of friction for a rough contact due to real contact area which is proportional to the applied normal load. The tangential displacement which was measured with the UNAT setup shows that at higher normal loads the maximum tangential displacement is constant. Increase or decrease of the normal load during sliding also does not affect the coefficient of friction which is constant. However, when an increasing trend for the coefficient of friction is observed with changing the applied normal load, the running - in effect may take place. Also, the tangential displacement for increasing normal load will show an increase. 


\section{Chapter 6}

\section{DESIGN OF SURFACES FOR POSITIONING ACCURACY}

\subsection{Introduction}

The previous chapters gave detailed descriptions of the single and multi asperity contact. It has been shown that the complete loop of the pre-sliding behaviour is determined by all the asperities in contact. Ultimately, a critical asperity will determine the tangential displacement of the complete multi asperity contact. Although the load carried by this asperity is determined by the complete set of asperities in contact, in the end it is this single asperity which determines the tangential displacement of the whole contact. Any change of the asperity which causes a larger or smaller tangential displacement in the frictional loop means drift. An example is shown in Figure 6.1, where the drift is graphically illustrated. Figure 6.1 shows two tangential displacement loops for the zirconia plate with an alumina ball, in reciprocating motion. Here, the roughness values change for each loop. Drift is defined as a difference between the tangential displacements of the system: 


$$
d r i f t=\left|\delta_{t \max 2}-\delta_{t \max 1}\right|
$$

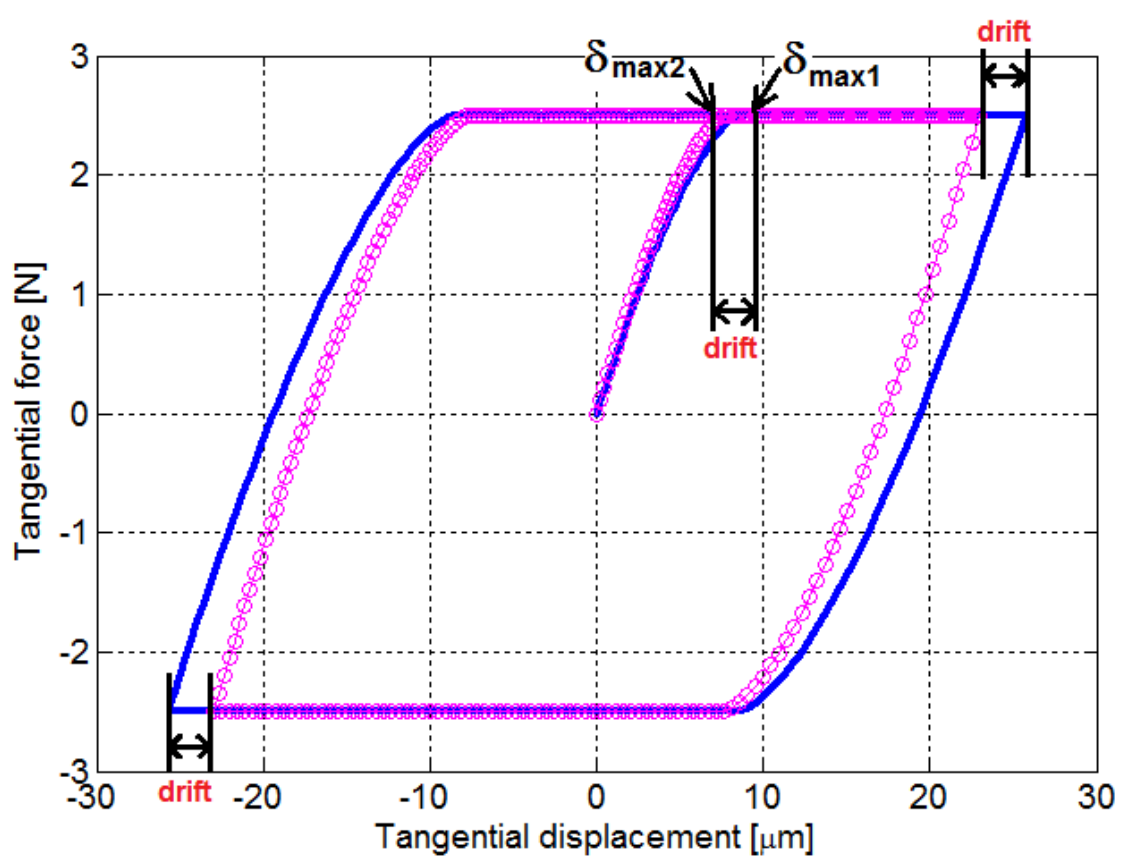

Figure 6.1: Example of the tangential loops for $\mathrm{ZrO}_{2}$ plate against alumina ball under $\mathrm{F}_{\mathrm{N}}=5 \mathrm{~N}$ to represent drift.

In this chapter, the drift of a positioning mechanism will be analysed due to changes in the contact. The theory developed in this thesis will also be used to analyse the positioning accuracy of a realistic ceramic-ceramic contact which has been operating for some time under ambient and vacuum conditions. The material properties of all used ceramics in this chapter are shown in Table B.1 in Appendix B, unless otherwise stated.

\subsection{Design of a surface for a positioning mechanism}

This section will describe the design criteria for surfaces suitable for positioning mechanisms. To calculate drift and to minimize the difference in the tangential displacement, the asperity distribution needs to be as stable as possible, even if the 
tribological contact shows changes. In Figure 6.2 an example of two surfaces is shown. In Figure 6.2 (a) all asperities have the same radius and the normal load is carried equally, so $F_{N} / n$ per asperity with $n$ the number of asperities. In Figure 6.2 (b) one asperity radius is larger than the others and, also, this asperity carries the normal load. To understand which set of asperities minimizes drift, the effect of parameters like radius, applied load and coefficient of friction can be analysed.

a)

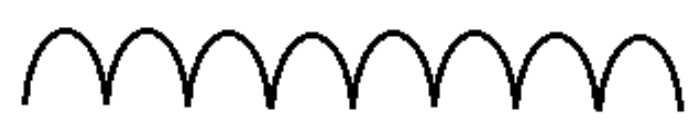

b)

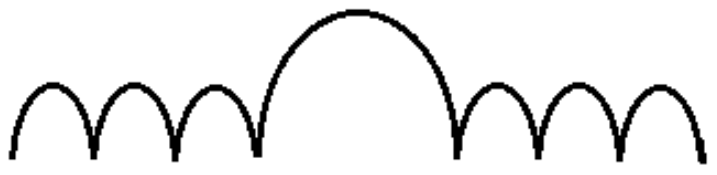

Figure 6.2: Asperity set for a rough surface a) with all radii equal, b) one asperity has a larger radius while the rest are equal.

Sections 6.2.1 and 6.2.2 will discuss design criteria for textured surfaces and for random rough surfaces.

\subsubsection{Textured surface}

A textured surface can be designed in several ways. In particular, the density of features and the shape of the texture can be designed. In this section textures will be analysed by the utilization of a scaling law [64]. In Figure 6.3 this is shown for two situations. The relation between the number of contacts and feature size is calculated as:

$$
\frac{n}{A^{2}}=\frac{1}{a^{2}}
$$

Where $n$ is the number of asperities, $A$ is the length and width of the area carried by each feature and $a$ is the asperity diameter of each feature after scaling. 

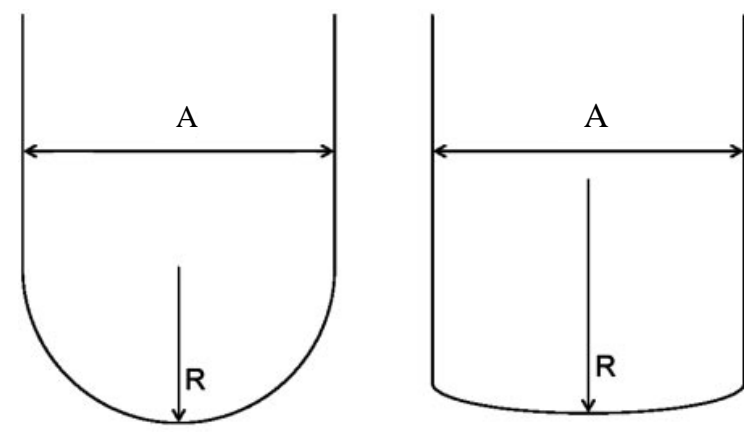

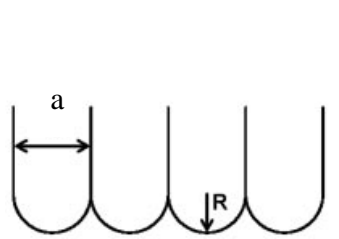

a

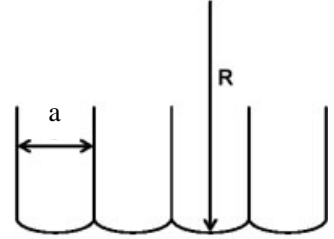

b

Figure 6. 3: Contact scaling for a) self-similarity: contact radius scales with contact size and b) curvature invariance: contact radius is independent of contact size [64].

In the case of self-similarity (Figure 6.3 (a)) the radius $R$ is scaling $(R / \sqrt{ } n)$ with the normal load $\left(F_{N} / n^{2}\right)$ and in the case of curvature invariance (Figure $\left.6.3(\mathrm{~b})\right)$ the radius $R$ is kept the same but the normal load per feature is reduced $\left(F_{N} / V_{n}\right)$ as the load is distributed over a larger number of asperities. In the following, the tangential displacement has been calculated with these scaling laws. In Figure 6.4 the radius $R$ of the asperity is assumed to be $0.5 \mu \mathrm{m}$, a normal load of $10 \mathrm{mN}$, and material properties for a contact between alumina and zirconia (see Appendix B), with a coefficient of friction equal to 0.5 . In the calculations $n$ is assumed to be $4,6,8$ and 12. The tangential displacement is calculated according to Equation 2.12 . 
a)

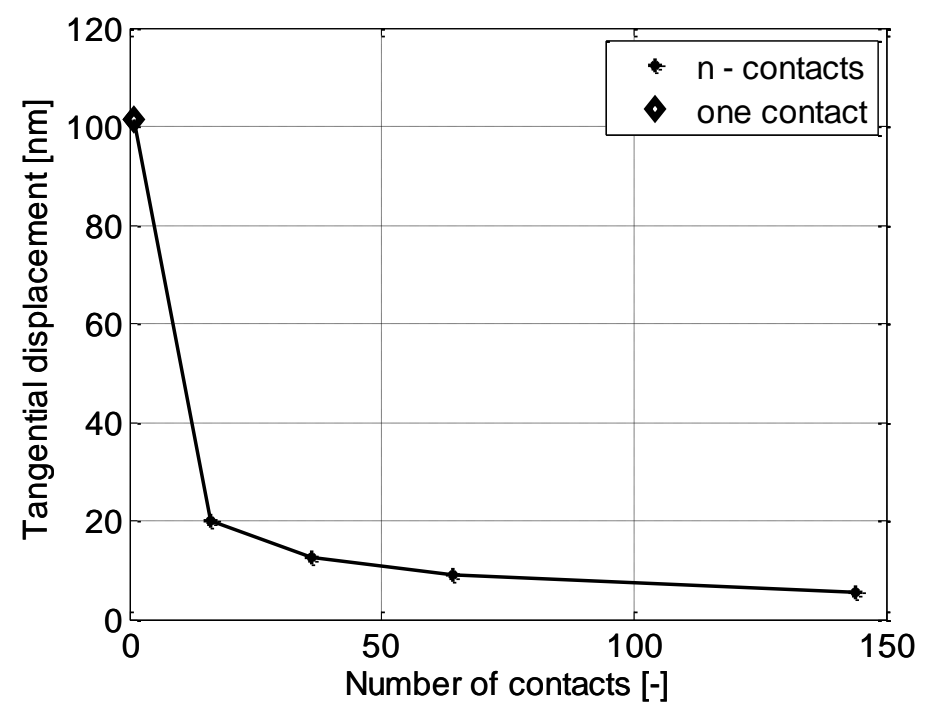

b)

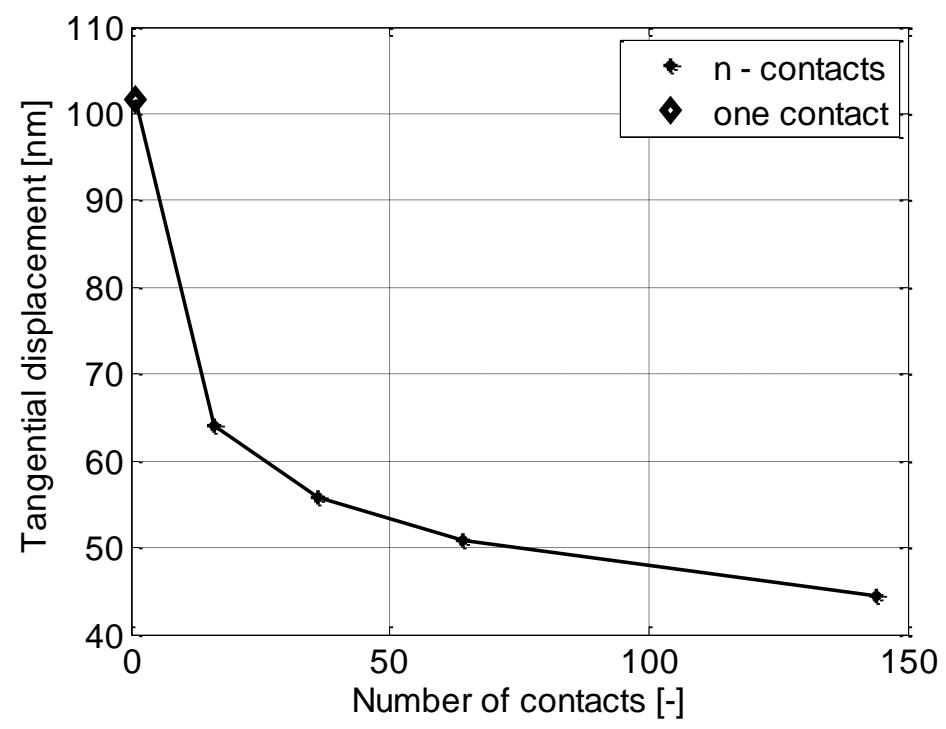

Figure 6. 4: Tangential displacement as a function of the number of contacts after scaling a) self-similarity and b) curvature invariance.

In Figure 6.4 the obtained results are shown and compared with a single contact before scaling and $n$ number of contacts after scaling. It is noticeable that for the contact of one asperity $(n=1)$ the tangential displacement in both situations is larger. In the case where the radius is scaled with the normal force, the tangential 
displacement reduces with an increasing number of contacts. The tangential displacement is becoming more constant with a higher number of contacts. When the asperities radii are kept the same (radius invariance scaling), the tangential displacement is reduced, but the value is higher. The drift calculations show a constant value for both cases after about 64 contacts, as small changes in radius will not change the tangential displacement to a large extent. It can be noticed that a set of asperities having all equal radii (Figure 6.1 (a)) causes a constant drift. When one asperity is larger than the others from the set (Figure 6.2 (b)) the drift will depend on the geometrical change of this asperity and might not be constant. Based on these calculations, a surface that has more equal contacts and scaling radius will cause less drift. The curves are relatively flat for a large number of contacts, which means that a small change will not cause a large change in tangential displacement and thus, drift.

The drift calculated for different radii $R$ is shown in Figure 6.5. First the system moves forward with ball radius $R_{l}$ on a flat and the tangential displacement is calculated, as shown in Figure 6.1, to obtain $\delta_{\operatorname{tmax} I}$. In the next step, the system moves backwards and the radius of the ball is changed to $R_{2}$ and again the tangential displacement is calculated (Figure 6.1 and marked as $\delta_{\operatorname{tmax} 2}$ ). The difference between those two tangential displacements is defined as drift. The applied normal load was $10 \mathrm{mN}$ and the coefficient of friction 0.5 for alumina in contact with zirconia (material properties in Appendix B). To obtain dimensionless values the following equation has been used for the relative change in radius $\Delta R$ :

$$
\Delta R=\frac{R_{2}-R_{1}}{R_{1}}
$$

The radius is assumed to change from $R_{1}$ to $R_{2}$, in this calculation from $0.1 \mu \mathrm{m}$ to 3 $\mu m$. To present different scales of radii, the value is multiplied by a factor 1,10 and 100. As can be seen in Figure 6.5 the drift is increasing with a larger difference in radius. This is an expected result, as a large difference during sliding will cause a large difference in tangential displacement. With a larger range, so for a radius multiplied by a factor of 100 , the drift is lower than $20 \mathrm{~nm}$. This difference is present 
due to the fact that the normal load is kept the same and the contact area is increasing with a larger radius.

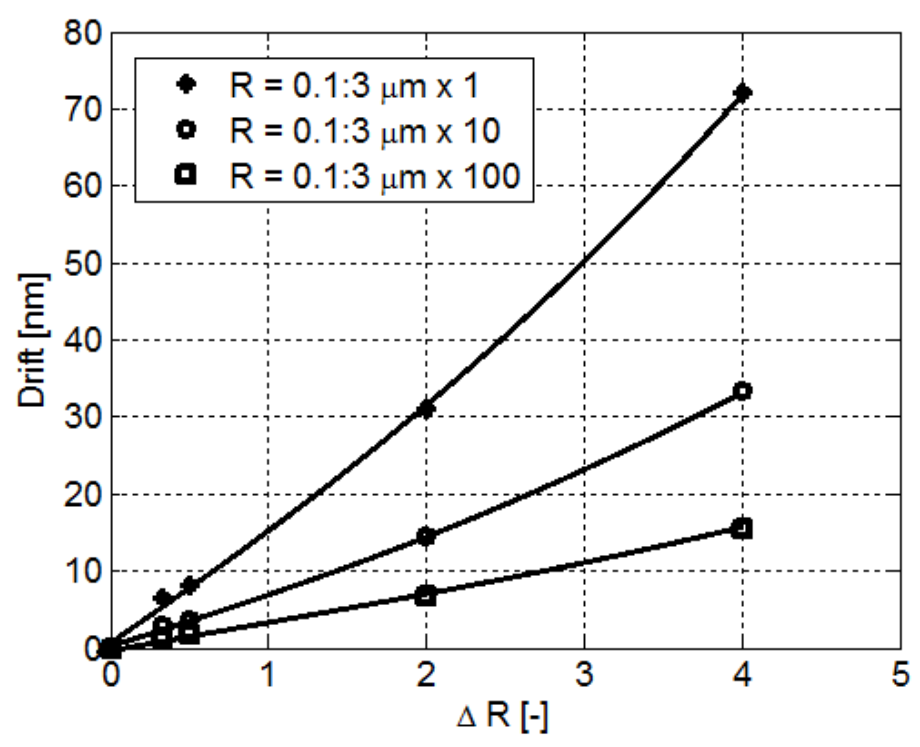

Figure 6.5: Drift as a function of the dimensionless asperity radius.

Another parameter which is important in the design of the contact is the applied normal load as shown in Figure 6.6. The normal load is increasing after each movement of the system (forward and backward direction) from $50 \mathrm{mN}$ to $100 \mathrm{mN}$ as is shown in Figure 6.6 (a) starting from this initial value. The load changes are studied as well. The difference between the normal loads $\left(F_{N \text { difference }}=F_{N 2}-F_{N 1}\right)$ is shown on the horizontal axis in Figure 6.6 (b). The radius in this case is assumed to be $0.5 \mu \mathrm{m}$ and the coefficient of friction is 0.5 . The drift is increasing with a higher normal load difference, as is shown in Figure 6.6 (b). In the next step the normal load is decreasing after changing the direction of the movement from $50 \mathrm{mN}$ to 1 $m N$, as is shown in Figure 6.6 (a). The tangential displacement is calculated for each load and the drift is shown on the vertical axis. For a decreasing normal load the drift is increasing with a higher difference of the increasing normal load. This means that for a system when the drift should be minimized, it is better to keep an increasing tendency of the normal load. A decreasing load can cause a drift, almost twice as high for the same difference in load as for an increasing load. Like, for example, as 
shown in Figure 6.6 (b) for a difference in load of $20 \mathrm{mN}$, where the drift for an increasing load is approximately $60 \mathrm{~nm}$ and for a decreasing load is $140 \mathrm{~nm}$.

a)

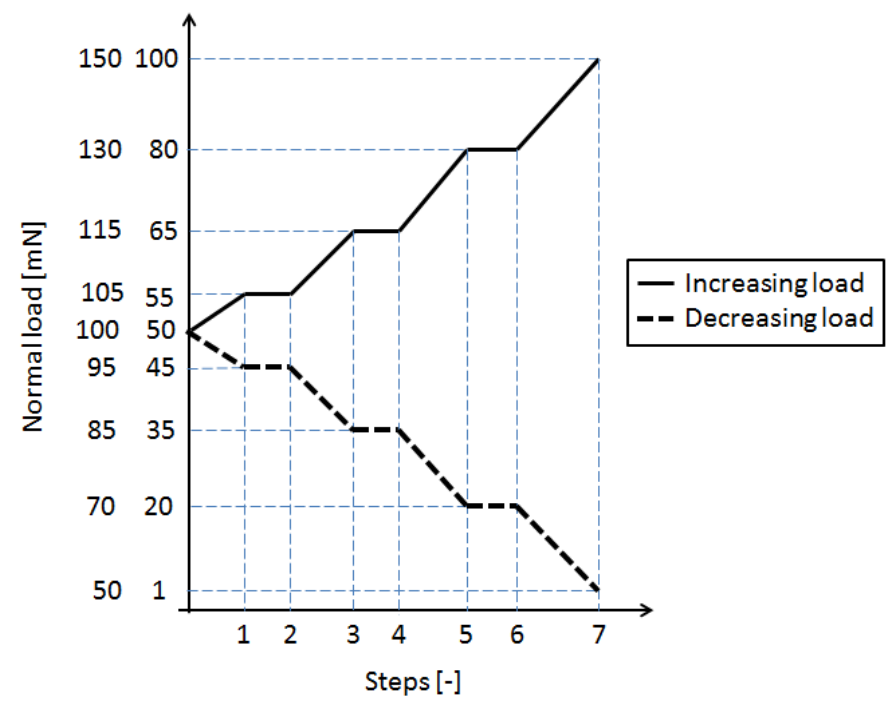

b)

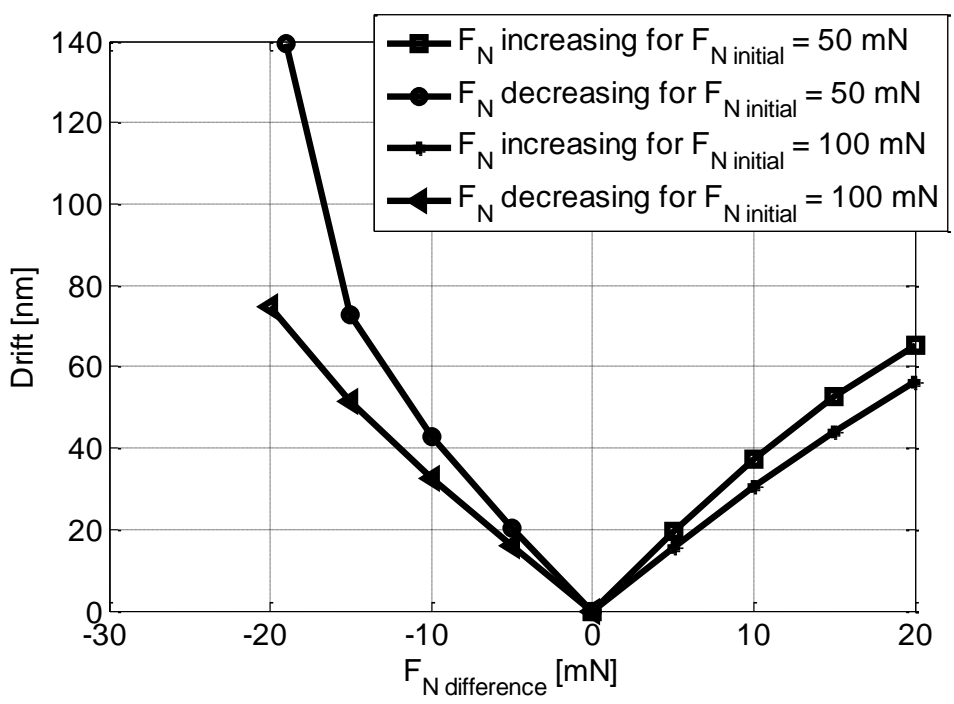

Figure 6.6: a) Schematic representation of sequence of increasing and decreasing load and b) drift as a function of the difference in applied normal load.

Similar steps of an increasing and decreasing normal load have been done for a higher normal load of $100 \mathrm{mN}$, as shown in Figure 6.6 (a). The normal load increases from $100 \mathrm{mN}$ to $150 \mathrm{mN}$ and decreases from $100 \mathrm{mN}$ to $50 \mathrm{mN}$. The difference in 
load is kept the same as for the initial load of $50 \mathrm{mN}$. In Figure 6.6 (b) the obtained drift is presented with a difference in the normal load. It can be seen that drift is reduced when the initial normal load is higher. For a decreasing normal load drift is also higher compared to an increasing load, but this difference is less visible. It can be concluded that a higher initial load causes less drift for an increasing and decreasing normal load.

In the same way, the effect of a change in the coefficient of friction has been analysed $\left(\mu_{\text {difference }}=\mu_{2}-\mu_{1}\right)$. The asperity radius is assumed to be $0.5 \mu \mathrm{m}$, the normal load is $10 \mathrm{mN}$, and initial coefficient of friction is $0.2,0.7$ and 0.9 . Furthermore, the change in the coefficient of friction ranges from 0.1 to 0.25 . Figure 6.7 shows that drift is increasing linearly with a larger difference in the coefficient of friction. Also, the coefficient of friction was decreased from 0.9 to 0.2 . The results show the drift equal for the same difference in $\mu$, irrespective of the initial value.

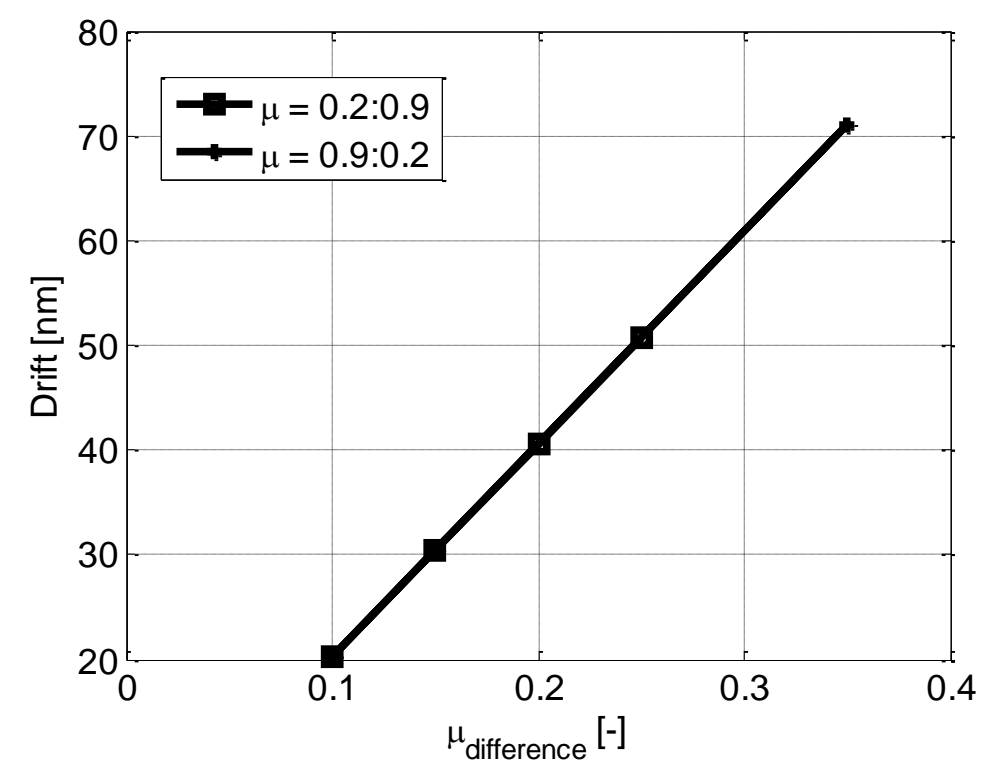

Figure 6.7: Drift as a function of the difference in coefficient of friction.

The effect of several parameters on drift was studied in this section. To minimize the drift, the surface needs to have a stable asperity radius. Drift can be minimized by a high value for the asperity radius. Furthermore, the difference between normal 
loads should be low. It was shown that an increasing normal load causes less drift than a decreasing trend. However, the initial applied normal load should be high in order to get less drift. Any change in the coefficient of friction will influence drift; a higher difference will cause more drift. In cases where the coefficient of friction increases or decreases in value, the effect on drift is not that important compared to the normal load. It is worth recalling that the aim is to design a surface with a low drift and positioning error. As an example, a schematic representation of such a surface is shown in Figure 6.8. The asperities do have large radii, but at the same time there are many asperities in contact carrying the load. When one asperity vanishes, there are many more which will carry the load and obtain the same tangential displacement. That means drift will be reduced.
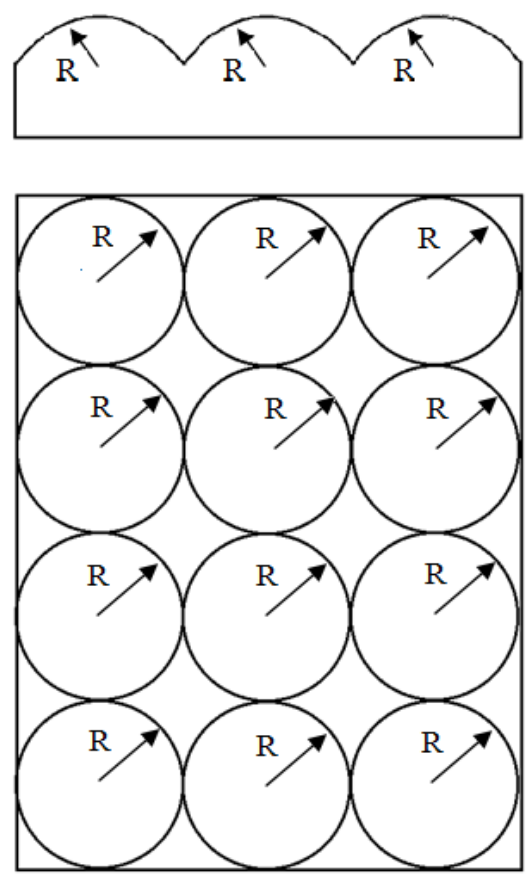

Figure 6. 8: Asperity distribution with a large radius and a lot of contacts.

More asperities with a larger radius will minimize drift, so curvature invariance scaling is a good method to obtain the most stable textured surface. 


\subsubsection{Random rough surfaces}

In order to find which surface results in less drift, the effect of the properties of random rough surfaces on drift will be analysed for an alumina ball against a zirconia plate from Chapter 5.3.4. Greenwood [66] explains how the distribution of height and radius change with autocorrelation length. For example, the density of summits becomes larger with smaller radii and lower autocorrelation length. Greenwood also shows that the average radius of curvature of the higher asperities is one third smaller than the average of the overall distribution.

Table 6.1: Radii and summit heights for surfaces used in the comparison.

\begin{tabular}{|c|c|c|c|}
\hline & $\begin{array}{c}\text { Autocorrelation } \\
\text { length }[\mu \mathrm{m}]\end{array}$ & $\begin{array}{l}\text { Mean } \\
{[\mu \mathrm{m}]}\end{array}$ & $\begin{array}{c}\text { Standard } \\
\text { deviation }[\mu \mathrm{m}]\end{array}$ \\
\hline \multirow{5}{*}{ Radius } & 10 & 0.83 & 0.38 \\
\hline & 20 & 1.15 & 0.52 \\
\hline & 40 & 1.64 & 0.76 \\
\hline & 60 & 1.97 & 0.89 \\
\hline & 80 & 2.29 & 1.09 \\
\hline \multirow{5}{*}{ Summit height } & 10 & 0.94 & 0.87 \\
\hline & 20 & 0.77 & 0.91 \\
\hline & 40 & 0.54 & 0.96 \\
\hline & 60 & 0.60 & 1.23 \\
\hline & 80 & 0.63 & 0.94 \\
\hline
\end{tabular}

The asperity distribution is shown in Appendix G. In Table 6.1 mean values of radii and summit heights with standard deviations are compared from generated surfaces with different autocorrelation length using the surface generation technique 
as described in Section 5.2. The autocorrelation length was changing for the same surface from $10 \mu \mathrm{m}$ to $80 \mu \mathrm{m}$ to represent the flattening of the surface, for example due to wear.

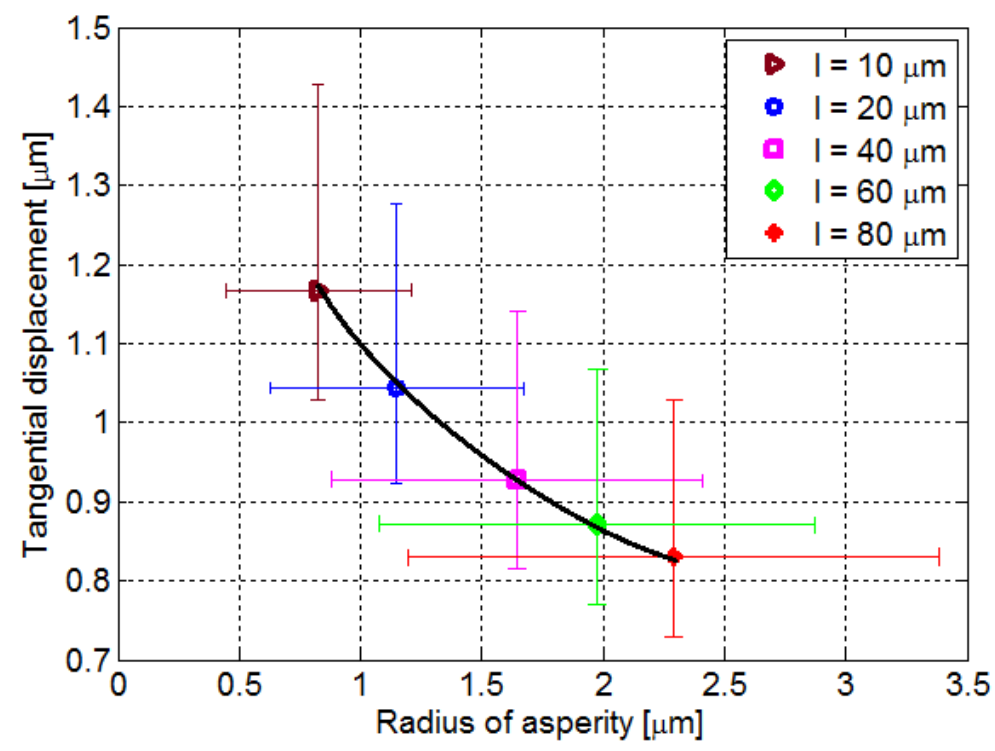

Figure 6. 9: Tangential displacement versus radius corresponding to autocorrelation length for surface with roughness $R q=1 \mu \mathrm{m}$.

In Figure 6.9 the calculated tangential displacement of the random rough surface contacting a flat is compared with the mean radius of the asperities. The horizontal error bars represent the distribution of the radii of asperities with mean value and +/the standard deviation. The tangential displacement is calculated for the mean value with $+/$ - standard deviation and is shown by vertical error bars. The mean value of the radius is increasing with a higher autocorrelation length resulting in a lower tangential displacement. From the results it can be seen that the standard deviation of the radii is increasing with a larger autocorrelation length. However, for a lower autocorrelation length the standard deviation of the resulting tangential displacement is large compared to a higher autocorrelation length. This means, in a real situation, a difference in tangential displacement, so drift might vary more for surfaces having short autocorrelation lengths. On the other hand, for a larger autocorrelation length the radius distribution is much wider than for low autocorrelation length, so the 
probability that a single critical asperity will influence the tangential displacement is higher.

To reduce errors in positioning accuracy, the geometrical changes of the asperities should be low to obtain less drift. Short autocorrelation lengths mean that the mean radius is smaller than for a longer autocorrelation length where the mean radius is larger and shows a larger variation. In Figure 6.4 it is shown that the tangential displacement is reducing with increasing radius, but also that fewer asperities are taken into account due to the limit of the calculated surface area. A larger asperity radius means that less tangential displacement will occur. An inverse exponential effect has been observed. To obtain better accuracy, the nominal area should be large to get better predictability of the asperities.

Another topic with respect to the tangential displacement is a changing roughness value $R q$. This is shown in Figure 6.10. The radii and height of asperities is numerically generated [61] in the same way as was already shown in Section 5.3.3 for an alumina ball against a zirconia plate. The applied normal load was $50 \mathrm{mN}$ and the coefficient of friction 0.5 . The radius of the critical asperity is lower for $R q=5$ $\mu m$, so the roughest surface is showing the highest value of tangential displacement. The tangential displacement is decreasing inverse exponentially with increasing roughness $R q$. The error bars have been calculated in the same way, as in Figure 6.9 , for a mean value with $+/$ - standard deviation of tangential displacement and radii of the asperities, in vertical and horizontal direction respectively. For a high roughness of $R q=5 \mu \mathrm{m}$ the error bar of tangential displacement is larger than for a low roughness $R q=0.1 \mu \mathrm{m}$. The range of asperity radius is larger for lower roughness and the tangential displacement range is reduced. There is more variation of the radii, but only a few carry the load and influence the tangential displacement. 


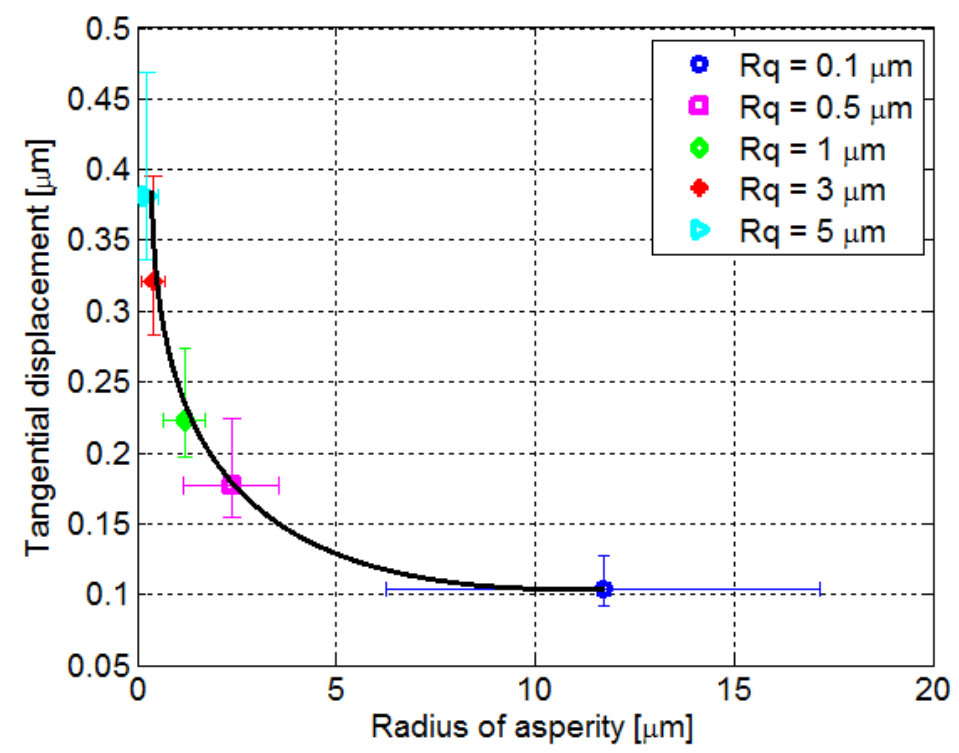

Figure 6.10: Tangential displacements versus asperity radius and corresponding to roughness $R q$ and autocorrelation length $20 \mu \mathrm{m}$.

It can be concluded that in the case of random rough surfaces when compared to a textured surface, the tangential displacement will be higher and will cause a higher drift. Further, the drift becomes much less predictable as can be seen from Figure 6.9 and Figure 6.10. The error bars presented in Figures 6.9 and 6.10 give information on how much the tangential displacement can vary in reality together with the radii of the asperities. When the roughness $R q$ is lower, the surface is smoother and asperities are more equal in height, so closer to a textured surface and, as a result, the drift will be less. In any case, textured surfaces are preferred over random rough surfaces as the positioning accuracy is much better defined for these surfaces.

\subsection{Analysis of a realistic case}

Experiments have been carried out to gain understanding of how friction and roughness changes during sliding under different conditions, influencing the drift and positioning accuracy. These experiments and an analysis in terms of drift will be described below. 


\subsubsection{Method and materials}

A mini vacuum system was used to perform pin-on-disc measurements as is shown in Figure 6.11. The sliding velocity of that system is in the range of 0.05 to $3 \mathrm{~m} / \mathrm{s}$ and the applied load from $1 \mathrm{~N}$ to $5 \mathrm{~N}$, with a vacuum pressure of $10^{-6} \mathrm{mbar}$. The pin diameter is $6 \mathrm{~mm}$ and the disc diameter is $35 \mathrm{~mm}$ with a thickness of $6 \mathrm{~mm}$. In the setup, the normal load and friction force are measured with Futek strain gauge transducers. The vacuum pressure is measured with a Pfeiffer MPT100 Pirani/Cold Cathode transducer. The disc is driven with a Maxon EC90 motor and transferred into vacuum with a Ferrotec ferrofluid feedthrough. The load is applied with a moving magnet actuator, contactless through the wall of the vacuum chamber.

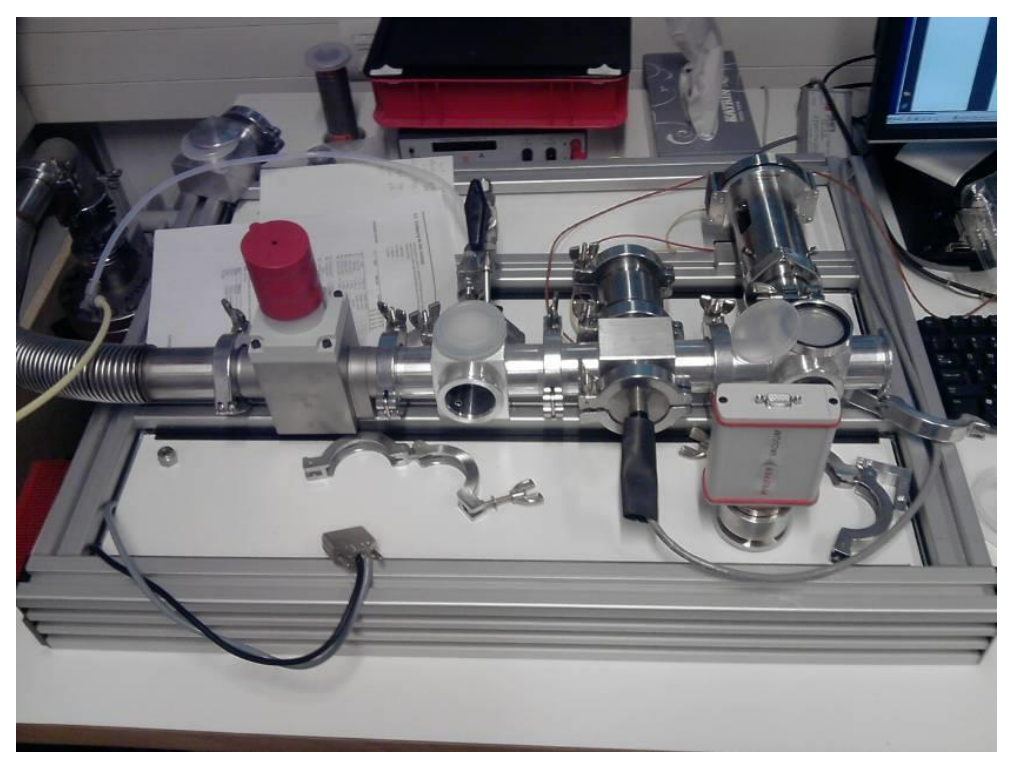

Figure 6.11: Mini vacuum system.

The materials used for the experiments were an alumina ball of $5 \mathrm{~mm}$ diameter, sliding against a zirconia disc. The material properties are given in Appendix B. The measurements have been performed for two sliding distances i.e. $100 \mathrm{~m}$ and $1000 \mathrm{~m}$. The applied normal load was $1 \mathrm{~N}$ and $5 \mathrm{~N}$, with a velocity of $0.1 \mathrm{~m} / \mathrm{s}$. 
The mini vacuum system is a pin-on-disc setup where the ball and disc are mounted vertically. Consequently, wear debris will not remain in the contact.

In Chapter 5 it was already described how the tangential displacement can be calculated for a multi asperity contact when the ball is rough and the plate is smooth. In Figure 6.12 the steps used to obtain the tangential displacement for each surface are shown.

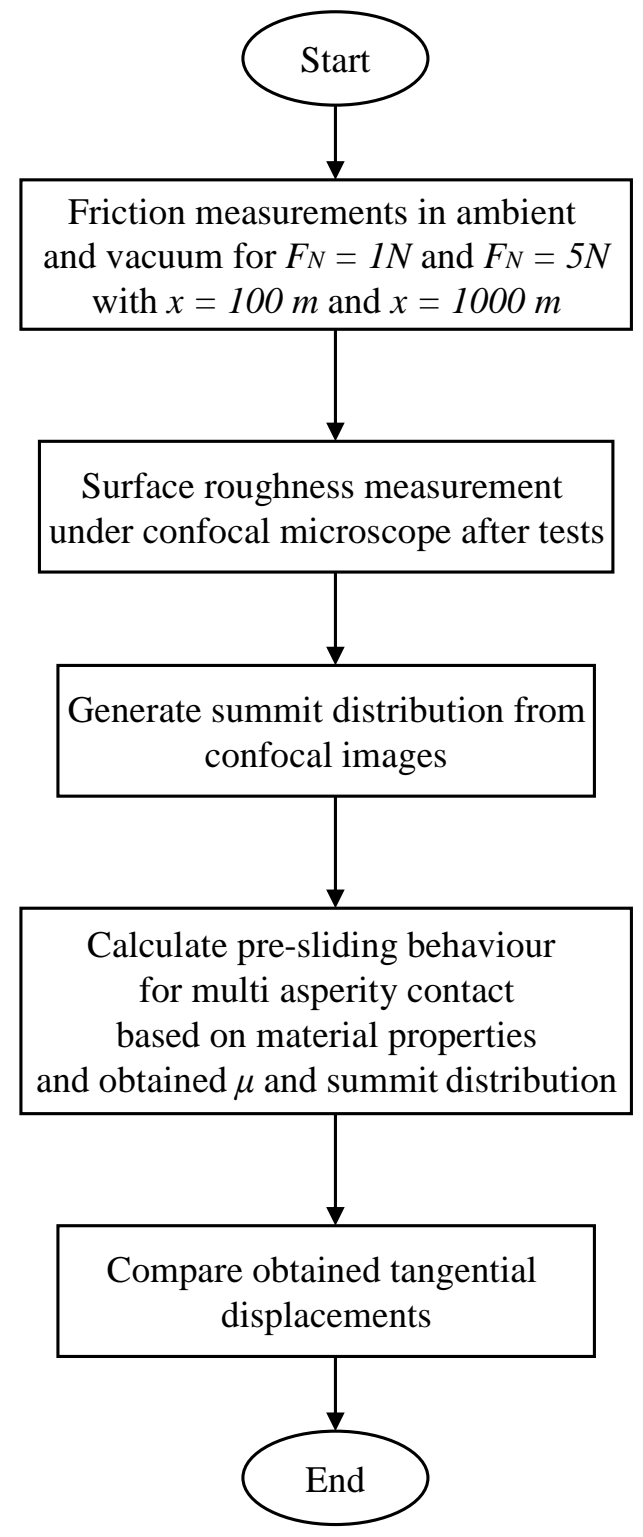

Figure 6.12: Flow chart of the steps used to calculate the tangential displacement. 


\subsubsection{Contact changes over sliding distance}

The coefficient of friction for an alumina ball sliding against a zirconia plate and a zirconia ball sliding against an alumina plate is shown in Appendix F. The confocal images from the samples are shown in Appendix B. It shows how the wear scar looks in each situation for the ball and plate. The coefficient of friction for short sliding distances has a lower value in a vacuum than under ambient conditions.

The confocal image obtained for an alumina ball in vacuum shows that in the contact area some typical changes are observed (Figure 6.13).

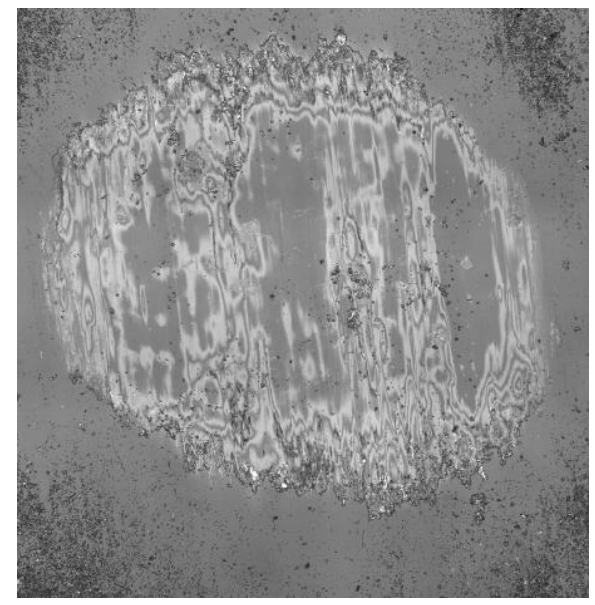

Figure 6.13: Alumina ball after measurement in vacuum for normal load $5 \mathrm{~N}$ and sliding distance $100 \mathrm{~m}$.

The Raman measurement was also done on the ball and plate to check if there was any material transfer. Due to the vertical setup of the pin against plate, the Raman measurement did not show changes in the contact. In such a configuration the material debris could not stay in the contact or else it was not visible due to limitation of the Raman setup. The spot diameter which can be measured with the Raman system is $2 \mu \mathrm{m}$, which is much larger than the expected material transfer in the contact. 


\subsubsection{Asperity change and tangential displacement}

The confocal images of the samples used in the tests are shown in Appendix B in Table B.1. The roughness values $R q$ obtained from the wear track are also given in Figure 6.14 and compared for different values of sliding distance and applied load. It is clear from Figure 6.14 that the roughness values are not directly depending on load or sliding distance, but some changes are observed. In the case of vacuum, the $R q$ value is reduced for the alumina ball and increased or equal for the zirconia plate when compared with the results obtained under ambient conditions. The differences in roughness values indicate that wear occurred.

The model described in detail in Chapter 5 was used to compare how the roughness changes after the experiments. In Figure G.2 of Appendix G the distribution of summit heights and radii are presented for different applied normal loads, sliding distances and environments. The summit values are calculated using confocal images from test samples by the same method as described in Chapter 5 and Appendix E. The pixel size of the measurement is equal to $1 \mu \mathrm{m}$.

The change of the summit distribution is depending on the applied normal load and sliding distance. Asperities after a longer sliding distance show a reduced asperity radius (Figure G.2). The height of the asperities is also shifted, which is typical for wear.

In the case of alumina also, a higher normal load means that the radius is reduced, which is opposite to the zirconia plate where the radius is higher for higher loads. When the roughness values do not change significantly, as is the case for a short

sliding distance, the summit distributions are very similar. However, for a few asperities the radius will change, as well as in height, and it might be that this one asperity is the critical one determining the tangential displacement. 
a)

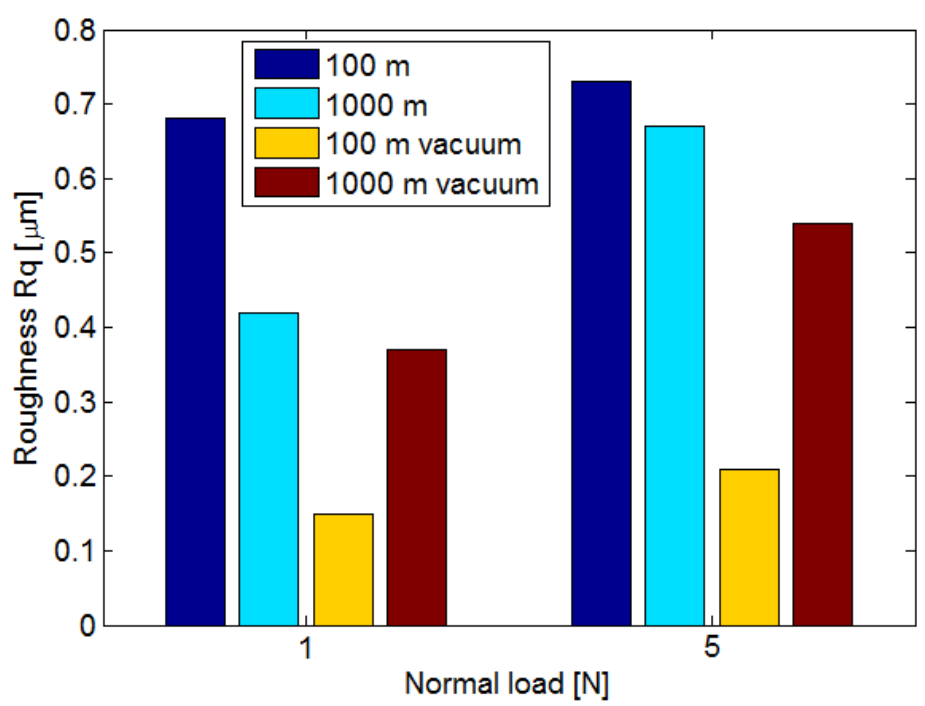

b)

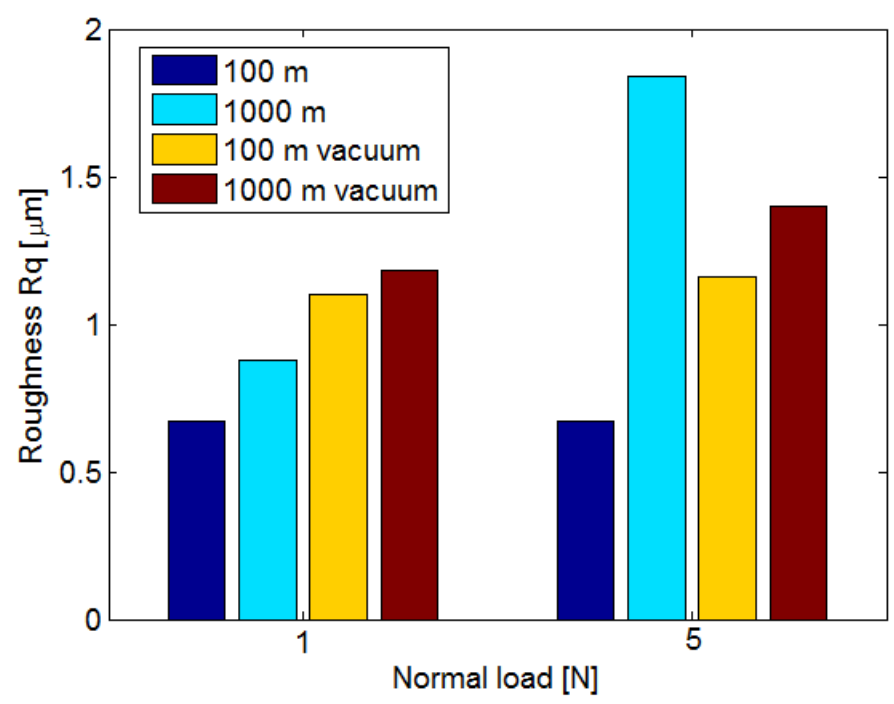

Figure 6.14: Roughness values obtained from confocal measurements after tests for a) alumina ball and b) zirconia plate.

In this chapter two rough surfaces are in contact. In the literature it has been shown that the contact area for two rough surfaces in normal contact is acting similarly to a sum surface contacting a flat [65]. In the calculations shown here, the sum surface is assumed to be in contact with a flat counter surface. Consequently, interlocking is neglected due to very close roughness values of both surfaces. In reality the 
tangential displacement can be larger due to the interlocking effect. Therefore, the calculations indicate a lower limit of drift. Figure 6.15 shows the values calculated based on the measured roughness data for the normal load of $1 \mathrm{~N}$ at sliding distance $100 \mathrm{~m}$ and $1000 \mathrm{~m}$ in ambient and vacuum. Similar to Figure 6.16, calculations are done for the same sliding distances and conditions for a normal load of $5 \mathrm{~N}$. The coefficient of friction is kept the same, namely 0.3 in the calculations shown in Figures 6.15 and 6.16. The calculated tangential displacement is higher for a higher applied normal load. In vacuum, for both sliding distances, the tangential displacement is higher compared to the results obtained under ambient conditions. A long sliding distance also increases the pre-sliding tangential displacement. However, the differences found are not that large.

The tangential displacement depends on roughness changes or how much wear occurs in the contact.

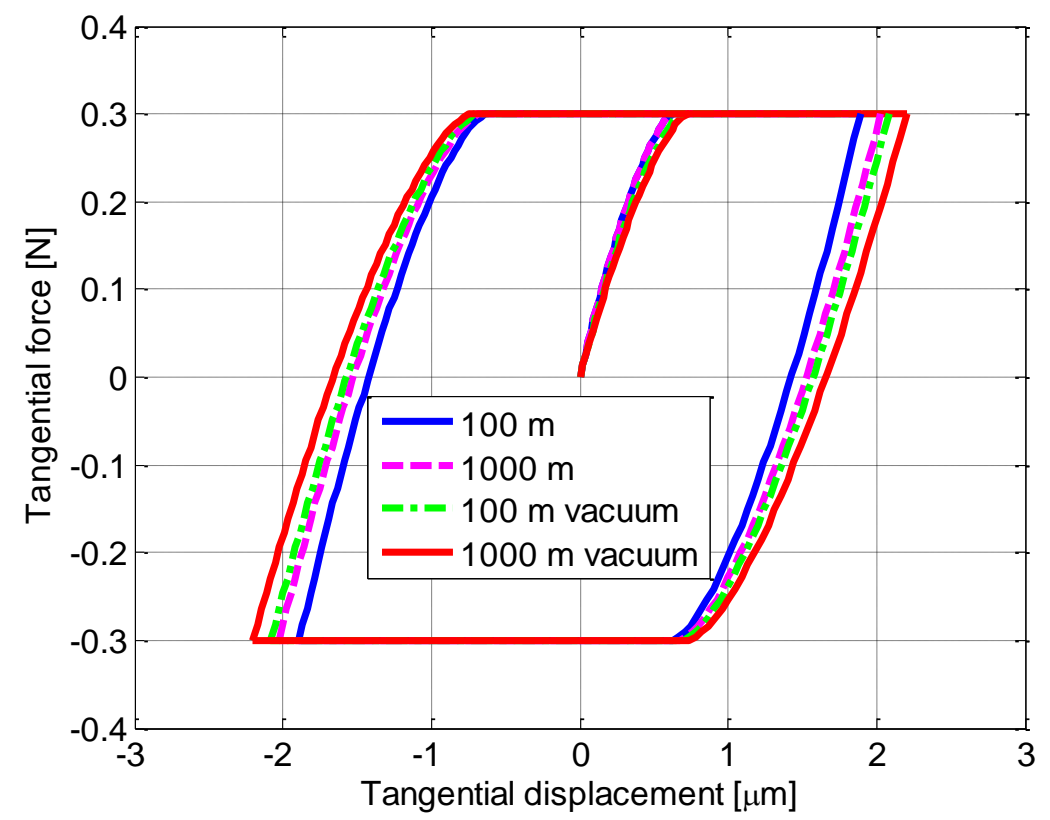

Figure 6.15: Tangential force versus tangential displacement for the normal load $1 \mathrm{~N}$, alumina ball against zirconia flat. 


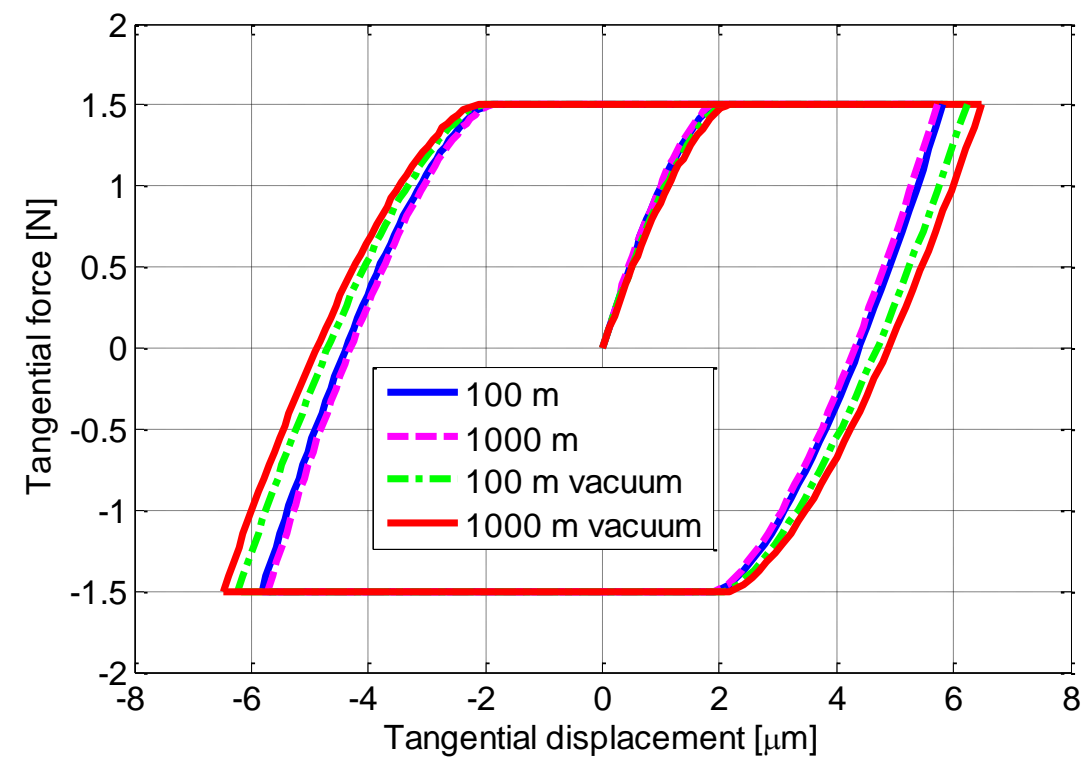

Figure 6.16: Tangential force versus tangential displacement for the normal load $5 \mathrm{~N}$, alumina ball against zirconia flat.

As was already shown in the theoretical calculation (Figure 5.13), a higher applied normal load results in an increased tangential displacement. In the case of low roughness changes the tangential displacement is also changing. The vacuum condition will cause a low value of roughness and at the same time wear, but the tangential displacement can increase after a longer sliding distance. The vacuum environment does not necessarily reduce drift.

\subsection{Effect of roughness and friction on positioning accuracy}

\section{for a realistic surface}

The effect of roughness from a measured surface and friction on positioning accuracy has been compared in this section. Calculations for the tangential displacement for zirconia plate in contact with alumina ball under a normal load of 1 $N$ is shown as a bar diagram in Figure 6.17. The coefficient of friction is assumed to be 0.25 and 0.3 for ambient conditions and 0.25 and 0.35 for vacuum. The sliding 
distance is $100 \mathrm{~m}$ and $1000 \mathrm{~m}$ respectively. The coefficient of friction increased in time in ambient and decreases in time for the vacuum case (Figure F.1 and Figure F.2). The calculated drift for $100 \mathrm{~m}$ is $0.05 \mu \mathrm{m}$ and for $1000 \mathrm{~m}$ sliding distance the drift is $0.003 \mu \mathrm{m}$.

For longer sliding distances, the tangential displacement is increased as well as the roughness values (see Figure 6.12b).

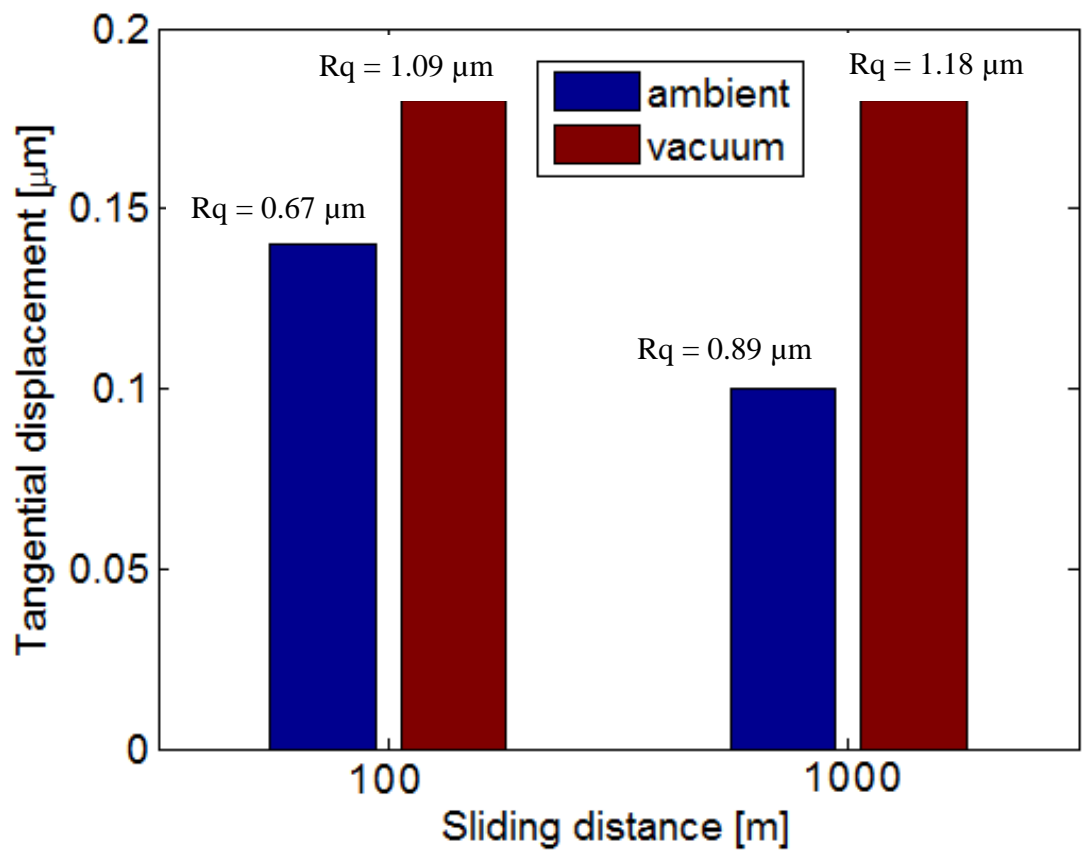

Figure 6.17: Tangential displacement versus sliding distance for zirconia plate in contact with alumina ball under normal load of $1 \mathrm{~N}$.

In order to determine the effect of the friction level on such behaviour, different coefficient of friction values have been assumed. The coefficient of friction is taken from measurements for an alumina ball $(R q=0.42 \mu \mathrm{m})$ and zirconia plate $(R q=$ $1.84 \mu \mathrm{m}$ ) under a normal load of $5 \mathrm{~N}$ and a sliding distance of $1000 \mathrm{~m}$ which is shown in Appendix F. The value of $\mu=0.74$ during running-in gives the largest tangential displacement. The values for the coefficient of friction and sliding distance taken from the experimental results, together with the calculated tangential displacement and drift, are shown in Table 6.2. 
Table 6.2 Calculated tangential displacement and drift based on measured values for the coefficient of friction and corresponding drift.

\begin{tabular}{|c|c|c|c|}
\hline $\begin{array}{c}\text { Coefficient } \\
\text { of friction } \\
{[-]}\end{array}$ & $\begin{array}{c}\text { Distance } \\
{[\mathrm{m}]}\end{array}$ & $\begin{array}{c}\text { Tangential } \\
\text { displacement } \\
{[\mu \mathrm{m}]}\end{array}$ & $\begin{array}{c}\text { Drift } \\
{[\mu \mathrm{m}]}\end{array}$ \\
\cline { 1 - 2 } 0.74 & 50 & 0.14 & \multirow{2}{*}{0.13} \\
\cline { 1 - 2 } 0.69 & 100 & 0.27 & \multirow{2}{*}{0.56} \\
\hline 0.58 & 200 & 0.55 & \multirow{2}{*}{0.28} \\
\hline 0.59 & 400 & 1.11 & \multirow{2}{*}{0.56} \\
\hline 0.56 & 600 & 1.66 & \multirow{2}{*}{0.94} \\
\hline 0.59 & 700 & 2.22 & \\
\hline 0.56 & 800 & 2.78 & \\
\hline 0.55 & 1000 & & \\
\hline
\end{tabular}

The drift during running-in is lower owing to less difference in tangential displacement. When the drift is calculated for the first measurement and the last measurement, the maximum difference will be obtained. That is the reason why the coefficient of friction needs to be as close as possible to get a low drift.

The experiments show that roughness is increasing in time (Figure $6.12 \mathrm{~b}$ ) and also the tangential displacement is increased. The friction level also has an important role when values from running-in are compared with ones obtained during steady-state sliding. Drift depends on the difference between the tangential displacements. For a lower sliding distance in both situations, the obtained drift has a higher value than after longer sliding. The coefficient of friction needs to be stable; the same holds for roughness to minimize drift.

\subsection{Summary}

Drift and positioning errors have been described in this chapter. The general rules for designing a surface to minimize drift have been discussed. First of all, the asperity distribution needs to have asperities with equal radii and height. Textured 
surface with small features and large radius will result in the least drift. The scaling law of curvature invariance explained in this chapter gives better results in minimizing drift for a textured surface. To minimize drift, the load applied on the surface should be high, but the normal load difference should be kept low, as well as the change in the coefficient of friction. In the case of random surfaces, a higher autocorrelation length is preferable as well as low roughness $R q$. When asperities are sharper, they then carry more loads and it can result in larger drift. For larger autocorrelation length and low surface roughness $R q$ the radii vary a lot, but the tangential displacement value changes less. From the results it can be seen that textured surfaces are a better solution than random surfaces to get minimized drift.

The experiments for a rough contact have been discussed. In the experiments, the results for two constant applied normal loads and two different sliding distances have been compared. The results presented drift values are predicted around 0.1 and $0.2 \mu \mathrm{m}$. Friction changes in the shown examples will influence the accuracy only during running-in, whereas in steady-state sliding the changes in friction are not so significant and therefore accuracy is higher. 


\section{Chapter 7}

\section{CONCLUSIONS AND}

RECOMMENDATIONS

\subsection{Introduction}

In this chapter, the final conclusions of the research will be outlined together with recommendations for future research.

\subsection{Conclusions}

\section{Chapter 2 Pre-sliding behaviour of contact}

- Adhesion has a large influence on the contact area for a single asperity contact. In a multi asperity contact, adhesion is not that significant and does not influence the contact behaviour much, as the real contact area is typically low compared to the nominal area at low roughness levels and low loads. 
- Asperity details like summit height and summit radii are important for the frictional behaviour.

- $\quad$ Roughness changes of the surface will affect the pre-sliding behaviour. The same is true for changes in the applied load.

\section{Chapter 3 Measurement technique for surface investigation and engineering materials}

- In the design setup, changes in surface topography inside and outside the wear track can be measured by a confocal height sensor and chemical changes can be measured by confocal Raman spectroscopy.

- The difference between mild and severe wear regimes for an $\mathrm{Al}_{2} \mathrm{O}_{3}$ surface slide against $\mathrm{ZrO}_{2}$ at room and elevated temperature $\left(600^{\circ} \mathrm{C}\right)$ conditions can be indicated by a surface roughness measurement.

- For the material combination studied, material transfer in the wear track was observed at higher temperature levels.

- In the case of zirconia, the phase transformation from tetragonal to monoclinic phase was observed also at higher temperatures using confocal Raman spectroscopy.

\section{Chapter 4 Constant applied normal load on a single asperity contact}

- The results from experiments at low contact pressures for a single asperity contact shows that the static friction force and preliminary displacement follow the theoretical trends for the normal load dependency.

- Mindlin's model can be used to calculate the preliminary displacement when a contact pressure is in order of $100 \mathrm{MPa}$, as shown by experimental results. At low contact pressures ( $<100 \mathrm{MPa}$ ), adhesion effects limit the agreement between model and experiments and the contact area is underestimated. 
- The results show that at the low applied normal load the shear stress will depend on the normal load, while for high loads it becomes constant. This effect indicates the significance of adhesion at low loads.

- In the case of only a shear contribution to friction in a single asperity contact the coefficient of friction should decrease with increasing load. An increase of the coefficient of friction with increasing normal load is an indication that wear has occurred in the contact and is related to ploughing effects.

\section{Chapter 5 Pre-sliding behaviour of a multi asperity contact}

- The detailed geometry of a surface at asperity level determines the presliding behaviour of a multi asperity contact. The presented model demonstrates that in a multi asperity contact a single critical asperity will determine whether a complete rough surface starts sliding over a smooth flat.

- A higher normal load applied to the same surface causes a smoother transition from sticking to sliding due to an increase in the number of micro contacts.

- The roughness value $R q$ and the autocorrelation length strongly influence the pre-sliding behaviour. A surface for which the roughness is decreased and autocorrelation is increased will result in a reduced pre-sliding displacement.

- Experimental results for an alumina or zirconia ball sliding against a glass plate have been compared with theoretical calculations in terms of applied normal load, coefficient of friction and tangential displacement. In the case of a low contact pressure the measured tangential displacement is almost constant for rough surfaces. For a higher normal load, the tangential displacement is increasing as well. 


\section{Chapter 6 Design of surface for positioning accuracy}

- Positioning accuracy errors can be correlated with the difference in the tangential displacements. Any significant change in the tangential displacement during sliding causes drift.

- Design parameters like radius, normal load and coefficient of friction need to be taken into account to minimize drift.

- A textured surface with more equal contacts and radius causes less drift. The scaling law of curvature invariance is a good method to analyse the most stable textured surface with respect to drift.

- Random surfaces give more variety in the tangential displacement. For such surfaces it is more difficult to control drift. In the case of surfaces with a lower $R q$ and longer autocorrelation length, drift will be reduced. Any significant change in the geometry of asperities will result in a change in drift.

- A larger nominal contact area and more asperities cause less variation in tangential displacement, so reproducibility is improved and less drift occurs.

- Normal load has more influence on drift than the coefficient of friction. When the initial normal load is high the drift will be reduced. A difference in normal load for an increasing normal load results in less drift than a decreasing normal load.

- A surface with low roughness with equal sized asperities, less change in normal load and stable friction level will minimize drift. 


\subsection{Recommendations}

Analysing the pre-sliding behaviour of rough contacts with respect to positioning accuracy errors gives more understanding in relation to that application. The main contributions to these errors as presented in the thesis are the surface roughness and the applied normal load. The recommendations based on this research are:

- Experiments should be conducted by measuring the drift during changes in direction to validate the model. An additional sensor, which can measure the position of the stage before and after the change in direction of the movement.

- The model to predict positioning errors should be extended with the interlocking effect. The local contact of each asperity between two rough surfaces can be calculated by sharing forces including friction [69].

- Textured surfaces are better suited to control position accuracy and drift. The geometry of the asperities of such a surface is equal. This means that a well-controlled tangential displacement and less drift are obtained. The literature shows that textured surfaces can reduce friction [67, 68], and, as a result, the tangential displacement will also be reduced. Experiments in which the drift is measured at textured surfaces should be performed. For surfaces, it is recommended that the nominal contact area should be relatively large to accommodate many asperities with large radii and equal summit

height. 



\section{APPENDICES}

\section{Appendix A}

\section{Calculations for tangential displacement and shear stress}

The calculation to obtain the tangential displacement in the pre-sliding regime was done according to the equations introduced by Mindlin [5].

The tangential displacement due to initial tangential loading is given by:

$$
\delta_{t}=\frac{3 \cdot \mu \cdot F_{N}}{16 \cdot a \cdot G^{*}}\left[1-\left(1-\frac{F_{f}}{\mu \cdot F_{N}}\right)^{2 / 3}\right]
$$

The tangential displacement during unloading is given by:

$$
\delta_{d}=\frac{3 \cdot \mu \cdot F_{N}}{16 \cdot a \cdot G^{*}}\left[2\left(1-\frac{F_{f}-F_{t}}{2 \cdot \mu \cdot F_{N}}\right)^{2 / 3}-\left(1-\frac{F_{t}}{\mu \cdot F_{N}}\right)^{2 / 3}-1\right]
$$

The tangential displacement for again tangential loading to close tangential loop is given by

$$
\delta_{i}=-\delta_{d}\left(-F_{t}\right)=-\frac{3 \cdot \mu \cdot F_{N}}{16 \cdot a \cdot G^{*}}\left[2\left(1-\frac{F_{f}+F_{t}}{2 \cdot \mu \cdot F_{N}}\right)^{2 / 3}-\left(1-\frac{F_{f}}{\mu \cdot F_{N}}\right)^{2 / 3}-1\right]
$$


To calculate the tangential displacement for increased or decreased normal load in the equations above, normal load $F_{N}$ will be replaced by normal load with added or subtracted value $\Delta F_{N}$, for example:

$$
\delta_{t \pm \Delta F_{N}}=\frac{3 \cdot \mu \cdot\left(F_{N} \pm \Delta F_{N}\right)}{16 \cdot a \cdot G^{*}}\left[1-\left(1-\frac{F_{f}}{\mu \cdot\left(F_{N} \pm \Delta F_{N}\right)}\right)^{2 / 3}\right]
$$

The shear stress during initial loading, where two areas are distinguishing i.e. the stick and slip zone, is given by:

$$
\begin{array}{rr}
\tau(r)=\frac{3 \cdot \mu \cdot F_{N}}{2 \cdot \pi \cdot a^{3}}\left(a^{2}-r^{2}\right)^{1 / 2} & s \leq r \leq a \\
\tau(r)=\frac{3 \cdot \mu \cdot F_{N}}{2 \cdot \pi \cdot a^{3}}\left[\left(a^{2}-r^{2}\right)^{1 / 2}-\left(s^{2}-r^{2}\right)^{1 / 2}\right] & r \leq s
\end{array}
$$

The shear stress during unloading with reverse sign to loading is given by:

$$
\begin{array}{rr}
\tau_{u}(r)=-\frac{3 \cdot \mu \cdot F_{N}}{2 \cdot \pi \cdot a^{3}}\left(a^{2}-r^{2}\right)^{1 / 2} & s \leq r \leq a \\
\tau_{u}(r)=-\frac{3 \cdot \mu \cdot F_{N}}{2 \cdot \pi \cdot a^{3}}\left[\left(a^{2}-r^{2}\right)^{1 / 2}-\left(s^{2}-r^{2}\right)^{1 / 2}\right] & r \leq s
\end{array}
$$

The shear stress as a resultant shear from loading and unloading is given by:

$$
\begin{array}{cc}
\tau_{r}(r)=-\frac{3 \cdot \mu \cdot F_{N}}{2 \cdot \pi \cdot a^{3}}\left(a^{2}-r^{2}\right)^{1 / 2} & b \leq r \leq a \\
\tau_{r}(r)=-\frac{3 \cdot \mu \cdot F_{N}}{2 \cdot \pi \cdot a^{3}}\left[\left(a^{2}-r^{2}\right)^{1 / 2}-2\left(b^{2}-r^{2}\right)^{1 / 2}\right] & s \leq r \leq b \\
\tau_{r}(r)=-\frac{3 \cdot \mu \cdot F_{N}}{2 \cdot \pi \cdot a^{3}}\left[\left(a^{2}-r^{2}\right)^{1 / 2}-2\left(b^{2}-r^{2}\right)^{1 / 2}+\left(s^{2}-r^{2}\right)^{1 / 2}\right] & r \leq s
\end{array}
$$




\section{Appendix B}

\section{Measured surface roughness of materials}

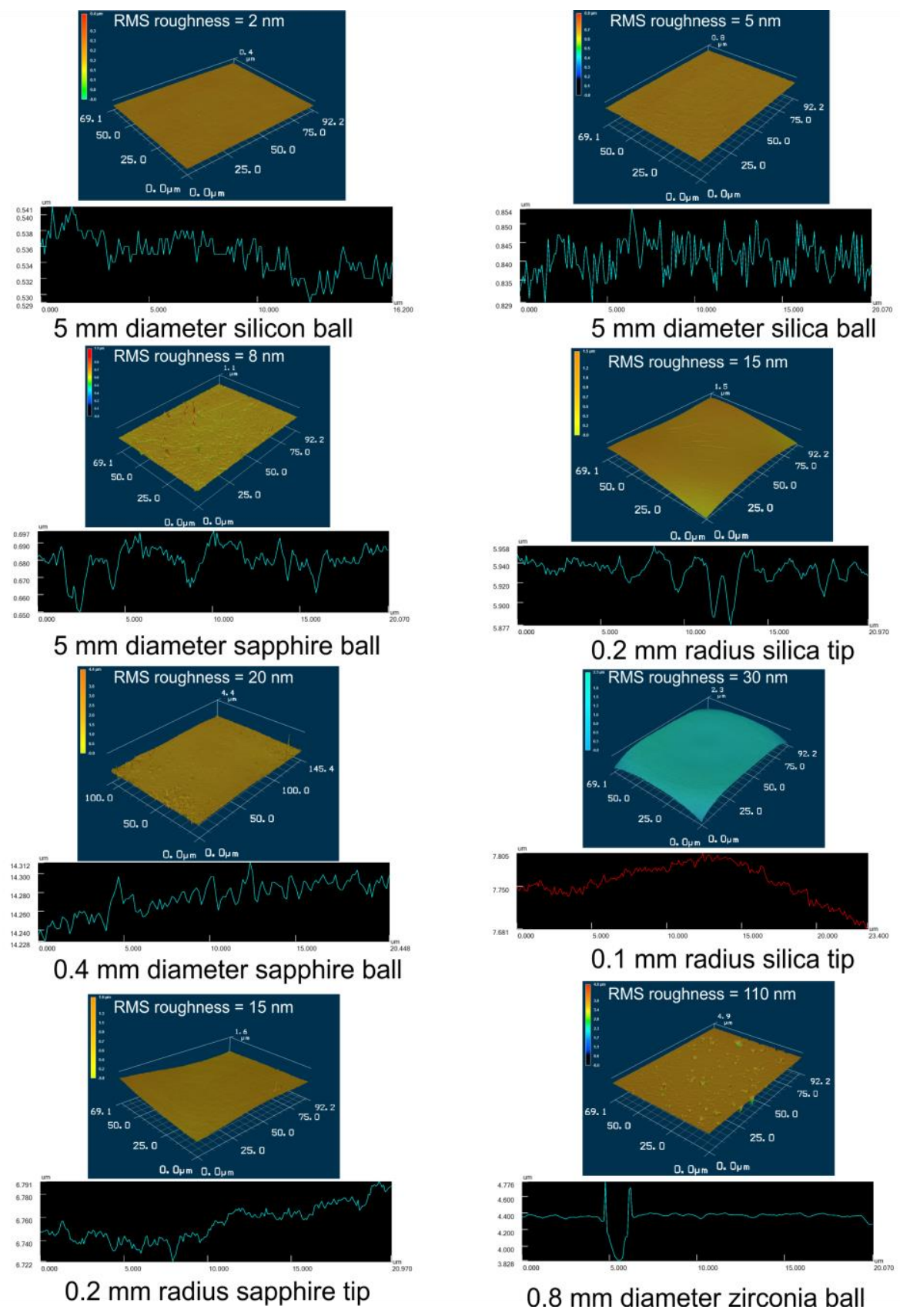

Figure B.1: Surface roughness measurements with the Confocal Microscope on different sized spheres and tips of silicon, silica, sapphire and zirconia. 


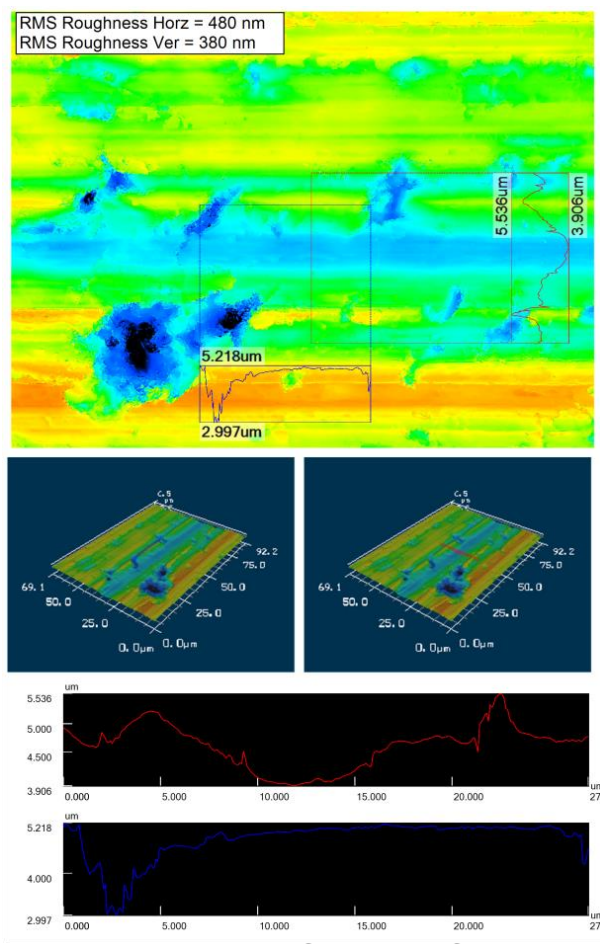

\section{zirconia flat surface}
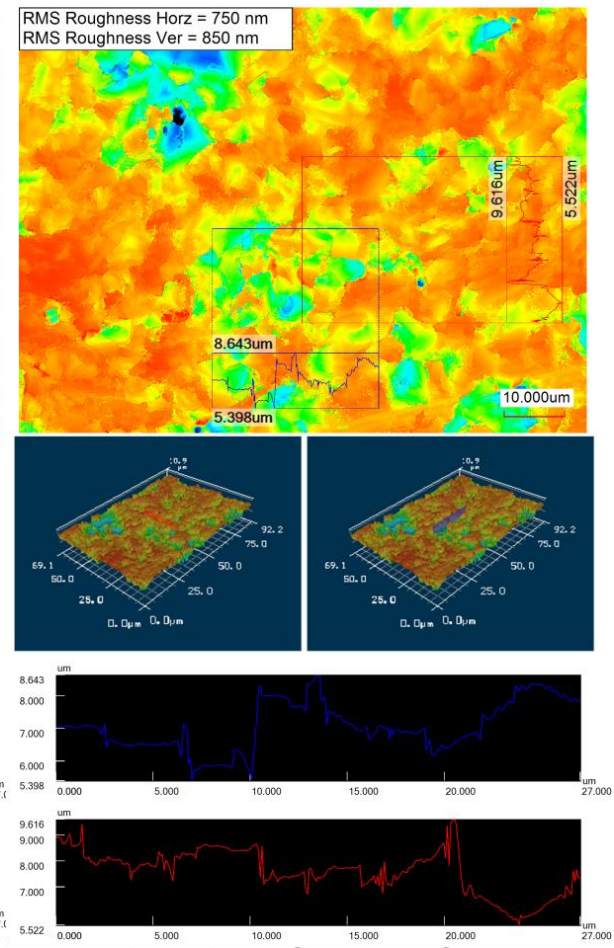

alumina flat surface
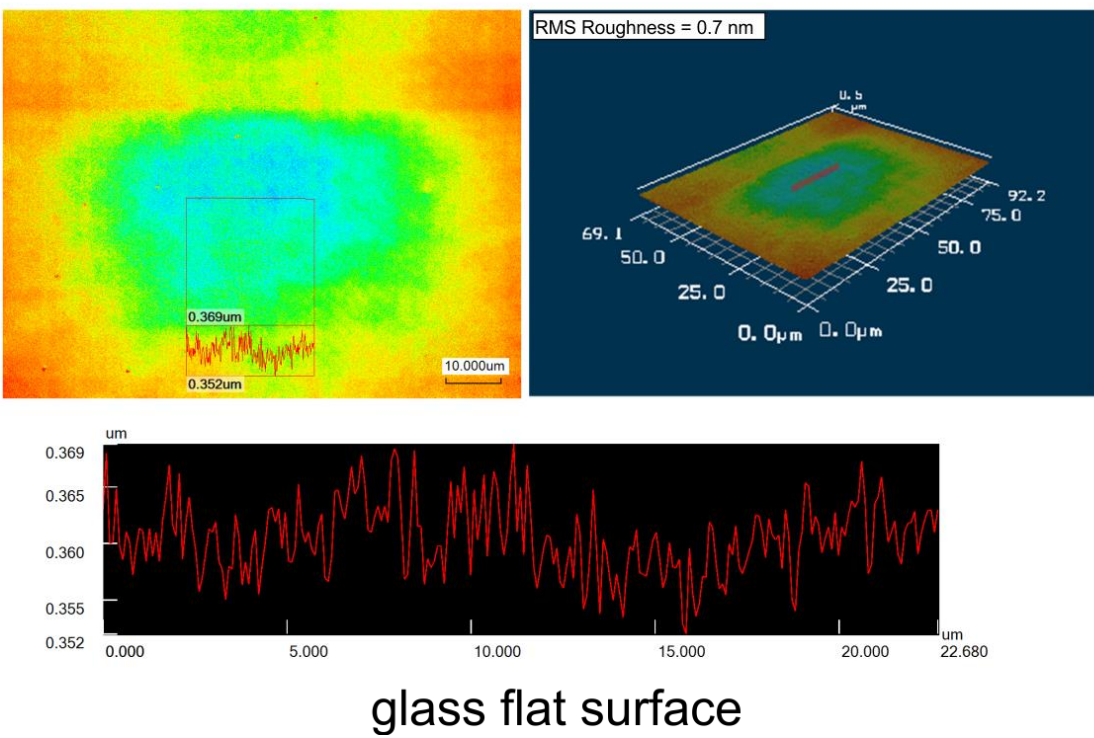

Figure B.2: Surface roughness measurements with the Confocal Microscope on different flats of zirconia, alumina and glass. 


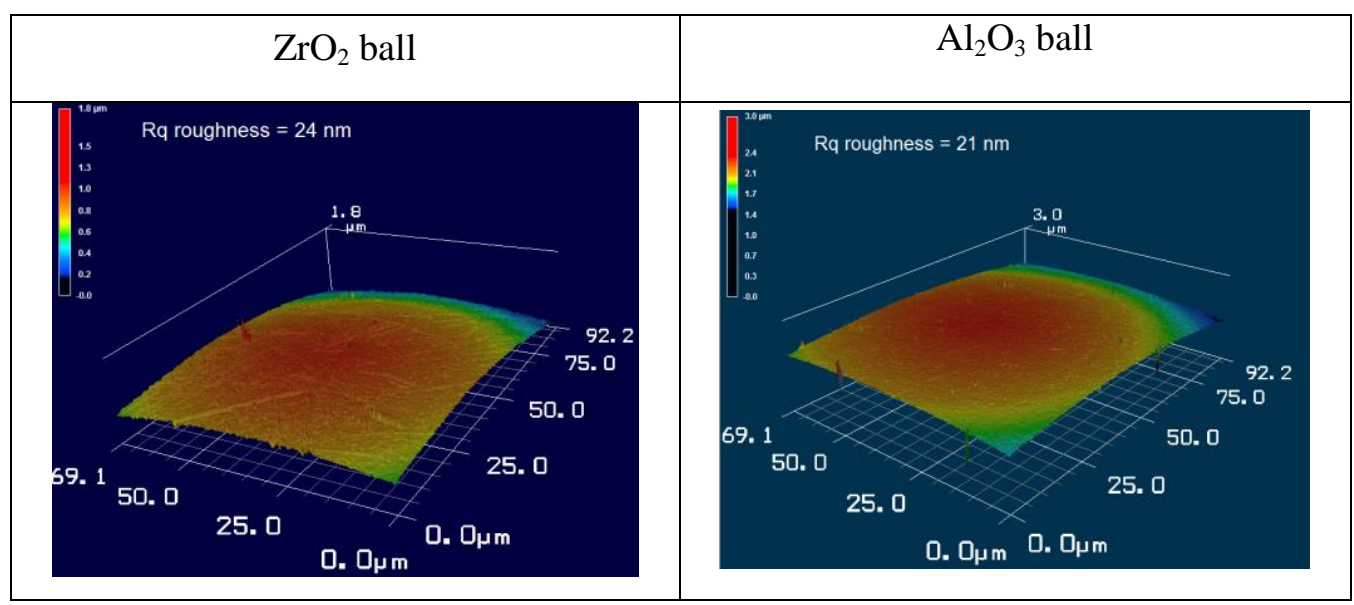

Figure B.3 Zirconia and alumina ball measured before experiments described in Chapter 4.

\begin{tabular}{|c|c|c|}
\hline & Zirconia & Alumina \\
\hline Before & $\begin{array}{c}\mathrm{Rq}=24 \mathrm{~nm}, \mathrm{Ra}=16 \mathrm{~nm}, \\
\mathrm{Rz}=1.337 \mu \mathrm{m}\end{array}$ & $\begin{array}{c}\mathrm{Rq}=21 \mathrm{~nm}, \mathrm{Ra}=11 \mathrm{~nm}, \\
\mathrm{Rz}=2.929 \mu \mathrm{m}\end{array}$ \\
\hline After & $\begin{array}{c}\mathrm{Rq}=24 \mathrm{~nm}, \mathrm{Ra}=15 \mathrm{~nm}, \\
\mathrm{Rz}=1.271 \mu \mathrm{m}\end{array}$ & $\begin{aligned} & \mathrm{Rq}= 72 \mathrm{~nm}, \mathrm{Ra}=25 \mathrm{~nm}, \\
& \mathrm{Rz}=3.687 \mu \mathrm{m}\end{aligned}$ \\
\hline
\end{tabular}

Figure B.4: Zirconia and alumina ball before and after tests described in Section 5.5 .2 
Table B.1 Properties used in calculations.

\begin{tabular}{lllllll}
\hline Materials & $R(\mathrm{~mm})$ & $E(\mathrm{GPa})$ & $v(-)$ & $G(\mathrm{GPa})$ & $\gamma\left(\mathrm{mJ} / \mathrm{m}^{2}\right)$ & $R_{q}(\mathrm{~nm})$ \\
\hline Silicon $(\mathrm{Si})$ & 2.5 & 112 & 0.28 & 44 & $44.1 \pm 3.1^{*}$ & $2-3$ \\
Silica $\left(\mathrm{SiO}_{2}\right)$ & 2.5 & 73.6 & 0.17 & 31.4 & $44.1 \pm 3.1$ & $3-5$ \\
Sapphire $\left(\mathrm{Al}_{2} \mathrm{O}_{3}\right)$ & 2.5 & 462.6 & 0.309 & 144.3 & 41.1 & $8-10$ \\
Float glass & $\infty$ & 64 & 0.2 & 26 & 83.4 & $0.7-1$ \\
Zirconia $\left(\mathrm{ZrO}_{2}\right)$ & 2.5 & 205 & 0.312 & 81 & 45.6 & - \\
\hline
\end{tabular}

${ }^{*}$ Surface energy of $\mathrm{SiO}_{2}$ because of oxide layers present on the surface

$R$ is the radius, $E$ is Young's modulus, $v$ is the Poisson's ratio, $G$ is the shear modulus, $\gamma$ is the surface energy and $R_{q}$ is the rms surface roughness.

Contact angles for ceramics in room temperature and surface tension [57].

Table B.2 Contact angles and surface tension for silicon, silica, float glass and water.

\begin{tabular}{lll}
\hline Materials & $\Theta\left(^{\circ}\right)$ & $\gamma(\mathrm{mN} / \mathrm{m})$ \\
\hline Silicon $(\mathrm{Si})$ & 46 & $44.1 \pm 3.1^{*}$ \\
Silica $\left(\mathrm{SiO}_{2}\right)$ & 35 & $44.1 \pm 3.1$ \\
Float glass & 36.5 & 83.4 \\
Water & - & 45.6 \\
\hline
\end{tabular}


Table B.3: Confocal microscope images from measurement described in Chapter 6

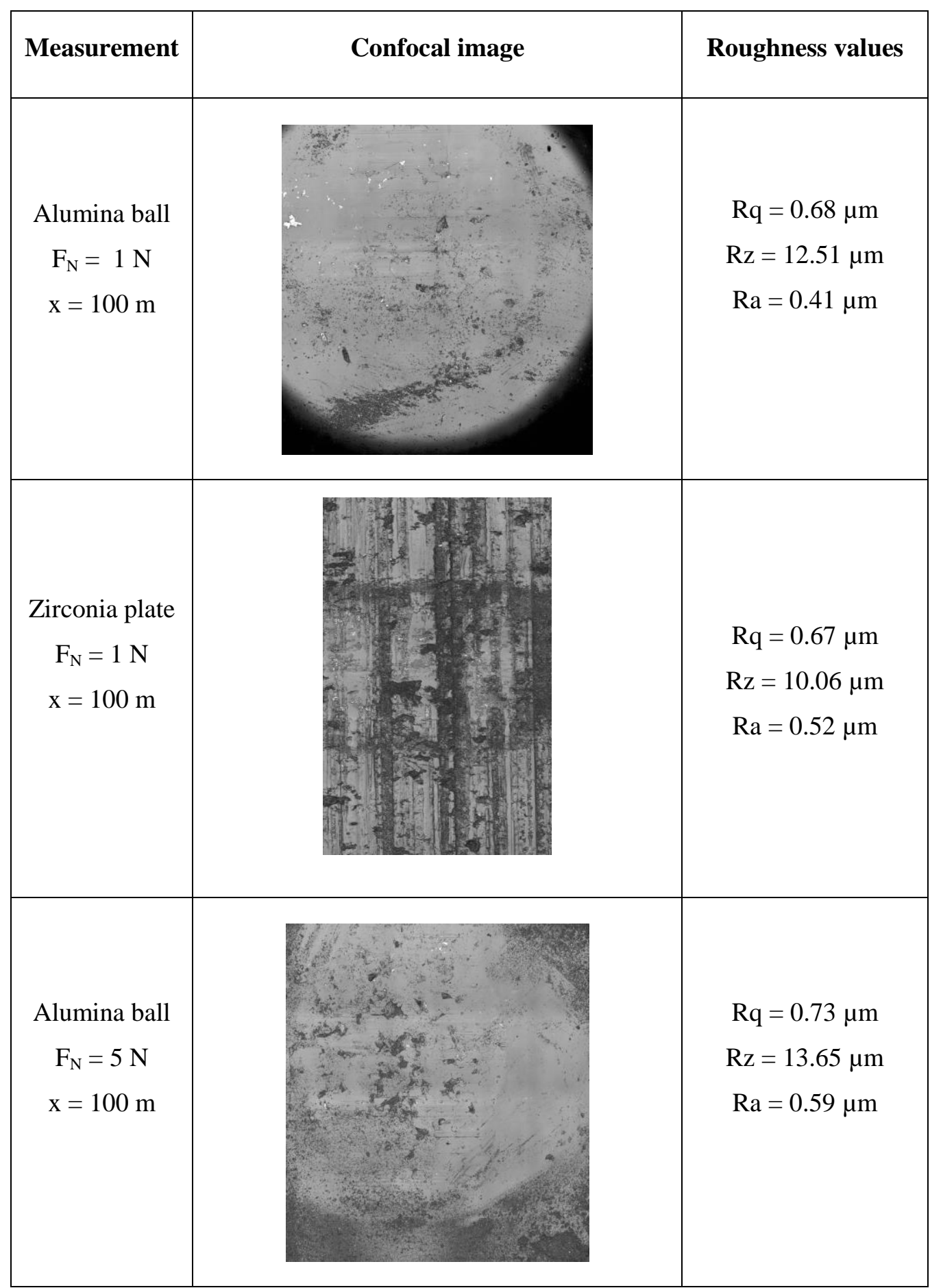




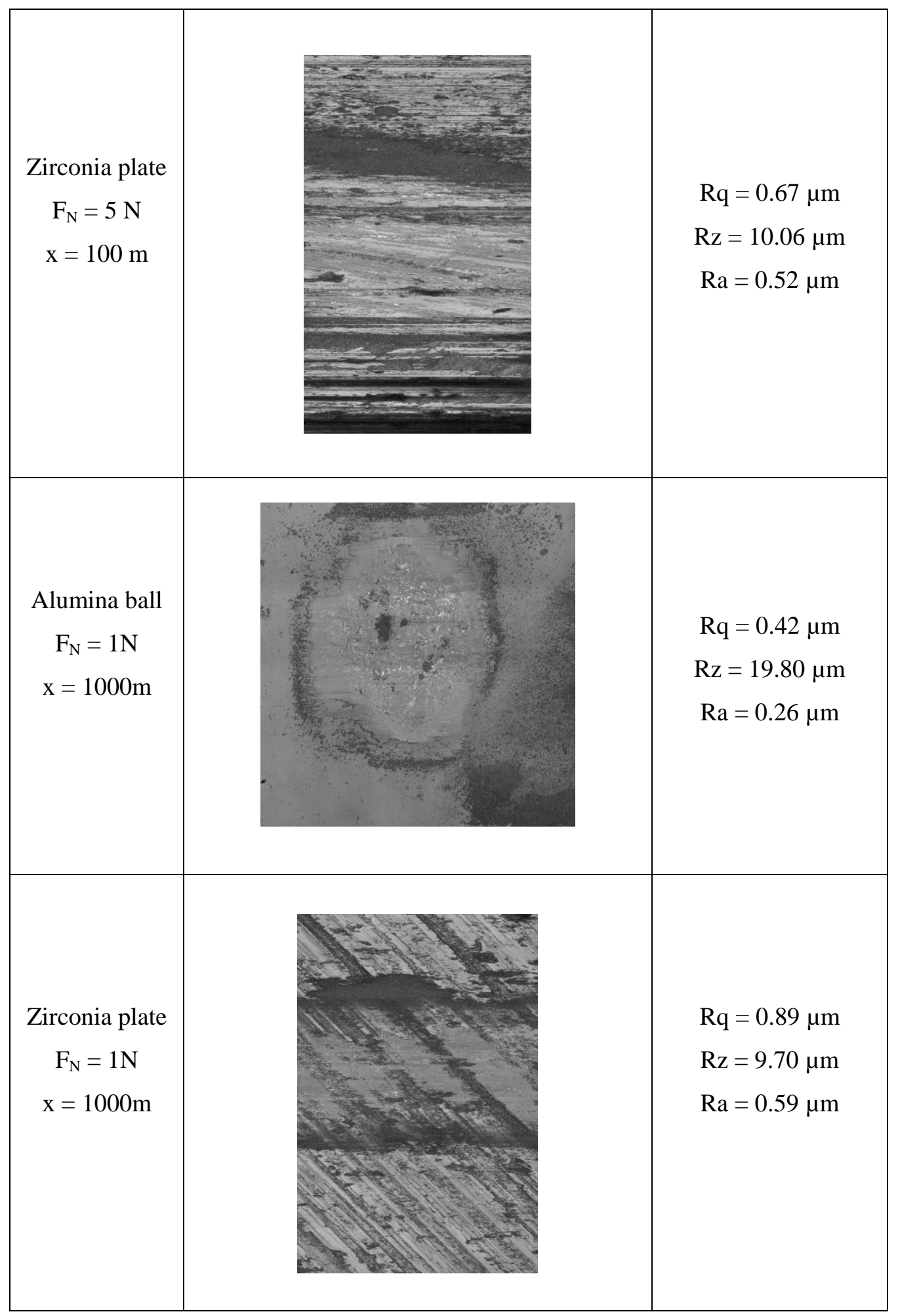




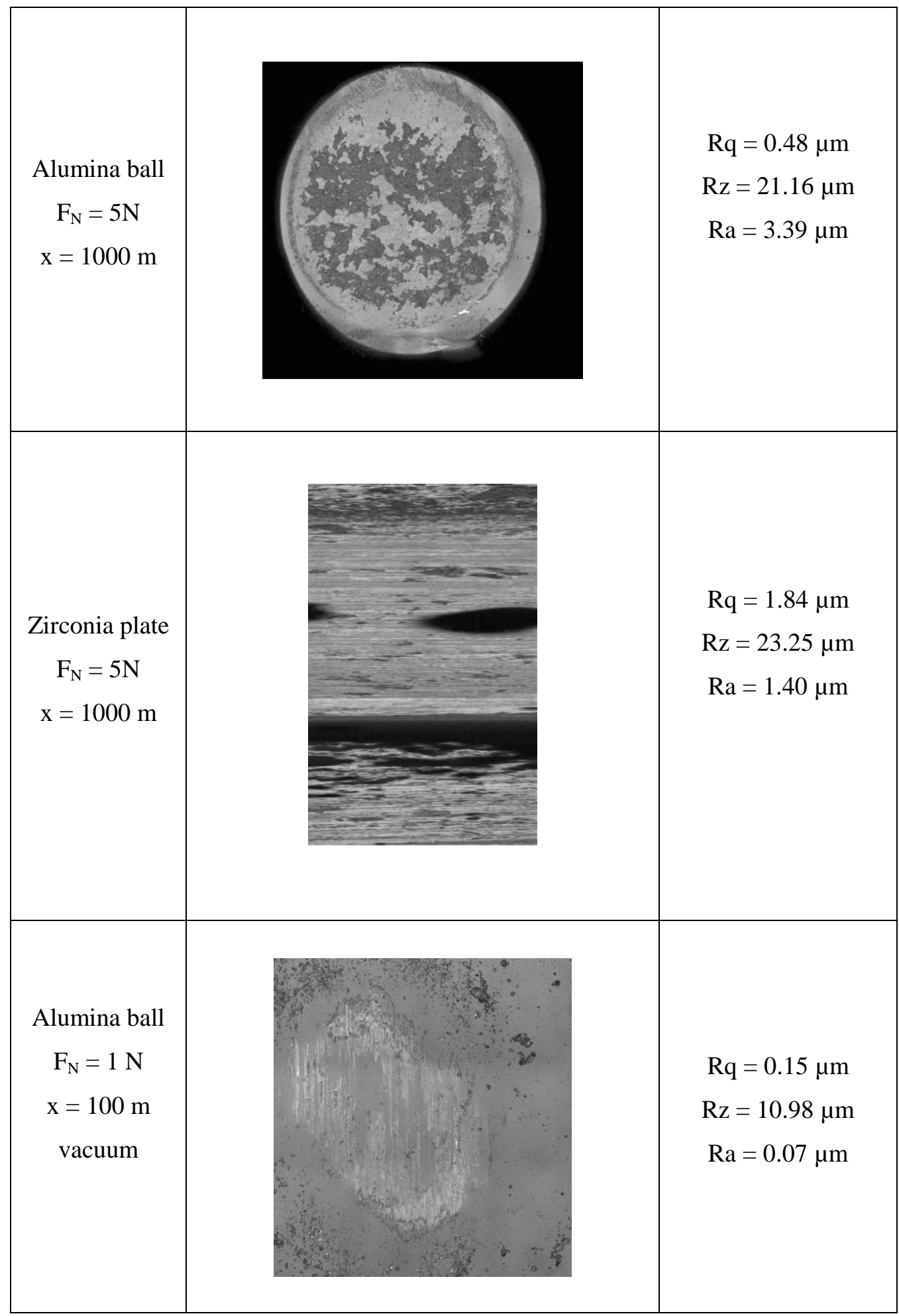




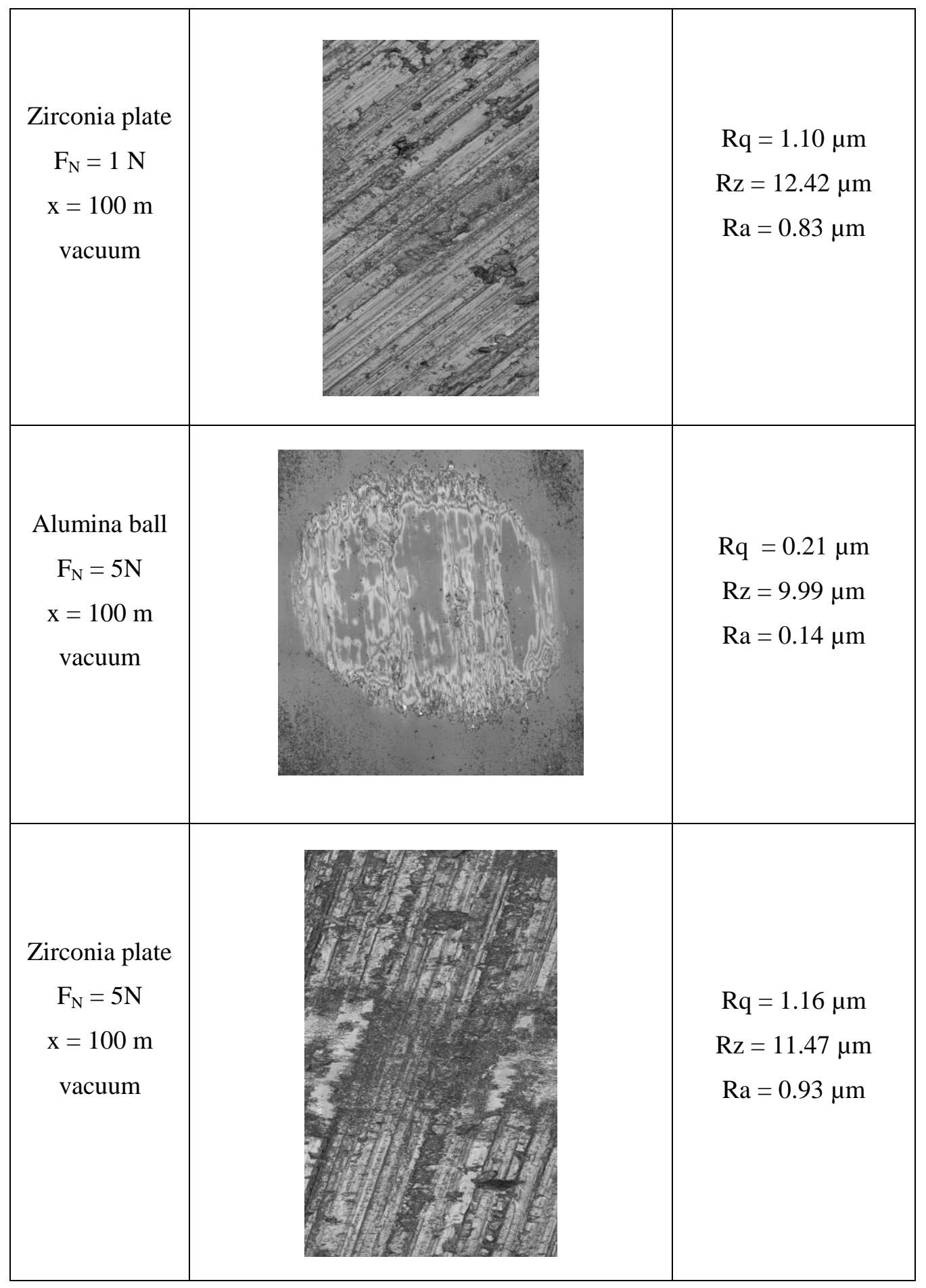




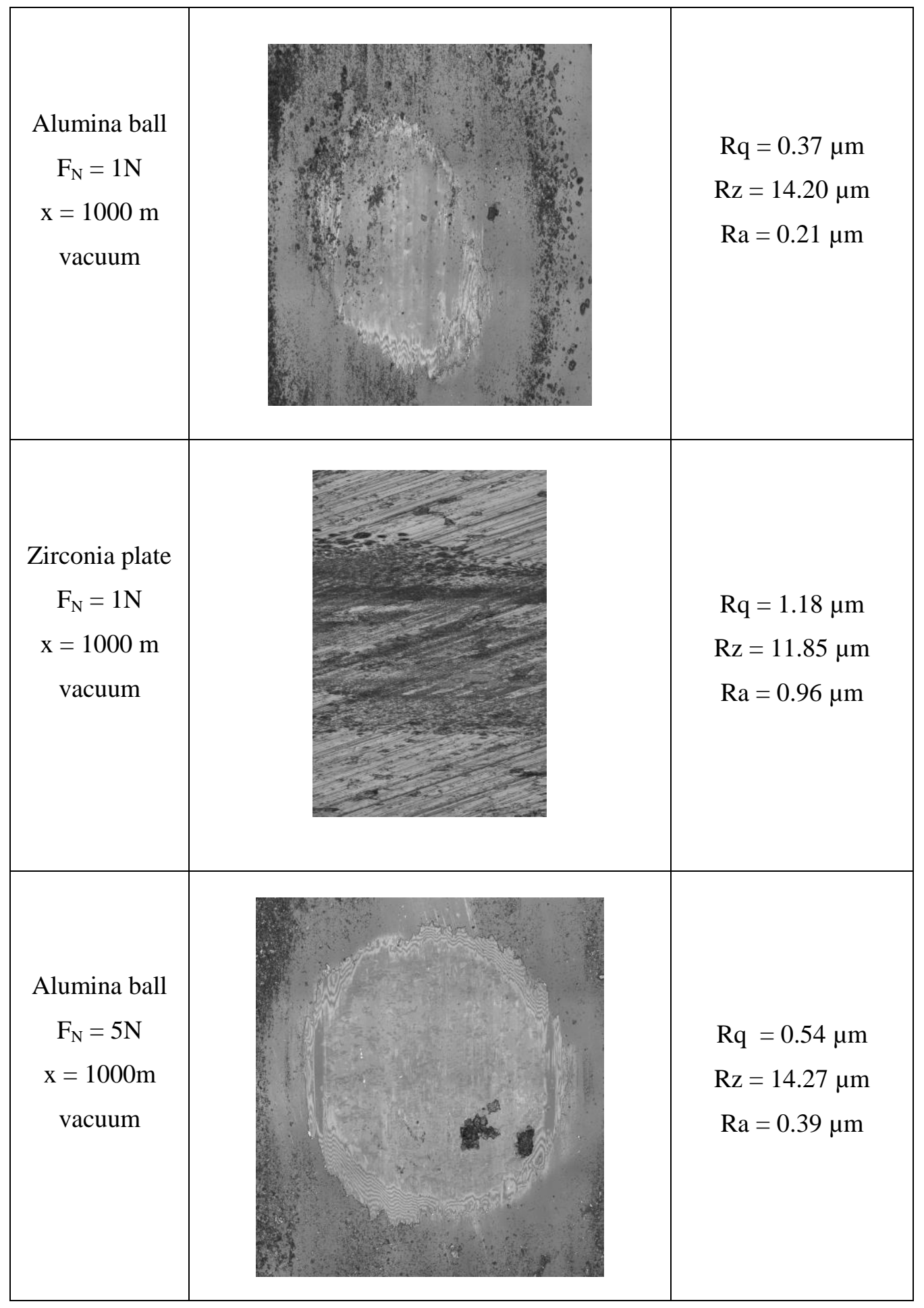




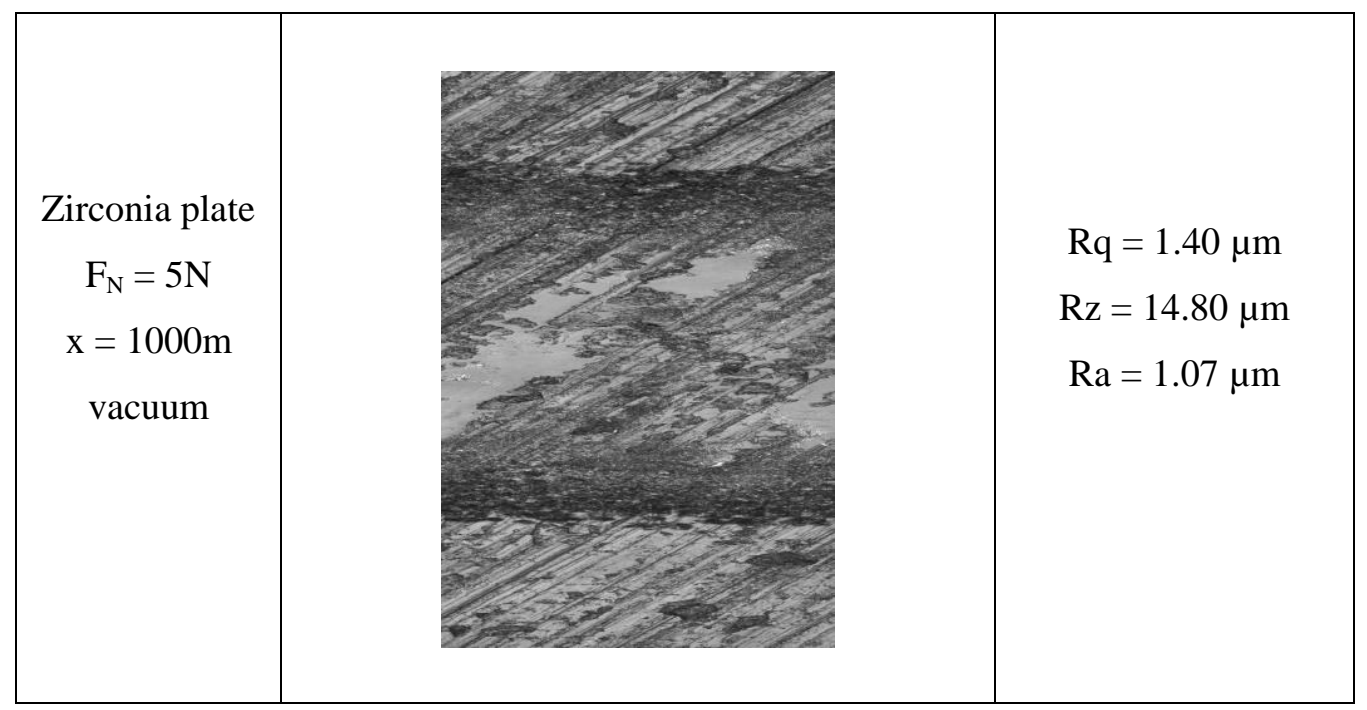




\section{Appendix C}

\section{Measurement sequences used in UNAT setup}

1. The normal load is increasing after four loops to a higher load without release of the normal load.

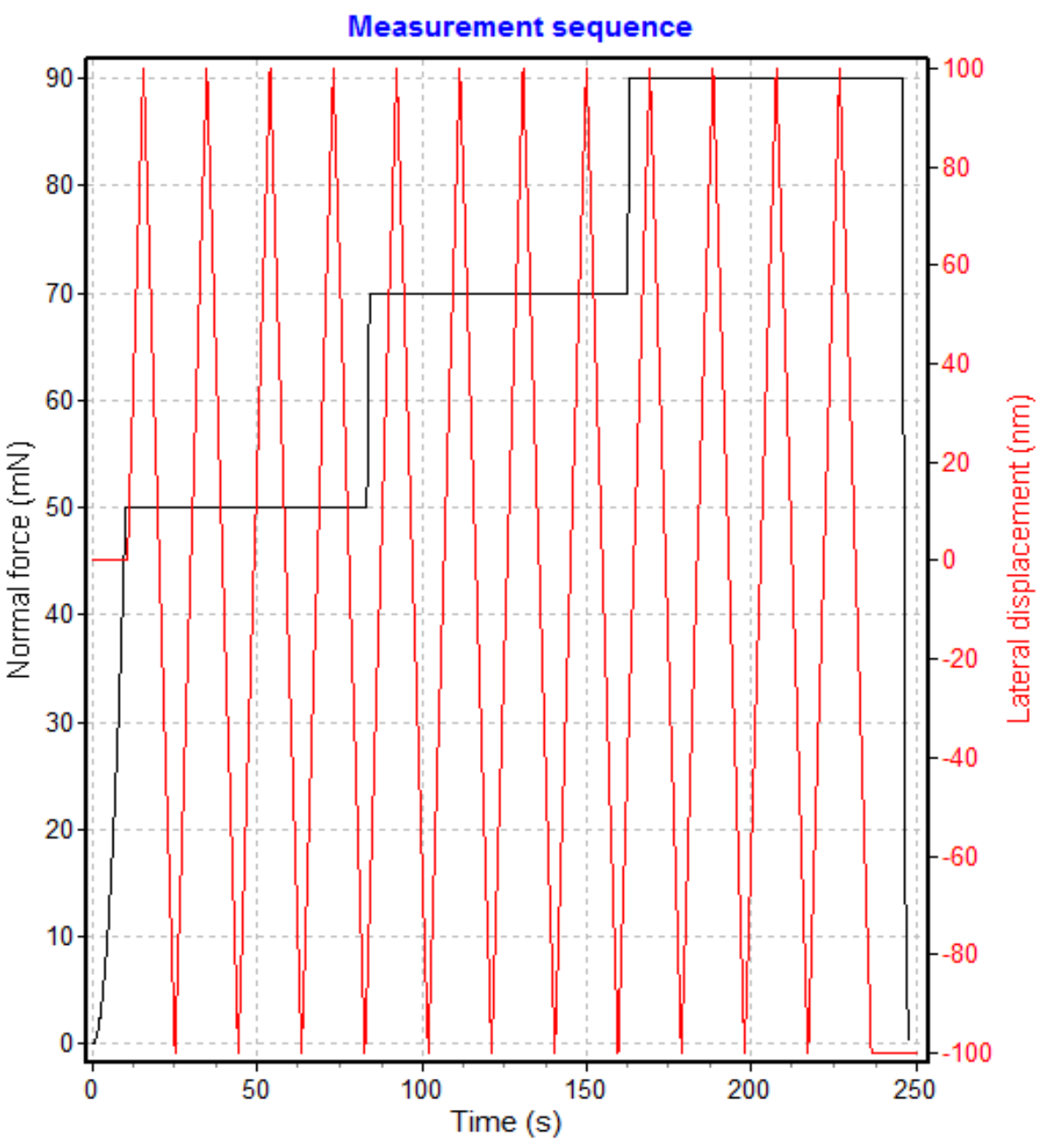


2. The normal load is decreasing after four loops to a lower load without release of the normal load.

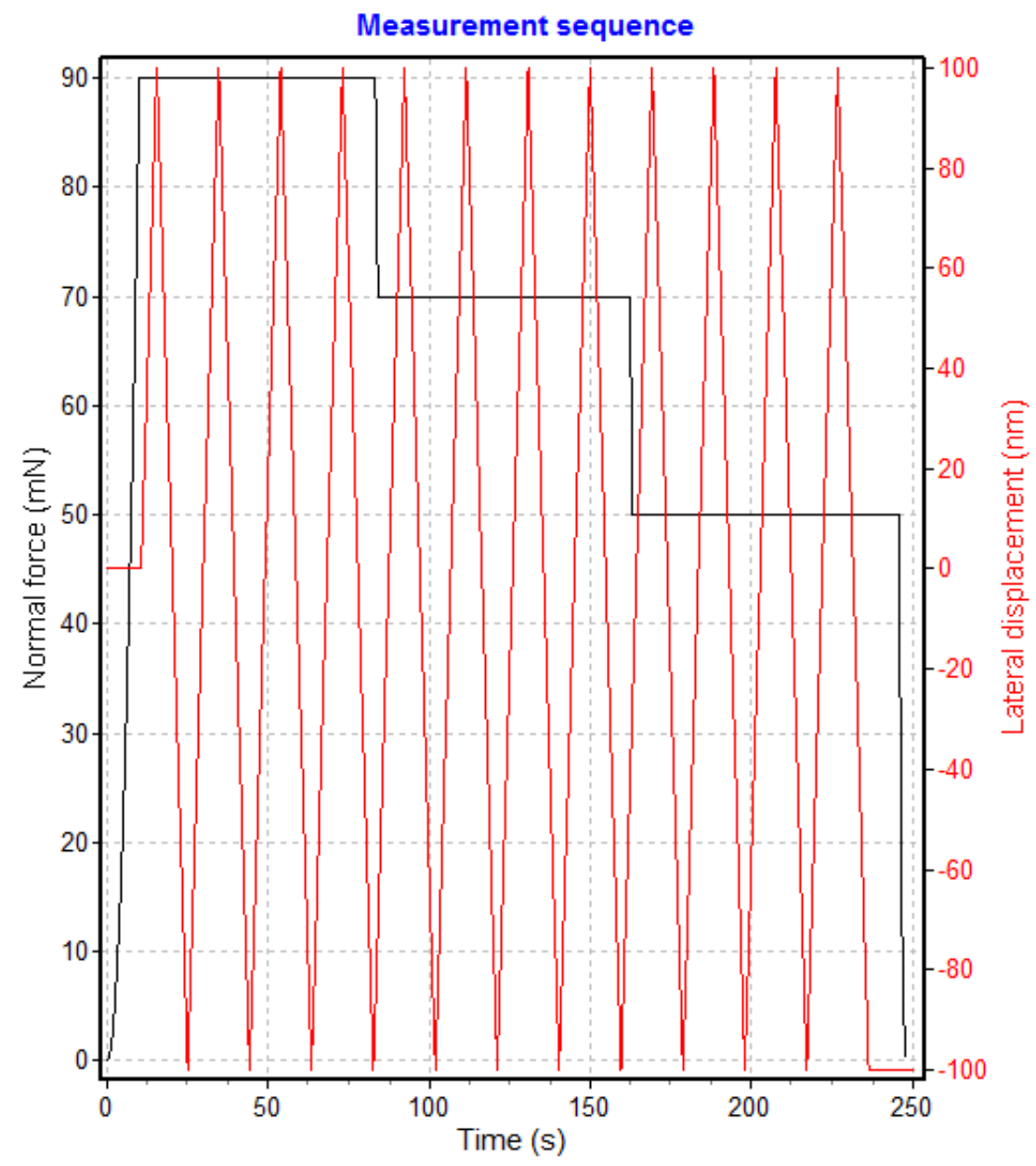




\section{Appendix D}

\section{Measurement results from VAFT setup with increasing normal load in vacuum}

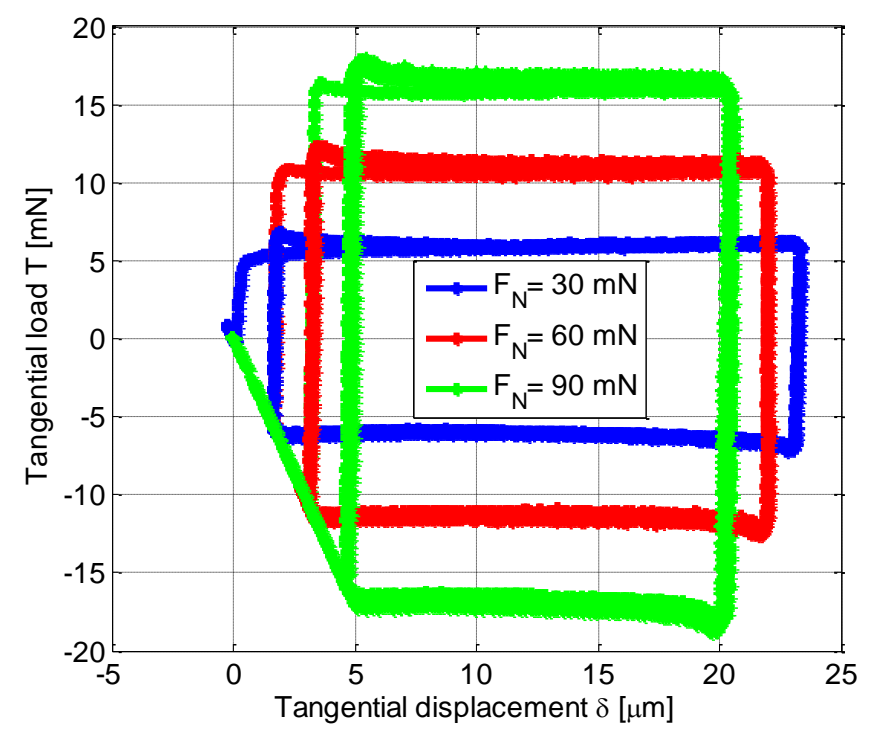

Figure D.1: Silica ball against glass with increasing normal load 30-60-90 $\mathrm{mN}$ in vacuum.

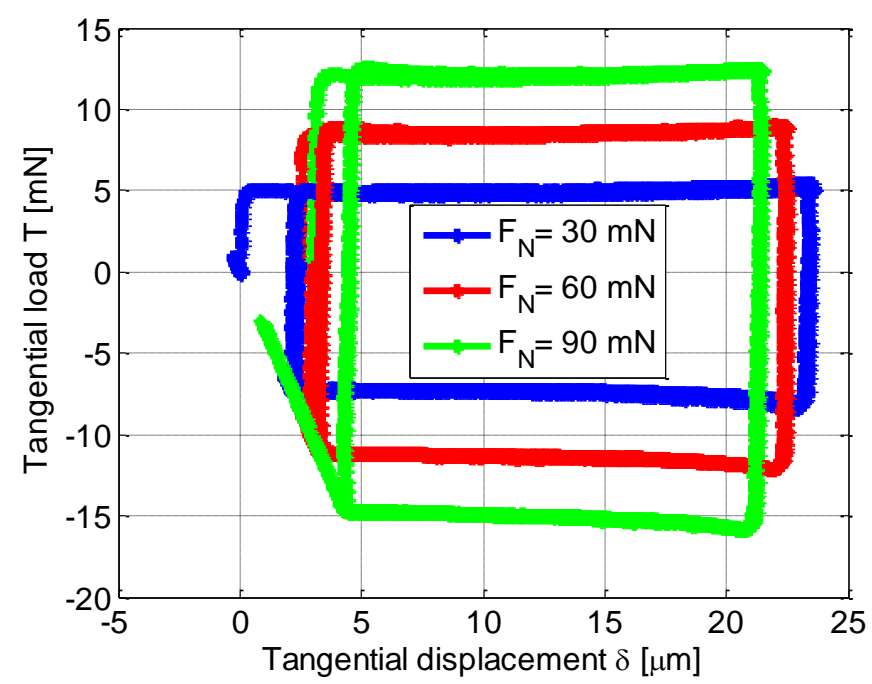

Figure D.2: Silicon ball against glass with increasing normal load 30-60-90 $\mathrm{mN}$ in vacuum. 
The confocal image of a silicon ball before and after wear is shown in Figure D.3.

a)

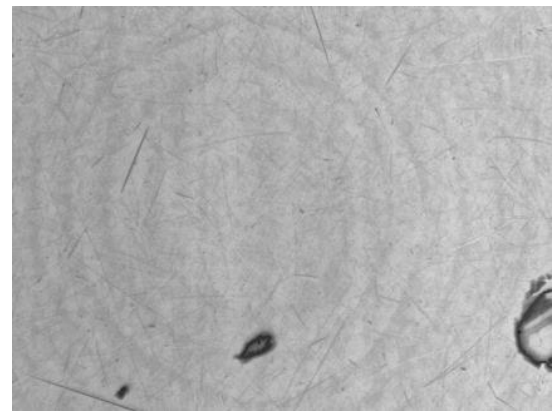

b)

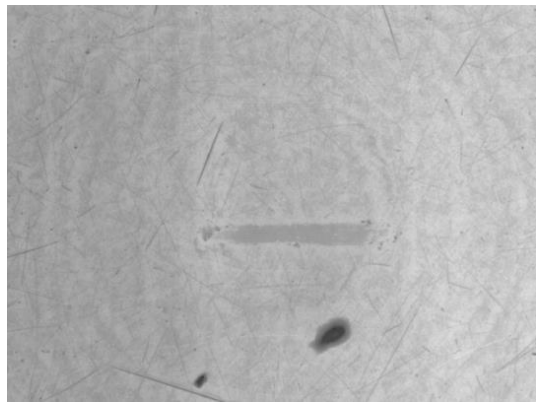

Figure D.3: Confocal image of laser intensity of silicon ball a) before test, and b) after test. 


\section{Appendix E}

\section{Surface roughness characterization}

A surface is determined by asperities with summit height $z$ and the total number of measurement heights/pixels $N$. The pixel size in the $x$ and $y$ directions of the surface is respectively $p_{x}$ and $p_{y}$. The summits are found by determining the heights, which are higher than their neighbouring heights. Three different methods are used: three point rule (for line profile), five points or nine point rule (for surface profile) as shown in Figure E.1.

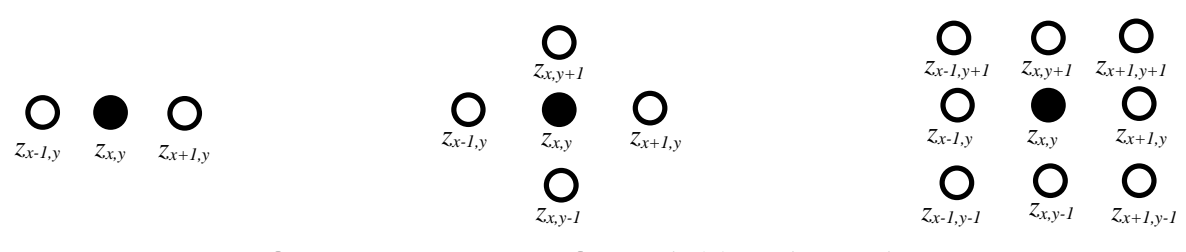

- Summit $\bigcirc$ Neighbouring points
a) Three point rule
b) Five point rule
c) Nine point rule

Figure E.1: Summit identification [63].

The standard deviation of the surface heights is given as:

$$
\sigma_{z}=\sqrt{\frac{1}{N} \sum_{i=1}^{N} z(i)^{2}}
$$

The slope of the summit/asperity of the given surface can be found from the height data of the neighbouring asperities using the finite difference method. The slope of the summit/asperity at the position $(x, y)$ in both directions is given as:

$$
s_{x}=\left|\frac{z(x, y)-z(x+1, y)}{p_{x}}\right| ; s_{y}=\left|\frac{z(x, y)-z(x, y+1)}{p_{y}}\right|
$$


The equivalent slope of a summit/asperity is given as:

$$
s=\frac{s_{x}+s_{y}}{2}
$$

If $n$ is the total number of summits/asperities, the standard deviation of the slopes is given as:

$$
\sigma_{s}=\sqrt{\frac{1}{n} \sum_{i=1}^{n} s(i)^{2}}
$$

The curvature of the summit/asperity at the position $(x, y)$ of the given surface is found as:

$$
\kappa_{x}=\left|\frac{z(x-1, y)-2 z(x, y)+z(x+1, y)}{p_{x}{ }^{2}}\right| ; \kappa_{y}=\left|\frac{z(x, y-1)-2 z(x, y)+z(x, y+1)}{p_{y}{ }^{2}}\right|
$$

The equivalent curvature of a summit/asperity is given as:

$$
\kappa=\frac{\kappa_{x}+\kappa_{y}}{2}
$$

The summit radius $R$ is found by calculating the local curvature in both directions.

$$
R=\left[\frac{\kappa_{x}+\kappa_{y}}{2}\right]^{-1}
$$

If $n$ is the total number of summits/asperities, the standard deviation of the curvatures is given as: 


$$
\sigma_{\kappa}=\sqrt{\frac{1}{n} \sum_{i=1}^{n} \kappa(i)^{2}}
$$

The bandwidth parameter of the surface from the power spectral density of the surface is given as:

$$
\psi=\left(\frac{\sigma_{z} \sigma_{\kappa}}{\sigma_{s}^{2}}\right)^{2}
$$

The autocorrelation length of the surface profile with $\mathrm{N}$ number of heights is:

$$
A C F=\frac{\sum_{x=1}^{N} z(x) z(x+1)}{N}
$$

The surface roughness lay gives the orientation of the asperities with respect to the sliding direction. The surface lay parameter, $\gamma_{l a y}$ is calculated from the autocorrelation length in both $\mathrm{x}$ and $\mathrm{y}$ directions as $[62,63]$ :

$$
\gamma_{\text {lay }}=A C F_{x} / A C F_{y}
$$





\section{Appendix F}

\section{Coefficient of friction results obtained from tests using Mini vacuum setup.}

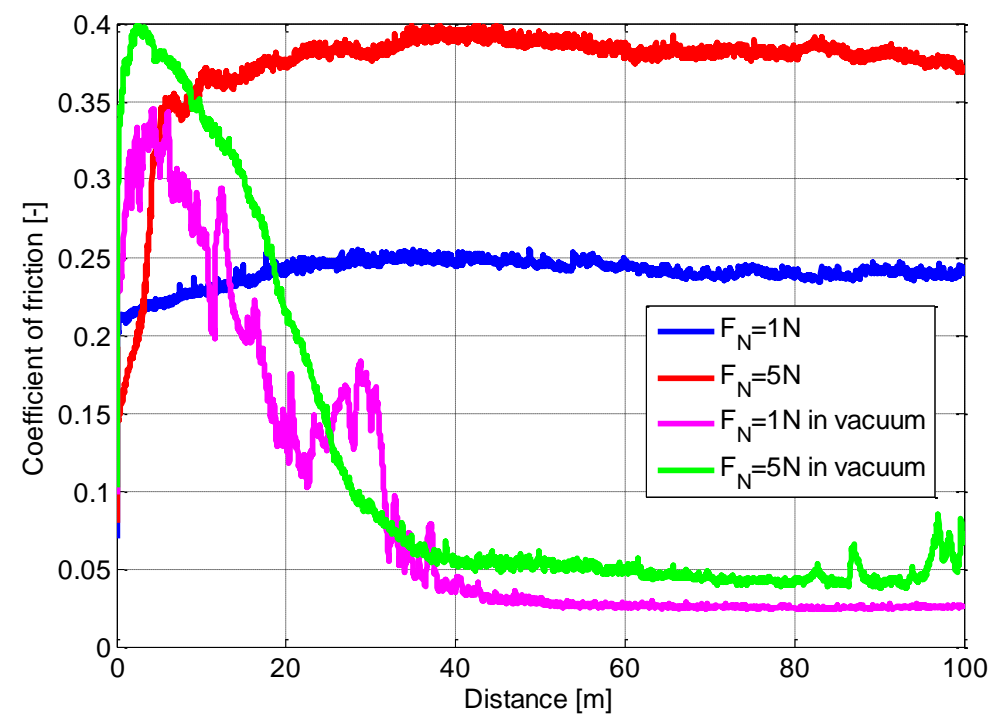

Figure F.1: The coefficient of friction results with sliding distance of $100 \mathrm{~m}$ for an alumina ball against a zirconia disc in ambient and vacuum conditions.

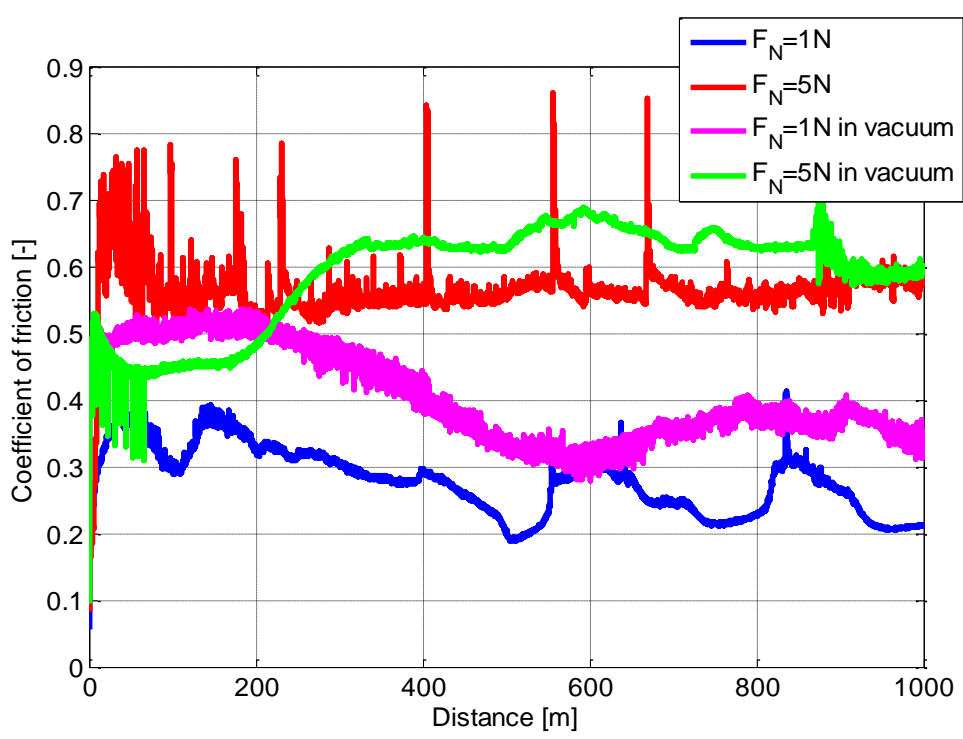

Figure F.2: The coefficient of friction results with sliding distance of $1000 \mathrm{~m}$ for an alumina ball against a zirconia disc in ambient and vacuum conditions. 



\section{Appendix G}

Asperity distribution from Chapter 6.2.2.

a)

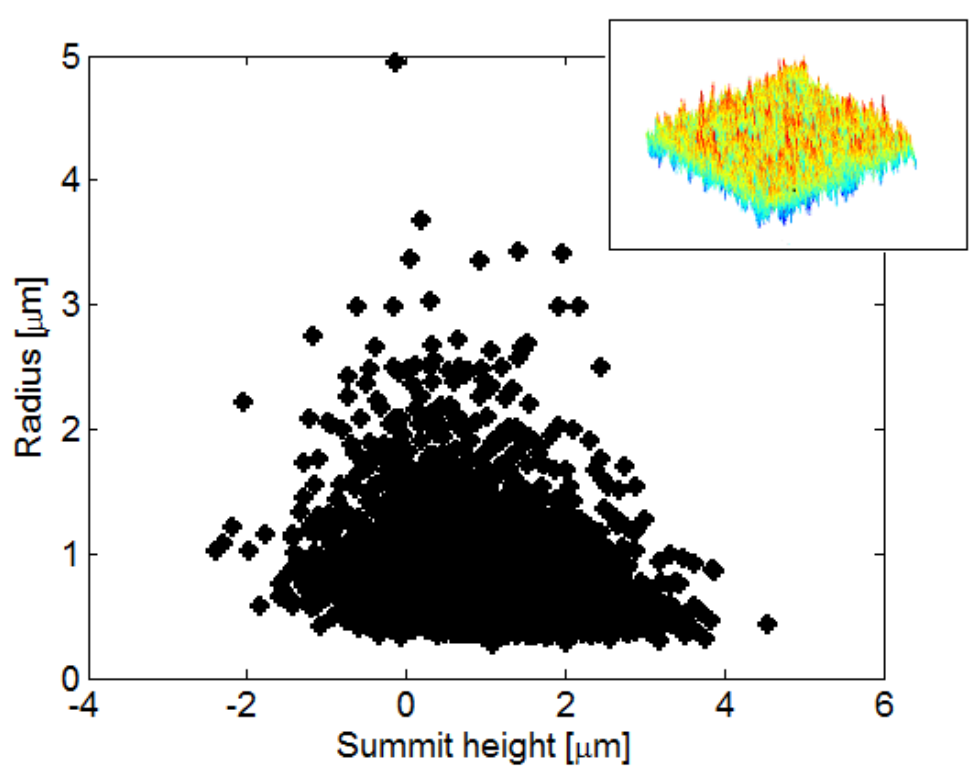

b)

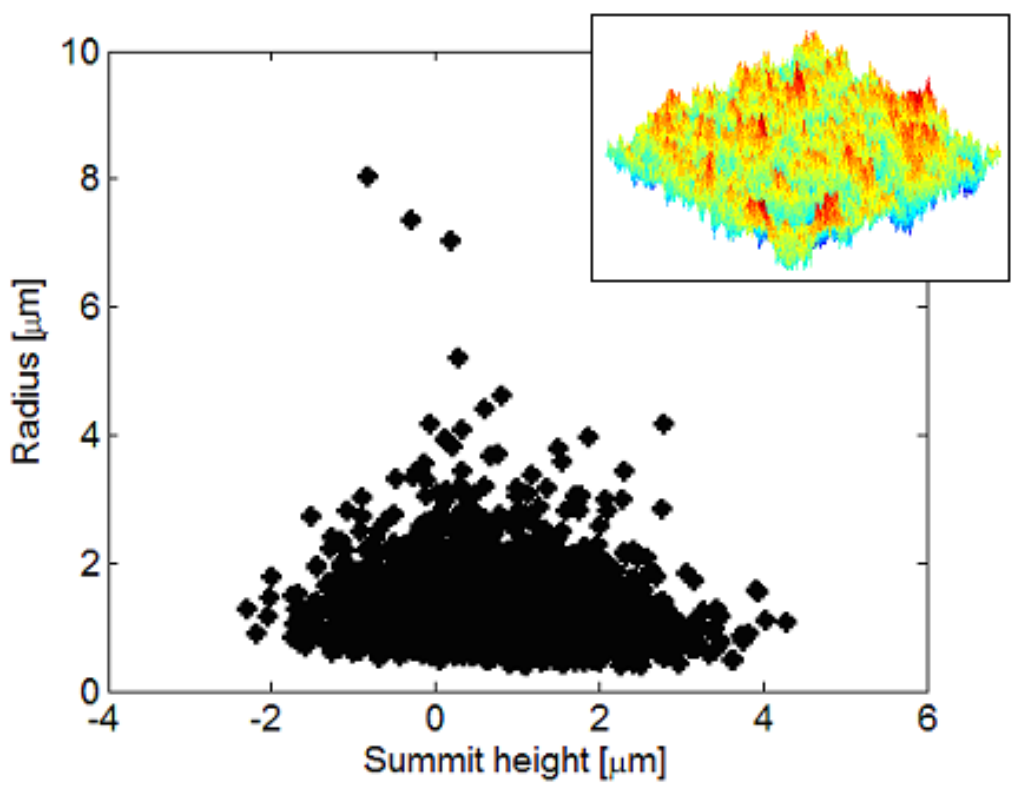


c)

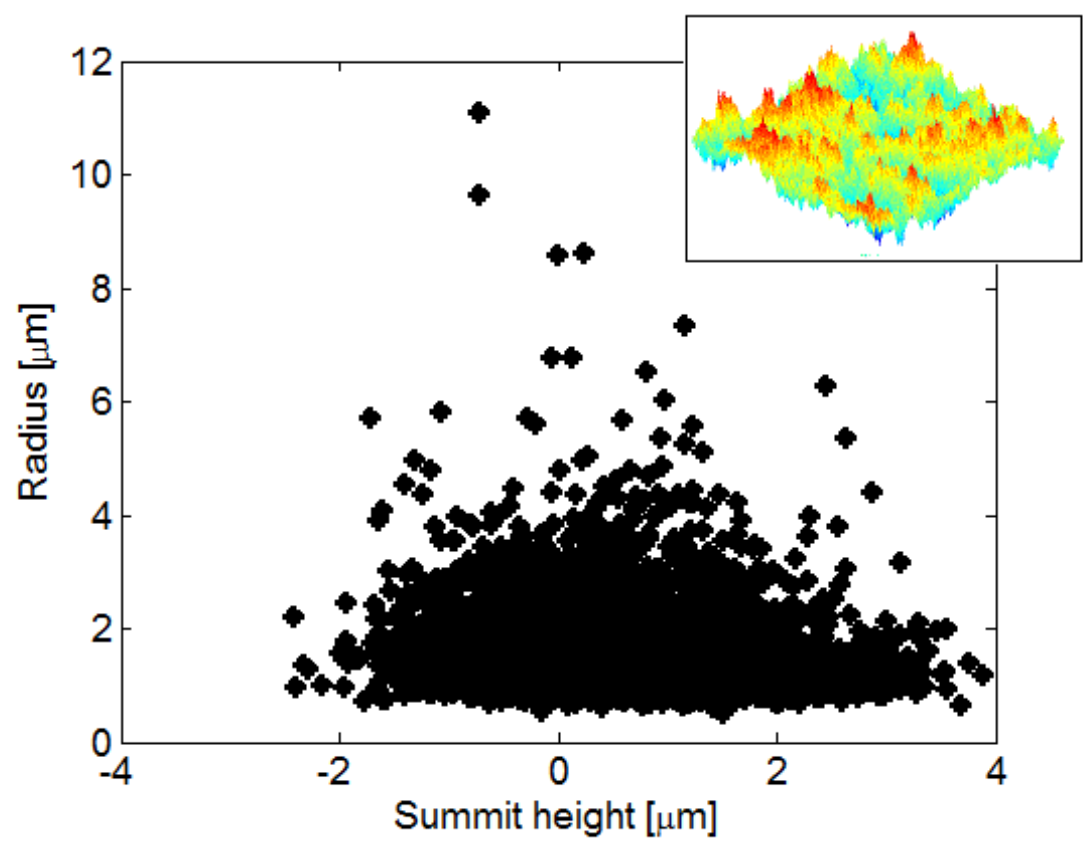

d)

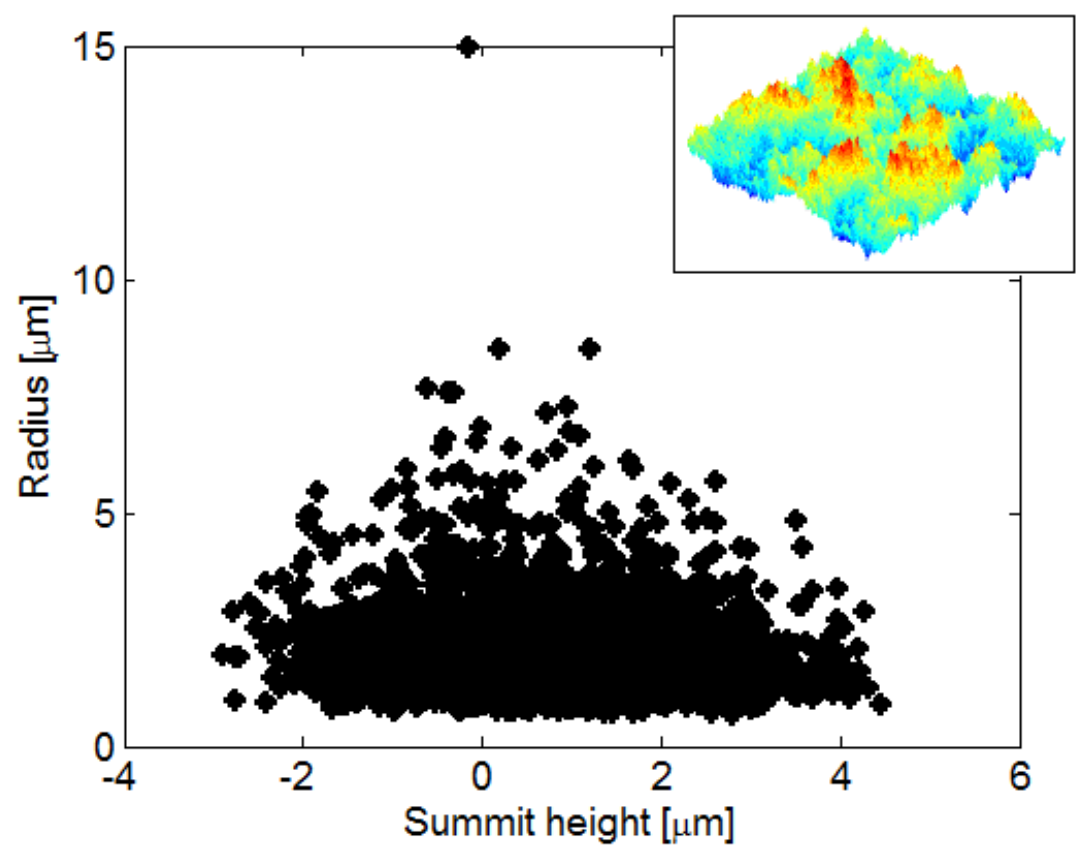


e)

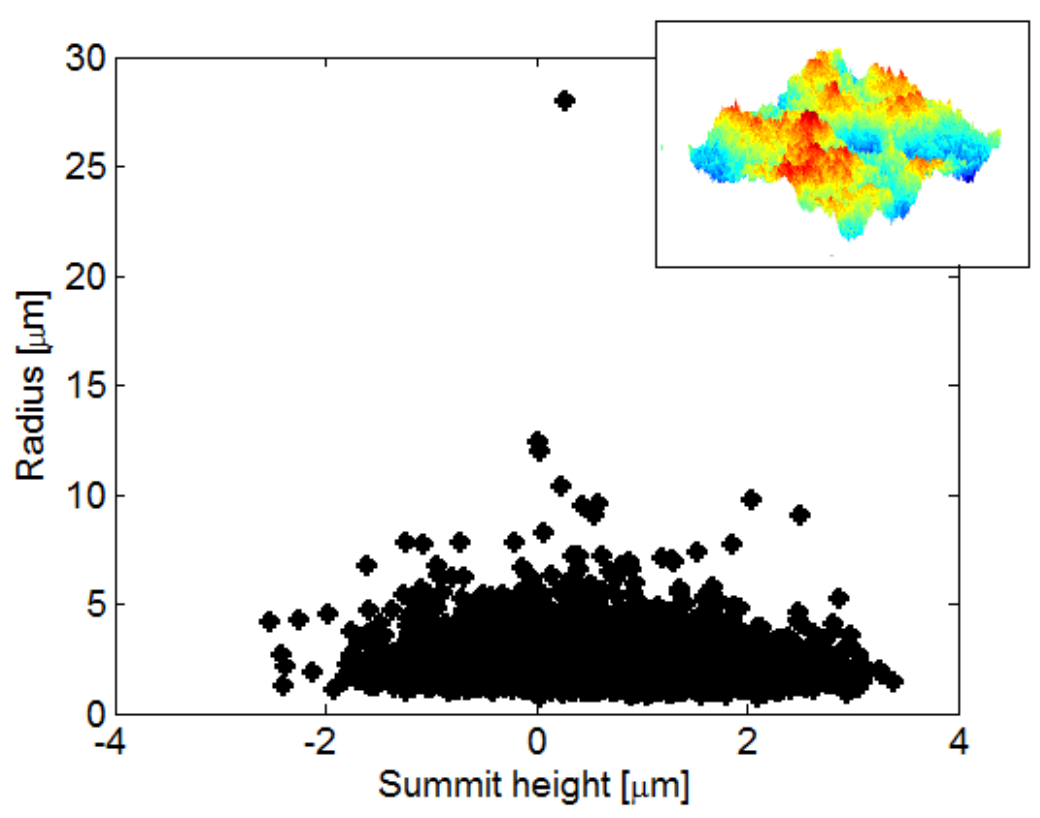

Fig.G.1: Asperity distribution for autocorrelation length a) $10 \mu \mathrm{m}, \mathrm{b}) 20 \mu \mathrm{m}$, c) $40 \mu \mathrm{m}$, d) $60 \mu \mathrm{m}$ and e) $80 \mu \mathrm{m}$.

a)

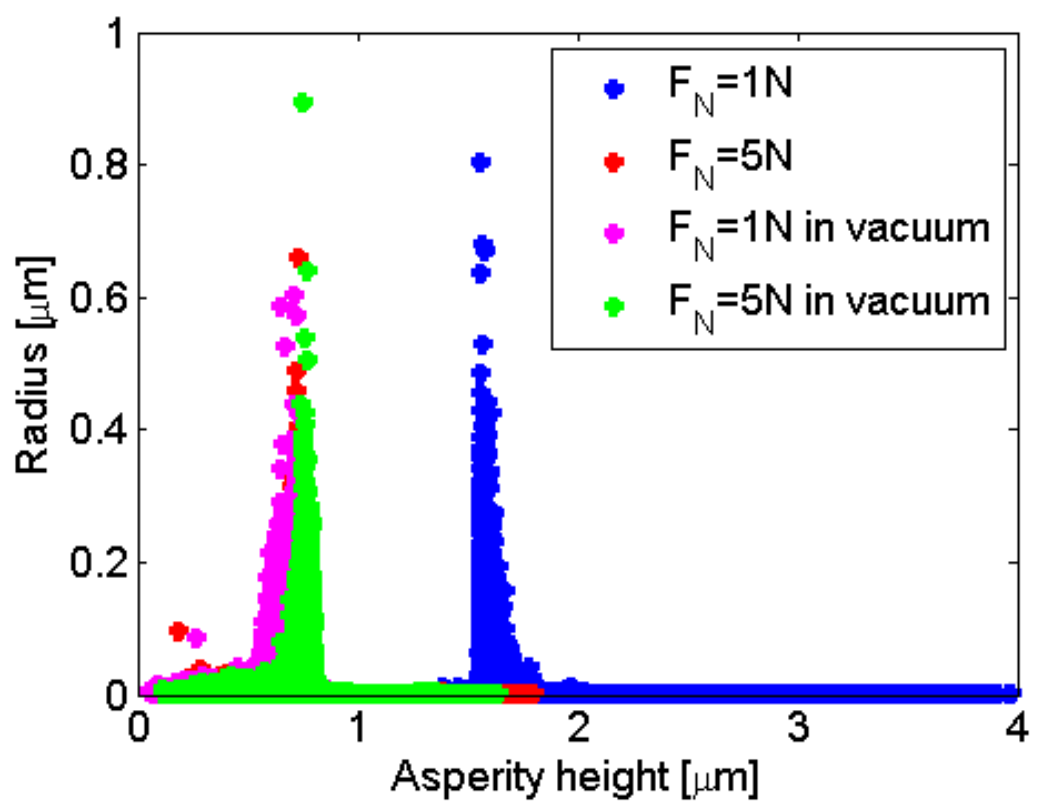


b)

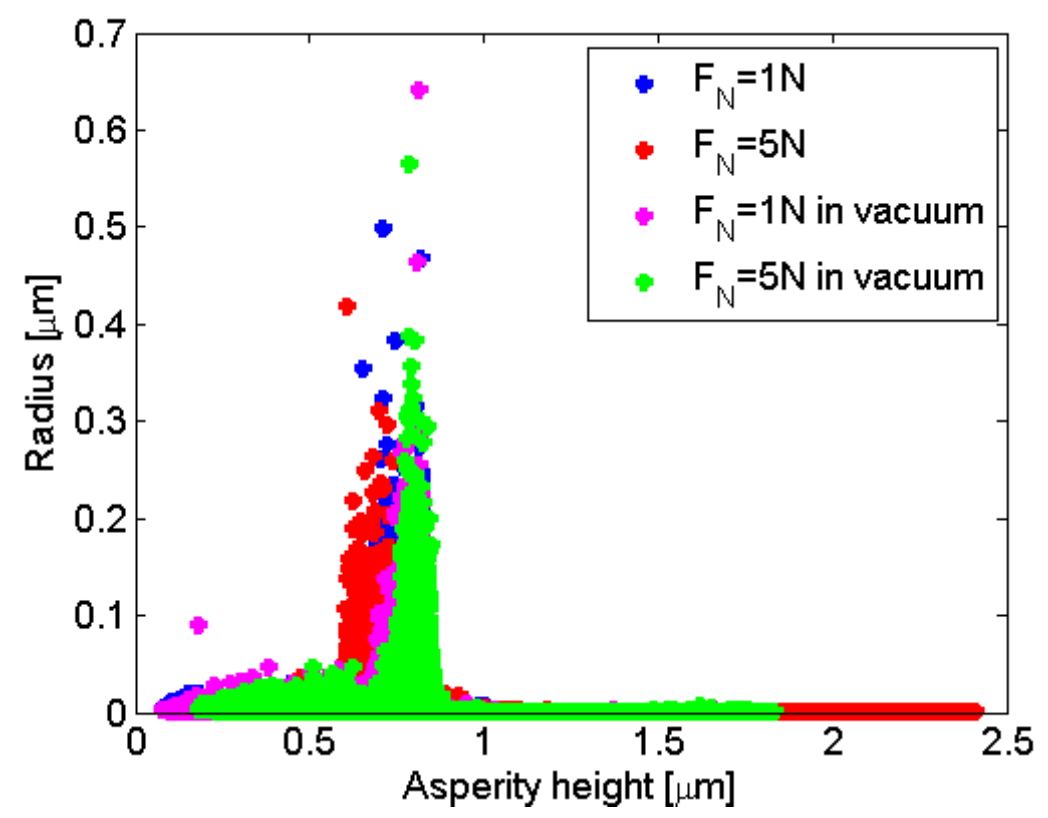

c)

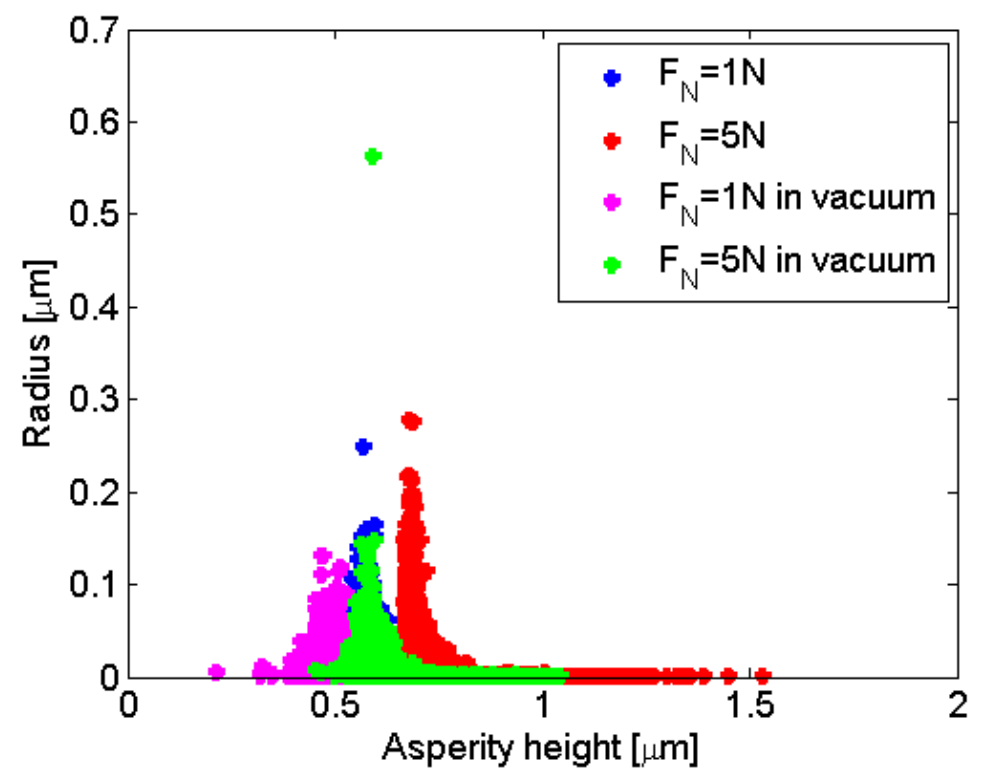


d)

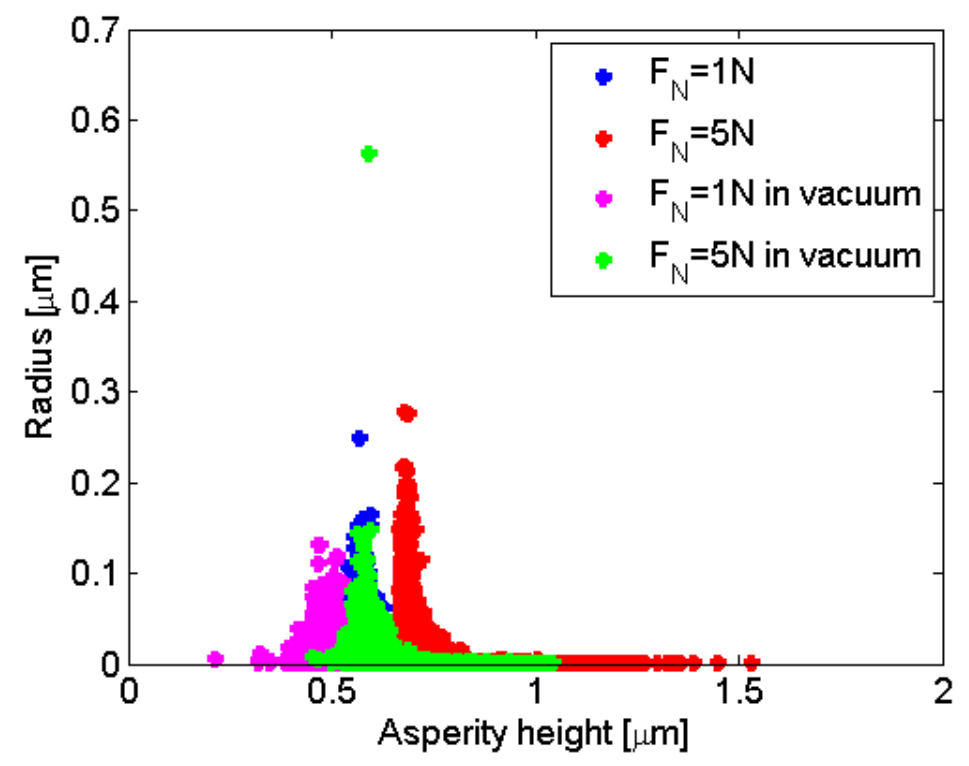

Figure G.2: Asperity distributions for asperity height and radius with different applied normal load and environment condition, a) alumina ball for $100 \mathrm{~m}$ distance, b) alumina ball for $1000 \mathrm{~m}$ distance, c) zirconia plate for $100 \mathrm{~m}$ distance and d) zirconia plate for $1000 \mathrm{~m}$. 



\section{REFERENCES}

1. Stolarski, T.A., 2000, Tribology in machine design, Butterworth-Heinemann, Oxford.

2. Czichos H., 1978, Tribology, a system approach to the science and technology of friction, lubrication and wear, Elsevier, The Netherlands.

3. Adams, G.G., Müftü, S., Azhar, N.M., 2003, A scale dependent model for multiasperity contact and friction, ASME Journal of Tribology, Vol.125.

4. Popov, V.L., 2010, Contact mechanics and friction. Physical principles and application, Springer, Germany.

5. Mindlin, R.D., 1949, Compliance of elastic bodies in contact, J. Appl. Mech-T ASME, Vol. 16, pp. 259-268.

6. Johnson, K.L., 1985, Contact Mechanics, Cambridge University Press, UK.

7. Johnson, K.L., 1998, Mechanics of adhesion, Tribology International, Vol. 31, No. 8, pp. 413-418.

8. Greenwood, J.A. and Williamson, J.B.P., 1966, Contact of nominally flat surfaces. Proceedings of Royal Society of London. Series A, Mathematical and Physical Sciences, Vol. 295, pp. 300-319.

9. Bhushan, B., 1998, Contact mechanics of rough surfaces in tribology: multiple asperity contact, Tribology Letters, Vol.4, pp. 1-35.

10. Butt, J., Graf, K. and Kappl, M., 2003, Physics and chemistry of interfaces, WILEY-VCH GmbH \& Co.KGaA, Weinheim.

11. Bowden, F.P. and Tabor, D., 1950, The friction and lubrication of solids, Oxford University Press. 
12. Yaqoob, A.M., 2012, Adhesion and Friction in Single Asperity Contact, $\mathrm{PhD}$ thesis, University of Twente, The Netherlands.

13. Johnson, K.L., Kendall, K. and Roberts, A.D., 1971, Surface energy and the contact of elastic solids, Proceedings of Royal Society of London. Series A, Mathematical and Physical Sciences.

14. Derjaguin, B.V., Muller, V.M. and Toporov, Yu.P., 1975, Effect of contact deformations on the adhesion of particles, Journal of Colloid and Interface Science,Vol.53, No.2.

15. Wang, H.L. and Hon, M.H., 1999, Temperature dependence of ceramic hardness, Ceramics International, Vol. 25, pp. 267-271.

16. Maugis, D., 1992, Adhesion of Spheres: The JKR-DMT Transition Using a Dugdale Model, Journal of Colloid and Interface Science, Vol.150, No.1.

17. Johnson, K.L. and Greenwood J.A., 1997, An adhesion map for the contact of elastic spheres, Journal of Colloid and Interface Science, Vol. 192, pp. 326-333.

18. Fuller, K.N.G. and Tabor, D., 1975, The effect of surface roughness on the adhesion of elastic solids. Proc. R. Soc. Lond. A 345, Vol. 247, pp. 327-342.

19. Mindlin, R.D. and Deresiewicz, H., 1953, Elastic spheres in contact under varying oblique forces, J. Appl. Mech-T ASME, Vol.20, pp. 327-344.

20. Prokopovich, P. and Starov, V., 2011, Adhesion models: From single to multiple asperity contacts, Advances in Colloid and Interface Science, Vol. 168, No.1-2, pp. 210-222.

21. Carbone, G. and Bottiglione, F., 2008, Asperity contact theories: Do they predict linearity between contact area and load?, Journal of the Mechanics and Physics of Solids, Vol. 56.

22. Onions, R.A and Archard, J.F., 1973, The contact of surfaces having a random structure, J.Phys.D:Appl.Phys, Vol.6, No. 3, pp. 289 - 304.

23. Bush, A.W. and Gibson, R.D., 1975, The elastic contact of a rough surface, Wear, Vol. 35, pp. 87-111.

24. Bureau, L., Caroli, C. and Baumberger, T., 2003, Elasticity and onset of frictional dissipation at a non-sliding multicontact interface, Proc. R. Soc. Lond. A, Vol. 459, pp. $2787-2805$. 
25. Huang, S., 2011, Micromechanical modelling of rough interface behaviour., $\mathrm{PhD}$ Thesis, University of Kansas, USA.

26. Huang, S. and Misra, A., 2012, Path-dependent analysis of elastic sphere contact subjected to tangential loading with varying directions, Proceedings of the Institution of Mechanical Engineers, Part J: Journal of Engineering Tribology, pp. 1-9.

27. Björklund, S., 1997, A random model for micro-slip between nominally flat surfaces, Journal of Tribology- transactions of the ASME, Vol.119, No.4, pp. 726-732.

28. Kogut, L. and Etsion, I., 2004, A static friction model for elastic-plastic contacting rough surfaces, Journal of Tribology- transactions of the ASME, Vol.126, No. 1, pp. 34-40.

29. De Moerlooze, K., Al-Bender, F., Van Brussel, H., 2010, A Generalised Asperity-Based Friction Model, Tribology Letters, Vol. 40, No. 1, pp. 113-130.

30. Boch, P. and Niépce, J.C., 2007, Ceramic materials. Processes, properties and applications, ISTE, London.

31. Bohm, J., Jech, M. and Vellekoop, M., 2010, Analysis of NM-Scale Scratches on High-Gloss Tribological Surfaces by Using an Angle -Resolved Light Scattering Method, Tribological Letters, No. 37, pp. 209-214.

32. Schrof, W., Klingler, J., Heckmann, W. and Horn, D., 1998, Confocal fluorescence and Raman microscopy in industrial research, Colloid \& Polymer Science,Vol.276, No.7, pp. 577-588.

33. Lange, D.A., Jennings, H.M. and Shah, S.P., 1993, Analysis of surface roughness using confocal microscopy, Journal of Materials Science, Vol. 28, pp. 3879-3884.

34. Miyake, K., Nakano, M., Korenaga, A., Mano, H. and Ando, Y., 2010, Tribological properties of nanostripe surface structures - a design concept for improving tribological properties, Journal of Physics D: Applied Physics, Vol. 43, pp. 1-14.

35. Paddock, S.W., 1999, Confocal microscopy. Methods and Protocols, Humana Press, New Jersey. 
36. Valefi, M., de Rooij, M.B., Schipper, D.J. and Winnubst, A.J.A., 2011, HighTemperature Tribological and Self-Lubricating Behavior of Copper OxideDoped Y-TZP Composite Sliding Against Alumina, J.Am.Ceram.Soc., Vol. 94 , No. 12 , pp. 4426-4434.

37. Vickerman, J.C. and Gilmore, I.S., 2009, Surface analysis. The principal techniques, John Wiley \&Sons, United Kingdom.

38. Ruchita, S.D. and Agrawal, Y.K., 2011, Raman spectroscopy: Recent advancements, techniques and applications, Vibrational Spectroscopy, Vol. 57, pp. 163-176.

39. Smith, E. and Dent, G., 2005, Modern Raman spectroscopy. A practical approach, John Wiley \& Sons, England.

40. Durand, J.C, Jacquot, B., Salehi, H., Fages, M., Margerit, J. and Cuisinier, F.J.G., 2012, Confocal Raman microscopic analysis of the zirconia/feldspathic ceramic interface, Dental Materials, Vol.28, pp. 661-671.

41. Kim, B.K. and Hamaguchi, H.O., 1997, Mode Assignments of the Raman Spectrum of Monoclinic Zirconia by Isotopic Exchange Technique, Phys.Stat.Spl. (b), Vol. 203, pp. 557-563.

42. Witke, K., Österle, W., Sopp, A. and Woydt, M., 2001, Raman microprobe spectroscopy and transmission electron microscopy of thermal sprayed $\mathrm{ZrO} 2$ coatings before and after rub testing of outer air seals, J. Raman Spectrosc., pp. 1008-1014.

43. Assih, T., Ayral, A., Abenoza, M. and Phalippou, J., 1988, Raman study of alumina gels, Journal of Materials Science, Vol. 23, pp. 3326-3331.

44. Cava, S., Tebcherani, S.M., Souza, I.A., Pianaro, S.A., Paskocimas, C.A., Longo, E. and Varela, J.A., 2007, Structural characterization of phase transition of $\mathrm{Al}_{2} \mathrm{O}_{3}$ nanopowders obtained by polymeric precursor method, Materials Chemistry and Physics, Vol.103, pp. 394-399.

45. Metselaar, H., 2001, Thermally induced wear transition in ceramics, $\mathrm{PhD}$ thesis, University of Twente, The Netherlands.

46. Pasaribu, H.R., 2005, Friction and wear of zirconia and alumina ceramics doped with $\mathrm{CuO}, \mathrm{PhD}$ thesis, University of Twente, The Netherlands.

47. http://en.wikipedia.org/wiki/File:Raman_energy_levels.svg. 
48. Pully, V.V, 2010, From Cells to Bone: Raman Microspectroscopy of the Mineralization of Stromal Cells, PhD thesis, University of Twente, The Netherlands.

49. Carter, C.B. and Grant, M., 2007, Norton, Ceramic materials: science and engineering, Springer Science + Business Media.

50. Laboratory classes from Material Science, 2005, University of Technology Wroclaw, Poland.

51. Everall, N.J., 2000, Modeling and Measuring the Effect of Refraction on the Depth Resolution of Confocal Raman Microscopy, Applied Spectroscopy, Vol.54, No. 6, pp. 773-782.

52. Andersson, P. and Holmberg, K., 1994, Limitations on the use of ceramics in unlubricated sliding applications due to transfer layer formation, Wear, Vol. 175, pp. 1-8.

53. Adachi, K., Kato, K. and Chen, N., 1997, Wear map of ceramics, Wear, Vol. 203-204, pp. 291-301.

54. Zum, Gahr, K.-H., Bundschuh, W. and Zimmerlin, B., 1993, Effect of grain size on friction and sliding wear of oxide ceramics, Wear, Vol. 162-164, pp. 269279.

55. Tucci, A. and Esposito, L., 2000, Second phases and material transfer in alumina ceramics sliding systems, Wear, Vol. 245, pp. 76-83.

56. Wang, H.L. and Hon, M.H., 1999, Temperature dependence of ceramic hardness, Ceramics International, Vol. 25, pp. 267-271.

57. Yaqoob, A.M, Winogrodzka, A., Fischer, H.R., Gelinck, E.R.M., de Rooij, M.B. and Schipper, D.J., 2013, Pre-sliding Behaviour of Single Asperity Contact, Tribology Letters, Vol. 49, No. 3, pp. 553-562.

58. Carpick R.W., Agrait, N., Ogletree, D.F. and Salmeron, M., 1996, Measurement of interfacial shear (friction) with an ultrahigh vacuum atomic force microscope. Journal of Vacuum Science and Technology, Vol. 14, No. 2, pp. 1289-1295.

59. Schwarz, U.D., Zworner, O., Koster, P. and Wiesendanger, R., 1997, Quantitive analysis of the frictional properties of solid materials at low loads. I. Carbon compounds, Physical Review B., Vol. 56, No. 11, pp. 6987-6996. 
60. www.asmec.de, 2012, Specifications of UNAT.

61. Hu, Y.Z. and Tonder, K., 1992, Simulation of 3-D random rough surface by 2D digital filter and Fourier analysis, Int. J. Mach. Tools Manufact., Vol. 32, No. 1/2, pp. 83-90.

62. de Rooij, M.B, 1998, Tribological aspects of unlubricated deepdrawing processes, PhD thesis, University of Twente, The Netherlands.

63. Karupannasamy, D.K., 2013, Friction modeling on multiple scales for deep drawing processes, $\mathrm{PhD}$ thesis, University of Twente, The Netherlands.

64. Arzt, E.,Gorb, S. and Spolenak, R., 2003, From micro to nano contacts in biological attachment devices, Proceedings of the National Academy of Sciences of the United States of America, Vol. 100, No. 19, pp. 10603-10606.

65. Greenwood, J.A. and Tripp, J.H., 1967, The Elastic Contact of Rough Surfaces, J. Appl. Mech, Vol. 34, No. 1, pp. 153-159.

66. Greenwood, J.A., 1984, A Unified Theory of Surface Roughness, Proceedings of the Royal Society of London. Series A, Mathematical and Physical Sciences, Vol. 393, No. 1804, pp. 133-157.

67. Sedlacek, M., Vilhena, L.M.S., Podgornik, B. and Vizintin J., 2011, Surface Topography Modelling for Reduced Friction, Journal of Mechanical Engineering, Vol. 57, No. 9, pp. 674-680.

68. Zhou, Y., Zhu,H., Zhang,W., Zuo,X., Li, Y. and Yang, J., 2015, Influence of surface roughness on the friction property of textured surface, Advances in Mechanical Engineering, Vol. 7, No. 2, pp. 1-9.

69. Karpenko, A.Y. and Akay, A., 2001, A numerical model of friction between rough surfaces, Tribology International, Vol. 34, pp. 531-545. 